\title{
INVESTIGATION ON THE CAPACITY OF TL-5 GFRP-REINFORCED CONCRETE BRIDGE BARRIER- DECK ANCHORAGE SUBJECTED TO TRANSVERSE VEHICLE IMPACT LOADING
}

\author{
by \\ Gledis Dervishhasani \\ BEng, Ryerson University, 2015
}

\author{
A thesis \\ presented to Ryerson University \\ in partial fulfillment of the \\ requirements for the degree of \\ Master of Applied Science \\ in the program of \\ Civil Engineering
}

Toronto, Ontario, Canada, 2018

(C) Gledis Dervishhasani, 2018 


\section{Author's Declaration}

I hereby declare that I am the sole author of this thesis. This is a true copy of the thesis, including any required final revisions, as accepted by my examiners.

I authorize Ryerson University to lend this thesis to other institutions or individuals for the purpose of scholarly research.

I further authorize Ryerson University to reproduce this thesis by photocopying or by other means, in total or in part, at the request of other institutions or individuals for the purpose of scholarly research.

I understand that my thesis may be made electronically available to the public. 


\begin{abstract}
INVESTIGATION ON THE CAPACITY OF TL-5 GFRP-REINFORCED CONCRETE BRIDGE BARRIERDECK ANCHORAGE SUBJECTED TO TRANSVERSE VEHICLE IMPACT LOADING
\end{abstract}

Master of Applied Science, 2018

Gledis Dervishhasani, Civil Engineering, Ryerson University

A new Ontario-based glass fiber reinforced polymer (GFRP) bar manufacturer developed highmodulus (HM) GFRP bars with headed ends for use in bridge construction. This thesis presents a structural qualification procedure to qualify the use of the developed GFRP bars in concrete bridge barriers-deck joint. The thesis is comprised of two phases. The first phase includes an experimental program to investigate the pullout capacity of the GFRP bar anchorage in normal strength concrete. In phase two, three sets of full-scale TL-5 barrier wall-deck system of $900 \mathrm{~mm}$ length were cast and tested to-collapse. The first set incorporated headed-end GFRP bars to connect the barrier wall to a deck slab cantilever for better pre-installed anchorage. The second set is identical to the first set but for non-deformable thick deck slab. The third set incorporated post-installed GFRP bars in non-deformable thick deck slab using a commercial epoxy adhesive. Experimental capacities of the tested specimen were then correlated with factored applied moments given by the 2006 Commentaries of the Canadian Highway Bridge Design Code and available equations in the literature. Based on the experimental findings, conclusions and recommendations were drawn. 


\section{Acknowledgements}

The author extends his sincerest gratefulness to his supervisor and mentor Dr. Khaled Sennah for proposing and initiating this research theme. Re-occurring discussions on a weekly basis allowed for continuous support, encouragement, and successful completion of this thesis. The author also extends his gratitude to Michael Rostami for providing suggestions and efficiency improvements throughout the duration of the experimental program. Gratitude is extended towards Ryerson's civil engineering lab technicians Khaleel Stoney, Nidal Jaalouk, Domenic Valle, and Min Yao for their guidance and expertise in conducting all experimental tests.

The efforts of Christopher Price, Abdalelah Alsehli, Fred Ouellette, Alex Ruta, Hosam Sennah, Ramy Hussein, and Sameh Elgamal are also acknowledged and the author is grateful to have had their assistance in preparing formwork, pouring/ finishing concrete, and their continuous assistance in the lab for conducting all appropriate tests.

The financial support from $B \& B$ FRP Manufacturing Inc. is greatly appreciated, as without their sponsoring this research would not have been possible. Also, the author extends his gratitude to Ryerson University for providing all necessary space and equipment required in seeing this project through, from start to finish. 


\section{Dedication}

To my dear and loving family

for their continuous love, support, and motivation in every step of my life 


\section{Table of Contents}

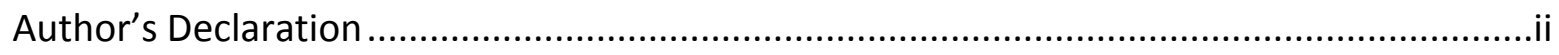

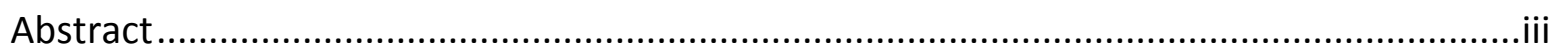

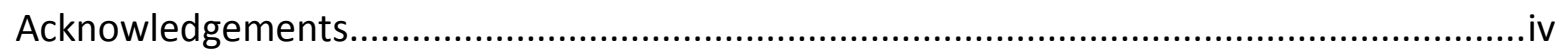

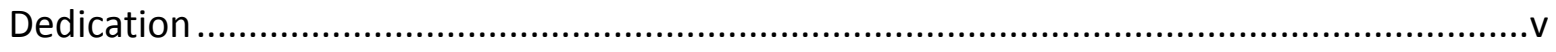

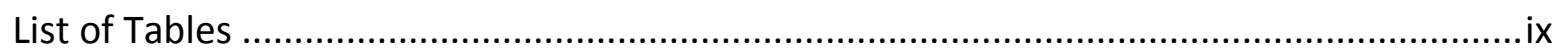

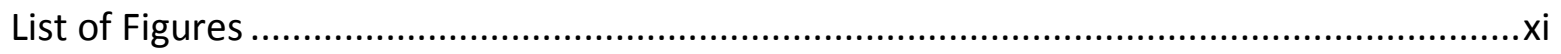

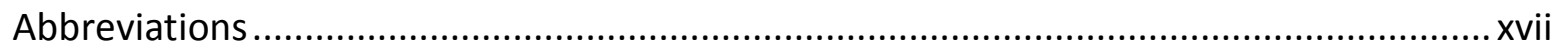

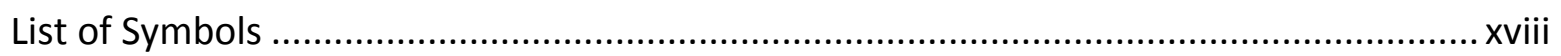

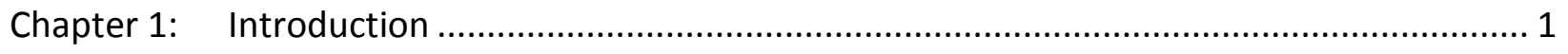

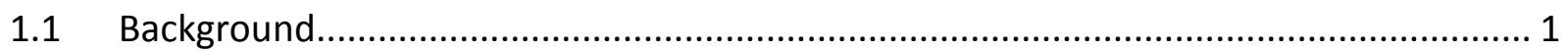

1.2 Problem Statement .............................................................................................. 1

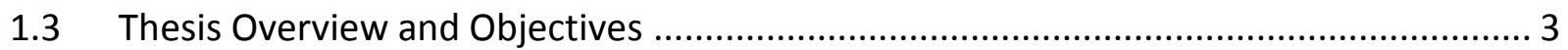

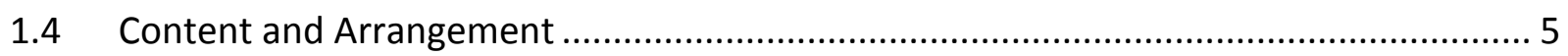

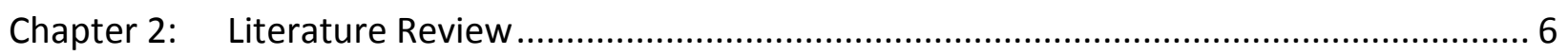

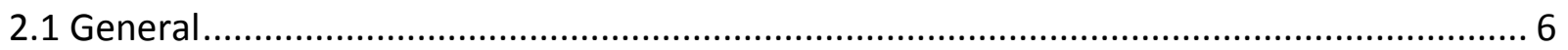

2.2 Brief Introduction of Concrete Reinforcement Evolution ............................................... 6

2.3 Bond Properties between GFRP and Concrete ……...................................................... 8

2.4 Bridge Barrier Rehabilitation .............................................................................. 11

2.5 Implementation of Anchor Headed GFRP Bars in Bridge Barriers.................................... 14

2.6 Improving Design Practices for TL-5 Bridge Barriers ....................................................... 16

2.7 GFRP Reinforced Concrete Exposed to Extreme Heat....................................................... 20

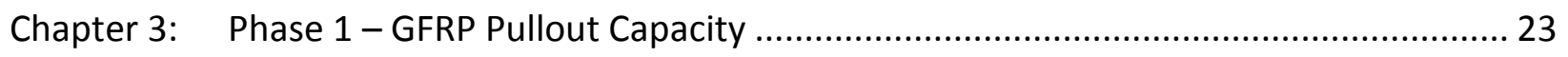

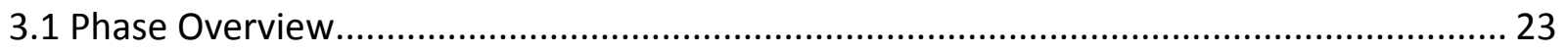

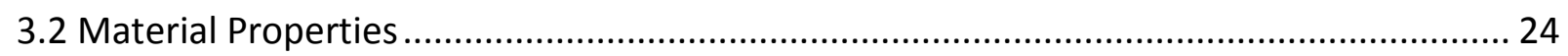

3.2.1 Concrete Properties .................................................................................... 24

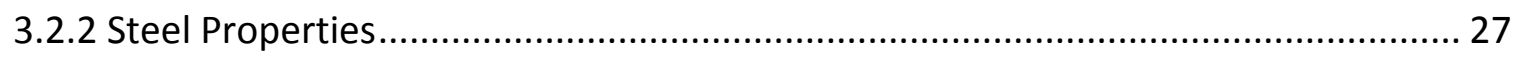

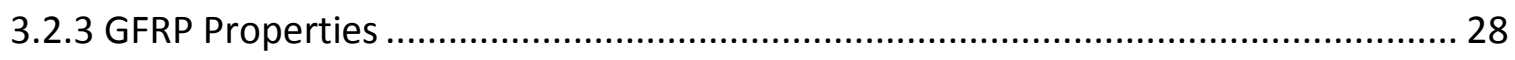

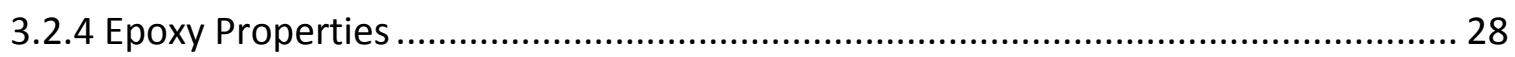




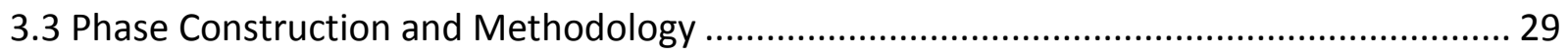

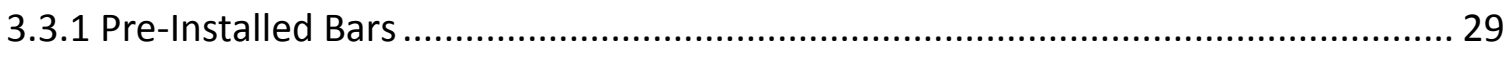

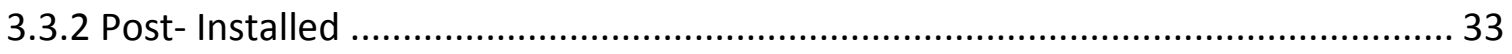

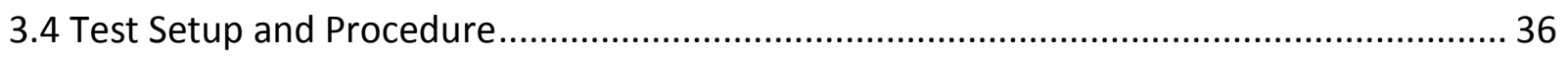

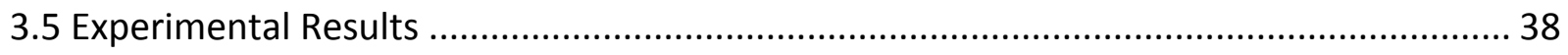

3.5.1 Pre-installed Straight Bar Test Results................................................................. 38

3.5.2 Preinstalled Headed Bar Test Results .................................................................. 41

3.5.3 Test Results of Pre-installed Headed-end Bar with Unbonded Straight Portion .... 43

3.5.4 Test Results for Post-Installed Bars with 150 mm Embedment Length ................... 44

3.5.5 Test Results for Post-Installed Bars with 175 mm Embedment Length ................... 46

3.5.6 Test Results for Post-Installed Bars with 200 mm Embedment Length .................. 48

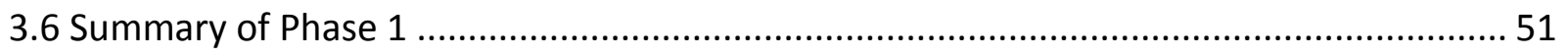

Chapter 4: Phase 2 - Static Load Tests on TL-5 Bridge Barriers ............................................. 53

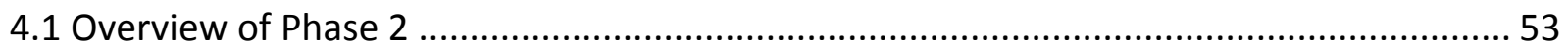

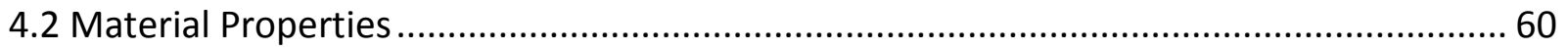

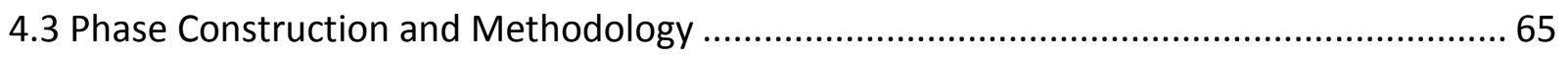

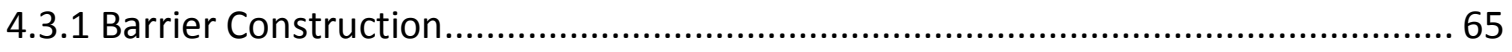

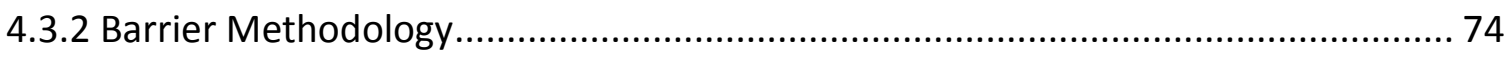

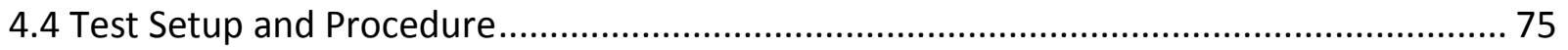

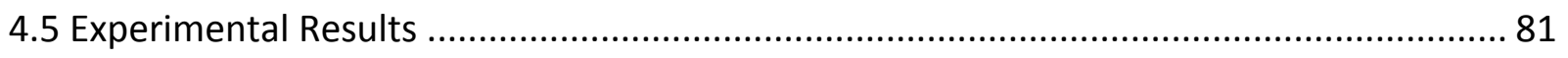

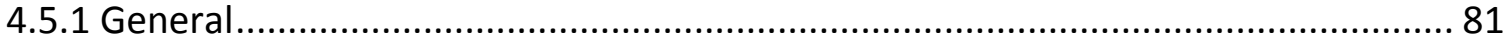

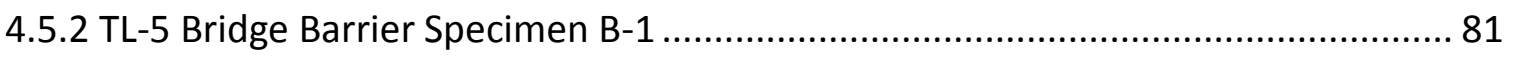

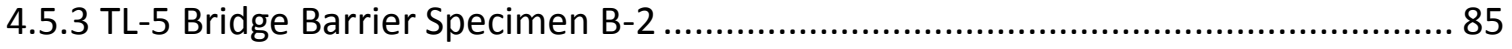

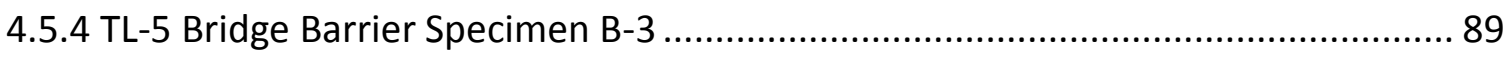

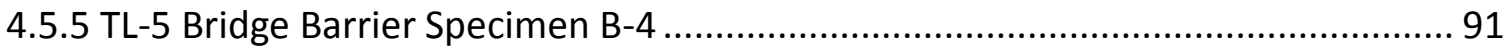

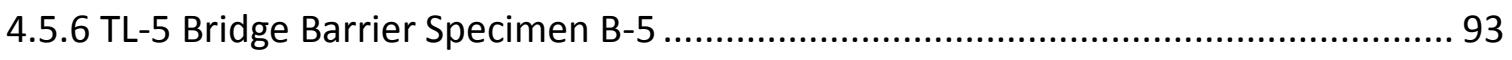

4.5.7 TL-5 Bridge Barrier Specimen B-6 ........................................................................ 96

4.6 Analysis of data obtained from sensors ..................................................................... 100

4.6.1 TL-5 Bridge Barrier Specimen B-1 ……….................................................. 100 
4.6.2 TL-5 Bridge Barrier Specimen B-2 …....................................................... 103

4.6.3 TL-5 Bridge Barrier Specimen B-3 ............................................................... 105

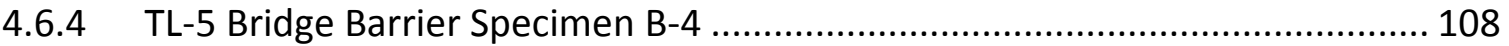

4.6.5 TL-5 Bridge Barrier Specimen B-5 ............................................................ 111

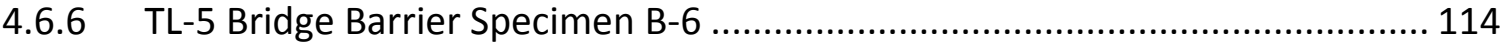

4.6.7 Barrier Maximum Moment Associated with Diagonal Tension Crack in Deck

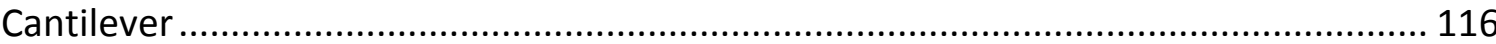

4.7 Discussion of the Load Carrying Capacity of the Studied Barrier-Deck System in Phase 2

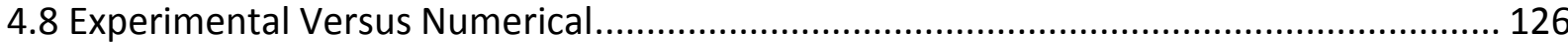

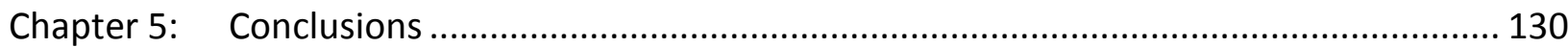

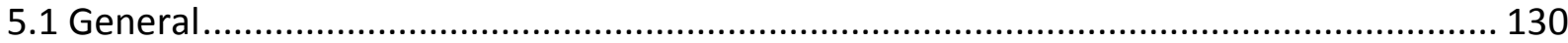

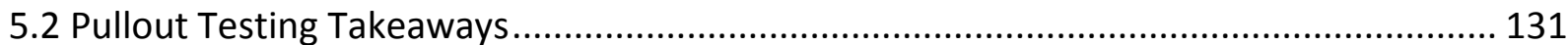

5.3 Static Load Testing on TL-5 Bridge Barrier Takeaways ............................................... 131

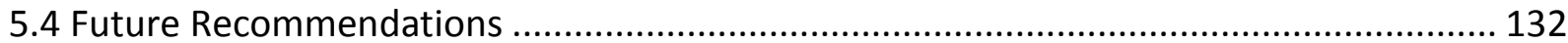

Appendix: Pullout load-POT reading relationships....................................................... 133

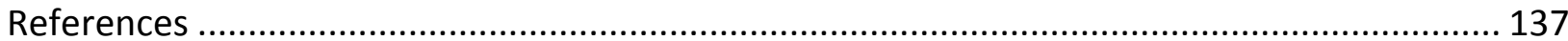




\section{List of Tables}

Table 3.1: Summary of pullout slab concrete strength ............................................................ 26

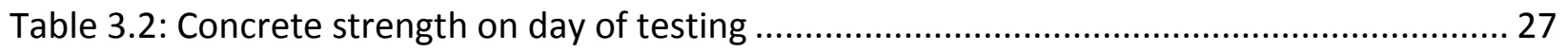

Table 3.3: GFRP Bar Specifications (B\&B FRP Manufacturing Inc., 2016) ................................... 28

Table 3.4: Epoxy Specifications (Hilti Canada Corporation, 2016) ............................................... 28

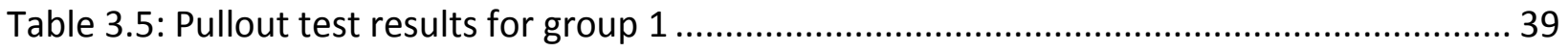

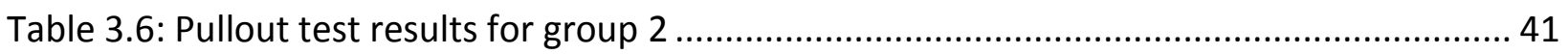

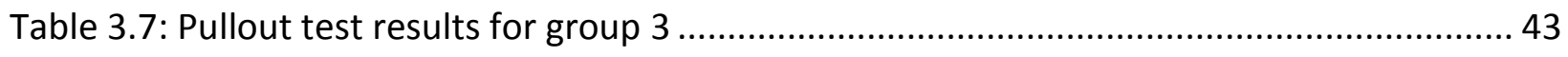

Table 3.8: Pullout test results for post-installed bars in group 1 ............................................... 45

Table 3.9: Pullout test results for post- installed bars in group 2 ............................................... 47

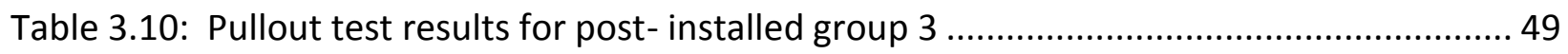

Table 3.11: Summary of bar pullout strength and associated failure modes ............................. 52

Table 4.1: Properties of GFRP Bar \#4 (B\&B FRP Manufacturing Inc., 2016) ................................. 61

Table 4.2: First concrete batch strength development for the pre-installed barriers and two

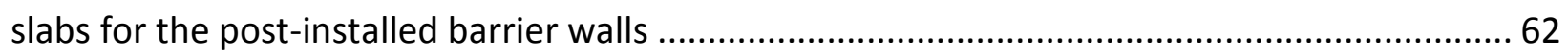

Table 4.3: Third concrete batch strength development for the two post installed walls ............. 63

Table 4.4: Concrete strength at the time of testing (first batch) ................................................ 64

Table 4.5: Concrete strength at the time of testing (second batch) ............................................ 64

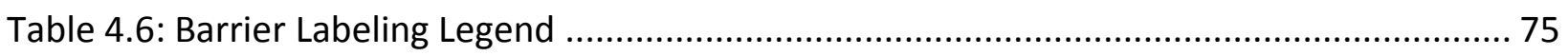

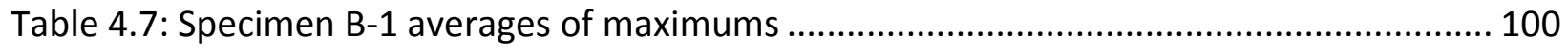

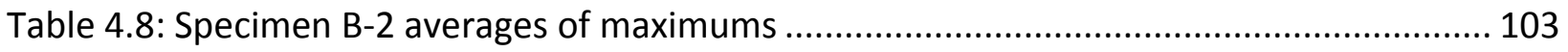

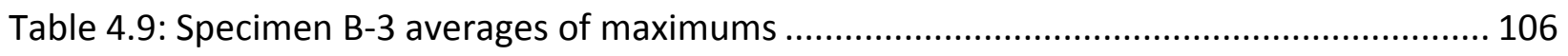

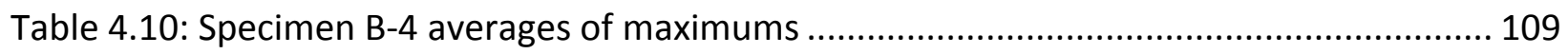

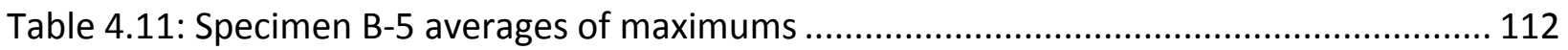


Table 4.12: Specimen B-6 averages of maximums

Table 4.13: Summary of results and comparing with experimental findings.......

Table 4.14: Experimental results benchmarked against CHBDC requirements and safety factors 125

Table 4.15: Formulas developed from FEA (Azimi et al., 2014).......................................... 126

Table 4.16: Data comparison using formulas by Azimi et al. (2014) ..... 129 


\section{List of Figures}

Figure 1.1: Photo of a deteriorated bridge barrier ............................................................ 3

Figure 1.2: Flowchart outlining experimental program ................................................ 4

Figure 2.1: The confined pullout test (a) and bending bond test (b) (Gudonis et al., 2014)......... 9

Figure 2.2: Specimens for testing; a) top view b) section view (Kabir et al., 2017) ................... 11

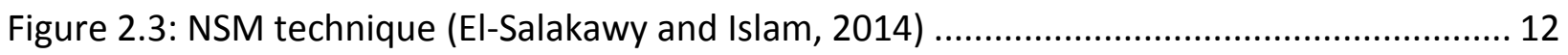

Figure 2.4: Planting technique (El-Salakawy and Islam, 2014) ........................................... 13

Figure 2.5: Detailing of the 6 barrier specimens (Azimi et al., 2014) ..................................... 15

Figure 2.6: Previous detailing (left) vs. the proposed new GFRP detailing for TL-5 barriers (right)

(Sennah and Khederzadeh, 2014).

Figure 2.7: Elevation details for the crash tested PL-3 barrier (Sennah and Khederzadeh, 2014)

Figure 2.8: Comparison of loading at room temperature vs. loading at 550 degrees Celsius

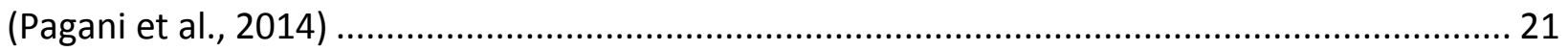

Figure 3.1: Cross-Section of a developed GFRP-reinforced barrier...................................... 23

Figure 3.2: Newly-developed HM GFRP bar (B\&B FRP Manufacturing Inc., 2016) ................... 24

Figure 3.3: Slab concrete maturity throughout 7 days after casting ................................... 25

Figure 3.4: Typical pullout slab reinforcement details ........................................................ 27

Figure 3.5: Plan of the concrete slab showing pre-installed GFRP bar locations ....................... 29

Figure 3.6: Group 1 - Straight fully-bonded GFRP bar in concrete ....................................... 30

Figure 3.7: Group 2 - Headed-end GFRP bar with fully-bonded straight length in concrete ...... 30

Figure 3.8: Group 3 - Headed-end GFRP bars with unbonded straight portion in concrete ....... 31

Figure 3.9: View of steel reinforcement prior to casting .................................................. 31

Figure 3.10: Final slab formwork with steel and GFRP reinforcement prior to casting .............. 32

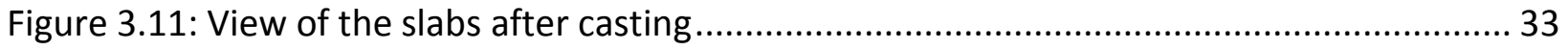


Figure 3.12: Post-installed GFRP bar with $195 \mathrm{~mm}$ embedment length in concrete 34

Figure 3.13: Plan of concrete slab showing GFRP post-installed bar locations........................ 34

Figure 3.14: Post installed GFRP bar installation procedure ............................................ 36

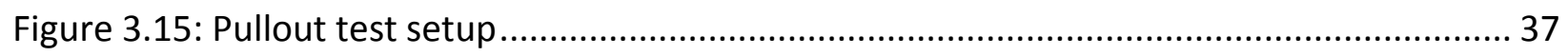

Figure 3.16: Views of the unbonded headed-end GFRP bars in concrete $300 \times 300 \times 300 \mathrm{~mm}$

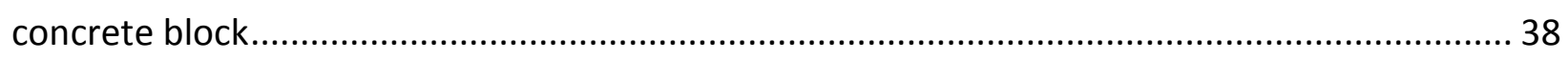

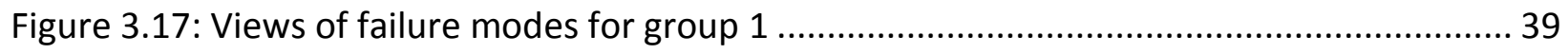

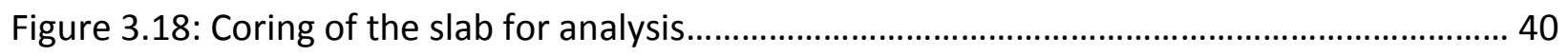

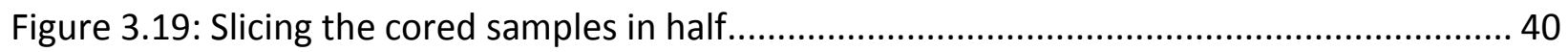

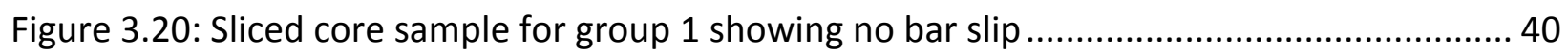

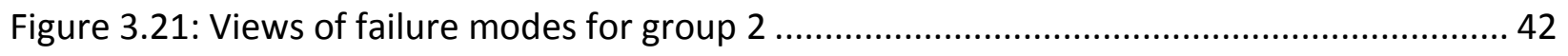

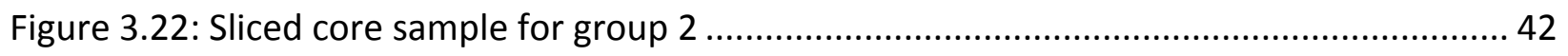

Figure 3.23: View of straight-end GFRP bar slippage from concrete .................................. 43

Figure 3.24: View of the sliced core samples for group 3 showing bar slip from head ............. 44

Figure 3.25: Views of failure modes for the group ....................................................... 45

Figure 3.26: Sliced core sample for post-installed bars in group 1 showing bar slip ................. 46

Figure 3.27: Close up view of slip of post-installed bar specimen D in group 1..................... 46

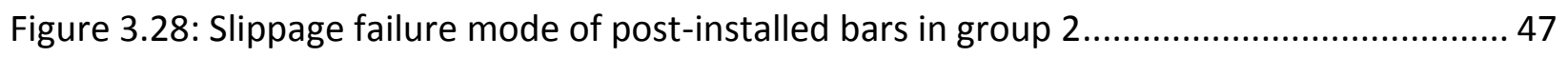

Figure 3.29: Sliced core sample for post-installed bars in group 2 showing bar slip ................ 48

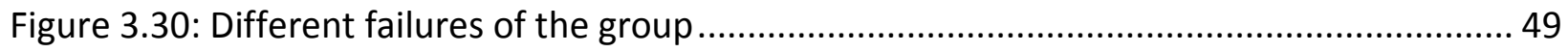

Figure 3.31: Sliced core sample for post-installed bars in group 3 showing bar slip ................ 50

Figure 3.32: Sliced core sample for post-installed bars in group 3 showing conical failure ........ 50

Figure 3.33: The different types of pullout failures: a) concrete cone breakout; b) adhesive/concrete interface pullout; c) GFRP/adhesive interface pullout d) pull through (adhesive/ concrete and GFRP); e) ribbed interface pullout; f) bar rupture (Azimi et al., 2014) 51 
Figure 4.1: Barrier specimen B-1 details (Interior Location - No Cantilever) ........................... 55

Figure 4.2: Barrier specimen B-2 details (Exterior Location - No Cantilever) ........................... 56

Figure 4.3: Barrier specimen B-3 details (Interior Location - With Cantilever) ........................ 57

Figure 4.4: Barrier specimen B-4 details (Exterior Location - With Cantilever) ........................ 58

Figure 4.5: Barrier specimen B-5 details (Interior Location - No Cantilever - Post-Installed) ...... 59

Figure 4.6: Barrier specimen B-6 details (Interior Location - No Cantilever - Post-Installed) ...... 60

Figure 4.7: Strength development for the two different concrete batches ........................... 61

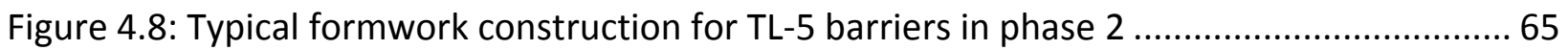

Figure 4.9: Slab steel reinforcement installation, and clear cover satisfaction ....................... 66

Figure 4.10: B-1 \& B-2 sensor placement (Note: B-1 only had 3 GFRP strain gauges) ............... 67

Figure 4.11: B-3 \& B-4 sensor placement (Note: B-3 only had 3 GFRP strain gauges) ................ 68

Figure 4.12: B-5 \& B-6 sensor placement (Note: B-5 only had 3 GFRP strain gauges) ................ 68

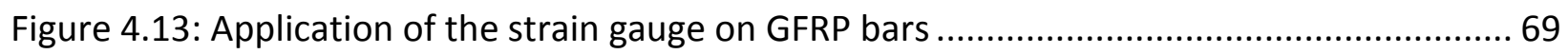

Figure 4.14: Typical GFRP wall mesh at exterior location ............................................... 70

Figure 4.15: Views of typical barriers after removal of formwork and while transporting it to the

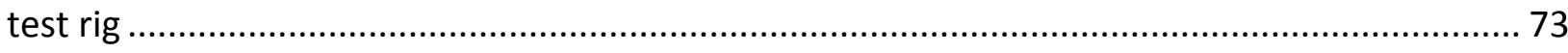

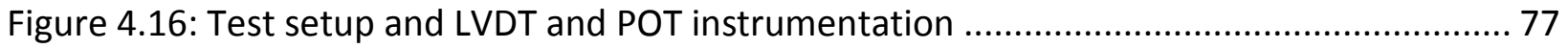

Figure 4.17: Typical test setup for a barrier resting over deck cantilever (test in progress in the

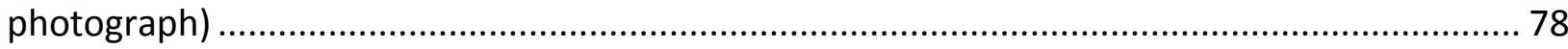

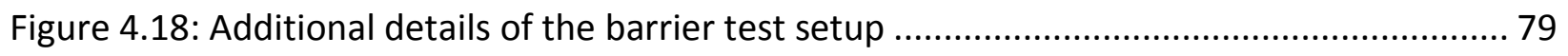

Figure 4.19: Views of typical sensor locations in tested specimens.................................... 80

Figure 4.20: Sections to be used for crack location reference ............................................. 81

Figure 4.21: Barrier B-1 bar detailing prior to casting ................................................... 82

Figure 4.22: View of crack pattern after failure of the tested specimen B-1 ......................... 83 
Figure 4.23: Close up view of crack pattern after failure of specimen B-1 ............................ 84

Figure 4.24: View of cracks at front side of specimen B-1 ............................................... 84

Figure 4.25: Close up of failed headed GFRP bar in specimen B-1 after jack hammering concrete

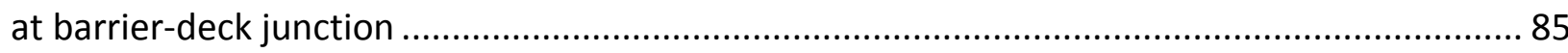

Figure 4.26: Barrier B-2 bar detailing prior to casting .................................................... 86

Figure 4.27: View of crack pattern after failure of the tested specimen B-2 …...................... 87

Figure 4.28: Close up view of crack pattern afterfailure of specimen B-2 …......................... 88

Figure 4.29: View of cracks at front and rear sides of specimen B-2 ….............................. 88

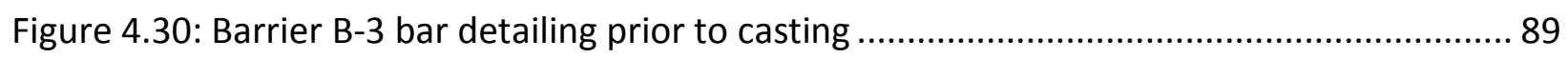

Figure 4.31: View of crack pattern after failure of the tested specimen B-3 ......................... 90

Figure 4.32: Close up view of crack pattern after failure of specimen B-2 ............................ 90

Figure 4.33: View of cracks at front face and deck area of specimen B-3............................. 91

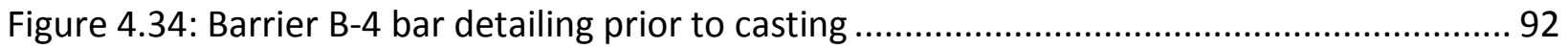

Figure 4.35: View of crack pattern after failure of the tested specimen B-4 ......................... 92

Figure 4.36: Close up view of crack pattern after failure of specimen B-4 ............................ 93

Figure 4.37: View of cracks at front face and deck area of specimen B-4.............................. 93

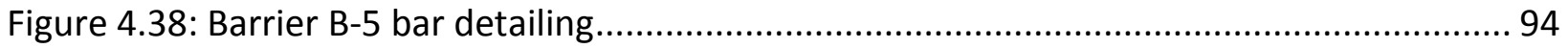

Figure 4.39: View of crack pattern after failure of the tested specimen B-5 ........................ 95

Figure 4.40: Close up view of crack pattern after failure of specimen B-5 ........................... 95

Figure 4.41: View of cracks at front face and deck area of specimen B-5............................. 96

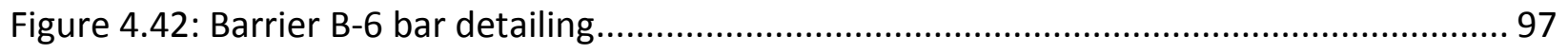

Figure 4.43: View of crack pattern after failure of the tested specimen B-6 ........................ 98

Figure 4.44: Close up view of crack pattern after failure of specimen B-6 ........................... 99

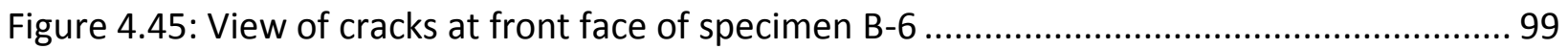


Figure 4.46: Displacement response of Barrier B-1 to increase in static load 101

Figure 4.47: GFRP strain response of Barrier B-1 to increase in static load 102

Figure 4.48: Concrete strain response of Barrier B-1 to increase in static load 102

Figure 4.49: Displacement response of Barrier B-2 to increase in static load 104

Figure 4.50: GFRP strain response of Barrier B-2 to increase in static load 104

Figure 4.51: Concrete strain response of Barrier B-2 to increase in static load 105

Figure 4.52: Displacement response of Barrier B-3 to increase in static load 107

Figure 4.53: GFRP strain response of Barrier B-3 to increase in static load 107

Figure 4.54: Concrete strain response of Barrier B-3 to increase in static load 108

Figure 4.55: Displacement response of Barrier B-4 to increase in static load 110

Figure 4.56: GFRP strain response of Barrier B-4 to increase in static load 110

Figure 4.57: Concrete strain response of Barrier B-4 to increase in static load. 111

Figure 4.58: Displacement response of Barrier B-5 to increase in static load 112

Figure 4.59: GFRP strain response of Barrier B-5 to increase in static load 113

Figure 4.60: Concrete strain response of Barrier B-5 to increase in static load 113

Figure 4.61: Displacement response of Barrier B-6 to increase in static load 115

Figure 4.62: GFRP strain response of Barrier B-6 to increase in static load 115

Figure 4.63: Concrete strain response of Barrier B-6 to increase in static load. 116

Figure 4.64: Internal forces in the barrier deck-wall junction (Khederzadeh, 2014) 117

Figure 4.65: Barrier B-3- Interior location cantilever; diagonal cracking is evident in areas and lengths mentioned above 118

Figure 4.66: Barrier B-4 exterior location; similar diagonal cracking is visible 119

Figure 4.67: Red line outlines the crack length to be used in analysis for this research 120

Figure 4.68: A close up of the deck-wall junction along with internal forces 120 
Figure 4.69: Dimensions necessary for crack length calculation ....................................... 121

Figure 4.70: Interior loaded barriers factor of safety representation ................................ 127

Figure 4.71: Exterior loaded barriers factor of safety representation ................................. 128

Figure A.1: Pullout load-POT reading relationship for pre-installed headed bar in a concrete

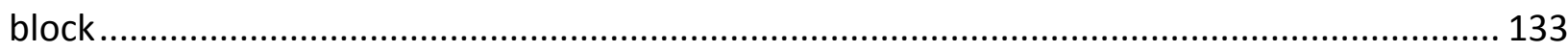




\section{Abbreviations}

AASHTO - American Association of State Highway and Transportation Officials

ABS - Acrylonitrile Butadiene Styrene

ASTM - American Society of Testing and Materials

CFRP - Carbon Fibre Reinforced Polymer

CHBDC - Canadian Highway Bridge Design Code

CSA - Canadian Standards Association

FEA - Finite Element Analysis

FRP - Fibre Reinforced Polymer

GFRP - Glass Fibre Reinforced Polymer

$\mathrm{HM}$ - High Modulus

LRFD - Load and Resistance Factor Design

LVDT - Linear Variation Displacement Transducer

MASH - Manual for Assessing Safety Hardware

MTO - Ministry of Transportation of Ontario

NCHRP - National Cooperative Highway Research Program

NSM - Near Surface Mounted

PL-2 - Performance Level 2

PL-3 - Performance Level 3

POT - Potentiometer

RCCAO - Residential and Civil Construction Alliance of Ontario

TTI - Texas Transportation Institute 


\section{List of Symbols}

$A$ - a constant value

$A_{b x}$ - cross-sectional area of one GFRP bar along x-axis

$A_{b y}$ - cross-sectional area of one GFRP bar along y-axis

$A_{f x}$ - total GFRP reinforcement in transverse direction per meter of wall

$A_{f y}$ - total GFRP reinforcement in longitudinal direction per meter of wall

$\alpha$ - inclination of diagonal tension crack

$\alpha_{s}$ - adjustment factor for shear strength support dimensions

$b$ - longitudinal width of barrier wall

$b_{o, 0.5 d}$ - critical perimeter length measured at $0.5 \mathrm{~d}$ from the loading patch

$\beta_{c}$ - ratio of long side to short side of the loading patch

$C_{d}$-compression force in the deck

$C_{w}$-compression force in the wall

$d$ - effective slab depth in $\mathrm{mm}$

$d_{d}$ - effective depth of deck

$d^{\prime}{ }_{d}$ - distance between tension and compression reinforcement $\left(\approx 0.9 d_{d}\right)$

$E_{f}$ - average modulus of elasticity of transverse and longitudinal GFRP at the tension face of the wall

$E_{f x}-$ GFRP modulus of elasticity along $\mathrm{x}$-axis

$E_{f y}-$ GFRP modulus of elasticity along y-axis

$E_{r}$ - modulus of elasticity of FRP bars

$\bar{f}_{c}$ - equivalent specified compressive strength

$f^{\prime}{ }_{c}$ - concrete compressive strength

$F_{\text {diag }}$ - applied transverse load on wall

$F_{\text {exp }}-$ Failure applied transverse force during experimental test

$f_{r}$ - concrete modulus of rupture

$\varphi_{c}$ - concrete resistance factor 
$H_{e}$ - height of transverse load from the deck

$k_{c}$ - Coefficient of variation modification factor (found on table A14.1.2 of the CHBDC by matching " $\mathrm{n}$ ")

$L_{d c}$ - diagonal tension crack length

$\lambda$ - concrete density factor (normal density concrete is 1 )

$M_{d, c r}$ - cracking moment in the deck

$M_{d, \exp }$ - Failure moment during experimental test

$\mathrm{n}$ - number of cylinders tested

$\rho_{f}$ - average of the two reinforcement ratios in both longitudinal and transverse directions

$\rho_{r}-$ FRP tensile reinforcement ratio

$\rho_{f x}-$ GFRP transverse reinforcement ratio along $\mathrm{x}$-axis

$\rho_{f y}-$ GFRP transverse reinforcement ratio along y-axis

$T$ - perpendicular tensile force on the diagonal tension crack

$t_{d}$ - deck thickness

$\mu \varepsilon$ - micro strain

$V$ - coefficient of variation of cylinder strengths

$V_{c}$ - Concrete shear strength 


\section{Chapter 1: Introduction}

\subsection{Background}

Public safety is considered to be the number one priority in any level of government. In Ontario, the public's safety relies heavily on the integrity of its ever evolving infrastructure. Thousands of kilometers of our linear infrastructure consists of bridges, where structural integrity is directly related to the public's well-being. Bridge maintenance, upgrades, and renewals exhaust tax dollars and minimize investment opportunities. By 2007, the Ministry of Transportation of Ontario (MTO) owned and operated about 2,800 bridges that were longer than 3 meters, while 12,000 bridges are owned by municipalities that were longer than the same threshold. By 2005 the total number of roads and bridges accounted for almost $39.9 \%$ of the government's infrastructure (MMM Group, 2007). With such a dense abundance of bridge infrastructure that appears as capital responsibility of Ontario's government, it is essential that tax dollars are effectively spent. The report published by the Residential and Civil Construction Alliance of Ontario, RCCAO (prepared by MMM Group) found out that most of Ontario's bridge inventory was developed in 1950-1970, and the typical life expectancy prior to repairs, rehabilitation, or renewal needs of bridges is about 50 years (MMM Group, 2007). This would place bridge infrastructure in Ontario near the top of the deferred requirements list. Emerging technologies in the sector should be sought after and government investment in research and development for the sector should not be held back, as root cause of the problems could potentially be resolved.

\subsection{Problem Statement}

The deterioration of steel reinforcement has significantly increased provincial capital spending and was a driving factor in funding for research revolving around glass fiber reinforcement polymer (GFRP) bars. GFRP bars will aim at eliminating a major factor in infrastructure deterioration, which is the corrosion of reinforcing steel in concrete. The corrosion of steel rebar compromises the material's load carrying ability and exerts additional stresses on the concrete elements ultimately causing for spalling and a loss of cross sectional area.

Bridge barriers are exposed to large amounts of de-icing salts during the winter season which act as catalysts in the corrosion of traditional steel reinforcement. Figure 1.1 shows a photo a deteriorated bridge barrier through steel bar corrosion and concrete spalling which showcases the need for an alternative to steel reinforcement. Due to the composition of GFRP bars excluding steel properties, corrosion is no longer an issue and is thought to be an appropriate replacement. 
Bridges are already involving the use of GFRP bars in its construction, and sufficient research for the Ministry of Transportation of Ontario (MTO) has been conducted on studying the proper implementation of the currently available products. After successful crash test and static load tests on a developed MTO TL-5, GFRP-reinforced, barriers (Sennah and Khederzadeh, 2014; Khederzadeh and Sennah, 2014), Ontario Ministry of Transportation, MTO, established Standard Drawing MTO-S110-92 for dimensioning and GFRP details for use by designers and contractors. In this design, GFRP bars are used to reinforce the barrier wall in the vertical and horizontal directions, while headed-end bars were used to reinforce the barrier-deck junction. A new competitor in the field of GFRP bar production has appeared (B\&B FRP Manufacturing Inc., 2016). This company developed headed-GFRP bar for better anchorage in concrete. The headed portion of the bar is expected to provide additional load bearing capabilities and ultimately provide for more efficient design practice. The developed GFRP bars, which are of close materials strength and modulus of elasticity to those used in the crash-tested barrier by other GFRP manufacturer, are proposed to be utilized in barrier reinforcement per MTO Drawing MTO-S110-92. Since GFRP bar is a proprietary product, it has to be evaluated for structural performance under vehicle impact. (CSA, 2014).

Since the GFRP bar with headed end will be used to reinforce the barrier-deck junction, and the amount and shape of reinforcement as well as other barrier dimensions are identical to those in the crash-tested barrier, a static test in a constructed MTO barrier segment in a laboratory would justify the change in GFRP bar type and arrangement at the barrier-deck junction. The Canadian Highway Bridge Design Code, CHBDC (CSA, 2014) requires that barrier design is to be based on the use of relevant and existing full-scale crash test data as well as commonly-used method for ensuring that the barrier design satisfies the crash test requirements. CHBDC (CL.12.4.3.4.5) specifies, "Changes to the details of a traffic barrier or traffic barrier transition that meets the requirements of Clause 12.4.3.4.2 to 12.4.3.4.4 may be made, provided that any changes affecting the geometry, strength or behavior of the traffic barrier can be demonstrated to not adversely affect vehicle- barrier interaction". This approach is consistent with the FHWA practice that approves barrier designs based on analytical/empirical methods, provided they have been calibrated to a crash-tested reference barrier. CHBDC Clause 12.4.3.5 for barrier anchorage states that "The suitability of a traffic barrier anchorage shall be based on its performance during crash testing of the traffic barrier. For an anchorage to be considered acceptable, significant damage shall not occur in the anchorage or deck during crash testing If crash testing results for the anchorage are not available, the anchorage and deck shall be designed to resist the maximum bending, shear, and punching loads that can be transmitted to them by the traffic barrier, except that these loads need not be taken as greater than those resulting from the loads specified in Clause 3.8.8 and applied as shown in Fig. 12.1." 
CHBDC commentaries (CL.C12.4.3.4.5) suggests the following examples where changes may potentially be acceptable:

a) Changes to an anchorage system, where failure of the anchorage is not exhibited during crash testing and the strength of the replacement anchorage is determined to be equivalent to that of the original;

b) Substituting materials with properties identical or superior to the original material as far as behavior during crash testing is concerned.

This research summarizes the experimental program to justify the modified barrier design and experimental findings when compared to the available factored applied moments specified in Commentaries of CHBDC of 2006 for the design of barrier-deck junction (CSA, 2006). After completing this phase of research to examine the strength of the barrier-deck junction with the newly-developed GFRP bars with headed ends, vehicle crash test is expected to be conducted on the barrier wall to qualify its use in bridge construction.

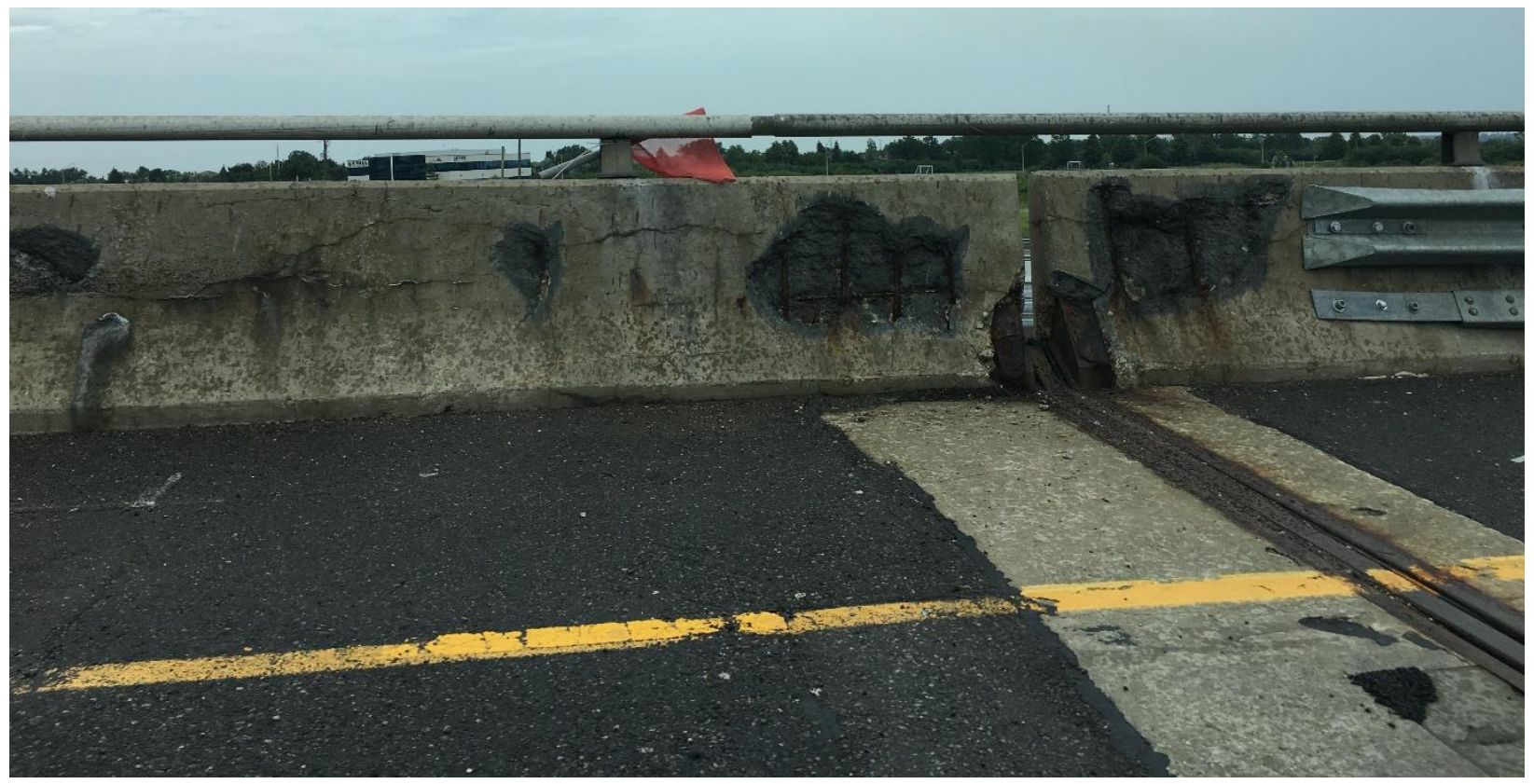

Figure 1.1: Photo of a deteriorated bridge barrier

\subsection{Thesis Overview and Objectives}

This thesis aims at achieving a comprehensive analysis for the implementation of the newly developed GFRP bars in TL-5 bridge barrier-deck anchorage. In addition, this thesis also explores 
the use of the developed GFRP bars as post-installed bars in deck slab to replace deteriorated barrier walls.

This thesis includes two phase of experimental research. The first phase includes an experimental investigation of the pullout capacity of GFRP with straight and head-end when embedded in a steel reinforced concrete slab. The results from this phase provides expectations for the axial resistance of the GFRP bars when installed within the concrete barrier. Three different bar embedment detailing were examined in two separate tests, representing pre- and post-installed construction. Pre-installed construction included (i) a fully bonded straight GFRP bar, (ii) a fully-bonded anchor-headed GFRP bar and (iii) a partially bonded anchor-headed GFRP bar embedded in a reinforced concrete deck slab. Post-installed construction included inserting the straight GFRP bar in a pre-existing concrete with epoxy as a bonding agent to the adjacent concrete. In each bar embedment type mentioned above for pre-installed construction, three embedment depths of the GFRP bars were considered, namely: 150, 175 and $200 \mathrm{~mm}$.

The second phase of the research involved the erection of six TL-5 bridge barrier-deck specimens, each being $900 \mathrm{~mm}$ in length, and reinforced with the new GFRP bars. Four out of the six specimens were pre-installed with newly developed anchor-headed GFRP bars, and the remaining two specimens were post-installed with straight GFRP bars. The barriers' crack patterns, and failure modes were analyzed and discussed. Figure 1.2 is a flowchart outlining the process that was undertaken throughout the research experimental program.

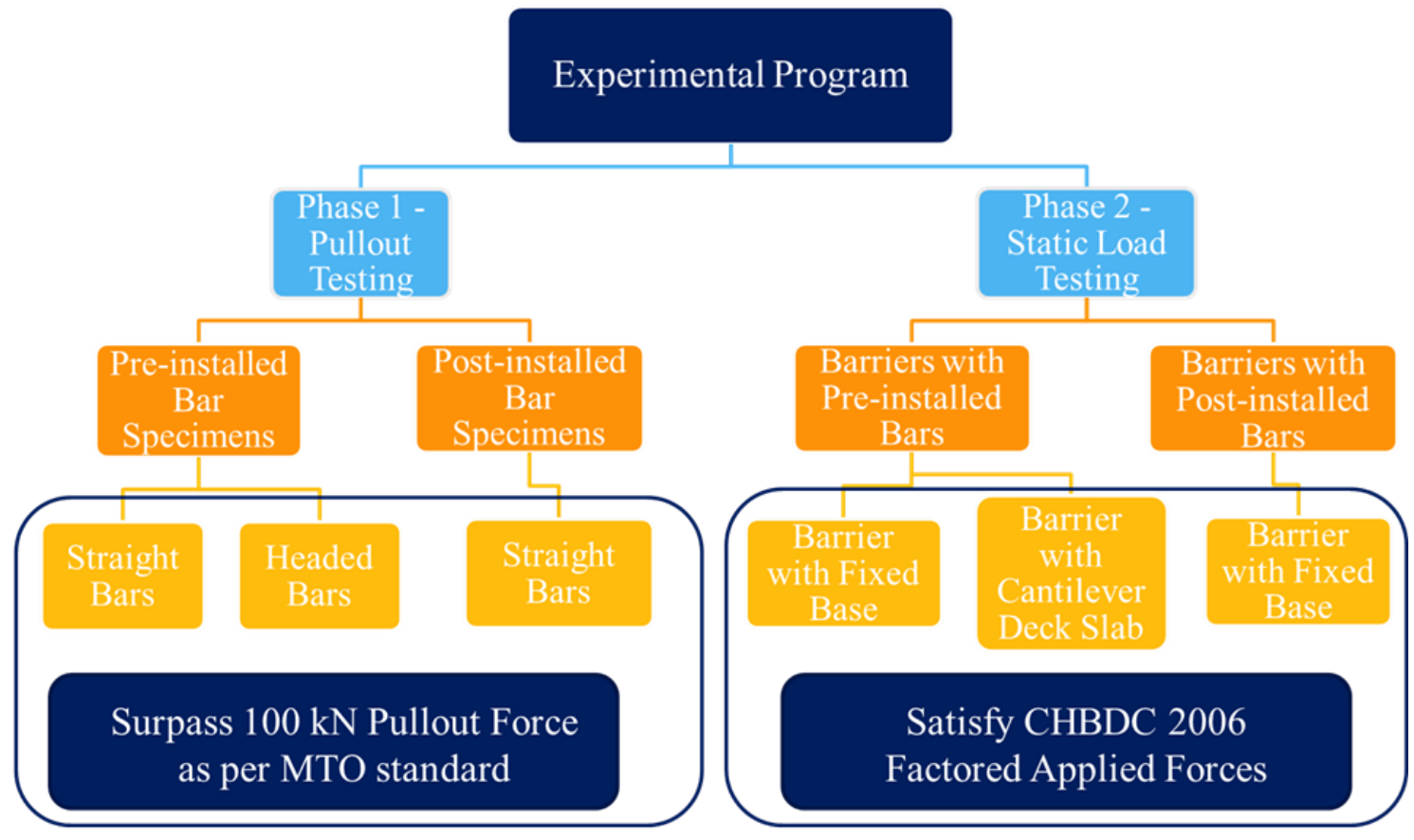

Figure 1.2: Flowchart outlining experimental program 


\subsection{Content and Arrangement}

This thesis is compiled in seven chapters. Chapter 1 provides some background and an overview of the research. Chapter 2 discusses a literature review on the subject of GFRP bars and various research that has been conducted in the past by others. Chapter 3 marks the beginning of the experimental program, and involves the pullout testing of the GFRP bars. Chapter 4 presents information on the construction, static load testing, and analysis of TL-5 bridge barrier specimens with the inclusion of the newly developed GFRP bars. Chapter 5 provides a summary of all the chapters and the findings associated with each topic. Chapter 5 is followed by an Appendix and a list of references. 


\section{Chapter 2: Literature Review}

\subsection{General}

This chapter includes a review of previous research conducted in a similar area of research. It is kept as relative as possible and attempts to deliver a perspective on what current technologies and practices are existing in the field. It follows an order of first providing an overview of the bond between the two primary elements, GFRP and concrete; then it continues to discuss pullout capacities with these bond conditions; environmental conditions; bridge rehabilitation techniques and anchorage methods; anchorage capacities of previously existing anchor-headed GFRP bars; the development of a cost effective TL- 5 bridge barrier design; and finally recent research conducted on GFRP barriers in bridge components subjected to extreme temperatures (heat/fire).

\subsection{Brief Introduction of Concrete Reinforcement Evolution}

Epoxy-coated reinforcement was developed in the early 1970's as an effective method of corrosion protection. After demonstration projects in the mid 1970's, the use of epoxy-coated bars in highway bridges expanded rapidly and became the preferred method of corrosion protection. The first evidence of unsatisfactory field performance emerged in 1986 in Florida Bridges in USA, with other examples of corrosion of coated reinforcement reported in USA and Canada in the 1990s, especially in bridge barriers (among them: Manning, 1996; Smith and Virmani, 1996). In de-icing environments, the heavy corrosion to the outer side of the vertical bars in the traffic side of the barrier wall was observed in association with section loss in the horizontal bars after 10 to 20 years in service. A recent study conducted by Ontario Ministry of Transportation, MTO, (Lai and Raven, 2010) revealed that epoxy coating of the steel bars is compromised after certain number of years in service, leading to corrosion and thus concrete cracks and spalling. Later, MTO banned the use of epoxy-coated bars in bridge decks while allowing the use of noncorrosive glass fiber reinforced polymer (GFRP) bars to promote bridge designs that improve the life expectancy and significantly reduce the maintenance cost of bridges.

Conventionally, GFRP bars are anchored to concrete through friction, mechanical adhesion and mechanical interlock through the bar surface profile. The required bar embedment length into concrete can be achieved through its bond strength to surrounding concrete and the type of end condition (i.e. straight end, $90^{\circ}$ bent or $180^{\circ}$ hook). Unlike hooked steel bars that can be formed manually, GFRP bar bents and hooks are prefabricated in the manufacturing plant and then shipped to the construction site for installation. Since GFRP bends and hooks provide significantly less pullout strength than the tensile capacity of the bar itself due to redirection of 
the fibres at the curved portion of the bar (Khederzadeh and Sennah, 2013, El-Sayed et al., 2010), GFRP manufacturers developed GFRP bar with cast headed-end anchorage. Such headed-anchor bar is expected to reduce reinforcement congestion at cast joints.

Few authors investigated the pullout capacity and bond strength of FRP bars embedded in normal concrete (among them: Achillides and Pilakoutas, 2004; Baena et al., 2009), high strength concrete (Hossain et al., 2014). Others investigated the pullout capacity of GFRP bars in fibrereinforced concrete (Won et al., 2008; Mazaheripour et al., 2013), in geopolymer normal concrete (Maranan et al., 2015b), and in UHPFRC (Amertano, 2011; Mak, 2011; Yoo et al., 2015). Firas et al. (2011) investigated the bond strength of carbon fibre-reinforced polymer (CFRP) bars in UHPFRC.

The use of fibre- reinforced concrete (FRC) has become more popular and is perceived as more acceptable in the industry due to its added benefits in addressing the concrete's brittle composition and low tensile strength. The effects of FRC on FRP bars should not be dismissed and due diligence should be conducted. Won et al. (2008) were among few researchers who carried out a comprehensive study on the bond relationship between the material types. They included an analysis on the relationship of carbon fibre reinforced polymer (CFRP) and the FRC. The concrete was reinforced with hooked steel fibre bundles as well as crimped polyolefin synthetic fibres. The reinforcing bars used in the execution of the experiment were 9 and $13 \mathrm{~mm}$ diameter CFRP and GFRP bars, respectively, which were both manufactured by Dongwon Construction in South Korea. They tested three concrete mixes with different fibre contents. The different fibre contents are outlined below: Steel 0,20 , and $40 \mathrm{~kg} / \mathrm{m}^{3}$; and Synthetic: 4.55 , and $9.10 \mathrm{~kg} / \mathrm{m}^{3}$. These five different fibre contents were kept consistent in each concrete mix to be able to conduct a parallel study on the effects of the concrete compressive strength. The three different FRC mixes were varied in compressive strength as 50, 70, and $90 \mathrm{MPa}$ for mix 1, 2, and 3 , respectively. The three different compressive strengths of the concrete allow to transparently identify any contributions of the concrete strength on the bond properties of the two material types (FRC and reinforcing bar type, CFRP and GFRP).

To maintain relativity in this review, only GFRP results will be discussed. While looking at the data retrieved by Won et al. (2008), it appears that the group with no fibre content from each of the three mixes realizes on average about 4.63 MPa extra pullout strength with approximately every $20 \mathrm{MPa}$ of added concrete compressive strength. And, while looking at the three different compositions of steel fibres in the concrete, the average extra pullout strength per $20 \mathrm{MPa}$ increase in concrete compressive strength increases to $4.68 \mathrm{MPa}$. The synthetic fibre FRC contribution was dismissed in this part of the review as there is believed to be an outlier in the data. 
The data is transparent and clearly identifies that the fibre reinforced concrete composition, regardless of the compressive strength, contributes $5 \%$ to $70 \%$ increase of the GFRP bar initial pullout capacity with the addition of fibre content. Hooked steel fibre bundles were concluded to provide the best strength properties at its peak content presence in the concrete, $40 \mathrm{~kg} / \mathrm{m}^{3}$. The largest increase in strength seen by adding this fibre content was in the mix of $90 \mathrm{MPa}$ compressive strength. Also, adding $40 \mathrm{~kg} / \mathrm{m}^{3}$ as opposed to no fibre content increased the pullout capacity of the GFRP bar by about $72 \%$. From this study done by Won et al. (2008), it can be concluded that the addition of fibres to concrete has a positive impact on the pullout capacity of GFRP bars. However, the need for efficiency in structural design continues to be a topic of discussion. To achieve better structural efficiencies and safer structures, investment in research and development has expanded.

Most recently a few GFRP manufacturers developed GFRP bars with cast headed end to increase anchorage with concrete. Few researchers investigated the pullout capacity and bond strength of the head-end GFRP bars in normal strength concrete (Benmokrane et al., 2017; Vint and Sheikh, 2015; Khederzadeh and Sennah, 2013; Vint, 2012; Mohamed et al., 2012), highstrength concrete (Islam et al., 2015; Lu et al., 2015), geopolymer normal concrete (Maranan et al., 2015a). Johnson and Sheikh (2013) studies experimentally the feasibility of using the doubleheaded GFRP bars as shear reinforcement for concrete beams. Sennah et. al. (2012) and Sennah and Khederzadeh (2014) utilized GFRP bars with headed ends to reinforce the bridge barrierdeck slab system to resist vehicle impact. Hasaballa and El-Salakawy (2014) studied the performance of beam-column joints reinforced with GFRP-headed bars under seismic loading. They concluded that headed bars exhibited better seismic performance than the bent ones. ElBadry et al. (2017) developed, and testing under fatigue and static loading, a hybrid GFRPreinforced bridge truss girder system incorporating headed-end of the GFRP bars for anchorage at truss joints.

\subsection{Bond Properties between GFRP and Concrete}

The bond relationship between GFRP bars and concrete elements could be rather complex and each testing method has its limitations. It is understood that GFRP bars offer a higher ultimate tensile strength, however at the cost of increased deformability and crack width in concrete. With such tradeoffs between using GFRP as opposed to steel, the serviceability limit state design typically governs in structural applications. Gudonis et al. (2014) conducted an experimental program in which they analyzed the bond relationship between GFRP and concrete. Some of the samples experimented were conducted with steel bars as opposed to GFRP to be able to provide a comparative analysis between the two reinforcing elements. They explained two different testing methods in determining the bond relationship between reinforcing bars and 
concrete, namely: the confined pullout test and the bending bond test. The bending bond test is argued to remove the compressive force and increased confinement of the bar in the concrete elements which do not allow for some cracking to occur. Whereas the confined pullout test removes the fact that there are two systems influencing the bond behavior (Gudonis, et al., 2014). Figure 2.1 shows schematic diagrams presented in the experimental program that was conducted. Diagram (a) represents the confined pullout test setup, while diagram (b) shows the bending bond tests. Gudonis et al. (2014) conducted a total of 11 separate tests which included five being done with the bending bond test method and six with the confined pullout test method. The parameters were kept relatively the same or very similar to allow for a comparative analysis. The bar diameters were all $12 \mathrm{~mm}$, including the steel specimens. In the bending bond test, there were 3 GFRP specimens and 2 steel specimens while there were 3 GFRP and 3 steel specimens in the confined pullout test.

(a)

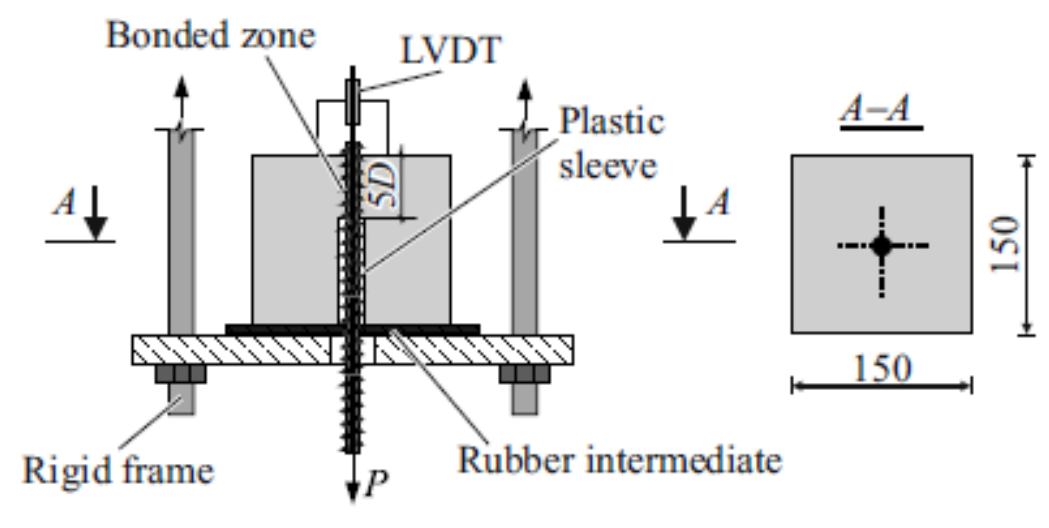

(b)

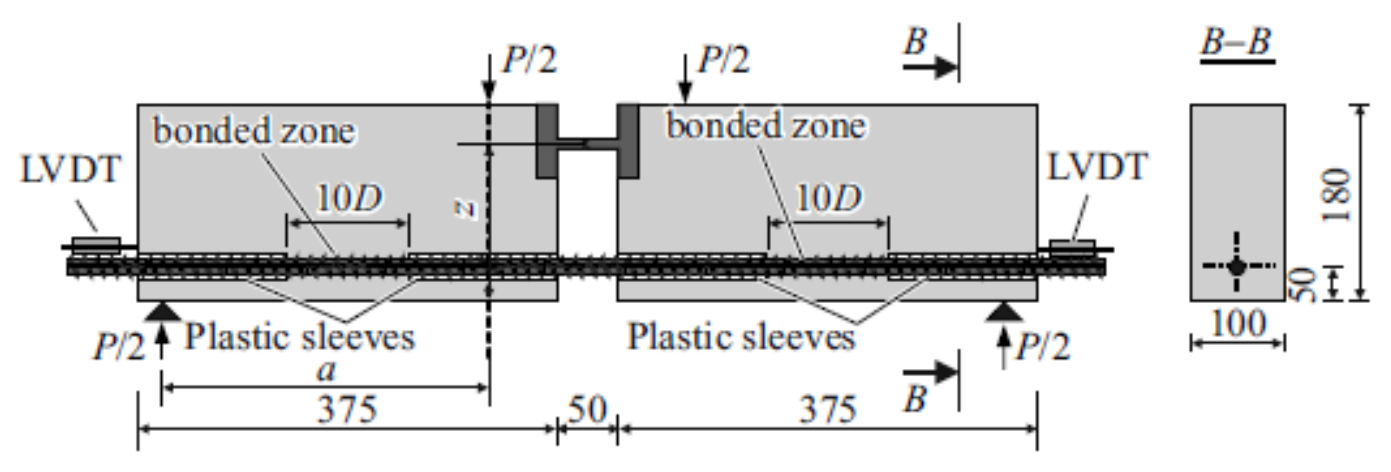

Figure 2.1: The confined pullout test (a) and bending bond test (b) (Gudonis et al., 2014)

After testing all of the samples, the results showcased an increased bond strength in the bending bond tests as opposed to the confined pullout tests. This was said to be due to the action 
of the bending bond test specimens as two separate members acting together (Gudonis et al., 2014). Generally, it was observed that the GFRP bond strength was lower than that of steel in both test methods. Steel bond strength was approximately $70 \%$ greater than that of GFRP in the confined pullout test, and only 10-15\% greater in the bending bond test; however, the bond stiffness was greater in the GFRP specimens in the bending bond tests (Gudonis et al., 2014). The study claims that due to factors such as crack width limitations by the serviceability limit state design, the bond strength would not be achieved and other factors will govern design. The higher bond stiffness showcased in the bending bond tests is said to be prospective reason for allowing construction to include GFRP bars (Gudonis et al., 2014).

Structural building elements undergo various exposures to different environments throughout their service lives. Rehabilitation work to these elements is needed throughout the concrete service life in order to prolong service and increase the construction economic feasibility. Also, the longer the economic service life of infrastructure is, the owners (taxpayers in public infrastructure) will gain more satisfaction. A contribution towards sustainable construction is the use of fibre reinforced polymer (FRP) sheets as they do not contain corrosion inhibitors. FRP could be externally applied to structural members or could be implemented in the concrete section acting as internal reinforcement. The use of FRP has many advantages such as low weight, noncorrosive, and high strength to name a few. However, the longevity of the product under different exposures and the consequential effects on the concrete section embedded in/on subsequent to the different exposures could be further investigated.

Kabir et al. (2017) carried out an experimental program which further analyzed externally applied Glass FRP sheets on concrete members under different environmental conditions. Temperature changes, wet-dry cycles, and outdoor environments were investigated as the environmental parameters in the experimental program. Kabir et al. (2017) conducted pullout tests, compressive tests, and strain monitoring on specimens to see how the different environmental conditions affected the concrete and GFRP strength as well as the bond between the GFRP sheet and the concrete surface. Two layers of GFRP sheets were applied atop one another, with $150 \mathrm{~mm}$ of the GFRP sheet being bonded on the concrete with the use of an epoxy adhesive. Control specimens which were not exposed to the elements were also cast in order to allow for comparison. The non-control samples were exposed to the environmental conditions up to 18 months. Figure 2.2 illustrates the construction of the samples. 
(a)

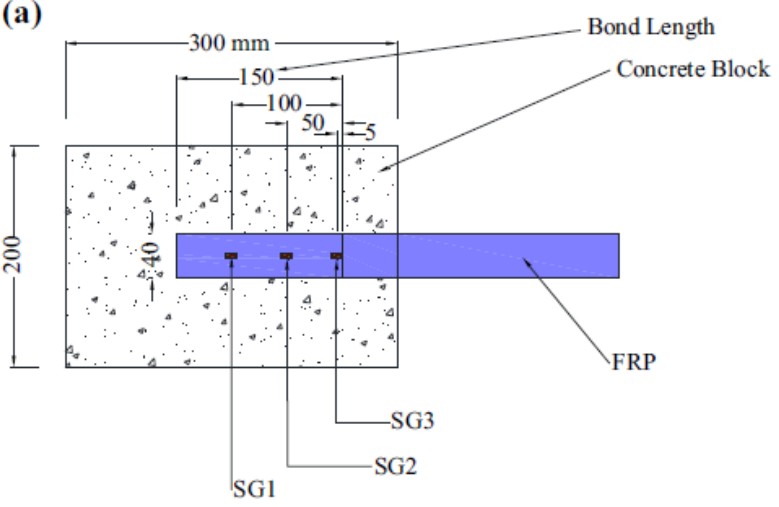

(b)

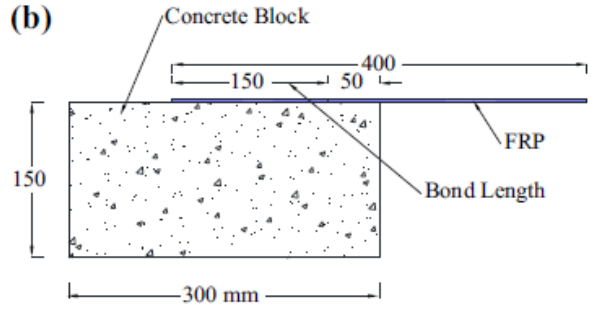

Figure 2.2: Specimens for testing; a) top view b) section view (Kabir et al., 2017)

A total of 54 specimens were tested throughout the experimental program by Kabir et al. (2017) with all being tested at different points in time (i.e. 9 temperature cycles were tested; 3 at 5 weeks, 3 at 3 months, and 3 at 12 months). The different time segments allowed to see any trends or outliers in the data set. Kabir et al. concluded that the most negative effects were noticed with the exposure to outdoor environmental condition (about 9\%), and wet-dry cycles coming in second with a degradation in pullout strength of about $6 \%$. Whereas, the temperature cycles resulted in an increase of pullout strength by about $8 \%$. They concluded that failure modes of the specimens would advocate that the pullout strength is more reliant on the epoxy properties and that more research needs to be conducted.

\subsection{Bridge Barrier Rehabilitation}

Modern day infrastructure is noted to be moving in the direction of implementing more GFRP reinforced structures; bridge barriers being a critical element moving in this direction. Research has been conducted for several decades on fibre reinforcement. A paper written by El-Salakawy and Islam (2014) proposed two different techniques in repairing GFRP reinforced bridge barriers. The two techniques they proposed were (i) NSM reinforcement which is an abbreviation for "Near-Surface-Mounted" bars and (ii) "Planting." The experimental program initiated in the paper consisted of 3 full scale ( 6 meters long each) TL-4 barriers which were reinforced entirely of GFRP bars. The specimens were first tested to failure. Then the failed segments were saw-cut, followed by being repaired with these two techniques. Finally, the repaired specimens were tested to collapse. El-Salakawy and Islam described NSM and planting as techniques to allow for continuity between the repaired barrier segments and the existing remainder of the untouched barrier. GFRP bars were used as anchors in the undamaged barrier segments. NSM bars were installed by creating grooves at the front and rear facades of the barrier wall and embedding the 
new reinforcement into such grooves which were filled with epoxy along the process. Planting is a methodology of drilling horizontally into the existing barrier portions, followed by injecting the drilled holes with epoxy and inserting the GFRP bars. The main difference between the two methods was that NSM provided less clear cover and no concrete elements to protect the bar other than the epoxy itself. Whereas, planting involved a slight shift of the reinforcement details, while maintaining the same clear cover specifications. Both techniques involved drilling into the existing barrier wall and injecting epoxy to install straight bars. Figures 2.3 and 2.4 show schematic diagrams and views of the two technologies used to connect the undamaged barrier segments together.

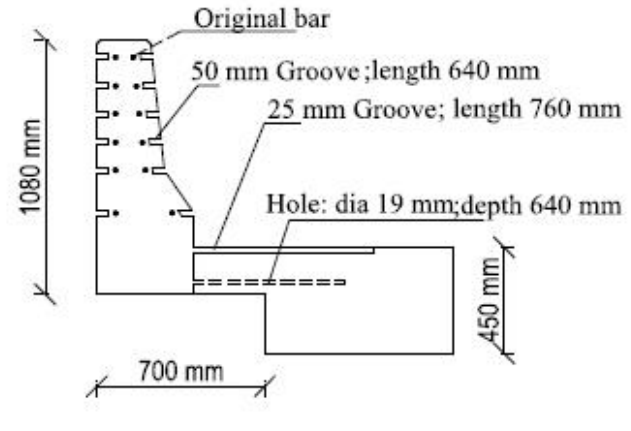

(a) NSM grooves layout

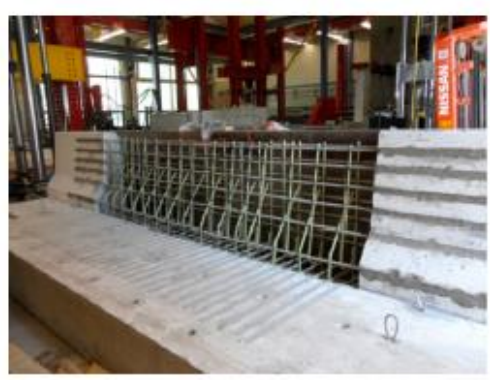

(c) New NSM reinforcement at middle

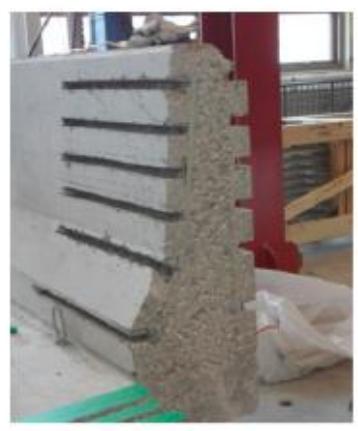

(b) Grooves for horizontal bars

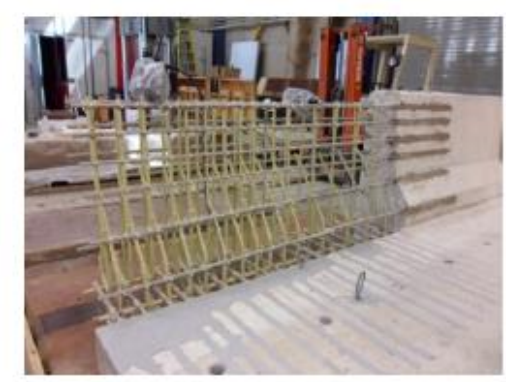

(d) New NSM reinforcement at edge

Figure 2.3: NSM technique (El-Salakawy and Islam, 2014) 


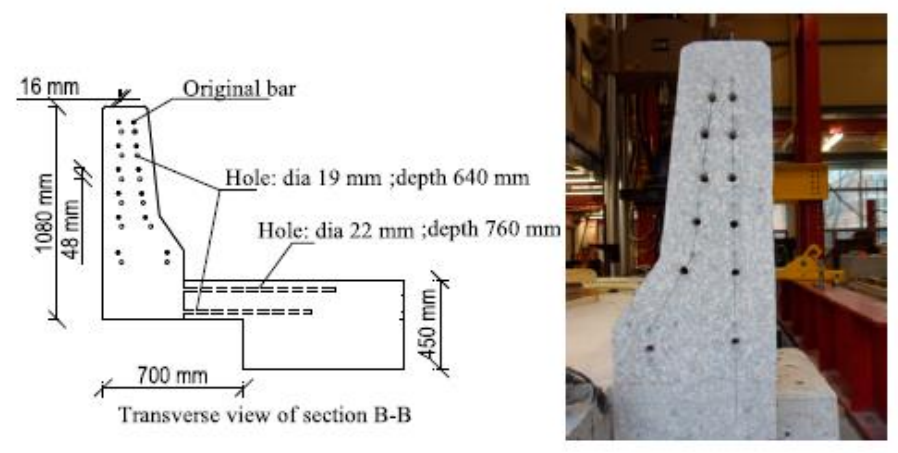

(a) Holes layout

(b) Holes to plant horizontal bars

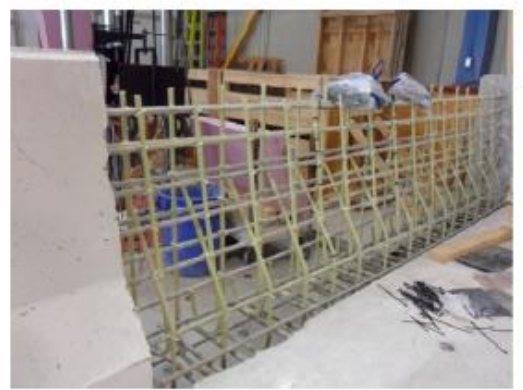

(c) New reinforcement at middle

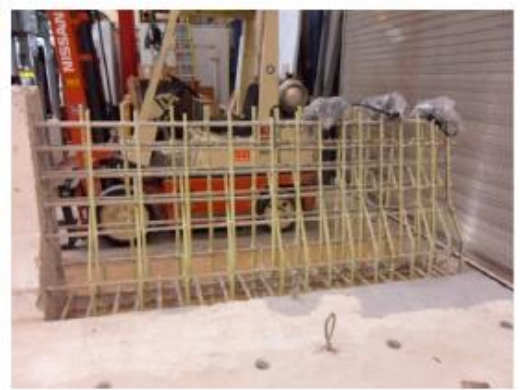

(d) New reinforcement at edge

Figure 2.4: Planting technique (El-Salakawy and Islam, 2014)

El-Salakawy and Islam (2014) concluded that when testing at the middle section of the barrier wall, the failure loads of the specimens with the repair methodologies exceeded the controlled specimen's failure loads. At the exterior sections, only one of the repair techniques surpassed the controlled counterpart, whereas the other one reached $92 \%$ of the controlled specimen's ultimate load. It was concluded that the NSM technique was deemed to be more efficient in terms of load carrying capacity, which can be directly related to the fact that it yields in a greater effective depth of concrete (El-Salakawy and Islam, 2014).

The GFRP bars used in bridge rehabilitation projects require anchorage component between the barrier wall and the deck. This section requires a certain embedment depth for proper anchorage to resist the imposed moments in the event of a collision. Azimi et al. (2014b) explored the pullout capacity of post-installed GFRP bars. This is a paper of high interest for the scope of this thesis as it explored similar areas of research conducted in this thesis but with GFRP bars produced by other manufacturers. Azimi et al. studied the effects of different parameters involved in post-installed bar applications and how they influence their pullout capacities. They tested a total of 120 GFRP bars with the changing parameters being the bar type, bar size, embedment depth, and the type of adhesive used. The tests were conducted on concrete slabs which were reinforced with steel bars. Upon determination of the respective pullout capacities, 
the authors proceeded to conduct regression analysis on the effects of the studied parameters. The considered two different types of GFRP bars, namely: sand coated bars and ribbed-surface bars. Three different bar sizes were examined, namely: $12 \mathrm{~mm}, 16 \mathrm{~mm}$, and $19 \mathrm{~mm}$. The sandcoated bars were of $16 \mathrm{~mm}$ and $19 \mathrm{~mm}$, diameters whereas the ribbed-surface bars were of 12 $\mathrm{mm}$ and $16 \mathrm{~mm}$. The testing included 4 series of 30 samples each. The first series included embedment depths of $100 \mathrm{~mm}, 150 \mathrm{~mm}$, and $200 \mathrm{~mm}$. The second, third, and fourth series included embedment depths of $150 \mathrm{~mm}, 200 \mathrm{~mm}$, and $250 \mathrm{~mm}$. The first and second series were for ribbed-surface bars, and the third and fourth were for sand-coated bars. Each series consisted of samples of identical diameter bar type and diameter but tested with the two different adhesives. Two adhesives were used in the research, namely: HIT RE 500 manufactured by Hilti as Type I adhesive and AnchorFix ${ }^{\circledR}-2011$ manufactured by Sika as Type II. The paper concluded that there was no significant change in results when changing the embedment length from 200 $\mathrm{mm}$ to $250 \mathrm{~mm}$, but a reasonable change was noted when increasing the depth from $150 \mathrm{~mm}$ to $200 \mathrm{~mm}$. Therefore, it was concluded that $200 \mathrm{~mm}$ was the optimal embedment depth of the GFRP bars into concrete (Azimi et al., 2014). Adhesive type I resulted in higher pullout capacities than type II although the paper states that the difference in temperature at the time of installation could have had an impact on these results. The paper also discussed the different failure mechanisms associated with each embedment depth and concluded with a developed equation for GFRP bond stress for design purposes.

\subsection{Implementation of Anchor Headed GFRP Bars in Bridge Barriers}

The deck-wall junction is a critical location of the barrier and bridge system in general. In the event of impact, there must be reassurance that the constructed barrier wall will resist the bending moments exerted by the subject vehicle. The need for becoming more efficient in our designs as engineers, and reducing materials and environmental impacts is of a high priority. Anchor-headed GFRP bars are proposed as they are believed to provide a more effective pullout capacity as opposed to their competition of hooked GFRP bars.

Azimi et al. (2014) conducted an experimental research program to investigate the use pf anchor-headed GFRP bars to connect the barrier wall with the deck slab. The paper also discusses a parametric study that was carried out by the authors to determine effects on design loads due to varying deck slab cantilever lengths and thicknesses as well as longitudinal barrier lengths. The parametric study resulted in developing numerical expressions to determine applied moment and tensile force requirements for designing the barrier- deck and cantilever portions of bridges. First, Azimi et al. proceeded to model TL-4 and TL-5 barriers using finite element modeling. The models generated were for transverse vehicle impacts at both interior and exterior locations of the barrier wall. Applied loads were compliant with the CHBDC requirements. The applied 
transverse loadings was taken as $170 \mathrm{kN}$ and $357 \mathrm{kN}$ for TL-4 and TL-5, respectively. At both locations, the increase in deck thickness of the overhang portion from $175 \mathrm{~mm}$ to $350 \mathrm{~mm}$ showcases a significant increasing effect on moment at the deck-wall junction; the cantilever length has more of an effect on the applied bending moment at the exterior location at the same junction and minimal on the interior locations (less than $10 \%$ ). These variations in deck thickness and cantilever length do not have significant effect on the tensile forces as they do on the magnitude of the moment. The last parameter the investigation considered was the effect of the barrier length. The highlighted lengths were between $4 \mathrm{~m}$ and $7 \mathrm{~m}$ where most of the change was noticed. The study states that there was a significant reduction in moments at both loading locations as the length of the barrier increased from $4 \mathrm{~m}$ to $7 \mathrm{~m}$ (i.e. 4 to $6 \mathrm{~m}$ for TL-4, and 5 to 7 $m$ for TL-5) and barrier lengths greater than such were insignificant; decreasing effects on tensile forces were also noted up to $4 \mathrm{~m}$ and afterwards were none to minimal.

The second part of the research conducted by Azimi et al. included the construction, and testing to complete collapse, full-scale barrier models of $1.2 \mathrm{~m}$ length and reinforced with headed-end GFRP bars to examine their capacities at the barrier-deck junction. The models included TL-4 and TL-5 barriers with tapered and parapet profiles. Two TL-4 and two TL-5 tapered profile barriers, and two TL-5 parapet profile barriers were constructed with each pair containing one barrier being steel reinforced as a control specimen. Figure 2.5 showcases the details of the constructed barriers.
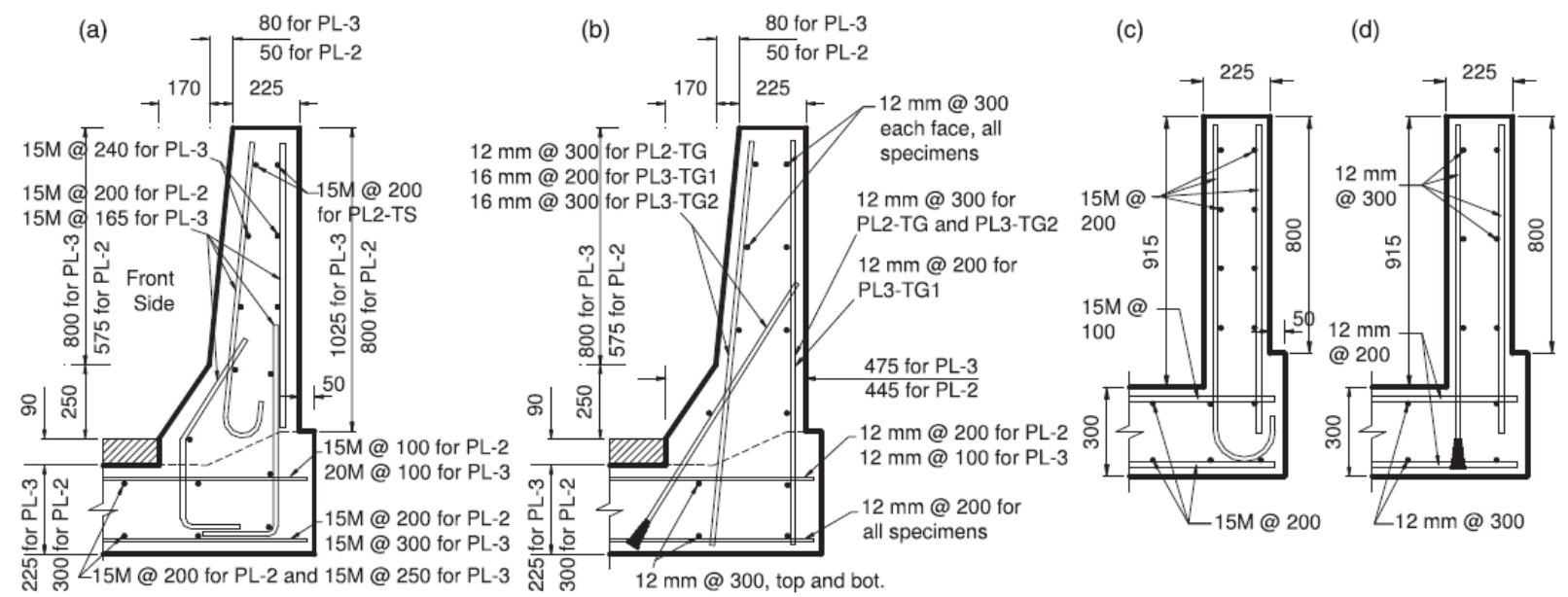

Figure 2.5: Detailing of the 6 barrier specimens (Azimi et al., 2014)

After Azimi et al. tested the 6 barrier specimens to complete failure, the results were benchmarked against the CHBDC factored applied moment at the barrier-deck junction (CSA, 2006). The takeaways from the full scale barrier specimens were that headed-end GFRP bars used 
in tapered profiles of TL-4 and TL-5 bridge barriers could confidently be implemented as they presented a high factor of safety by greatly exceeding CHBDC factored applied bending moments. Whereas the TL-4 parapet profile barrier reinforced with GFRP bars showcased a resistance which was lower than the code requirements and modifications such as increasing bar size or reducing spacing would be required to satisfy code.

\subsection{Improving Design Practices for TL-5 Bridge Barriers}

New and emerging technologies yield way for efficiency upgrades in industry practices. GFRP is emerging as new products are released and industry professionals' interest continues to grow. This is an opportunity for improvements in terms of design and safety of structures. Research conducted at Ryerson University by Sennah and Khederzadeh (2014) took initiative to improve the design, which would increase production efficiency, reduce labor time, and overall cost. The proposed design included a straight 13M GFRP bar at the rear of the barrier wall which extended into the deck portion. This $13 \mathrm{M}$ bar would ultimately result in the elimination of the splice with a hooked bar as was previously designed. The front face of the barrier would now include a 15M GFRP bar with a headed end, which would replace the hooked bar previously required at this location. The spacing of the vertical bars would also be extended to $300 \mathrm{~mm}$. The rear bars do not require the previous heavy reinforcement due to the fact that they will always be under compression in the event of a vehicle colliding with the front face of the barrier (Sennah and Khederzadeh, 2014). Figure 2.6 showcases the difference between the previous design guideline and the proposed one.

Sennah and Khederzadeh presented the proposed research in two separate publications, one consisting of static load testing and one with vehicle crash testing. The static load test was conducted in an outdoor environment at the Texas Transportation Institute (TTI) site (Sennah and Khederzadeh, 2014). The research was conducted using sand-coated GFRP bars, with the front $15 \mathrm{M}$ bars being headed. A $27.6 \mathrm{~m}$ barrier wall was constructed with construction joints at every $4 \mathrm{~m}$, and a characteristic concrete compressive strength of $30.9 \mathrm{MPa}$. Testing was done at interior and exterior locations. In both tests, the governing failure mode was punching shear, with interior and exterior ultimate loads at $654.9 \mathrm{kN}$ (15.71 mm deflection) and $541 \mathrm{kN}$ (26.67 $\mathrm{mm}$ deflection), respectively. When the authors compared the experimentally deduced values with the CHBDC value $(357 \mathrm{kN})$, reserve in strength in the order of 1.83 and 1.52 times the design values for interior and exterior locations were achieved. 

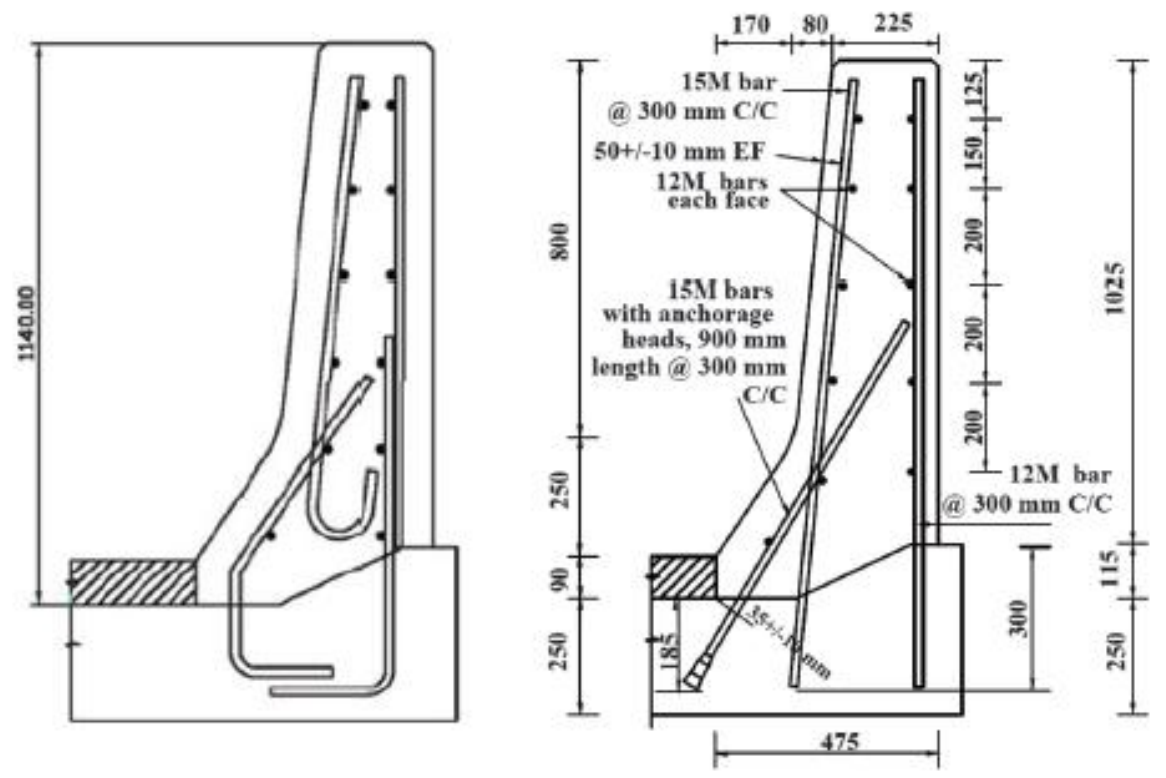

Figure 2.6: Previous detailing (left) vs. the proposed new GFRP detailing for TL-5 barriers (right) (Sennah and Khederzadeh, 2014)

Many of the design codes around the world offer punching shear formulas to guide in design and setting the adequate standards for engineering design. These formulas are modifications of steel reinforcement design standards, but attempt to take into consideration the higher modulus of elasticity of GFRP bars (Khederzadeh and Sennah, 2014). The different codes/standards were applied to the barrier used in Khederzadeh and Sennah's research to deduce a comparative analysis on the accuracy of punching shear prediction amongst the different formulas. Ratios of the experimentally tested models over the predictions calculated by the codes/standards were analyzed for over or underestimation. The most conservative design proved to be by using the punching shear equation specified in CSA-S806-12 (CSA, 2012) based on the calculations presented in the paper by Khederzadeh and Sennah. The authors then developed an empirical formula by attempting to combine the CSA-S806-12 and Jacobson D. et al. (2005) formulas listed below.

$V_{c}=4.5\left(\rho_{f} f_{c}^{\prime}\right)^{\frac{1}{3}} x(1 / d)^{\frac{1}{4}} x b_{o, 1.5 d} x d$ (Jacobson et al., 2005)

CSA-S806-12 specifies the punching shear strength to be the lowest of the three formulas listed below.

$V_{c}=\left(1+\frac{2}{\beta_{c}}\right) \times 0.028 \lambda \varphi_{c}\left(E_{r} \rho_{r} f^{\prime}{ }_{c)}\right)^{\frac{1}{3}} \times b_{o, 0.5 d} x d$ 


$$
\begin{aligned}
& V_{c}=\left(\alpha_{s} d / b_{o, 0.5 d}\right) \times 0.147 \lambda \varphi_{c}\left(E_{r} \rho_{r} f^{\prime}{ }_{c)}\right)^{\frac{1}{3}} \times b_{o, 0.5 d} \times d \\
& V_{c}=0.056 \lambda \varphi_{c}\left(E_{r} \rho_{r} f^{\prime}{ }_{c)}\right)^{\frac{1}{3}} \times b_{o, 0.5 d} \times d
\end{aligned}
$$

The symbols used in the above formulas are outlined below:

$\rho_{f}=$ average of the two reinforcement ratios in both longitudinal and transverse directions

$f^{\prime}{ }_{c}=$ concrete compressive strength in $\mathrm{MPa}$

$d=$ effective slab depth in $\mathrm{mm}$

$b_{o, 0.5 d}=$ critical perimeter length measured at $0.5 \mathrm{~d}$ from the loading patch

$\beta_{c}=$ ratio of long side to short side of the loading patch

$\lambda=$ density factor (normal density concrete is 1 )

$\varphi_{c}=$ concrete resistance factor

$\alpha_{s}=$ adjustment factor for $V_{c}$ for support dimensions

$E_{r}=$ modulus of elasticity of FRP bars

$\rho_{r}=$ FRP tensile reinforcement ratio

Khederzadeh and Sennah (2014) analyzed the above equations and modified them to better suit their experimental results in effort to provide a more accurate representation of the punching shear resistance prediction. The formula derived by the authors is as follows:

$$
V_{c}=\left(1+\frac{2}{\beta_{c}}\right) \times 0.136 \lambda \varphi_{c} \frac{\left(E_{f} \rho_{f} f^{\prime}{ }_{c}\right)^{\frac{1}{3}}}{d^{1 / 4}} \times b_{o, 1.5 d} \times d
$$

Where,

$\rho_{f}=\left(\rho_{f x} E_{f x}+\rho_{f y} E_{f y}\right) /\left(E_{f x}+E_{f y}\right)=$ average reinforcement ratio of transverse and longitudinal GFRP at the tension face of the wall

$E_{f}=\left(\rho_{f x} E_{f x}+\rho_{f y} E_{f y}\right) /\left(\rho_{f x}+\rho_{f y}\right)=$ average modulus of elasticity of transverse and longitudinal GFRP at the tension face of the wall

$\rho_{f x}=A_{f x} /(b d)=$ GFRP transverse reinforcement ratio along x-axis

$\rho_{f y}=A_{f y} /(b d)=$ GFRP transverse reinforcement ratio along y-axis

$A_{f x}=A_{b x} 1000 / S_{y}=$ total GFRP reinforcement in transverse direction per meter of wall 
$A_{f y}=A_{b y} 1000 / S_{x}=$ total GFRP reinforcement in longitudinal direction per meter of wall

$E_{f x}=$ GFRP modulus of elasticity along $\mathrm{x}$-axis

$E_{f y}=$ GFRP modulus of elasticity along y-axis

$A_{b x}=$ cross-sectional area of one GFRP bar along $\mathrm{x}$-axis

$A_{b y}=$ cross-sectional area of one GFRP bar along y-axis

The experimental values were then benchmarked against the newly derived punching shear formulas and a good correlation was determined. Ratios of experimental failure load to the proposed formula failure load for interior and exterior locations were 1.19 and 1.11, respectively (Khederzadeh and Sennah, 2014). The static load testing, which included loading certain sections of a $27.6 \mathrm{~m}$ TL-5 barrier wall to failure, was concluded that the newly proposed cost effective GFRP bar layout was adequate and successful in satisfying CHBDC criteria (Khederzadeh \& Sennah, 2014). CHBDC Clause 12.4.3.4 requires conducting full scale crash testing involving a tractor trailer to satisfy the 2009 AASHTO Manual for Assessing Safety Hardware (MASH, 2009). MASH specifies certain criteria that need to be satisfied in order for the crash test to be deemed successful. The three criteria are: 1) structural adequacy - controlling the vehicle movement after impact; 2) occupant risk - minimal risk exposure to persons in the vehicle colliding and surrounding environment (including pedestrians/workers); 3) vehicle trajectory after collision potential risks of impact with other traffic/ objects (Sennah and Khederzadeh, 2014).

In the full scale crash test, the constructed barrier wall was of $27.6 \mathrm{~m}$ and with the same detailing as the static load testing. The barrier details for the crash test are depicted in Figure 2.7. The vehicle used in the crash test was a 36000V van-type tractor trailer (cab-behind-engine model with a total mass of $36,000 \mathrm{~kg})$ which had to be traveling at $80 \mathrm{~km} / \mathrm{h}(+/-4 \mathrm{~km} / \mathrm{h})$ and impact at a $15^{\circ}$ angle $\left(+/-1.5^{\circ}\right)$ in order to satisfy the MASH requirements (Sennah and Khederzadeh, 2014). The vehicle used in the test satisfied these criteria and was within the tolerance levels. The tractor-trailer was loaded with concrete and ballast to achieve the weight requirements for the test. Upon testing the authors deemed the best location for impact was at the control joint, which would be a more critical location and possibility of failure is increased (Sennah and Khederzadeh, 2014). 


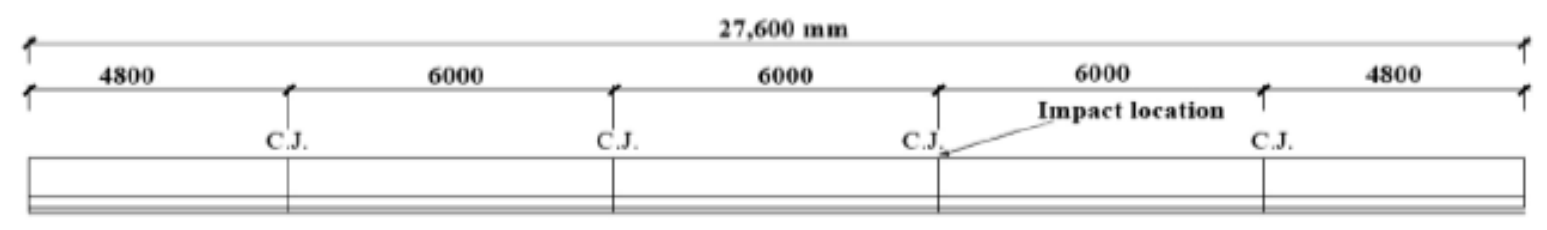

a) Barrier elevation with four control joints

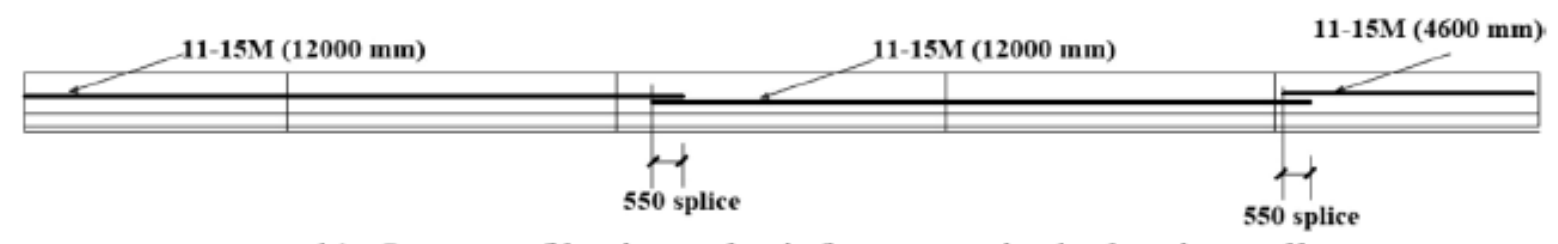

b) Layout of horizontal reinforcement in the barrier wall

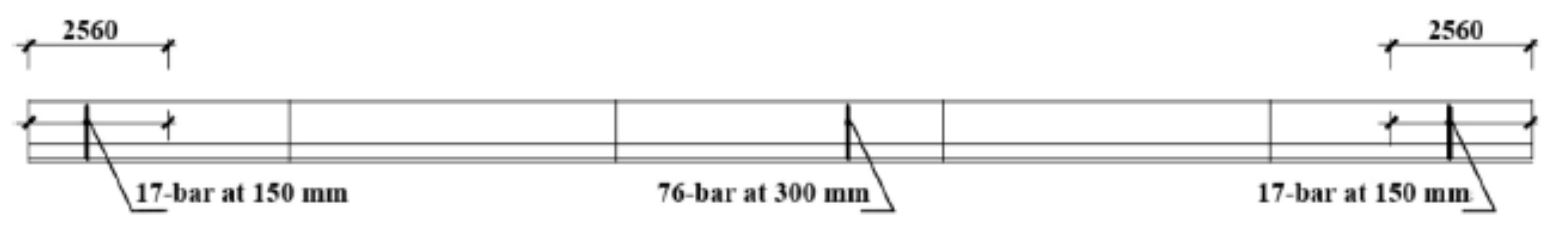

c) Layout of vertical reinforcement in the barrier wall

Figure 2.7: Elevation details for the crash tested PL-3 barrier (Sennah and Khederzadeh, 2014)

The truck was then remote controlled to collide with the barrier wall and numerous accelerometers and LVDTs were placed on the truck and barrier to monitor the behaviors of all elements. Data then showed that the barrier was imposed to three separate collisions from the truck, due to the redirecting influence the barrier brought upon the truck causing the rear portions of the vehicle and trailer to collide with slight delays from the front, initial, impact (Sennah and Khederzadeh, 2014). The authors' research concluded that the crash test was successful in satisfying all relative criteria, with the vehicle not over-riding, under-riding, or penetrating the barrier wall; the vehicle was redirected appropriately; the occupant's cabin was within the thresholds put in place by MASH, and no deformability was apparent; no detached debris from the barrier was found which could be a risk to the surrounding setting; and the vehicle remained upright the entire time, before, during, and after the test (Sennah and Khederzadeh, 2014).

\subsection{GFRP Reinforced Concrete Exposed to Extreme Heat}

Although the climate in North America is relatively cold and corrosion of steel reinforcement is an imminent threat to the structural integrity of our infrastructure, namely bridges, it is important to cover all grounds with respect to temperature variance. GFRP bars may be used in infrastructure situated in environments of dense forests and bushes, which would then be more 
vulnerable to extreme heat due to fires. Fire could ignite due to forests and bushes being exposed to extreme heat via the sun, or a collision on a bridge causing a vehicle to erupt into flames. It is an important field which requires investigation and a paper written by Pagani et al. (2014) addressed some of these concerns in the engineering society. The paper studied the effects of a fire acting directly under a GFRP reinforced bridge deck while being exposed to loading conditions. The authors argue that due to the glass transition phase temperature GFRP performance in infrastructure under elevated temperatures will be negatively impacted.

Pagani et al. stated the conditions necessary for a bridge deck to achieve temperatures which would be higher than the glass transition temperature. They stated various conditions in a sense of which would apply to everyday situations and others which would indicate more rare instances such as a truck carrying chemicals and igniting underneath a fly-over. A vehicle burning on the bridge deck would not yield temperatures in excess of $600^{\circ} \mathrm{C}$ due to the fact that the flames would rise and not apply constant heat to the deck which in combination with asphalt acts as added protection for the GFRP bars (Pagani et al., 2014). The temperature of $600^{\circ} \mathrm{C}$ was determined to be a point in concrete elements where most strength and reliability is lost (Di Luzio et al., 2009). According to Pagani et al., a bridge would need to have a clearance beneath of a minimum 20 meters to allow for dense trees to grow and simulate a higher temperature bushfire, and even then the flames would not be constantly applied directly beneath the bridge deck. Nevertheless, their experiment proceeded and the objective was achieved, which was to study the effects of elevated temperatures on a GFRP reinforced bridge deck.
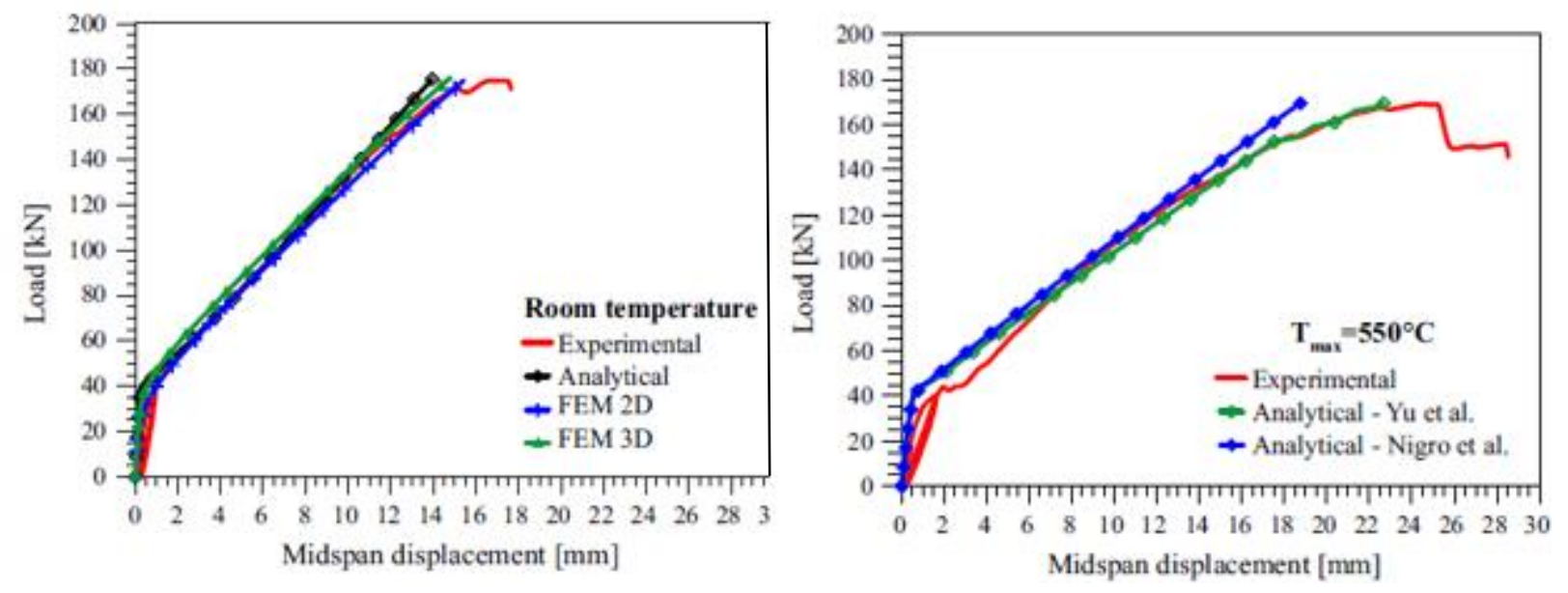

Figure 2.8: Comparison of loading at room temperature vs. loading at 550 degrees Celsius (Pagani et al., 2014)

Pagani et al. conducted the experiments under room temperature conditions and also under elevated temperature conditions. The concrete was heated for a period of 2.5 hours and 
managed to reach a temperature of $550^{\circ} \mathrm{C}$. When comparing the two results (room temperature vs. elevated temperature) from the published paper, it is noticed that deflection nearly doubled. However, the ultimate strength only saw a reduction of about $10 \%$. Both of the specimens tested in the experiment failed due to shear, which is mainly due to the concrete elements. Thus the paper concludes that the tensile capacity of bridge decks is not greatly influenced by the exposure of such elevated temperatures, but the bond strength and Young's modulus of the reinforcing bars may be compromised which would mean external rehabilitation would need to take place (Pagani et al., 2014). Figure 2.8 shows a comparison of loading at room temperature vs. loading at 550 degrees Celsius (Pagani et al., 2014). 


\section{Chapter 3: Phase 1 - GFRP Pullout Capacity}

\subsection{Phase Overview}

Vertical reinforcement in cantilever walls is critical to their structural integrity due to the flexure that is being exerted on the concrete elements. In order for these bars to effectively serve their purpose, the development length into the adjacent member must be effectively designed and implemented. In bridge barrier walls, this development length is critical to public safety as the moment exerted on the barrier-slab junction could potentially be in great magnitudes due to the event of a tractor trailer collision. This development length needs to be sufficient in order to prevent the wall from failing by the connecting bars physically pulling out of the concrete slab.

As depicted in Figure 3.1, there are three rows of vertical GFRP bar reinforcement on the barrier which act as a connection between the slab and the wall. The front side of the barrier includes the most critical $63^{\circ}$ angled bar and the $84^{\circ}$ bar at the top and bottom tapered portion of the wall. The $63^{\circ}$ angled bar is made of high modulus (HM) anchor-headed bar, shown in Figure 3.2, which is expected to possess a higher pullout capacity at the barrier-deck junction. In phase 1 of this research, GFRP bar pullout capacities were explored and benchmarked against a regular straight GFRP bar. Also, the pullout capacity of the headed portion was tested under pullout force as a stand-alone feature. The anchor-headed GFRP bar was then implemented in phase 2 of this research to strength the barrier-deck junction as shown in Figure 3.2.

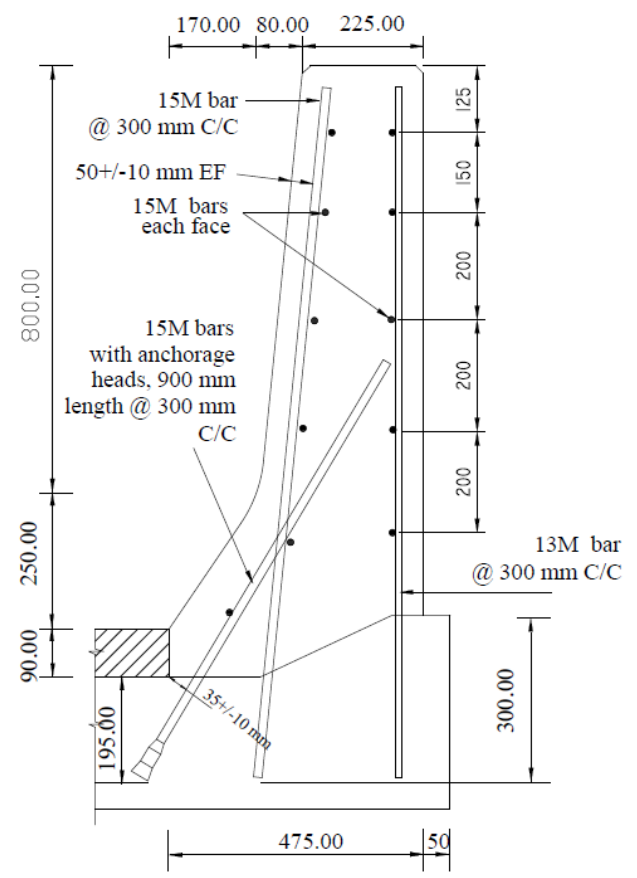

Figure 3.1: Cross-Section of a developed GFRP-reinforced barrier

(Sennah and Khederzadeh, 2014) 


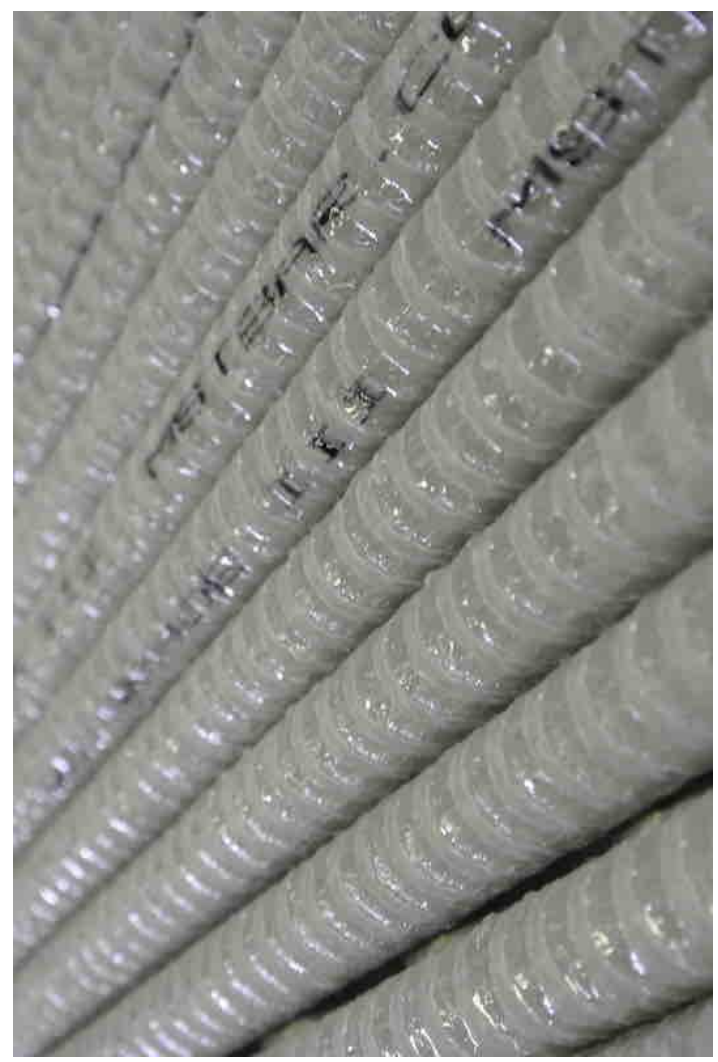

a) Straight bars

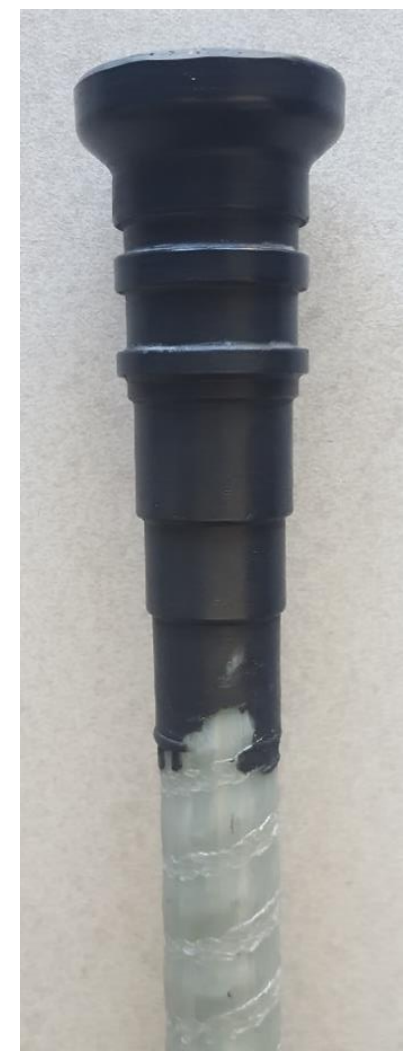

b) Headed-end bar

Figure 3.2: Newly-developed HM GFRP bar (B\&B FRP Manufacturing Inc., 2016)

For bridge-barrier rehabilitation the use of post-installed straight bars will have to be implemented and appropriate epoxy will need to be used. Drilling into pre-existing concrete will typically be of constant diameter, and the headed bar possesses a conical shape making installation extremely difficult and would yield in improper use of epoxy (overuse at the top). For the purpose of determining appropriate embedment length into the pre-existing concrete, three different depths were explored in this study, namely: depths of 150, 175, and $200 \mathrm{~mm}$. The reports research in Phase 1 includes specimen construction and testing to collapse, followed by presentation of experimental findings and conclusion of this research.

\subsection{Material Properties}

\subsubsection{Concrete Properties}

Concrete ordered for phase 1 in this research was of high-early strength $30 \mathrm{MPa}$ compressive strength and included superplasticizer to increase workability at the time of casting. Three concrete cylinders $(100 \times 200 \mathrm{~mm})$ were tested daily for the first 7 days while three cylinders 
were tested on each day of pullout testing. Table 3.1 depicts the maturing of the concrete along the 7 days after casting, while Table 3.2 outlines the concrete compressive strength on the day of testing. It should be noted that the characteristic value of concrete compressive strength was used in calculations. The characteristic value was calculated using the following formula as per CHBDC Clause A14.1.2 (CSA Group, 2014).

$f^{\prime}{ }_{c}=0.9 \bar{f}_{c}\left[1-1.28\left[\frac{\left(k_{c} V\right)^{2}}{n}+0.0015\right]^{0.5}\right]$

Where,

$\bar{f}_{c}=$ average cylinder strength

$V=$ coefficient of variation of cylinder strengths

$\mathrm{n}=$ number of cylinders tested

$k_{c}=$ found on Table A14.1.2 of the CHBDC by matching " $\mathrm{n}$ "

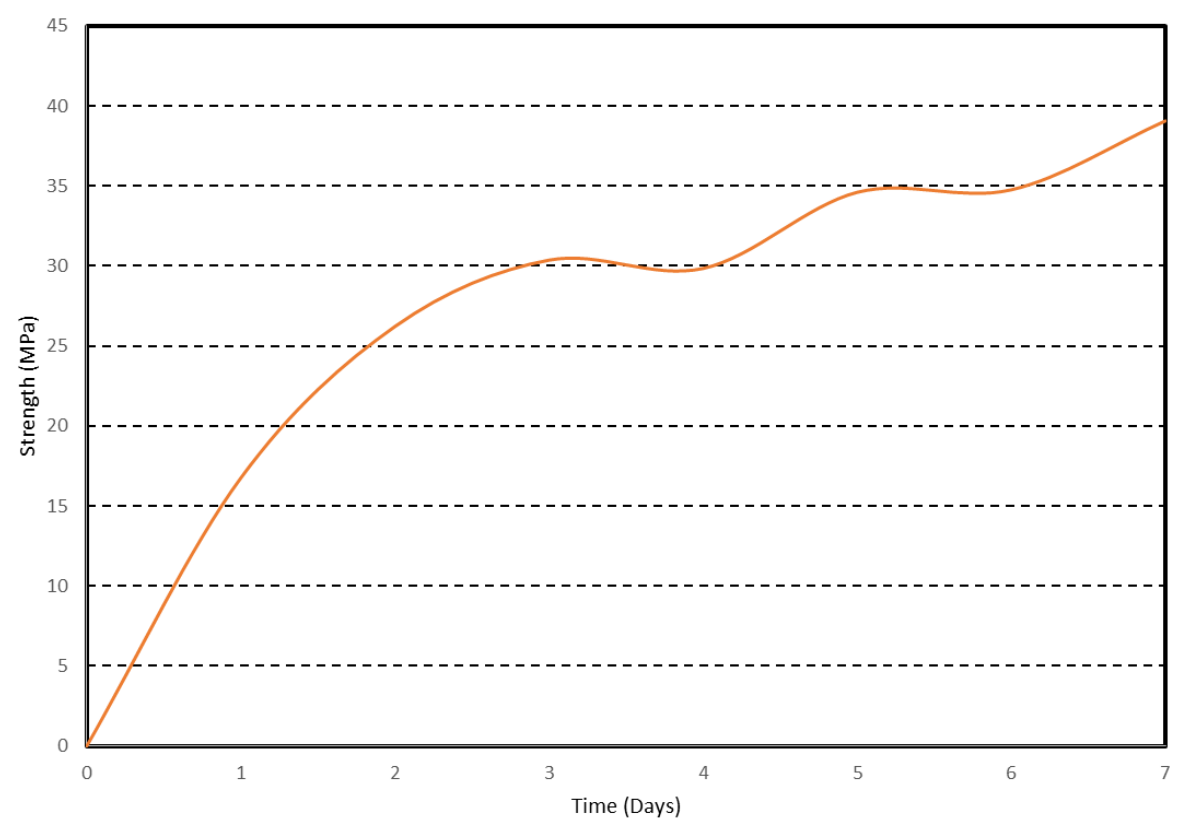

Figure 3.3: Slab concrete maturity throughout 7 days after casting

The concrete maturity has also been shown in a graphical format to observe any unusual trends in strength attainment. Figure 3.3 depicts the maturity of the concrete used in the concrete slab. One may observe no unusual trend in concrete maturity history. It can also be observed that the concrete strength is slightly higher than anticipated, however, it is consistent with the testing of the barrier specimens which is shown in the next chapter. 
Table 3.1: Summary of pullout slab concrete strength

\begin{tabular}{|c|c|c|c|c|c|c|}
\hline $\begin{array}{l}\text { Time } \\
\text { (Days) }\end{array}$ & Specimen & $\begin{array}{c}\text { Strength } \\
\text { (MPa) }\end{array}$ & $\begin{array}{l}\text { Strength } \\
(\mathrm{kN})\end{array}$ & $\begin{array}{c}\text { Average strength } \\
\text { (MPa) }\end{array}$ & $\begin{array}{c}\text { Average } \\
\text { strength }(\mathrm{kN})\end{array}$ & $\begin{array}{c}\text { Characteristic } \\
\text { value }(\mathrm{MPa})\end{array}$ \\
\hline \multirow{3}{*}{1} & 1 & 19.64 & 154.26 & \multirow{3}{*}{19.60} & \multirow{3}{*}{154.71} & \multirow{3}{*}{16.76} \\
\hline & 2 & 19.63 & 156.5 & & & \\
\hline & 3 & 19.53 & 153.38 & & & \\
\hline \multirow{3}{*}{2} & 1 & 32.11 & 252.19 & \multirow{3}{*}{31.09} & \multirow{3}{*}{244.20} & \multirow{3}{*}{26.22} \\
\hline & 2 & 31.26 & 245.51 & & & \\
\hline & 3 & 29.91 & 234.91 & & & \\
\hline \multirow{3}{*}{3} & 1 & 35.73 & 280.61 & \multirow{3}{*}{35.66} & \multirow{3}{*}{280.11} & \multirow{3}{*}{30.37} \\
\hline & 2 & 34.94 & 274.45 & & & \\
\hline & 3 & 36.32 & 285.27 & & & \\
\hline \multirow{3}{*}{4} & 1 & 37.88 & 297.49 & \multirow{3}{*}{36.33} & \multirow{3}{*}{285.30} & \multirow{3}{*}{29.85} \\
\hline & 2 & 33.57 & 263.65 & & & \\
\hline & 3 & 37.53 & 294.76 & & & \\
\hline \multirow{3}{*}{5} & 1 & 40.42 & 317.45 & \multirow{3}{*}{40.47} & \multirow{3}{*}{317.87} & \multirow{3}{*}{34.61} \\
\hline & 2 & 40.31 & 316.58 & & & \\
\hline & 3 & 40.69 & 319.57 & & & \\
\hline \multirow{3}{*}{6} & 1 & 38.90 & 305.53 & \multirow{3}{*}{44.04} & \multirow{3}{*}{345.92} & \multirow{3}{*}{34.77} \\
\hline & 2 & 45.63 & 358.35 & & & \\
\hline & 3 & 47.60 & 373.88 & & & \\
\hline \multirow{3}{*}{7} & 1 & 46.53 & 365.42 & \multirow{3}{*}{45.84} & \multirow{3}{*}{360.01} & \multirow{3}{*}{39.07} \\
\hline & 2 & 45.01 & 353.52 & & & \\
\hline & 3 & 45.98 & 361.1 & & & \\
\hline
\end{tabular}


Table 3.2: Concrete strength on day of testing

\begin{tabular}{|c|c|c|c|c|c|c|c|}
\hline $\begin{array}{c}\text { Type of } \\
\text { test }\end{array}$ & Time & Specimen & $\begin{array}{l}\text { Strength } \\
(\mathrm{MPa})\end{array}$ & $\begin{array}{l}\text { Strength } \\
(\mathrm{kN})\end{array}$ & $\begin{array}{c}\text { Average } \\
\text { strength } \\
(\mathrm{MPa})\end{array}$ & $\begin{array}{c}\text { Average } \\
\text { strength } \\
(\mathrm{kN})\end{array}$ & $\begin{array}{c}\text { Characteristic } \\
\text { value (MPa) }\end{array}$ \\
\hline \multirow{3}{*}{$\begin{array}{c}\text { Pre- } \\
\text { Installed }\end{array}$} & \multirow{3}{*}{$\begin{array}{c}10 \\
\text { Days }\end{array}$} & $\mathrm{C}-1$ & 46.53 & 365.48 & \multirow{3}{*}{46.34} & \multirow{3}{*}{363.95} & \multirow{3}{*}{39.62} \\
\hline & & $C-2$ & 46.06 & 361.74 & & & \\
\hline & & $C-3$ & 46.43 & 364.63 & & & \\
\hline \multirow{3}{*}{$\begin{array}{c}\text { Pre- } \\
\text { Installed }\end{array}$} & \multirow{3}{*}{$\begin{array}{c}12 \\
\text { Days }\end{array}$} & $A B-1$ & 48.84 & 383.58 & \multirow{3}{*}{45.33} & \multirow{3}{*}{356.05} & \multirow{3}{*}{34.40} \\
\hline & & $A B-2$ & 49.00 & 384.84 & & & \\
\hline & & $A B-3$ & 38.16 & 299.73 & & & \\
\hline \multirow{3}{*}{$\begin{array}{c}\text { Post- } \\
\text { Installed }\end{array}$} & \multirow{3}{*}{$\begin{array}{l}47 \\
\text { Days }\end{array}$} & 1 & 53.96 & 423.77 & \multirow{3}{*}{52.91} & \multirow{3}{*}{415.52} & \multirow{3}{*}{44.87} \\
\hline & & 2 & 51.28 & 402.70 & & & \\
\hline & & 3 & 53.49 & 420.08 & & & \\
\hline
\end{tabular}

\subsubsection{Steel Properties}

The cast slab was reinforced with steel bars as shown in Figure 3.4. The steel used was regular $400 \mathrm{~W}$ and was consistent throughout all construction phases of this experiment as well as the barrier construction. Steel bars were $15 \mathrm{M}$ in size and spacing of $300 \mathrm{~mm}$ center-to-center both ways. Top and bottom of the slab was reinforced with the same amount of steel bars as depicted in Figure 3.4. A $50 \mathrm{~mm}$ clear cover to steel reinforcement was used.

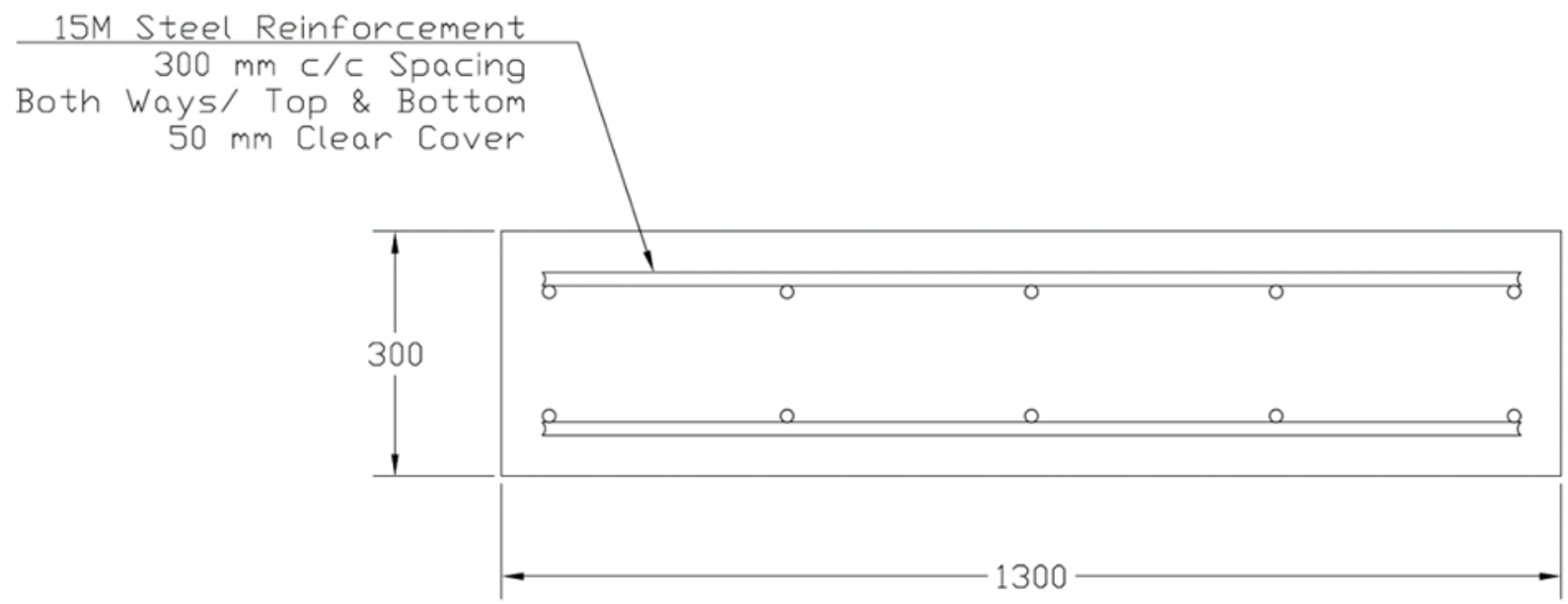

Figure 3.4: Typical pullout slab reinforcement details 


\subsubsection{GFRP Properties}

The GFRP bars used in this research included straight bars of $16 \mathrm{~mm}$ diameter (\#5 MST-Bar Grade III). The anchor-headed bars were of the same bar diameter but with cast head of $100 \mathrm{~mm}$ length and $38 \mathrm{~mm}$ maximum diameter at the bar end. Bar specifications as provided by the manufacturer are depicted in Table 3.3.

Table 3.3: GFRP Bar Specifications (B\&B FRP Manufacturing Inc., 2016)

\begin{tabular}{|c|c|c|c|c|c|c|}
\hline $\begin{array}{c}\text { Imperial } \\
\text { size }\end{array}$ & $\begin{array}{c}\text { Metric size } \\
(\mathrm{mm})\end{array}$ & $\begin{array}{c}\text { Ultimate tensile } \\
\text { strength (MPa) }\end{array}$ & $\begin{array}{c}\text { Young's modulus } \\
\text { of elasticity (MPa) }\end{array}$ & $\begin{array}{c}\text { Ultimate } \\
\text { strain } \\
(\%)\end{array}$ & $\begin{array}{c}\text { Bond } \\
\text { strength } \\
(\mathrm{MPa})\end{array}$ & $\begin{array}{c}\text { Weight } \\
(\mathrm{Kg} / \mathrm{m})\end{array}$ \\
\hline$\# 5$ & 16 & 1000 & 70,000 & $1.5 \%$ & 20 & 0.55 \\
\hline
\end{tabular}

\subsubsection{Epoxy Properties}

The epoxy used for the post-install bar portions of the experiment was purchased directly from Hilti. Hilti offers a wide variety of epoxies which could be used with concrete elements, however the product satisfying conditions pertaining to this experiment was Epoxy HIT-RE 500 V3 (Hilti, 2016). The epoxy possessed properties in which this research depends on, and allows for flexibility in timing and planning of the work. Table 3.4 depicts the specifications as per the product sheet provided by the manufacturer. The epoxy is loaded with two separate cartridges in one unit, which is mixed at the time of use. The application of the epoxy into the concrete matrix was achieved through a distinct Hilti manual dispenser (caulking gun). The product was named HDM 500, and press the two components of the epoxy together which would in turn minimize mixing ratio errors.

Table 3.4: Epoxy Specifications (Hilti Canada Corporation, 2016)

\begin{tabular}{|c|c|c|c|c|c|}
\hline $\begin{array}{c}2 \text { Day cure - } \\
\text { bond strength } \\
(\mathrm{MPa})\end{array}$ & $\begin{array}{c}\text { Compressive } \\
\text { strength (MPa) }\end{array}$ & $\begin{array}{c}\text { Compressive } \\
\text { modulus (MPa) }\end{array}$ & $\begin{array}{c}\text { 7 Day tensile } \\
\text { strength } \\
(\mathrm{MPa})\end{array}$ & $\begin{array}{c}\text { Elongation } \\
\text { at break } \\
(\%)\end{array}$ & $\begin{array}{c}\text { Absorption } \\
(\%)\end{array}$ \\
\hline 10.8 & 82.7 & 2600 & 49.3 & 1.1 & 0.18 \\
\hline
\end{tabular}




\subsection{Phase Construction and Methodology}

\subsubsection{Pre-Installed Bars}

The cast concrete slab had three separate regions to allow for testing different bar configurations, namely: (i) pre-installed GFRP bars with straight ends, (ii) pre-installed GFRP bars with headed ends, and (iii) post-installed GFRP bars with straight ends. These regions as marked as Groups 1 through 3 in Figure 3.5. Group 1 of bar pullout testing consisted of five straight GFRP bars which are fully bonded to concrete with an embedment length of $195 \mathrm{~mm}$, as shown in Figure 3.6. Group 1 tests would provide research information on the pullout capacity of the middle vertical bar in the barrier wall shown in Figure 3.1. Group 2 incorporates the same type and number of bars with the same embedment length as those for Group 1, however in this group the bar was fully bonded for the entire $247 \mathrm{~mm}$ embedment length as depicted in Figure 3.7. Group 2 tests would provide research information on the pullout capacity of the diagonal headed-end bar reinforcing the lower tapered portion of the barrier wall shown in Figure 3.1. Group 3 consisted of five headed GFRP bars which were not fully bonded to the concrete. The total embedment length of the bar was taken as $247 \mathrm{~mm}$ from the top of the slab, however, only the bottom $100 \mathrm{~mm}$ was fully bonded to the concrete as depicted in Figure 3.8. The bottom 100 $\mathrm{mm}$ of the embedment length is the portion of the bar that is headed while the top $147 \mathrm{~mm}$ of the embedment length consists of straight GFRP bar which was left un-bonded. In order to achieve the un-bonded condition, pipe insulation foam was used to wrap around the top $147 \mathrm{~mm}$ of the embedded length of the bar. The reasoning behind using these conditions is to investigate the true pull-out strength contribution of the added anchor head. The three groups are split up in their own individual slabs as depicted in Figure 3.5. In addition, each bar was spaced enough to avoid interference of the individual bar failure modes.

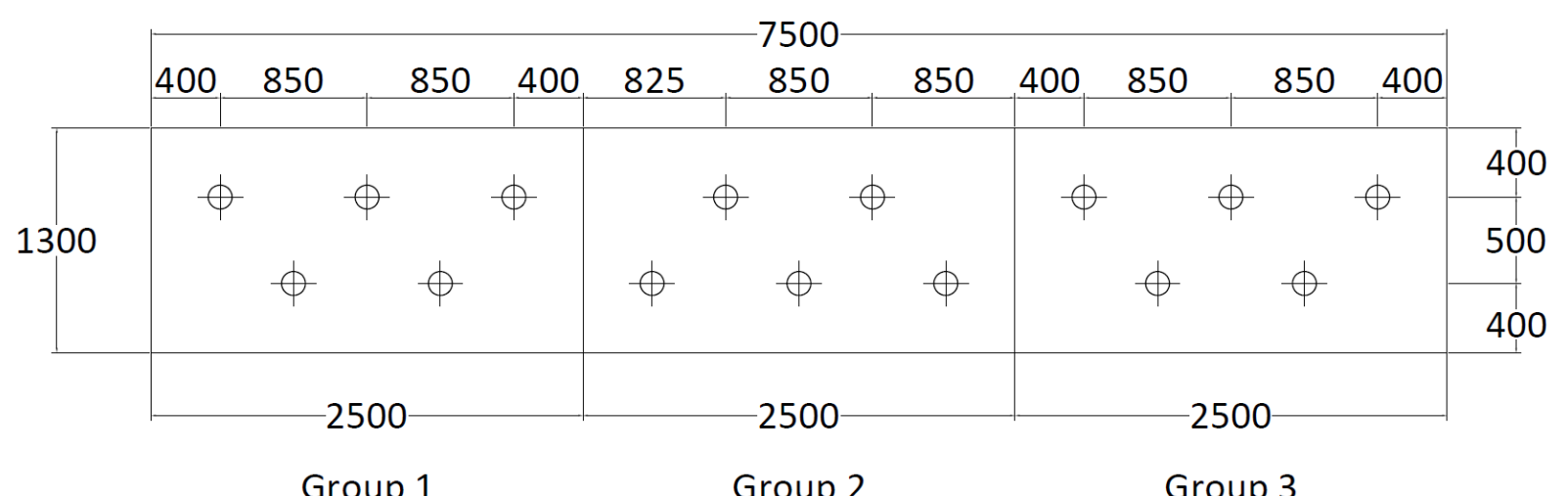

Figure 3.5: Plan of the concrete slab showing pre-installed GFRP bar locations 


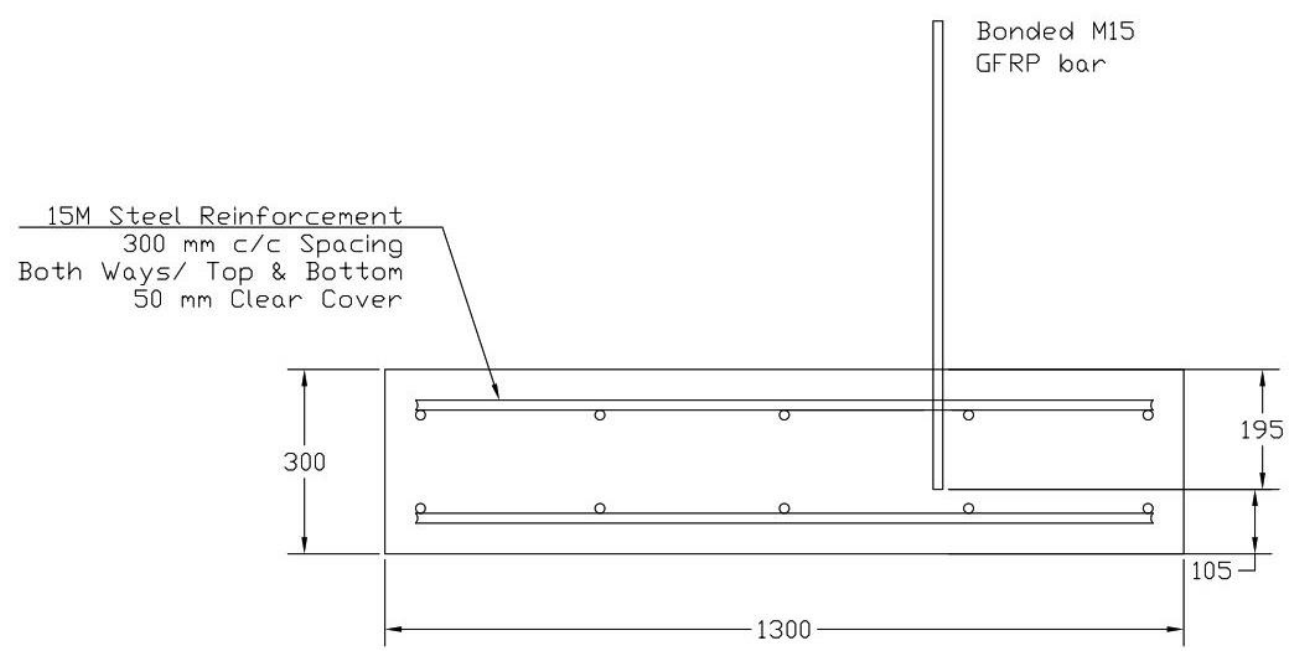

Figure 3.6: Group 1 - Straight fully-bonded GFRP bar in concrete

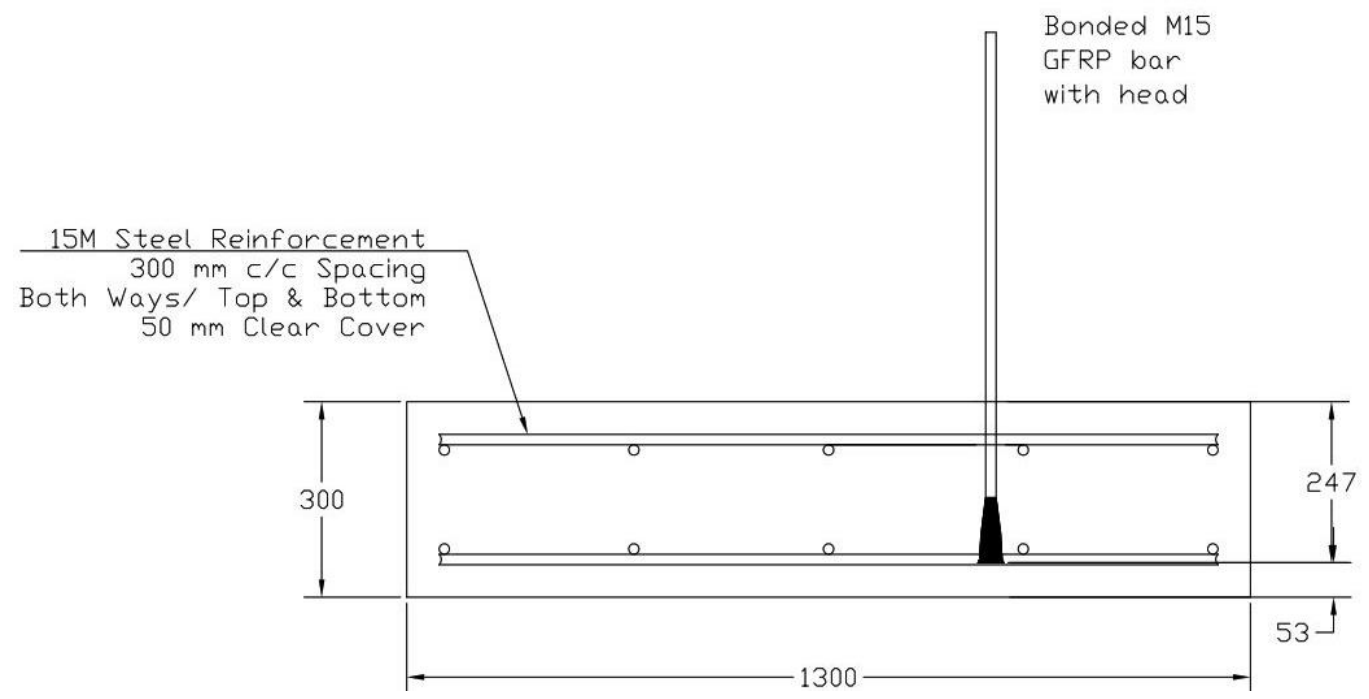

Figure 3.7: Group 2 - Headed-end GFRP bar with fully-bonded straight length in concrete

The necessary timber forms were built ensuring adequate reinforcing lumber to avoid bulging of the forms and maintain level during the concrete pour. Formwork and steel bar layout is depicted in Figure 3.9. After installing the steel bar meshes in the wood forms, the installation and securing of the GFRP in their respective positions took place. Figures 3.10 and 3.11 below showcase the slab before and after the concrete pour with the GFRP bars secured in place. 


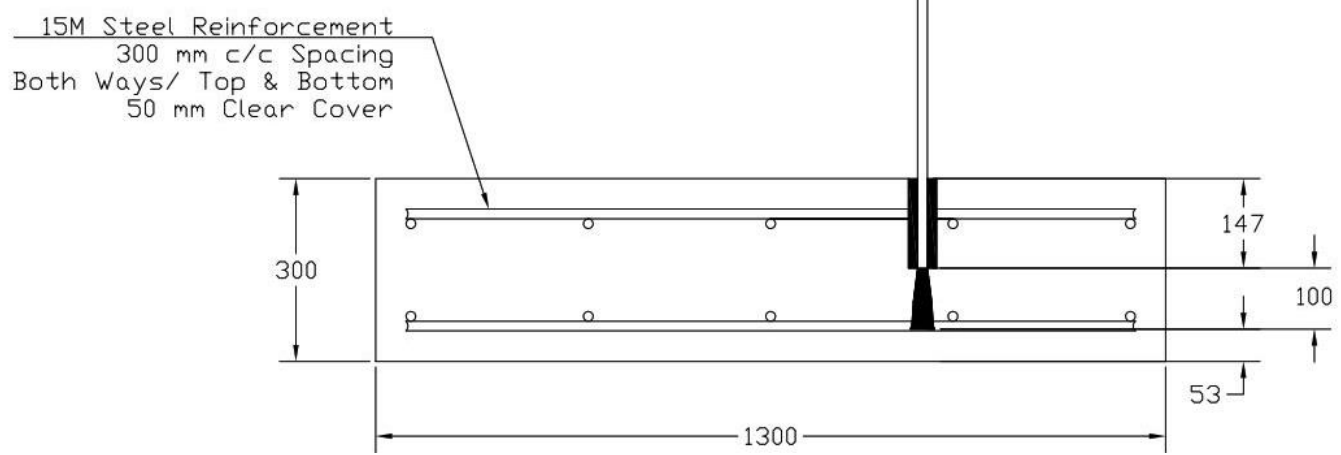

Figure 3.8: Group 3 - Headed-end GFRP bars with unbonded straight portion in concrete

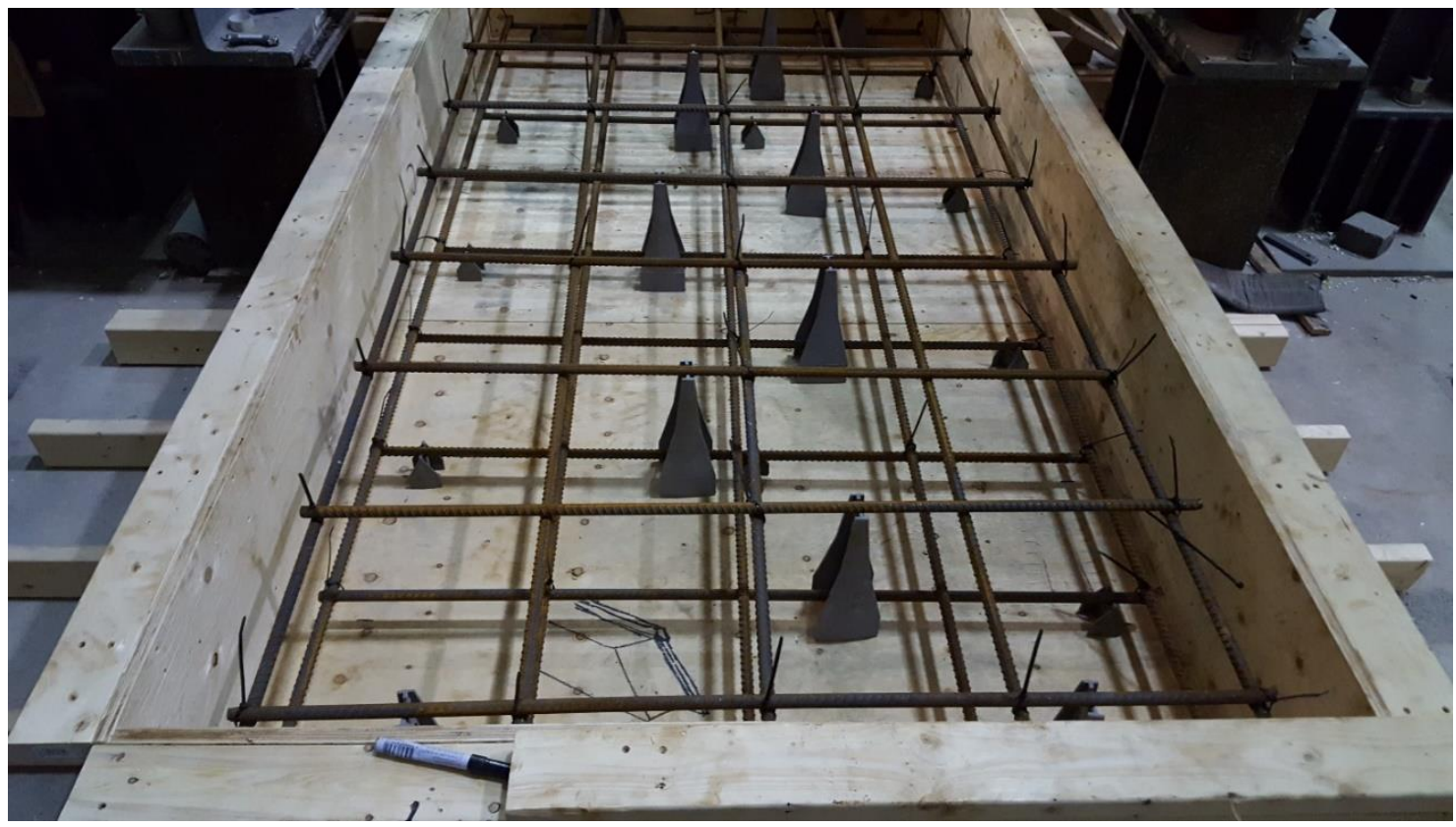

Figure 3.9: View of steel reinforcement prior to casting 


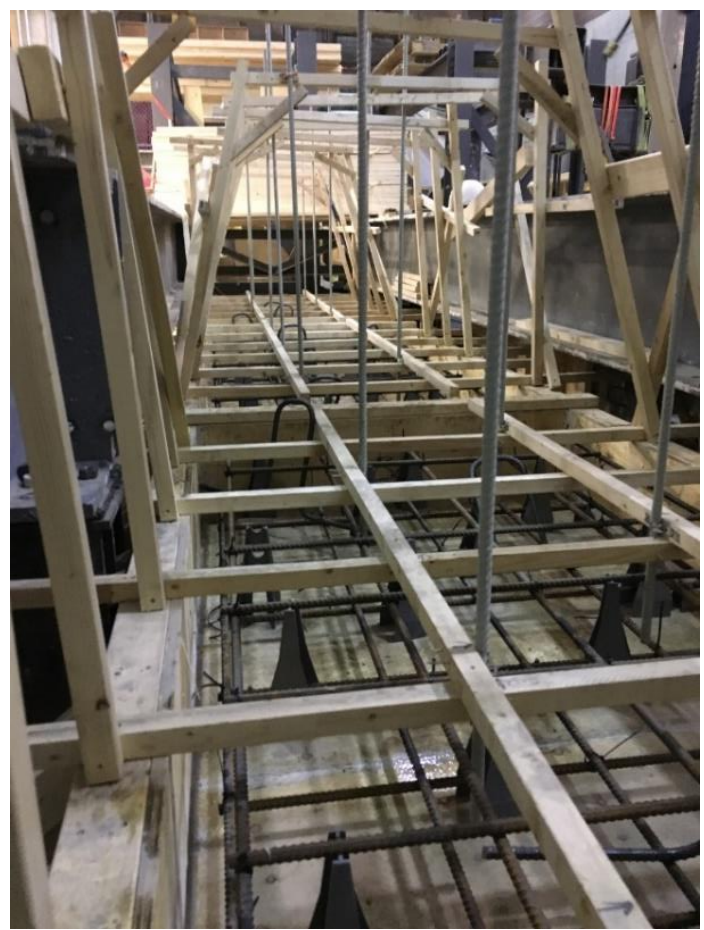

a) Longitudinal view of the timber form

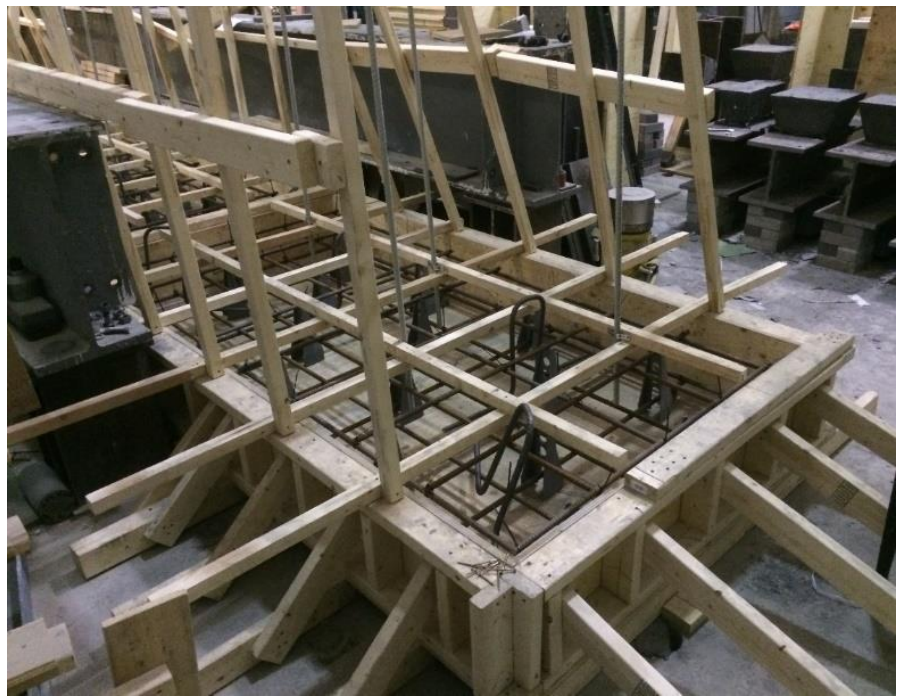

b) Transverse view of the timber form

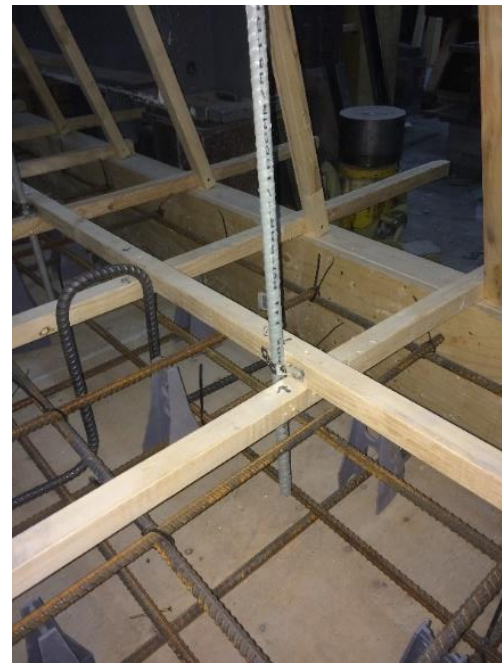

c) Close-up views of the bar with straight end

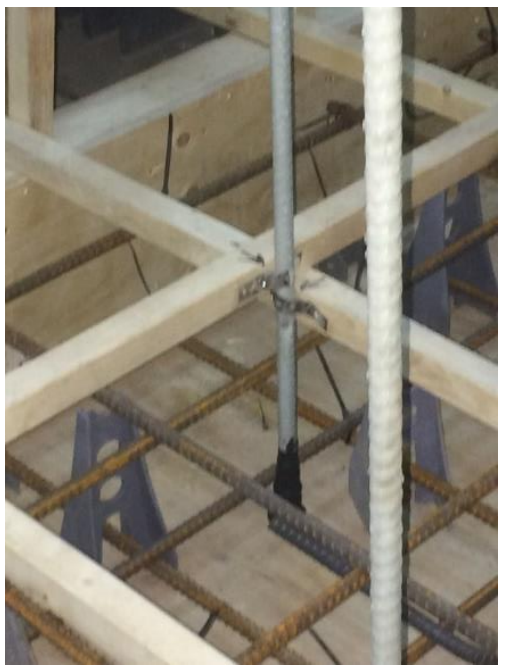

b) View of headed bar with fully-bonded embedment

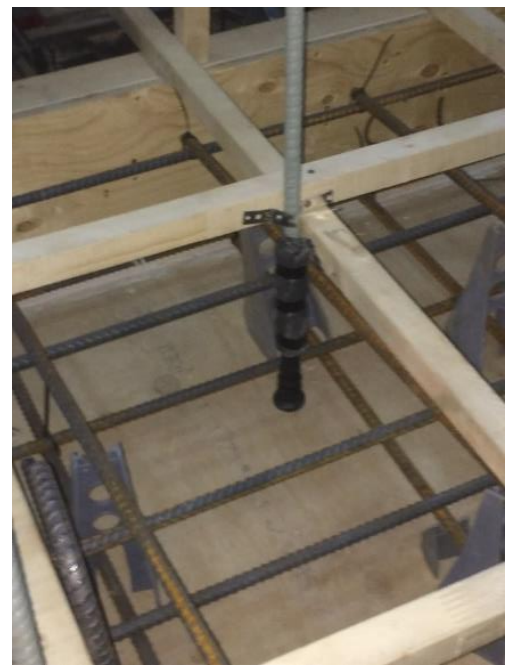

c) View of the headed bar with unbonded straight portion

Figure 3.10: Final slab formwork with steel and GFRP reinforcement prior to casting 


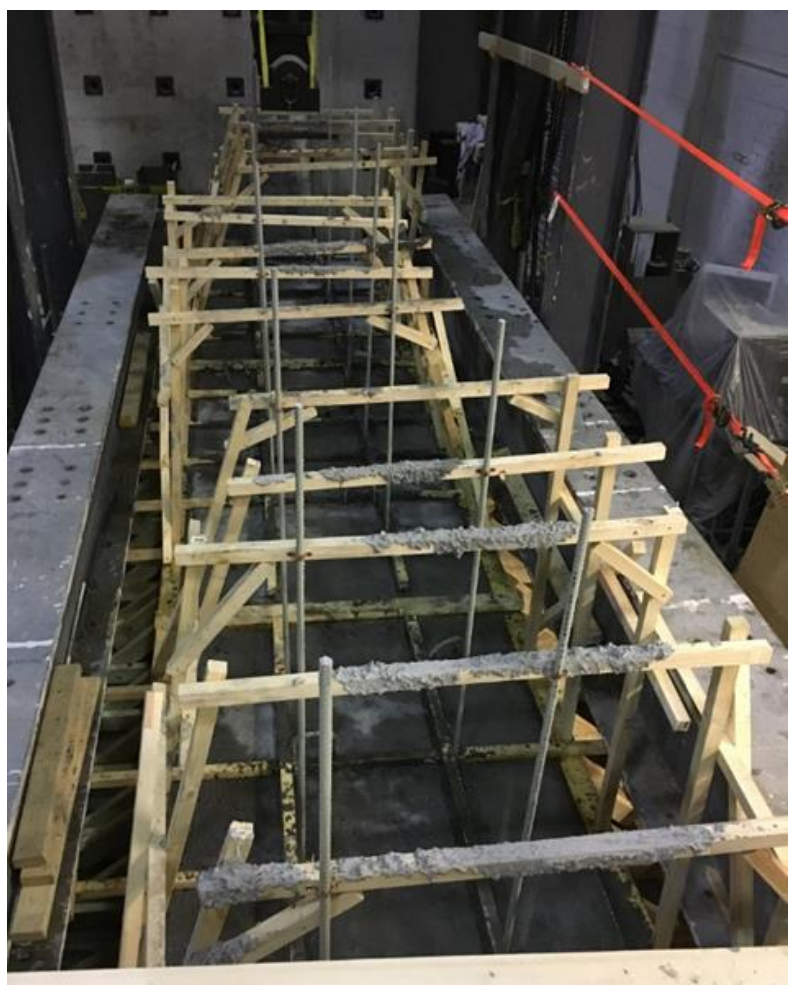

Figure 3.11: View of the slabs after casting

\subsubsection{Post- Installed}

In post-install bar pullout capacity testing, the same slabs used for pre-installed bar testing were utilized, which would also add to the bridge rehabilitation imitation initiative. Three groups were also introduced in this part of the experiment, however the groups herein had slightly different definitions. In practice, deteriorated barriers can be demolished. Then, GFRP bar anchors with straight ends are inserted in drilled holes in the existing deck slab and bonded to it using high strength adhesive. Then, the new barrier wall is cast on top of the deck while the GFRP bar anchors are intended to provide full moment capacity at the barrier-deck junction. To examine the pullout capacity of post-installed straight-ended GFRP bars in concrete, 3 bar groups were installed in the deck slab in locations marked with solid circles in Figure 3.13. Each group has the same \#5 bar but with different embedment lengths. In groups 1, 2, and 3, embedment lengths of $150 \mathrm{~mm}, 175 \mathrm{~mm}$, and $200 \mathrm{~mm}$ respectively, were used. Each group consisted of 5 bars, for a total of 15 bars. The three different embedment lengths would allow the designer to visualize the relationship in pullout strength between such short differences in embedment lengths.

When installing the bars, first a hole was drilled using a concrete impact drill. The drill bit used was $27 \mathrm{~mm}\left(1-1 / 16^{\prime \prime}\right)$ in diameter to suffice the \#5 bar diameter and allow for adequate bond 
between the epoxy, bar, and concrete elements. On the drill bit, a mark was made to indicate the required depth for each bar group. After drilling the hole, it must be cleaned in a specific manner (i.e. first, using compressed air to blow out all concrete residue in the hole, then scrubbing the entire hole with a brush and using compressed air). This step was repeated 5 times before injecting the epoxy. After epoxy injection of about three quarters of the hole depth, the GFRP bar was slowly put in place by applying pressure while rotating the bar back and forth. Figure 3.14 presents photos of the procedure to install the GFRP bars in the slab.

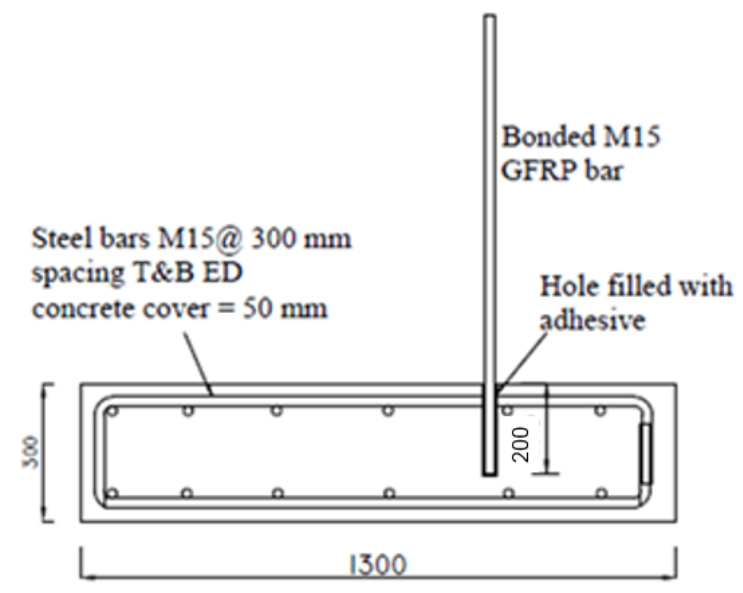

Figure 3.12: Post-installed GFRP bar in concrete slab

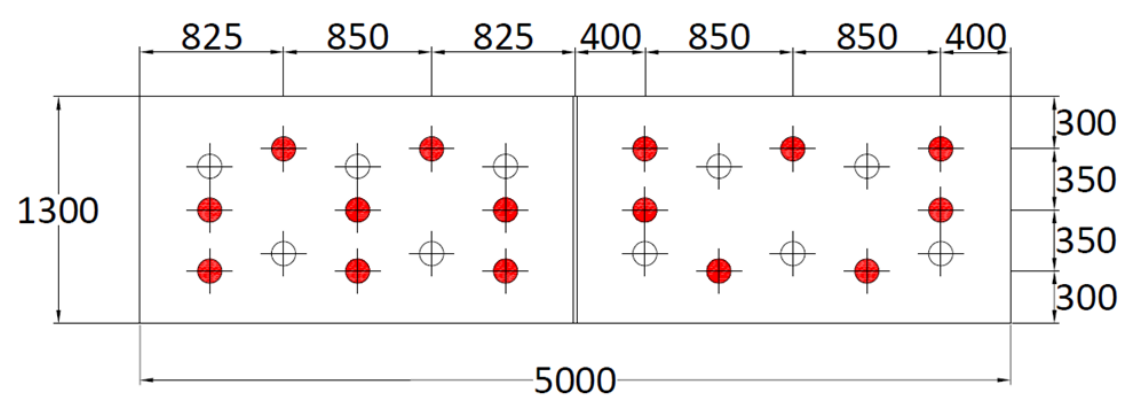

Figure 3.13: Plan of concrete slab showing GFRP post-installed bar locations 


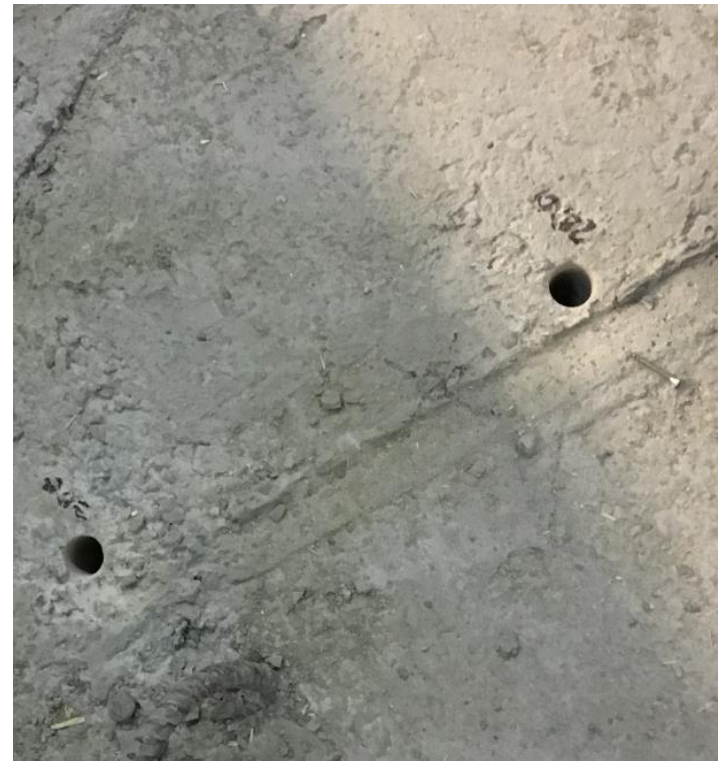

a) Post-Installed holes after drilling

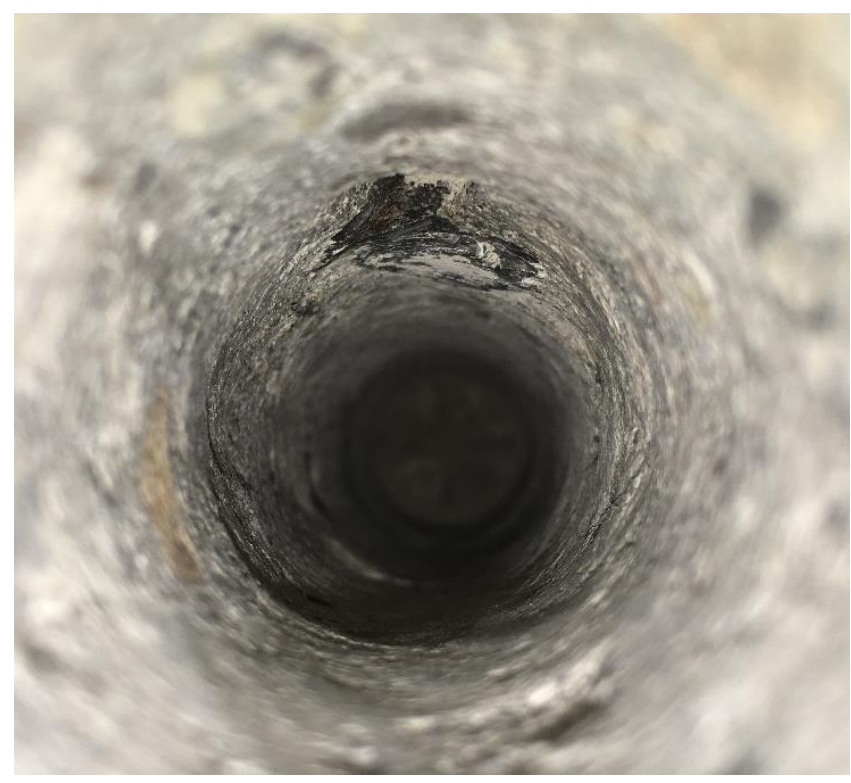

c) Inside of hole after cleaning

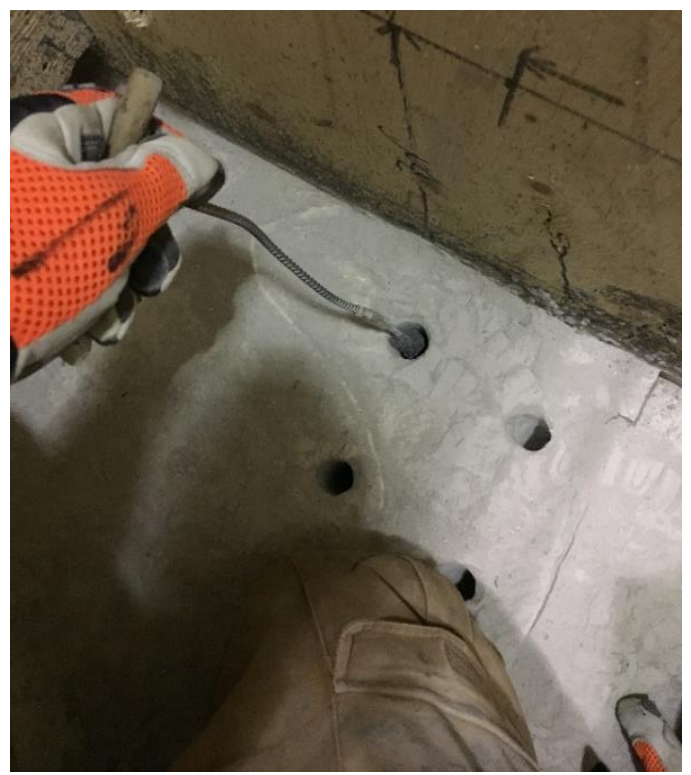

b) Cleaning of post-install barrier anchor holes

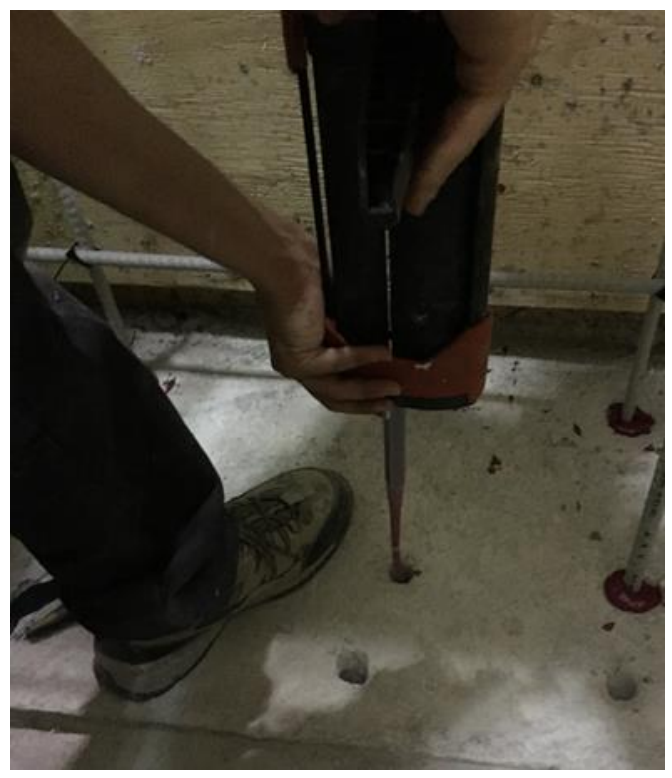

d) Injecting epoxy into drilled hole 


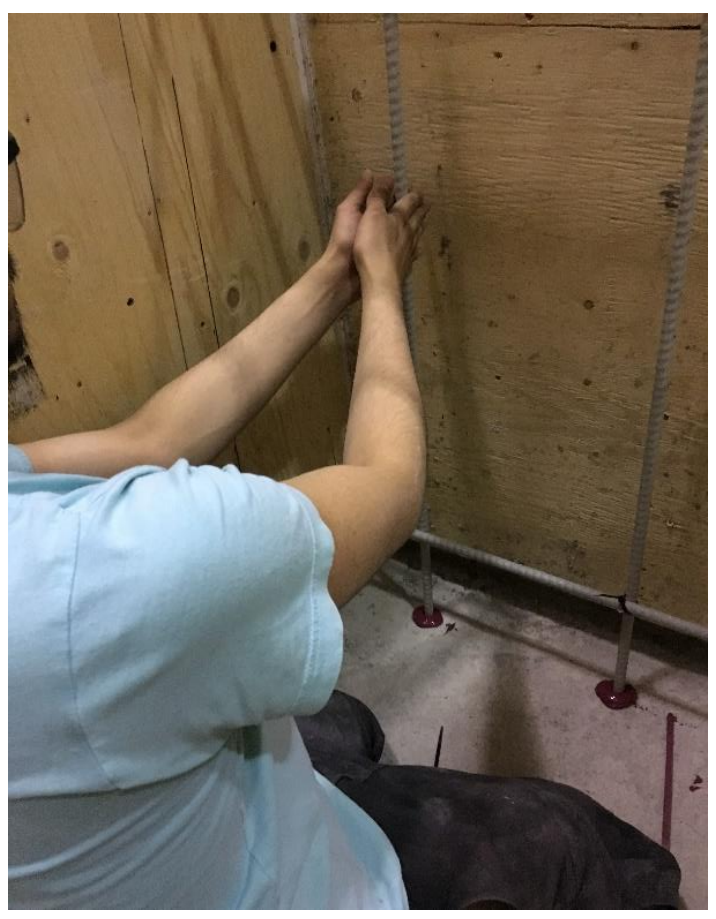

e) Installing GFRP Bar while slowly rotating left and right

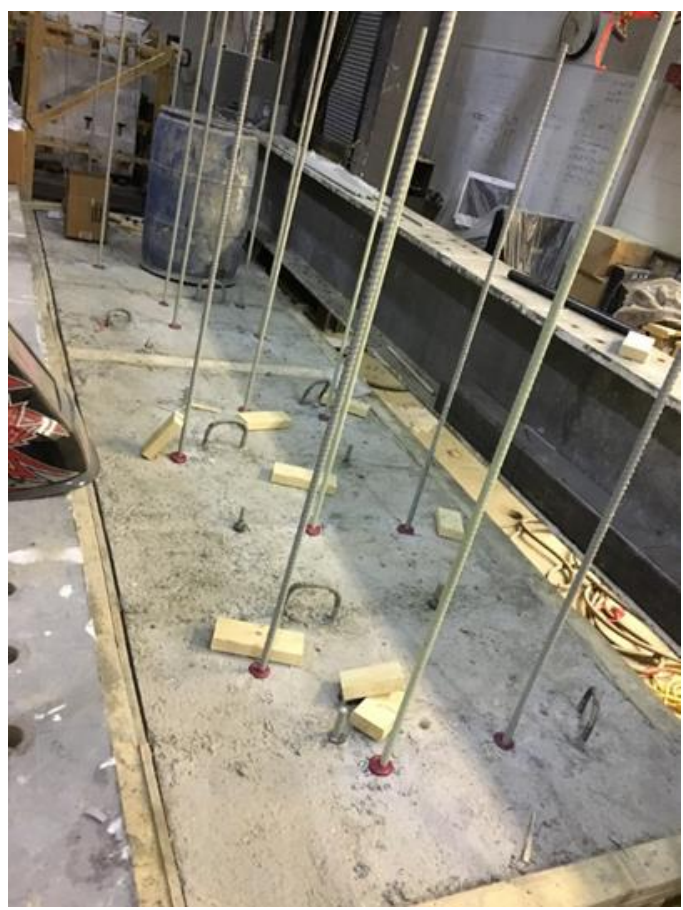

f) Final view of the post-installed bars in the slab

Figure 3.14: Post installed GFRP bar installation procedure

\subsection{Test Setup and Procedure}

The pullout test follows ASTM E488/E488M-15 test method (ASTM, 2015) which describes all appropriate equipment and setup needed to conduct the experiment. The test setup consisted of a series of HSS sections resting on metal bearing plates that were spaced in a manner so that there was a minimum clearance radius of about two times the bar embedment length, from the bar being tested to each individual support. The ASTM test method specifies this clearance radius in order to allow for all types of pullout failures. Three HSS sections stacked on top of one another on one side of the bar and in a parallel fashion on the opposite side of the bar, all of which were resting on 4 square metal plates. On top of these 6 HSS sections were two longer HSS sections which were perpendicular to the supporting HSS members, while the GFRP bar of interest was centered between them. On top of these two sections proceeds a series of plates, rubber pad, load cell, hydraulic jack, and pull-out grips. This setup is clearly demonstrated in Figure 3.15. Once the rigorous steel setup is complete, a potentiometer (POT) was placed adjacent and connected to the bar, while the tip of the needle was on the top of the concrete, as shown in Figure 3.15. This procedure was then repeated a total of 15 times for the pre-installed bars, and another 15 times for the post-installed bars. Maintaining a consistent setup, allows for properly analyzing data and limit variables in the experiment. 


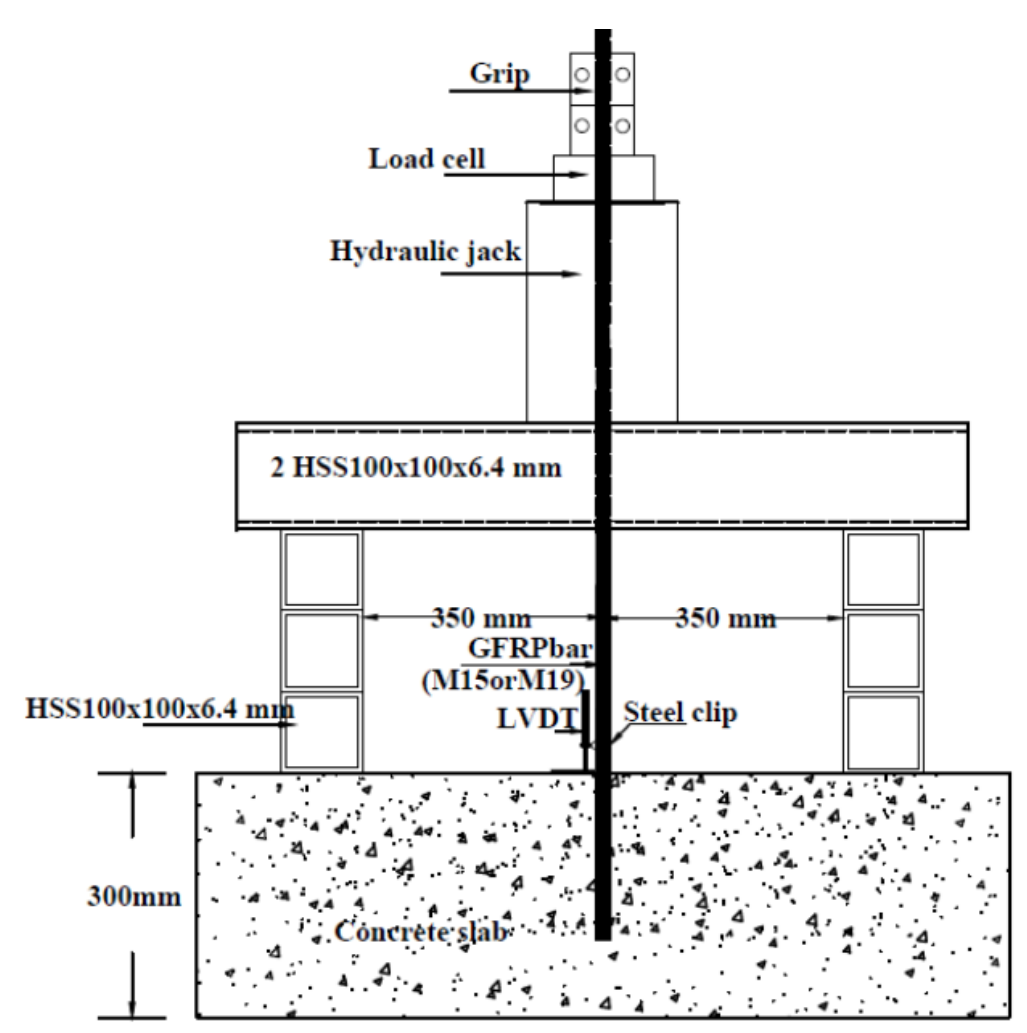

a) Schematic diagram of the test setup

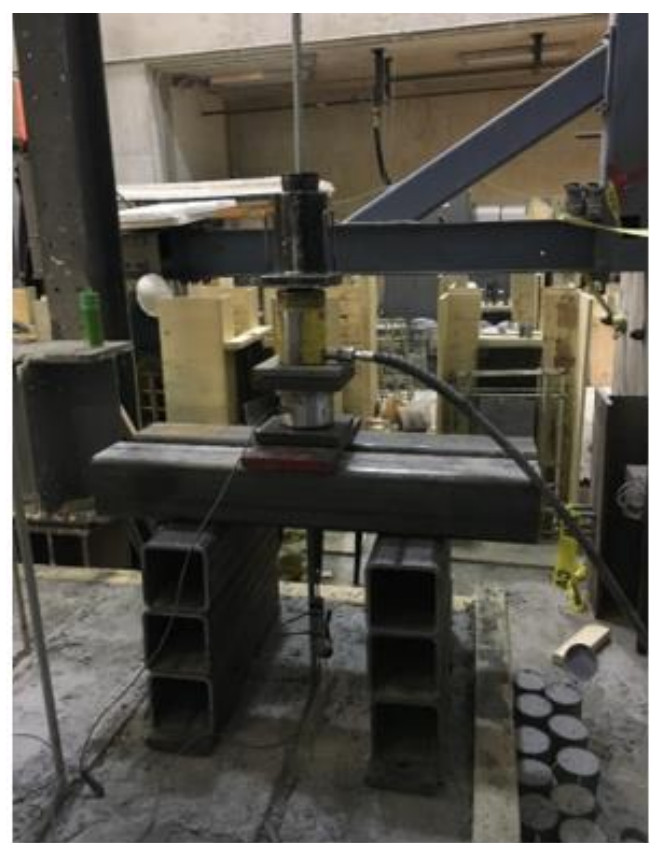

b) Front view of test setup

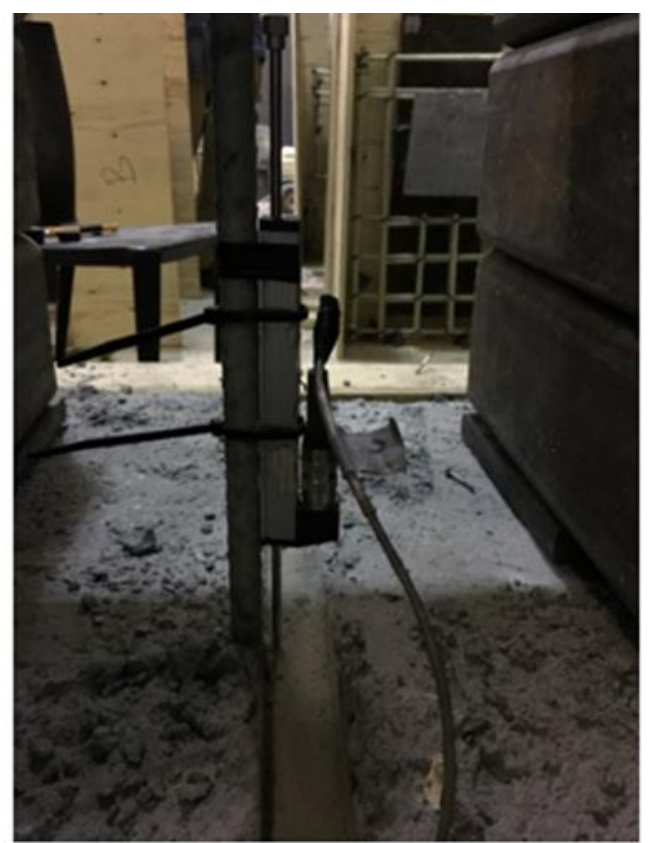

c) Close-up view of the POT to measure bar slip

Figure 3.15: Pullout test setup 


\subsection{Experimental Results}

As a first step to examine the capacity of the headed-end GFRP bar developed by the GFRP manufacturer, a timber form of $300 \times 300 \mathrm{~mm}$ cross-section and $500 \mathrm{~mm}$ deep was constructed as shown in Figure 3.16(a) to form a concrete block with a headed-end GFRP embedded from the top. The total bar embedment length was $200 \mathrm{~mm}$. The first portion of the embedment length represents an unbonded straight portion of the bar, followed by the bonded head of $100 \mathrm{~mm}$ length. The bar was pulled out of concrete resulting in an experimental pullout force of $119 \mathrm{kN}$ which is more than the $100 \mathrm{kN}$ limit specified in MTO Standard Drawing for \#5 headed-end GFRP bars when tested to slip the headed bar from concrete. Figure 3.16(b) shows concrete splitting when bar slipped from concrete. Figure A-1 in the Appendix shows the load-slip curve for the tested bar. It can be observed the bar slip at ultimate load was $0.72 \mathrm{~mm}$, with $0.61 \mathrm{~mm}$ value at the 100 kN MTO specified limit.

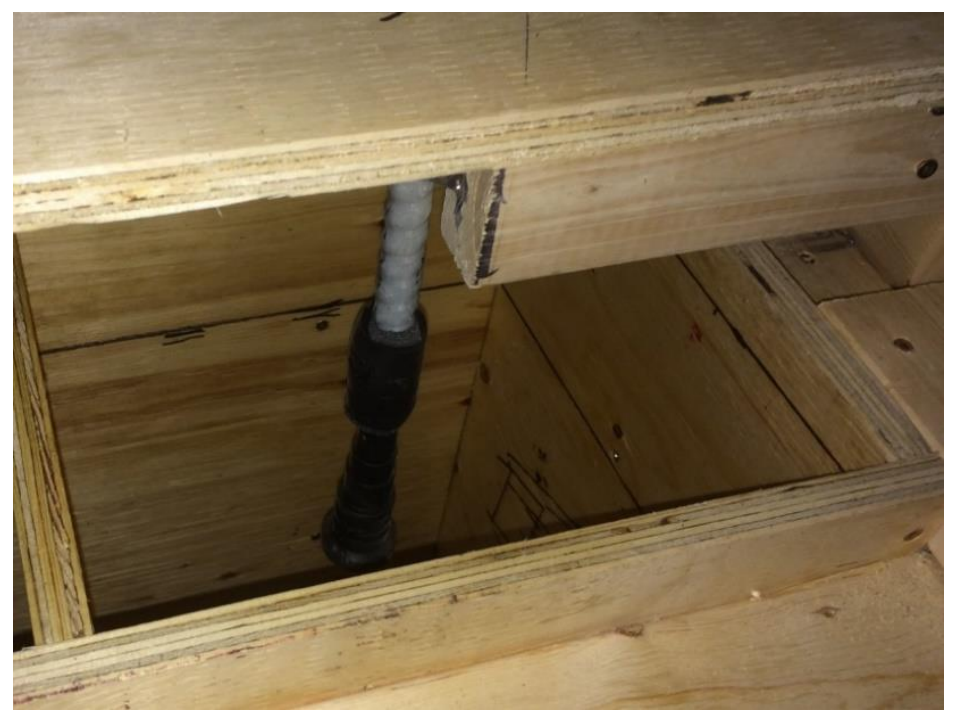

a) View of the timber form and unbonded headed bar

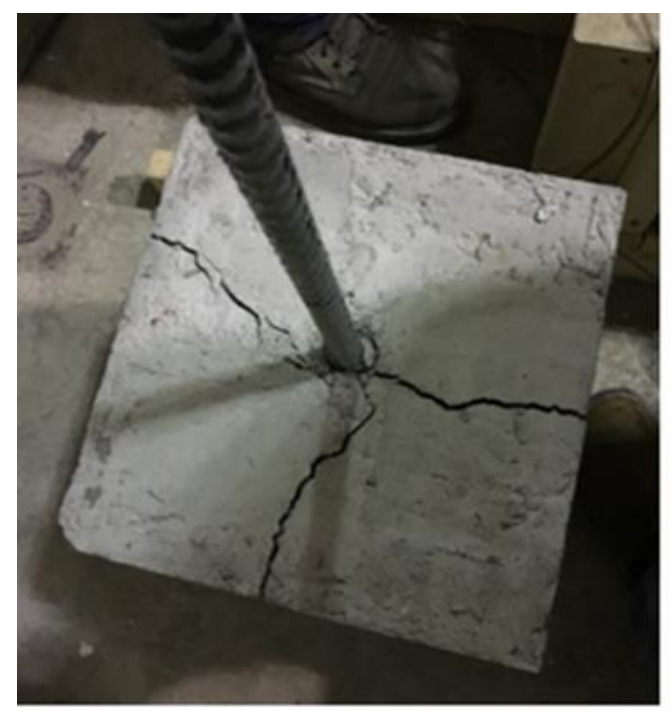

b) View of concrete splitting failure

Figure 3.16: Views of the unbonded headed-end GFRP bars in concrete $300 \times 300 \times 300 \mathrm{~mm}$ concrete block

\subsubsection{Pre-installed Straight Bar Test Results}

Test results showed that the straight bars failed primarily due to bar crushing at grip location to the extent that the part split laterally along the free-standing length between the grips and the top of the concrete slab as depicted in Figure 3.17. Although the bars did not manage to achieve their nominal ultimate tensile capacity and the bar did not visually appear to slip out of concrete, the test results showed an average pullout force of $145.48 \mathrm{kN}$. Which is about $73 \%$ of the tension capacity of the bar. Table 3.5 summarizes the pullout capacity of each bar in this group 1 along with the corresponding POT readings. Figure A.2 in the Appendix depicts the 
pullout load-POT reading relationship for this bar group, showing average POT reading at failure in the order of $3.1 \mathrm{~mm}$. After pullout tests, concrete core samples were taken at bar location as shown in Figure 3.18. Subsequently, the core samples were sliced in half using a concrete saw as shown in Figure 3.19. The intent of slicing the samples directly in half (cutting the GFRP bar in half as well) was to examine whether any slippage or other forms of failure within the concrete matrix occurred during the test. Figure 3.20 shows that the bar had no visual slippage at is end in the concrete slab. The bar appeared to be fully bonded to the concrete surrounding after the test.

Table 3.5: Pullout test results for group 1

\begin{tabular}{|c|c|c|}
\hline Specimen & $\begin{array}{c}\text { POT displacement } \\
\text { reading }(\mathrm{mm})\end{array}$ & $\begin{array}{c}\text { Maximum load } \\
(\mathrm{kN})\end{array}$ \\
\hline $1-\mathrm{A}$ & 3.67 & 150.88 \\
\hline $1-B$ & 3.27 & 146.02 \\
\hline $1-\mathrm{C}$ & 3.99 & 140.35 \\
\hline $1-\mathrm{D}$ & 2.87 & 144.67 \\
\hline $1-\mathrm{E}$ & 1.74 & 145.48 \\
\hline \multirow{2}{*}{} & Average & 145.48 \\
\cline { 2 - 3 } & & \\
\end{tabular}

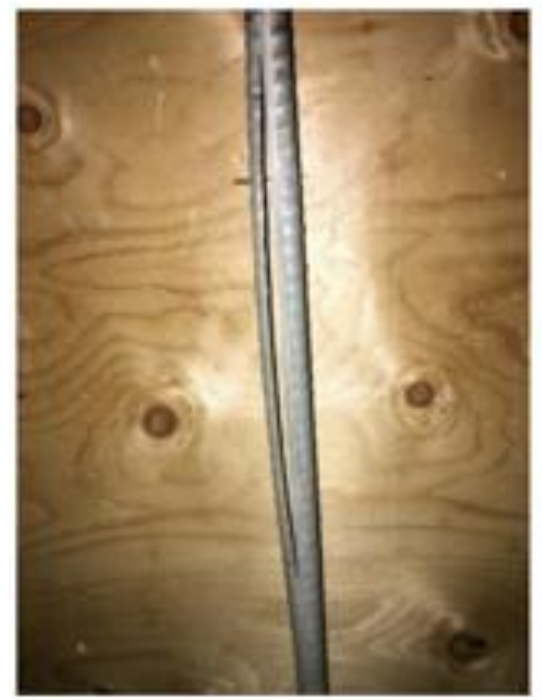

a) Bar rupture

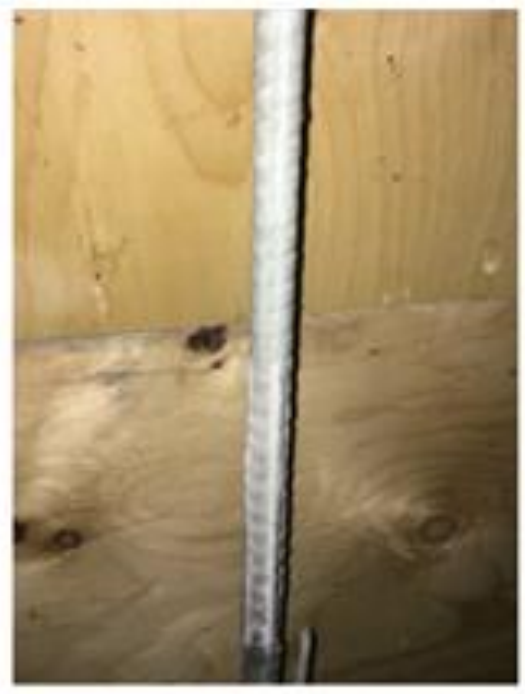

b) bar rupture at grip area

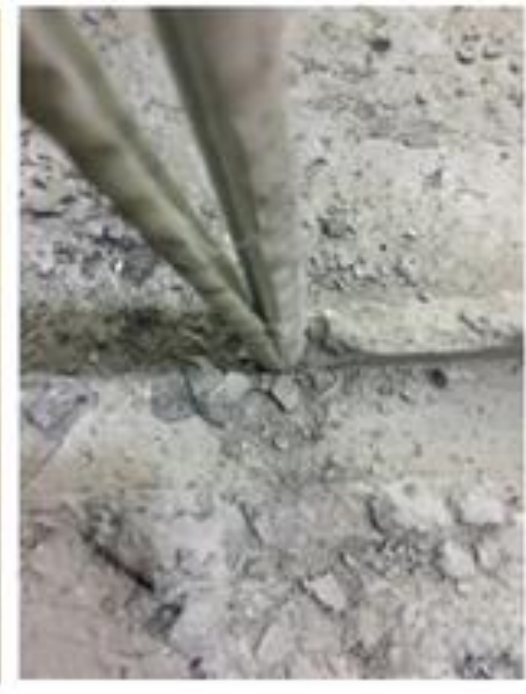

c) Light concrete crushing around the bar

Figure 3.17: Views of failure modes for group 1 


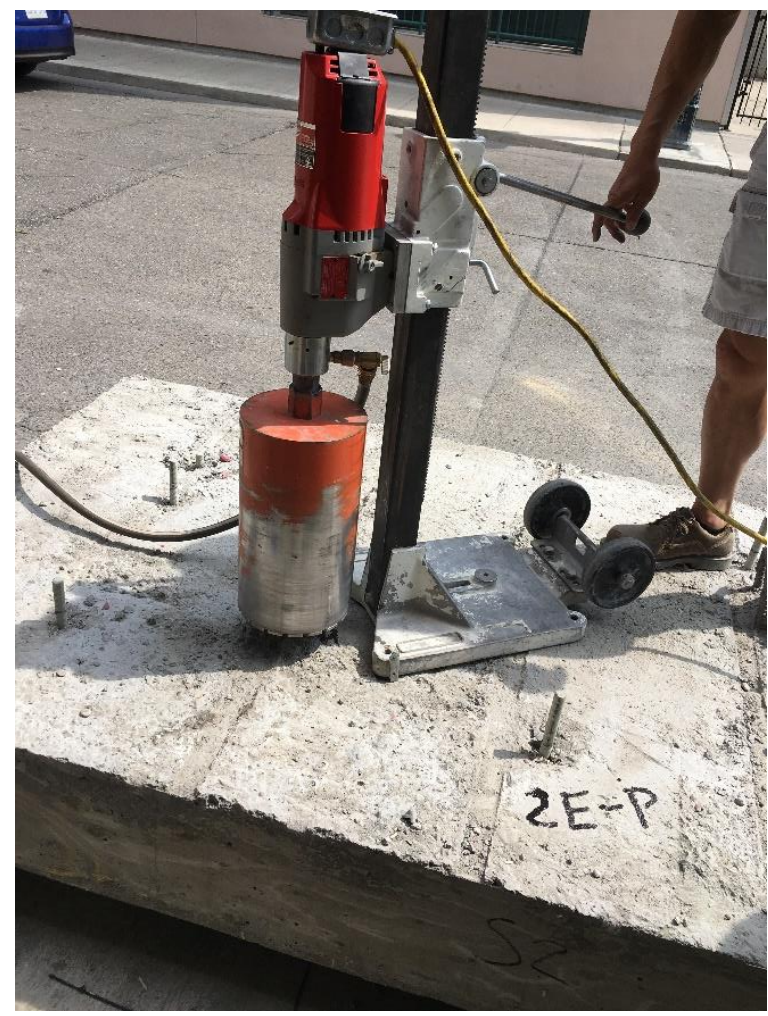

Figure 3.18: Coring of the slab for analysis

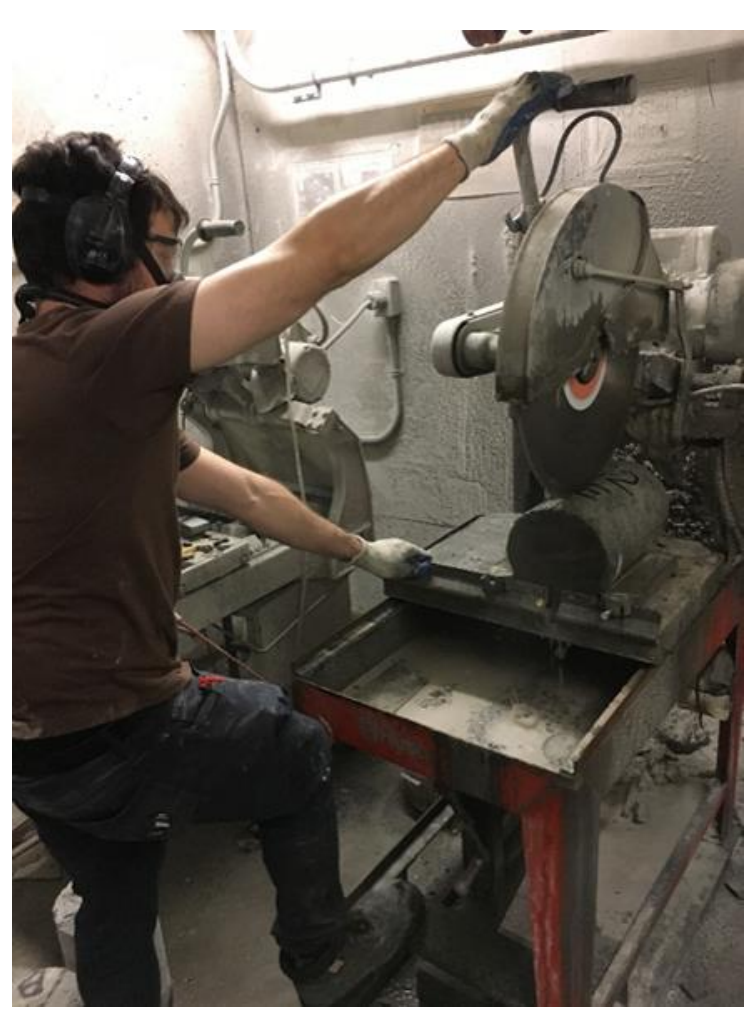

Figure 3.19: Slicing the cored samples in half

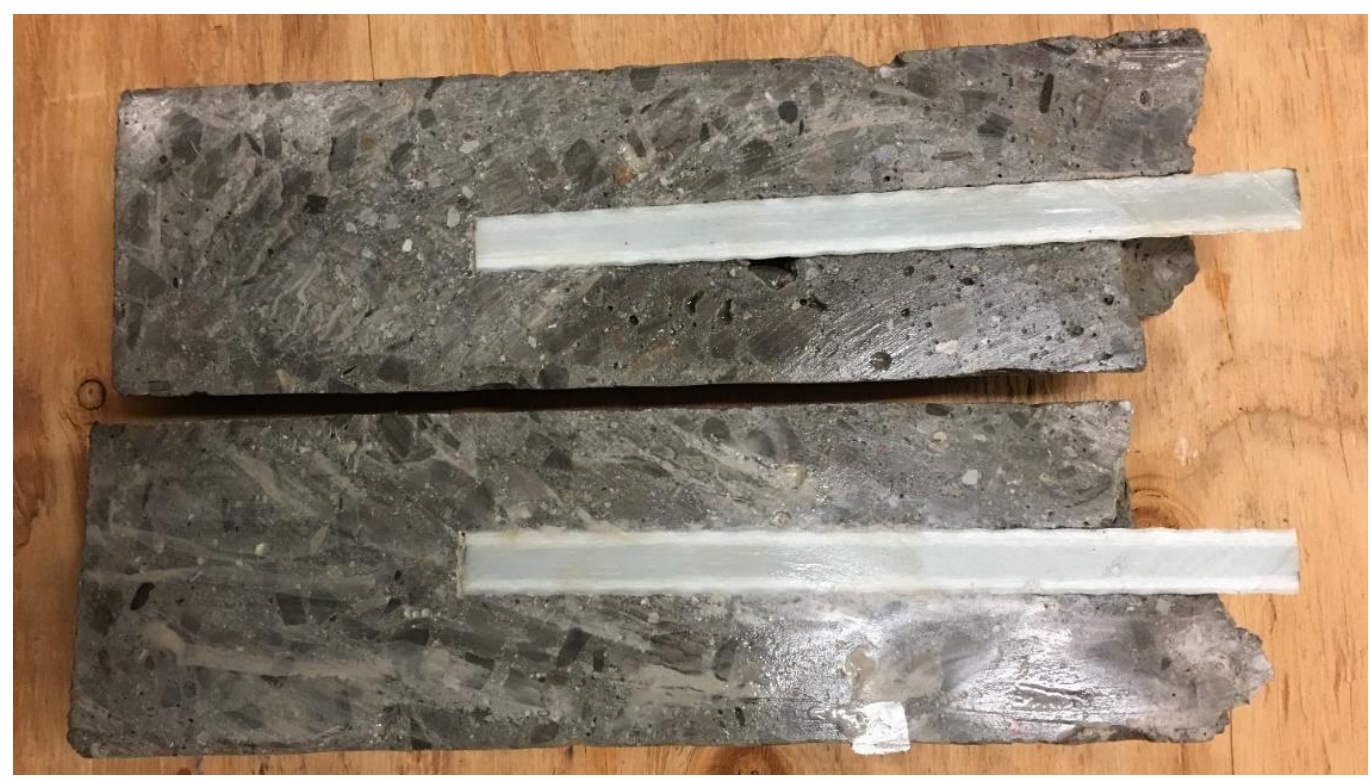

Figure 3.20: Sliced core sample for group 1 showing no bar slip 


\subsubsection{Preinstalled Headed Bar Test Results}

Test results showed that the headed-end bars with fully-bonded straight portion shown in Figure 3.7 failed primarily due to bar crushing at grip location to the extent that the part split laterally along the free-standing length between the grips and the top of the concrete slab as depicted in Figure 3.21. Although the bars did not manage to achieve their nominal ultimate tensile capacity and the bar did not visually appear to slip out of concrete, the test results showed an average pullout force of $148.34 \mathrm{kN}$. Which is about $74 \%$ of the tension capacity of the bar. Table 3.6 summarizes the pullout capacity of each bar in this group 2 along with the corresponding POT readings. Figure A.3 in the Appendix depicts the pullout load-POT reading relationship for this bar group, showing average POT reading at failure in the order of $2.88 \mathrm{~mm}$. After pullout tests, concrete core samples were taken at bar location. Subsequently, the core samples were sliced in half using a concrete saw. Figure 3.22 shows that the bar had no visual slippage at is end in the concrete slab. The bar appeared to be fully bonded to the concrete surrounding after the test. Also, no fracture in the anchor head was observed. Moreover, no shear failure was visually observed at the bar-head interface.

Table 3.6: Pullout test results for group 2

\begin{tabular}{|c|c|c|}
\hline Specimen & $\begin{array}{c}\text { POT displacement } \\
\text { reading }(\mathrm{mm})\end{array}$ & $\begin{array}{c}\text { Maximum load } \\
(\mathrm{kN})\end{array}$ \\
\hline $2-\mathrm{A}$ & 2.85 & 157.89 \\
\hline $2-\mathrm{B}$ & 1.35 & 127.67 \\
\hline $2-\mathrm{C}$ & 4.22 & 161.94 \\
\hline $2-\mathrm{D}$ & 3.06 & 151.69 \\
\hline $2-\mathrm{E}$ & 2.92 & 142.51 \\
\hline \multirow{2}{*}{} & Average & 148.34 \\
\cline { 2 - 3 } & & \\
\end{tabular}



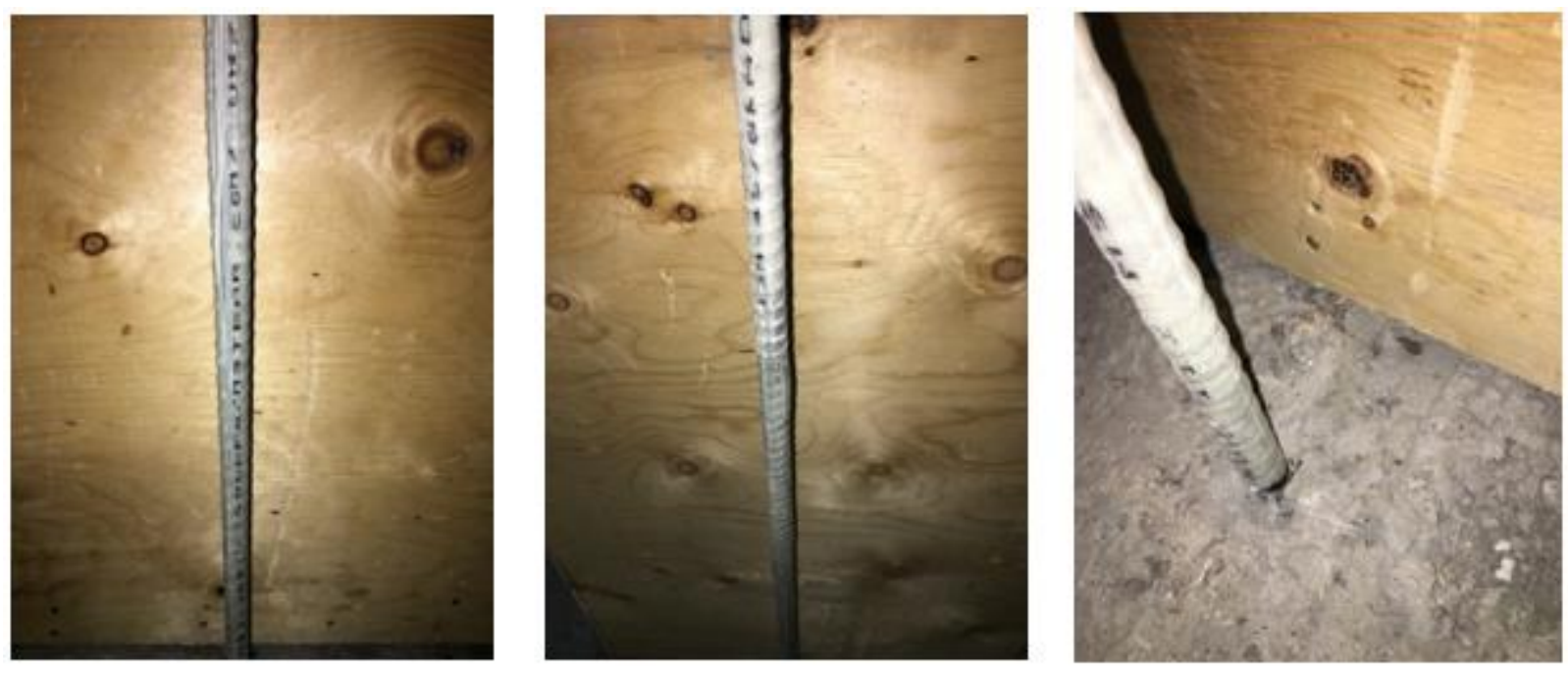

a) Bar rupture

b) bar rupture at grip area c) Light concrete crushing around the bar

Figure 3.21: Views of failure modes for group 2

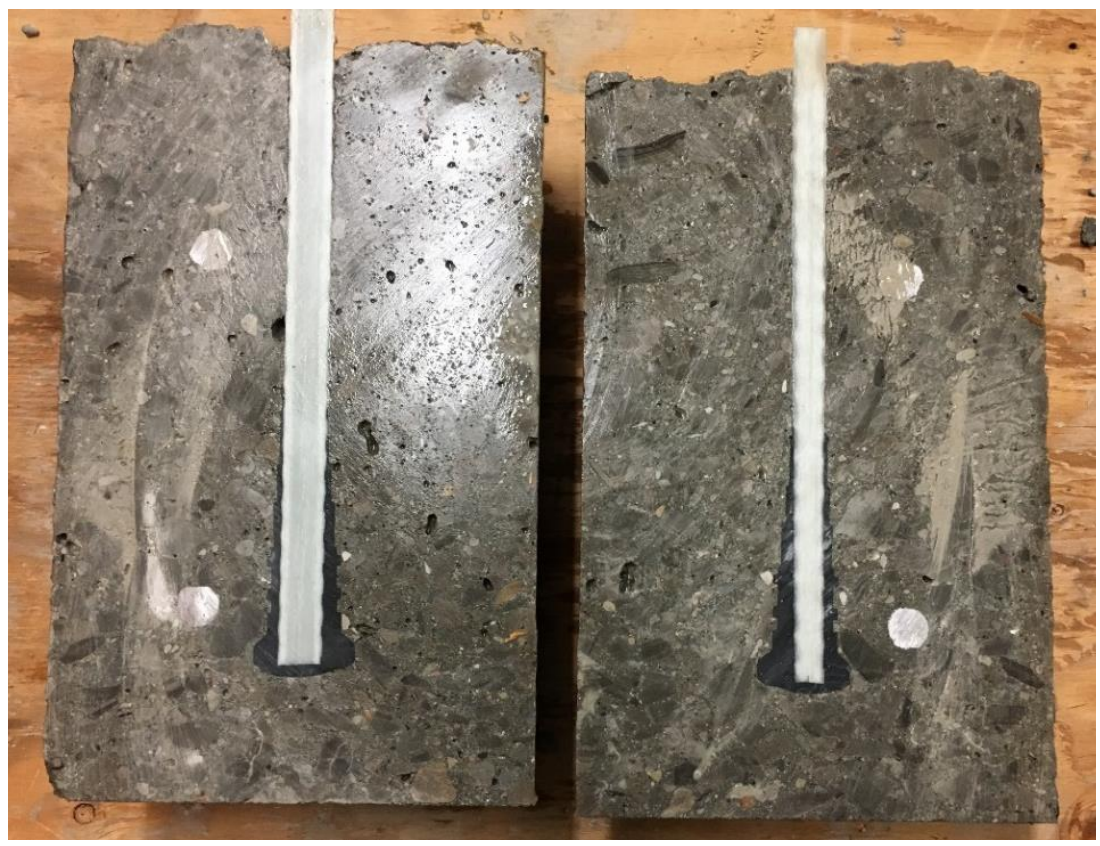

Figure 3.22: Sliced core sample for group 2 


\subsubsection{Test Results of Pre-installed Headed-end Bar with Unbonded Straight Portion}

Test results showed that the headed-end bars with unbonded straight portion shown in Figure 3.8 failed primarily due to bar slippage from the end head. Figure 3.23 shows the bar slipped out of concrete at its top surface. After pullout tests, concrete core samples were taken at bar location. Subsequently, the core samples were sliced in half using a concrete saw. Figure 3.24 shows that the bar straight end was slipped from the black-colored head end. Also, no fracture in the anchor head was observed. Although the bars did not manage to achieve their nominal ultimate tensile capacity, the test results showed an average pullout force of $131.04 \mathrm{kN}$. Which is about $66 \%$ of the tension capacity of the bar. Table 3.7 summarizes the pullout capacity of each bar in this group 3 along with the corresponding POT readings. Figure A.4 in the Appendix depicts the pullout load-POT reading relationship for this bar group, showing average POT reading at failure in the order of $3.73 \mathrm{~mm}$.

Table 3.7: Pullout test results for group 3

\begin{tabular}{|c|c|c|}
\hline Specimen & $\begin{array}{c}\text { POT displacement } \\
\text { reading }(\mathrm{mm})\end{array}$ & $\begin{array}{c}\text { Maximum load } \\
(\mathrm{kN})\end{array}$ \\
\hline $3-\mathrm{A}$ & 3.65 & 137.38 \\
\hline $3-B$ & 3.33 & 122 \\
\hline $3-\mathrm{C}$ & 4.13 & 137.38 \\
\hline $3-D$ & 3.88 & 127.40 \\
\hline \multirow{2}{*}{} & Average & 131.04 \\
\cline { 2 - 3 } & \multicolumn{2}{|c}{} \\
\cline { 2 - 3 }
\end{tabular}

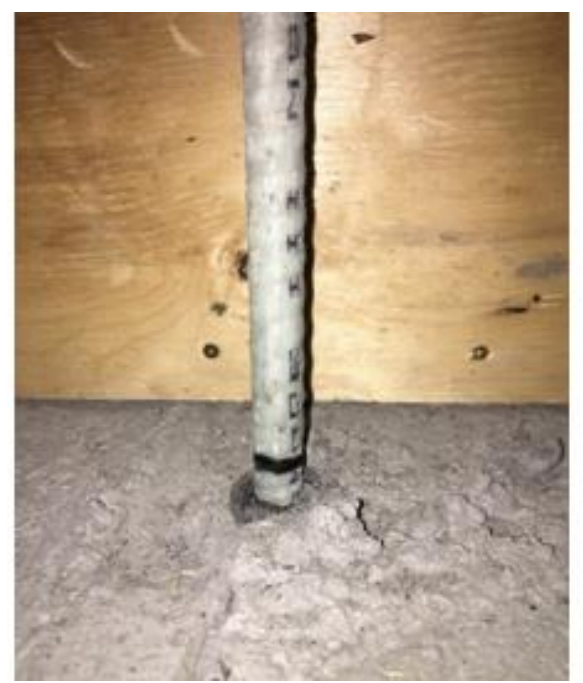

Figure 3.23: View of straight-end GFRP bar slippage from concrete 


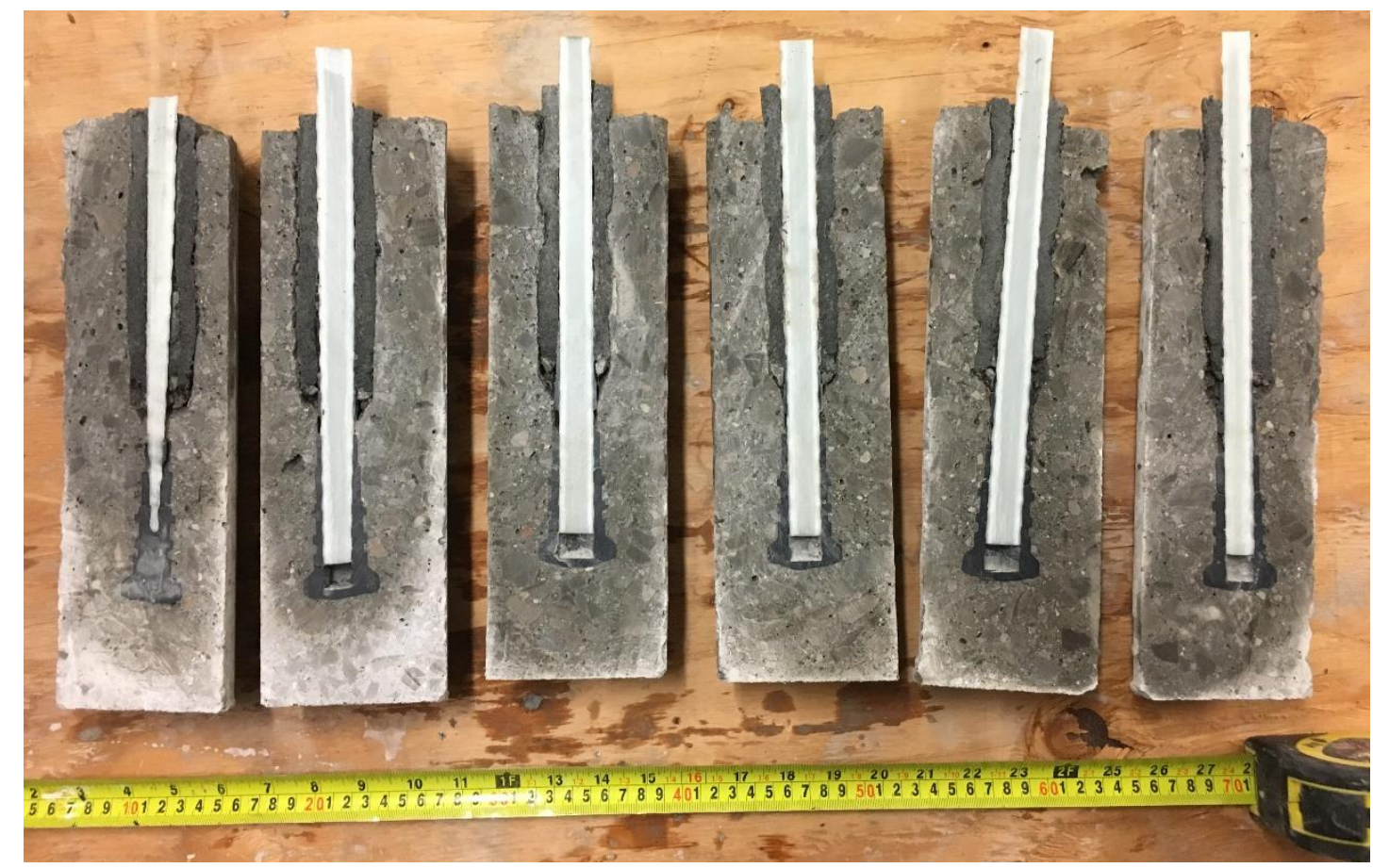

Figure 3.24: View of the sliced core samples for group 3 showing bar slip from head

\subsubsection{Test Results for Post-Installed Bars with 150 mm Embedment Length}

Test results showed that the post-installed straight bars, with $150 \mathrm{~mm}$ embedment length as shown in Figure 3.12, failed primarily due to bar slippage at bar-adhesive interface while the bar ruptured at the anchorage location outside the concrete specimen as depicted in Figure 3.25. After pullout tests, concrete core samples were taken at bar location and then sliced in half to view the bar with surrounding adhesive and concrete as shown in Figures 3.26 and 3.27. Visual bar slippage at bar-adhesive interface was observed while the adhesive appeared fully bonded to the surrounding concrete after the test. Also, no slippage between the adhesive and concrete was observed. Another important aspect to note by looking at these core samples is the presence of air voids in the epoxy composition. Although the bars did not manage to achieve their nominal ultimate tensile capacity, the test results showed an average pullout force of $152.49 \mathrm{kN}$. Which is about $76 \%$ of the tension capacity of the bar. Table 3.8 summarizes the pullout capacity of each bar in this post-installed bar group 1 along with the corresponding POT readings. Figure A.5 in the Appendix depicts the pullout load-POT reading relationship for this bar group, showing average POT reading at failure in the order of $2.35 \mathrm{~mm}$. 
Table 3.8: Pullout test results for post-installed bars in group 1

\begin{tabular}{|c|c|c|}
\hline Specimen & $\begin{array}{c}\text { POT displacement } \\
\text { reading }(\mathrm{mm})\end{array}$ & $\begin{array}{c}\text { Maximum load } \\
(\mathrm{kN})\end{array}$ \\
\hline $1-\mathrm{A}$ & 2.37 & 158.70 \\
\hline $1-B$ & 2.86 & 194.87 \\
\hline $1-\mathrm{C}$ & 2.31 & 146.83 \\
\hline $1-\mathrm{D}$ & 2.11 & 158.97 \\
\hline $1-\mathrm{E}$ & 2.11 & 103.10 \\
\hline \multirow{2}{*}{} & Average & 152.49 \\
\cline { 2 - 3 } & & \\
\end{tabular}

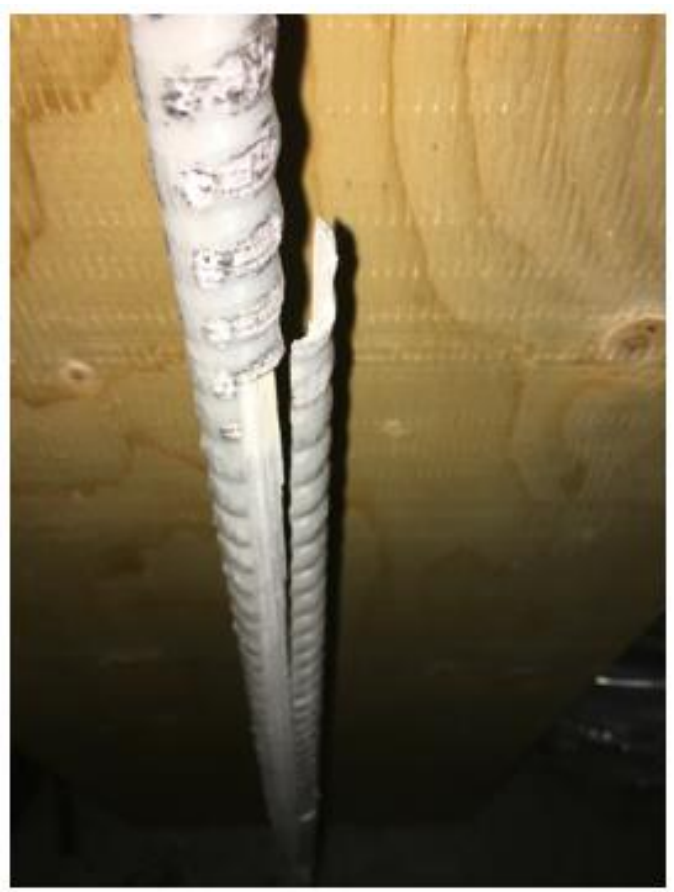

a) Bar A rupture at the anchorage

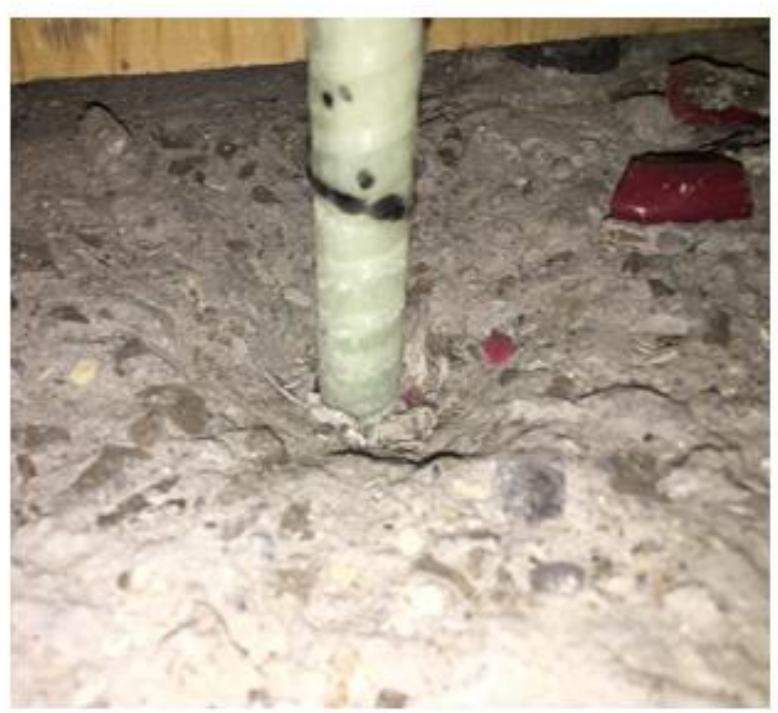

b) Bar B slippage

Figure 3.25: Views of failure modes for the group 


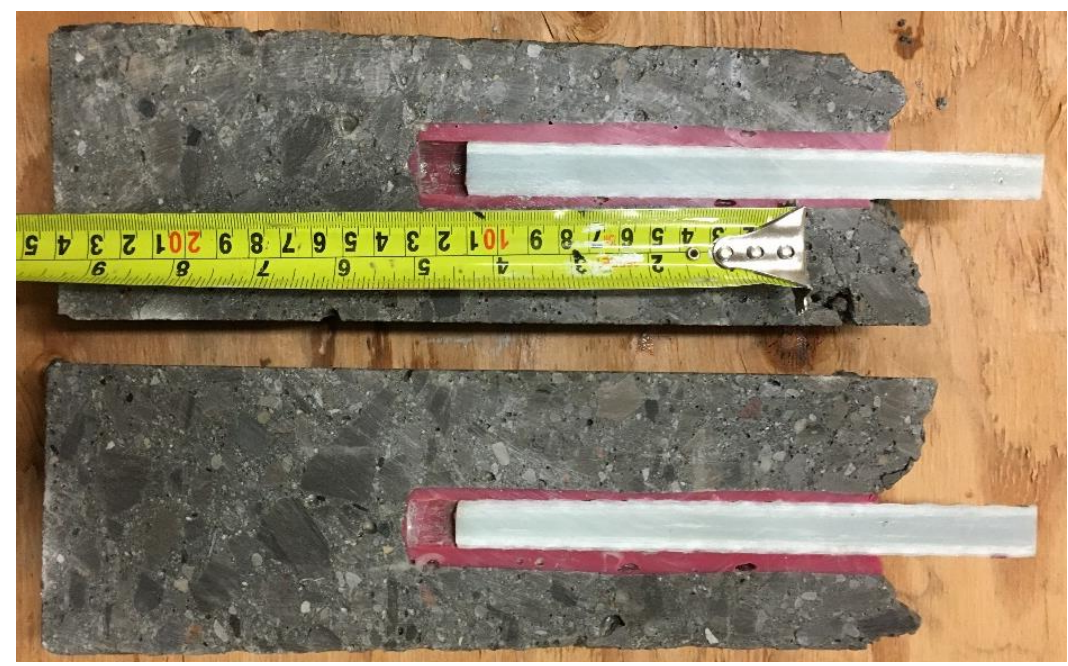

Figure 3.26: Sliced core sample for post-installed bars in group 1 showing bar slip

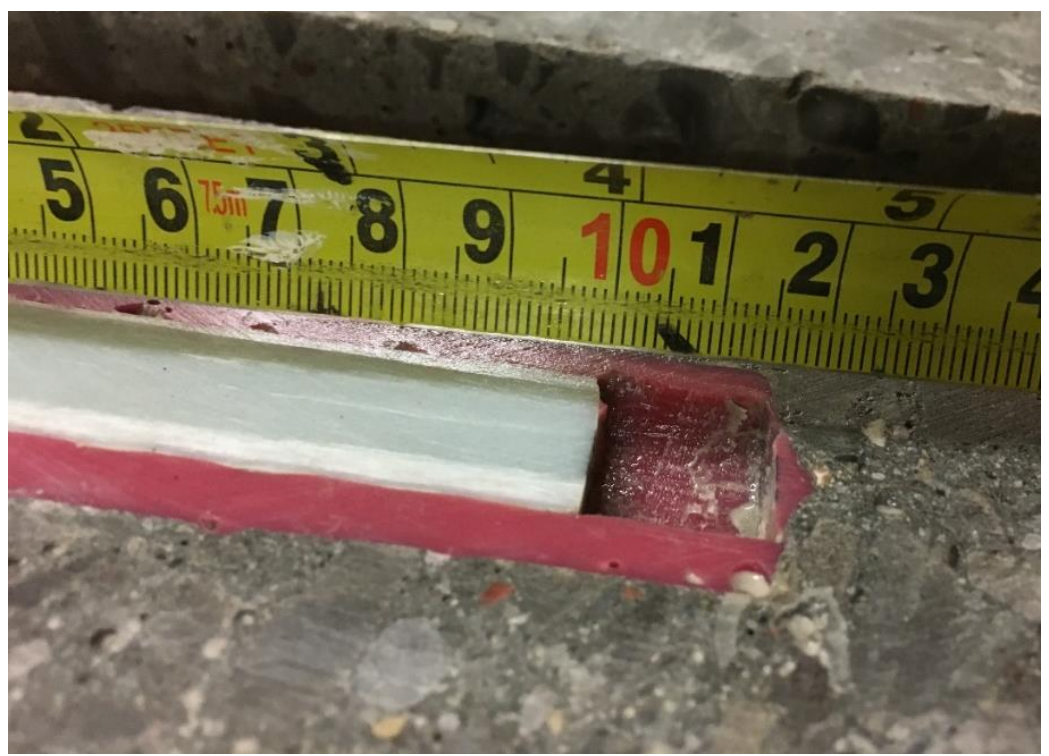

Figure 3.27: Close up view of slip of post-installed bar specimen D in group 1

\subsubsection{Test Results for Post-Installed Bars with 175 mm Embedment Length}

Test results showed that the post-installed straight bars, with $175 \mathrm{~mm}$ embedment length as shown in Figure 3.12, failed primarily due to bar slippage out of concrete slab as depicted in Figure 3.28. After pullout tests, concrete core samples were taken at bar location and then sliced in half to view the bar with surrounding adhesive and concrete as shown in Figure 3.29. Visual bar slippage at bar-adhesive interface was observed while the adhesive appeared fully bonded to the surrounding concrete after the test. Also, no slippage between the adhesive and concrete 
was observed. Another important aspect to note by looking at these core samples is the presence of air voids in the epoxy composition. Test results showed an average pullout force of $112.82 \mathrm{kN}$. Which is about $56 \%$ of the tension capacity of the bar. Table 3.9 summarizes the pullout capacity of each bar in this post-installed bar group 2 along with the corresponding POT readings. Figure A.6 in the Appendix depicts the pullout load-POT reading relationship for this bar group, showing average POT reading at failure in the order of $2.35 \mathrm{~mm}$.

Table 3.9: Pullout test results for post- installed bars in group 2

\begin{tabular}{|c|c|c|}
\hline Specimen & $\begin{array}{c}\text { POT displacement } \\
\text { reading }(\mathrm{mm})\end{array}$ & $\begin{array}{c}\text { Maximum load } \\
(\mathrm{kN})\end{array}$ \\
\hline $2-\mathrm{A}$ & 2.76 & 134.68 \\
\hline $2-\mathrm{B}$ & 1.64 & 96.09 \\
\hline $2-\mathrm{C}$ & 1.78 & 120.38 \\
\hline $2-\mathrm{D}$ & 1.44 & 89.61 \\
\hline $2-\mathrm{E}$ & 1.52 & 123.35 \\
\hline & Average & 112.82 \\
\hline
\end{tabular}

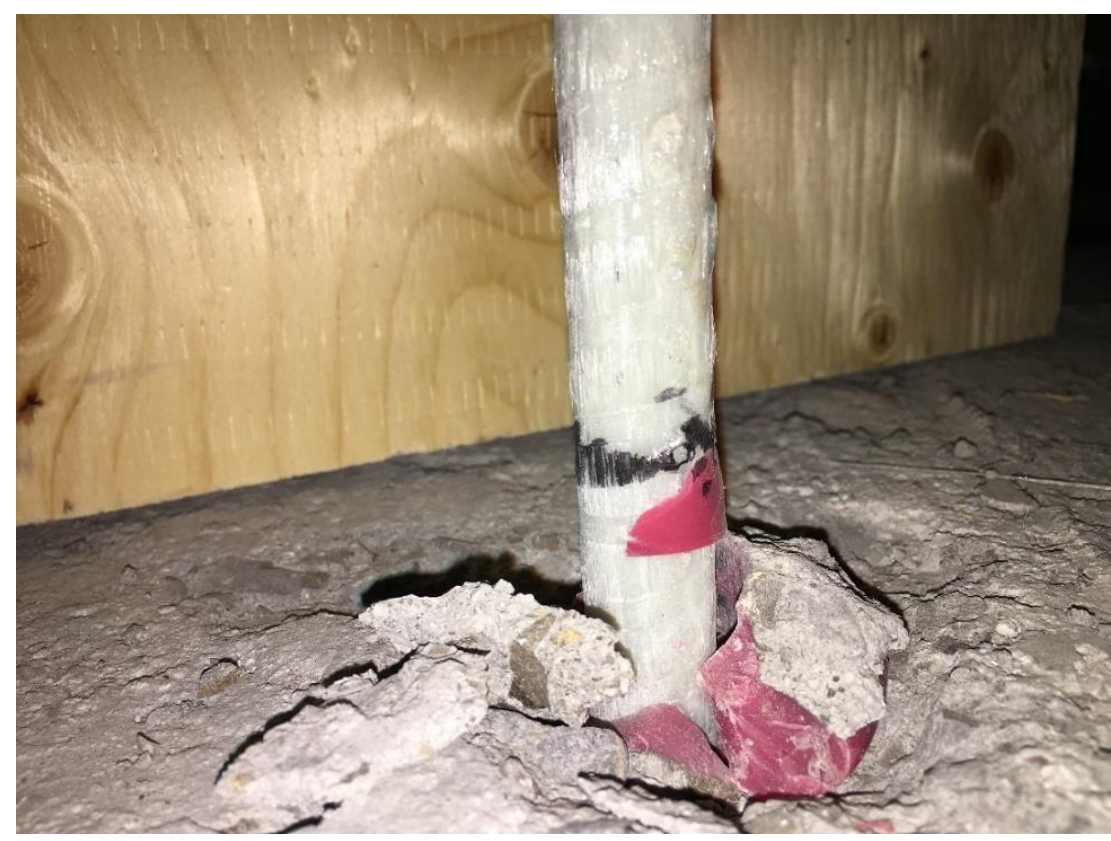

Figure 3.28: Slippage failure mode of post-installed bars in group 2 


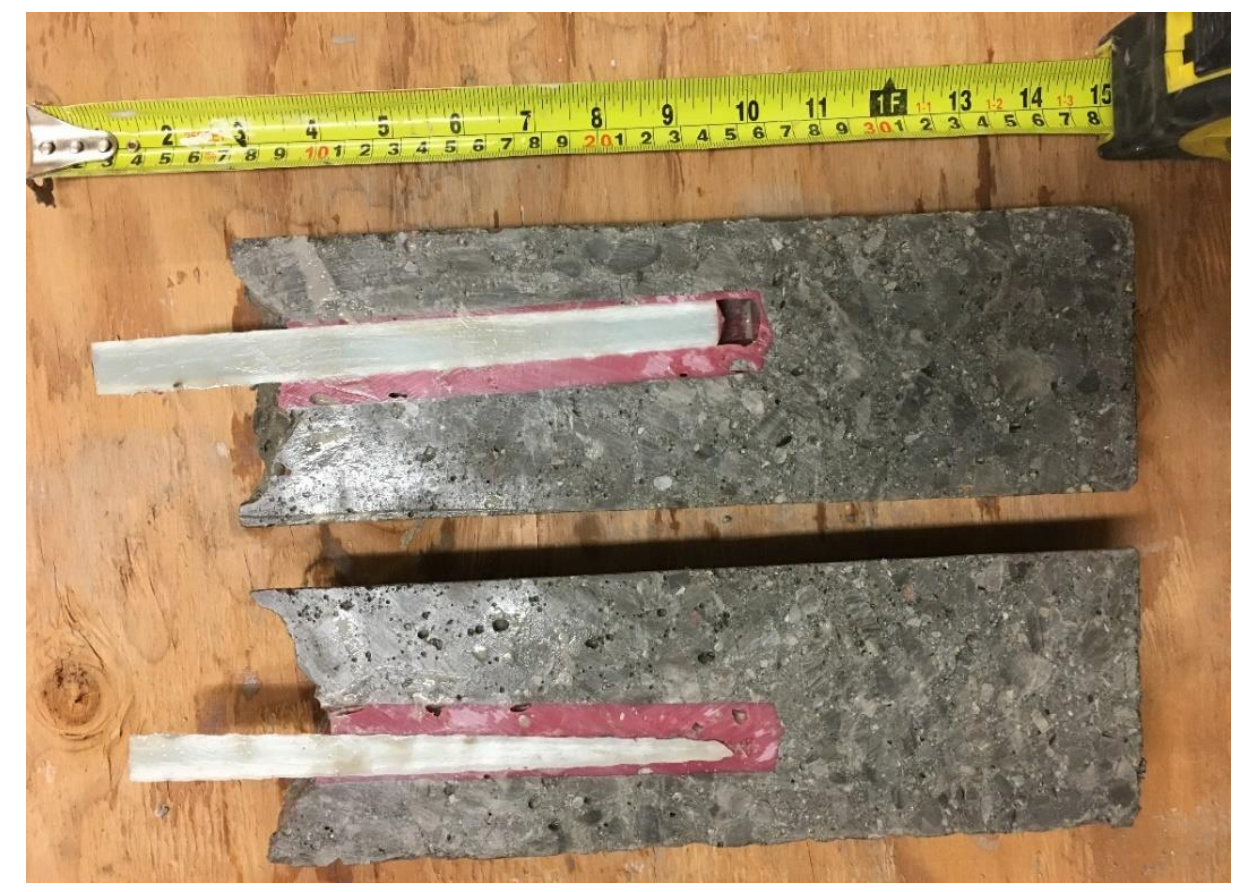

Figure 3.29: Sliced core sample for post-installed bars in group 2 showing bar slip

\subsubsection{Test Results for Post-Installed Bars with 200 mm Embedment Length}

Test results showed that the post-installed straight bars, with $200 \mathrm{~mm}$ embedment length as shown in Figure 3.12, failed with mixed failure modes in different specimens. Specimen 3-A failed due to bar slippage combined with concrete conical failure at the top surface of the slab as depicted in Figure 3.30(b) as well as the sliced core sample in Figure 3.32. Specimens 3-B and 3E failed due to bar slippage as depicted in Figure 3.30(a) as well as the sliced core sample in Figure 3.31. Specimens 3-C and 3-D failed due to bar crushing at its anchorage as depicted in Figure 3.30(c). Visual bar slippage at bar-adhesive interface was observed while the adhesive appeared fully bonded to the surrounding concrete after the test. Also, no slippage between the adhesive and concrete was observed. Another important aspect to note by looking at these core samples is the presence of air voids in the epoxy composition. Test results showed an average pullout force of $144.83 \mathrm{kN}$. Which is about $72 \%$ of the tension capacity of the bar. Table 3.10 summarizes the pullout capacity of each bar in this post-installed bar group 3 along with the corresponding POT readings. Figure A. 6 in the Appendix depicts the pullout load-POT reading relationship for this bar group, showing average POT reading at failure in the order of $2.38 \mathrm{~mm}$. 
Table 3.10: Pullout test results for post- installed group 3

\begin{tabular}{|c|c|c|}
\hline Specimen & $\begin{array}{c}\text { POT displacement } \\
\text { reading }(\mathrm{mm})\end{array}$ & $\begin{array}{c}\text { Maximum load } \\
(\mathrm{kN})\end{array}$ \\
\hline $3-\mathrm{A}$ & 1.96 & 163.56 \\
\hline $3-\mathrm{B}$ & 1.58 & 116.60 \\
\hline $3-\mathrm{C}$ & 1.86 & 153.58 \\
\hline $3-\mathrm{D}$ & 3.69 & 156.01 \\
\hline $3-\mathrm{E}$ & 2.81 & 134.41 \\
\hline \multirow{2}{*}{} & Average & 144.83 \\
\cline { 2 - 3 } & & \\
\cline { 2 - 3 }
\end{tabular}
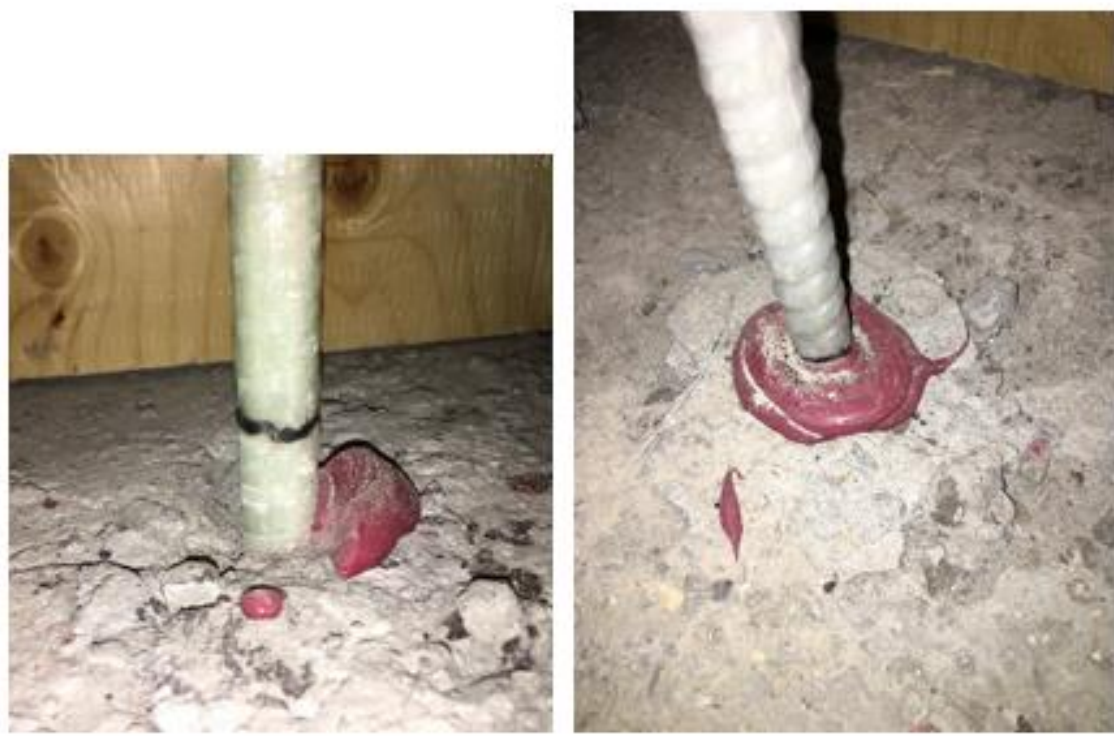

a) Bar slippage in 3-B b) Conical concrete failure in 3-A c) Bar rupture in 3-C

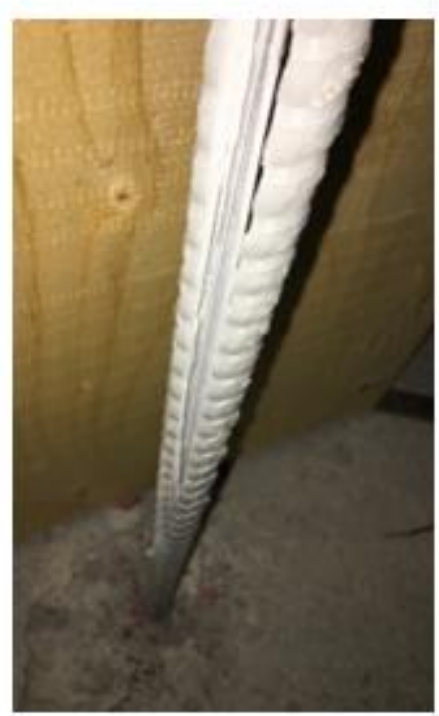

Figure 3.30: Different failures of the group 


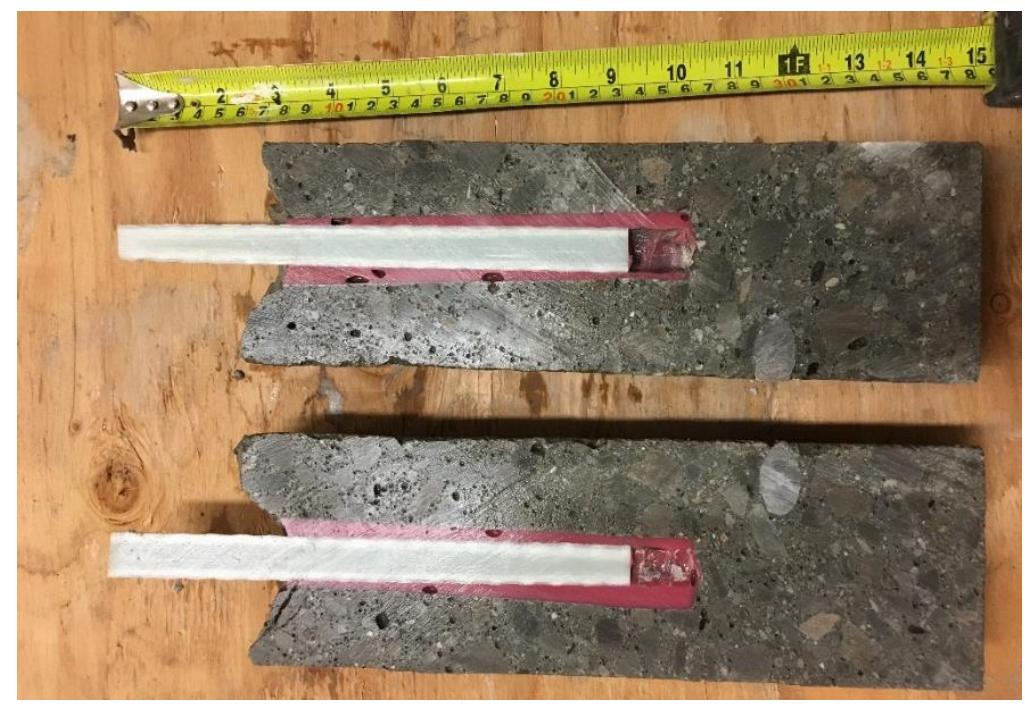

Figure 3.31: Sliced core sample for post-installed bars in group 3 showing bar slip

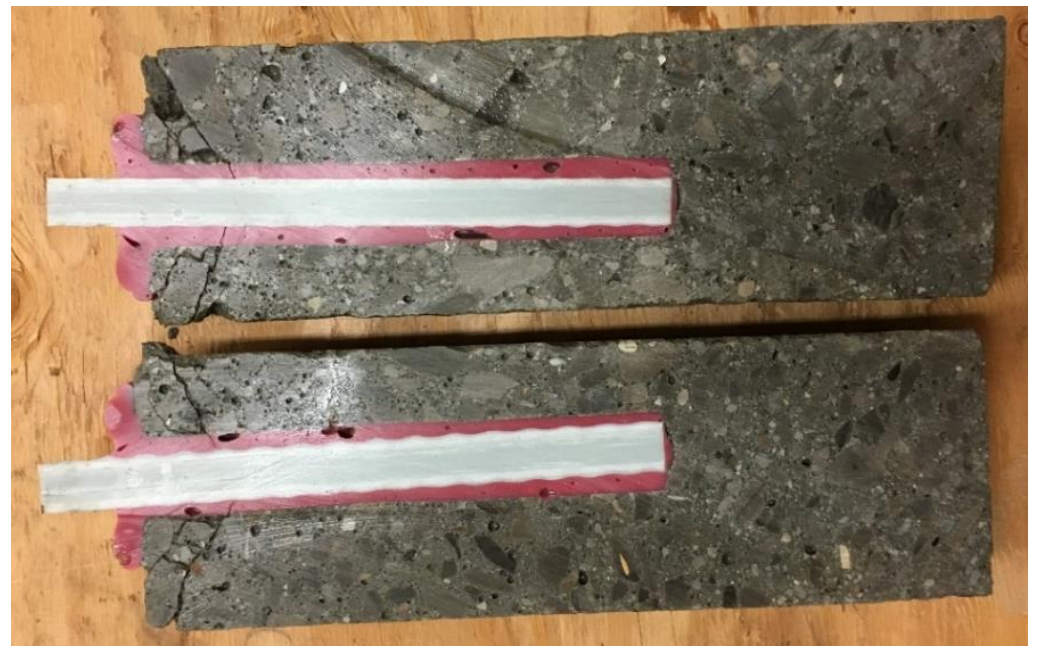

Figure 3.32: Sliced core sample for post-installed bars in group 3 showing conical failure 


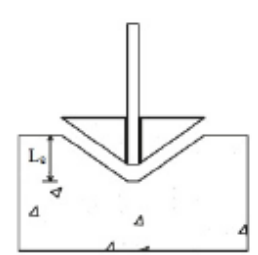

(a)

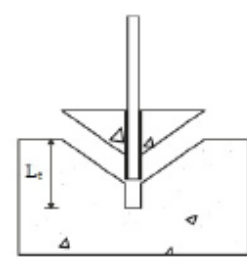

(b)

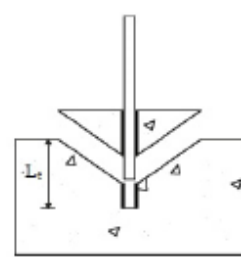

(c)

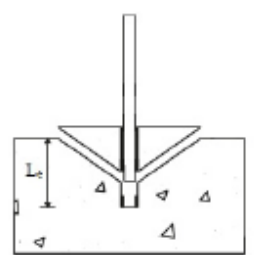

(d)

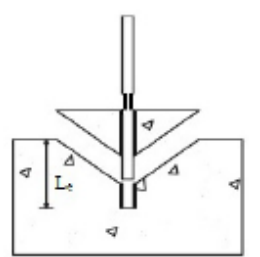

(e)

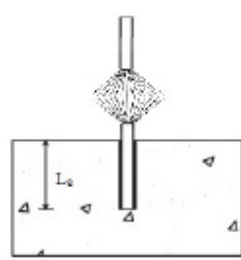

(f)

Figure 3.33: The different types of pullout failures: a) concrete cone breakout; b) adhesive/concrete interface pullout; c) GFRP/adhesive interface pullout d) pull through (adhesive/ concrete and GFRP); e) ribbed interface pullout; f) bar rupture (Azimi et al., 2014)

\subsection{Summary of Phase 1}

Table 3.11 summarizes the results from the pullout tests conducted in phase 1 while Figure 3.33 shows a summary of different failure modes that may result from pullout testing of the GFRP bars embedded in concrete. In all tested specimens, no bar rupture under direct tension occurred. A summary of the findings can be derived as follows:

1- The pullout capacity of the straight pre-installed bars, $145.48 \mathrm{kN}$, yielded a bond strength of $14.85 \mathrm{MPa}$ for $195 \mathrm{~mm}$ embedment length. Given the failure mode of bar crushing at the grip, the bar can still carry more tensile force to be pulled out of concrete. Similar observation can be drawn for the post-installed bar with $200 \mathrm{~mm}$ embedment length that reached a pullout capacity of $144.83 \mathrm{kN}$ with mixed failure modes in the tested samples. These mixed failure modes include (i) bar slip, (ii) bar slip combined with concrete conical failure, and (iii) bar crushing at grip.

2- The capacity of the GFRP bar to break its anchorage with the $100-\mathrm{mm}$ length cast headed end was $128.63 \mathrm{kN}$ while the capacity of a similar headed end bar with $147 \mathrm{~mm}$ bonded straight portion of the bar was $148.34 \mathrm{kN}$. This leads to an increase in headed bar capacity by $15 \%$ with the addition of bonded portion to transfer the tensile for in the bar to concrete.

3- In pre-installed bar tests, it can be observed that the pullout capacity decreased from $152.49 \mathrm{kN}$ to $144.83 \mathrm{kN}$ (i.e. by 5\%) with the increase in bar embedment length from 150 to $200 \mathrm{~mm}$. However, results for $175 \mathrm{~mm}$ embedment length did not follow the same trend. This may be attributed to possible flaws in the bar installation as a result of uneven distribution of adhesives around the bar.

4- The average pullout capacity of the tested GFRP bars with straight or headed-ends exceeded the minimum value of $100 \mathrm{kN}$ specified in MTO Standard Drawing for TL-5 barriers. 
Table 3.11: Summary of bar pullout strength and associated failure modes

\begin{tabular}{|c|c|c|c|c|c|}
\hline $\begin{array}{c}\text { Type of } \\
\text { construction }\end{array}$ & Group & Sample & $\begin{array}{c}\text { Failure } \\
\text { load (kN) }\end{array}$ & Type of failure & $\begin{array}{c}\text { Group average } \\
\text { failure load (kN) }\end{array}$ \\
\hline \multirow{14}{*}{$\begin{array}{l}\text { Pre-Installed } \\
\text { bars }\end{array}$} & \multirow{5}{*}{1} & A & 150.88 & Bar crushing at grip & \multirow{5}{*}{145.48} \\
\hline & & B & 146.02 & Bar crushing at grip & \\
\hline & & C & 140.35 & Bar crushing at grip & \\
\hline & & D & 144.67 & Bar crushing at grip & \\
\hline & & $\mathbf{E}$ & 145.48 & Bar crushing at grip & \\
\hline & \multirow{5}{*}{2} & A & 157.89 & Bar crushing at grip & \multirow{5}{*}{148.34} \\
\hline & & B & 127.67 & Bar crushing at grip & \\
\hline & & C & 161.94 & Bar crushing at grip & \\
\hline & & D & 151.69 & Bar crushing at grip & \\
\hline & & $\mathbf{E}$ & 142.51 & Bar crushing at grip & \\
\hline & \multirow{4}{*}{3} & A & 137.38 & Bar slip from head & \multirow{4}{*}{131.04} \\
\hline & & B & 122.00 & Bar slip from head & \\
\hline & & C & 137.38 & Bar slip from head & \\
\hline & & D & 127.40 & Bar slip from head & \\
\hline \multirow{15}{*}{$\begin{array}{l}\text { Post-Installed } \\
\text { bars }\end{array}$} & \multirow{5}{*}{1} & A & 158.70 & Bar crushing at grip & \multirow{5}{*}{152.49} \\
\hline & & B & 194.87 & Bar slip & \\
\hline & & C & 146.83 & Bar crushing at grip & \\
\hline & & D & 158.97 & Bar slip & \\
\hline & & $E$ & 103.10 & Bar slip & \\
\hline & \multirow{5}{*}{2} & A & 134.68 & Bar slip & \multirow{5}{*}{112.82} \\
\hline & & B & 96.09 & Bar slip & \\
\hline & & C & 120.38 & Bar slip & \\
\hline & & D & 89.61 & Bar slip & \\
\hline & & $\mathbf{E}$ & 123.35 & Bar slip & \\
\hline & \multirow{5}{*}{3} & A & 163.56 & Bar slip, concrete cone & \multirow{5}{*}{144.83} \\
\hline & & B & 116.60 & Bar slip & \\
\hline & & C & 153.58 & Bar crushing at grip & \\
\hline & & D & 156.01 & Bar crushing at grip & \\
\hline & & $\mathbf{E}$ & 134.41 & Bar slip & \\
\hline
\end{tabular}




\section{Chapter 4: Phase 2 - Static Load Tests on TL-5 Bridge Barriers}

\subsection{Overview of Phase 2}

Upon phase 1 completion, the experimental program moves on to phase 2 to examine the use of straight- and headed-end GFRP bars to provide rigid joint at the barrier-deck slab junction. A total of 6 actual-size barrier-deck slab segments were constructed and tested to collapse to determine their ultimate load carrying capacities under transverse loading simulating vehicle impact. Four out of the six barriers were built as in the case of new construction, while two barriers were built to simulate a barrier replacement. Specific details that speak to the construction and methodologies used are discussed in the following sub-sections. This chapter investigates the crack patterns associated with each individual barrier and failure mechanisms involved with each scenario. Ultimate load are then benchmarked against the CHBDC current requirements. At the end of the chapter, a summary of the experimental findings is presented.

Six full-scale TL-5 barrier specimens of $900 \mathrm{~mm}$ length were erected and tested to-collapse to determine their ultimate load-carrying capacities and failure modes at deck barrier joint. Designations of specimens used in this research are tabulated in Table 4.6. In case of barrier walls installed on top of solid slab bridges and voided slab bridges, the barrier wall is considered connected to non-deformable thick slab. Specimen B-1 shown in Figure 4.1 represents this scenario where the barrier wall is fixed to a $500 \mathrm{~mm}$ thick slab resting on the laboratory floor to prevent its flexural deformation. The dimensions and GFRP arrangement are identical to TL-5 barrier specified in MTO Standard Drawings. The barrier is reinforced with M15 GFRP vertical bars at the front face at $300 \mathrm{~mm}$ spacing and 13M GFRP vertical bars at the back face of the barrier wall at $300 \mathrm{~mm}$ spacing. All vertical GFRP bars are embedded into the deck slab with vertical embedment length of $195 \mathrm{~mm}$. The deck slab was reinforced in the main direction with M20 steel bars at $100 \mathrm{~mm}$ spacing. This barrier specimen represents the interior portions between the expansion joints or ends of the barrier wall. However, the exterior portion of the barrier wall expects to be more critical than the interior location when impacted by vehicle. As a result, MTO Standard Drawings specifies vertical bar spacing at the traffic side of the barrier as half the spacing between similar bars at interior locations. So, Figure 4.2 shows schematic diagram of specimen B-2 that represents the exterior segment of the TL-5 barrier on which the vertical reinforcement at the front face of the barrier is doubled. In this case, M15 GFRP vertical bars were used at the front face of the barrier at $150 \mathrm{~mm}$ spacing while the vertical reinforcement at the back face of the barrier was kept as M13 at $300 \mathrm{~mm}$ spacing. 
Specimens B-3 and B-4 represent barrier wall installed over deck slab cantilever in a slab-ongirder bridge. Figure 4.3 shows schematic diagram of specimen B-3 that represent the interior segment of TL-5 barrier. The barrier is reinforced with M15 GFRP vertical bars at the front face at $300 \mathrm{~mm}$ spacing and 13M GFRP vertical bars at the back face of the barrier wall at $300 \mathrm{~mm}$ spacing. All vertical GFRP bars are embedded into a $250-\mathrm{mm}$ thick deck slab cantilever with vertical embedment length of $195 \mathrm{~mm}$. The cantilever deck slab was reinforced in the main direction with M20 steel bars at $100 \mathrm{~mm}$ spacing. Figure 4.4 shows schematic diagram of specimen B-4 that represents the exterior segment of TL-5 barrier on which the vertical reinforcement at the front face of the barrier is doubled. In this case, M15 GFRP vertical bars were used at the front face of the barrier at $150 \mathrm{~mm}$ spacing while the vertical reinforcement at the back face of the barrier was kept as M13 at $300 \mathrm{~mm}$ spacing.

Specimen B-5 and B-6 represent the case of the replacement of deteriorated bridge barrier in existing bridges. Figure 4.5 shows a schematic diagram of the post-installed barrier wall into thick concrete slab at interior location on which vertical bars are spaced every $300 \mathrm{~mm}$. The barrier vertical bars are post-installed into the deck over a vertical embedment length of $195 \mathrm{~mm}$ using Hilti epoxy. Figure 4.6 shows a schematic diagram of the post-installed barrier wall into thick concrete slab at exterior location on which vertical bars at the front face are spaced every 150 $\mathrm{mm}$ while the rest of the reinforcement is identical to those in specimen B-5 at interior location. 


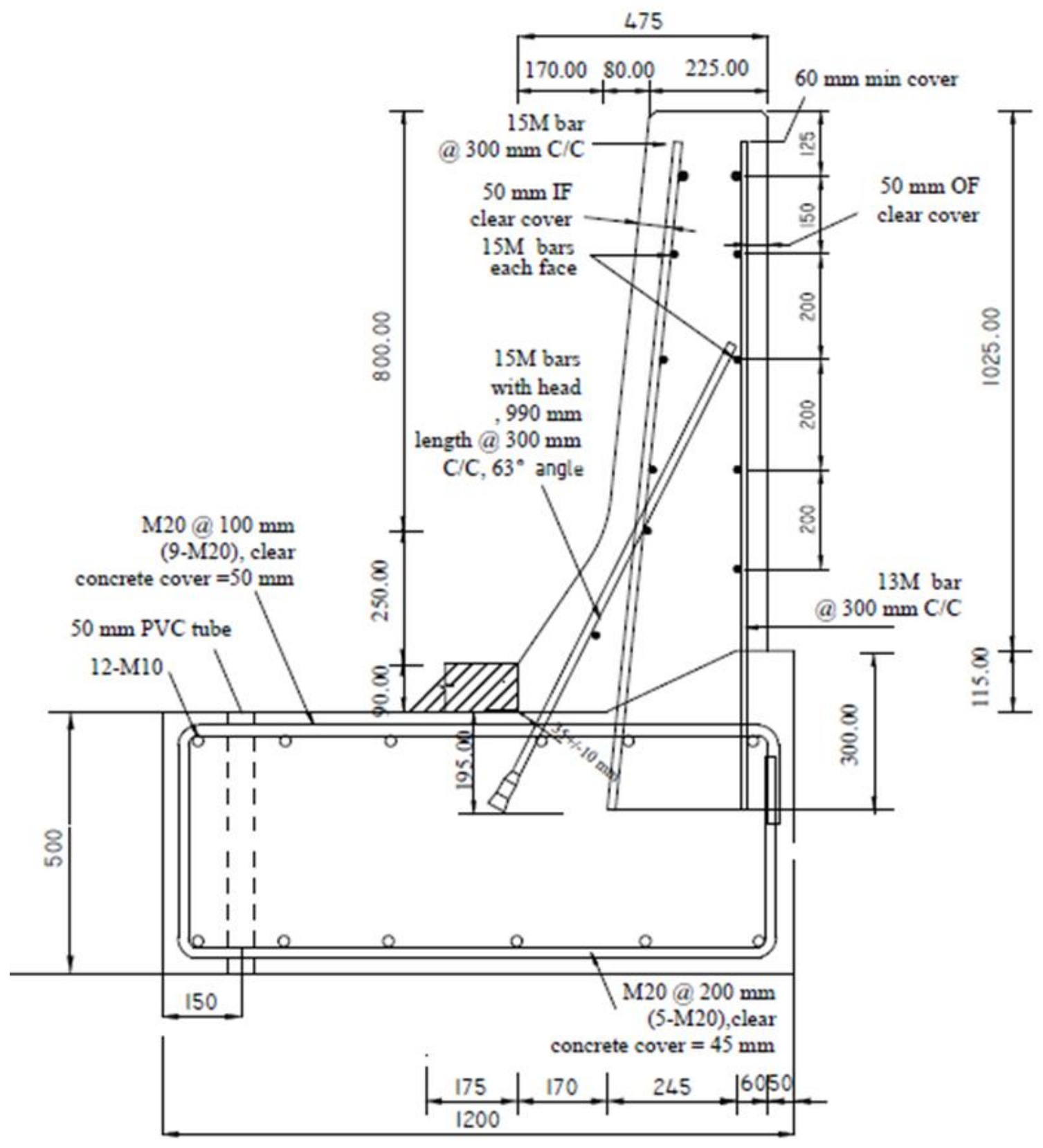

Figure 4.1: Barrier specimen B-1 details (Interior Location - No Cantilever) 


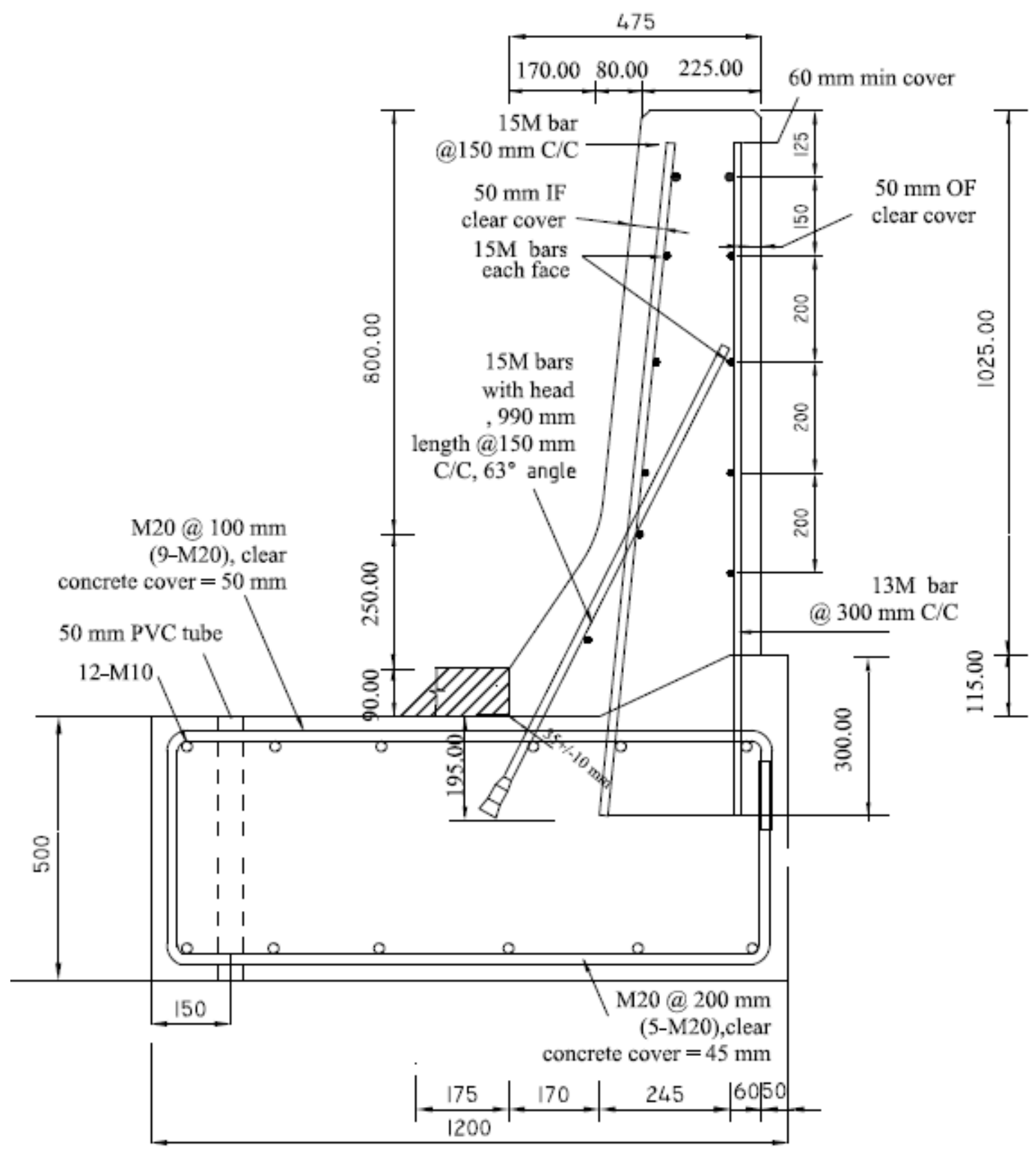

Figure 4.2: Barrier specimen B-2 details (Exterior Location - No Cantilever) 


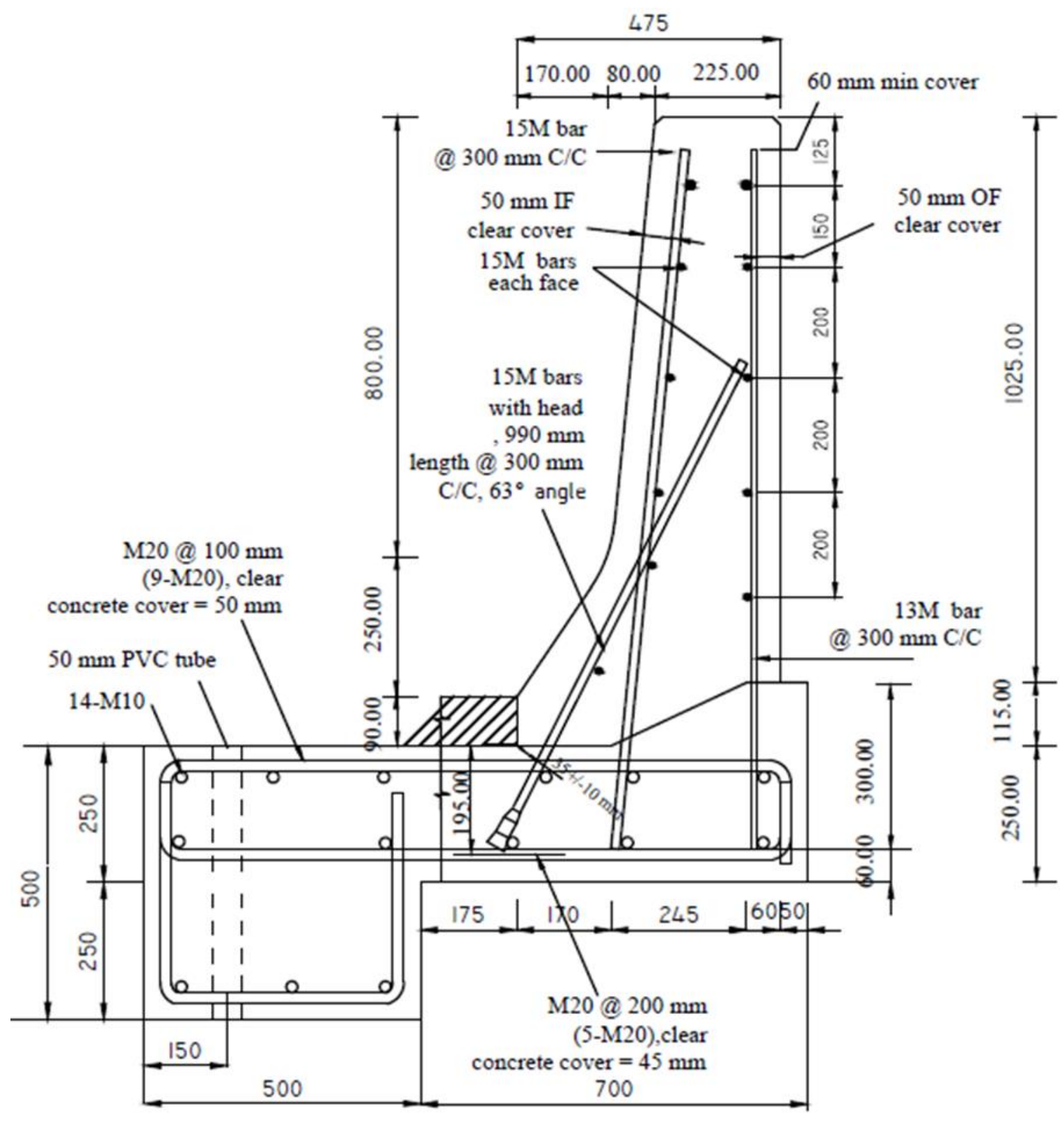

Figure 4.3: Barrier specimen B-3 details (Interior Location - With Cantilever) 


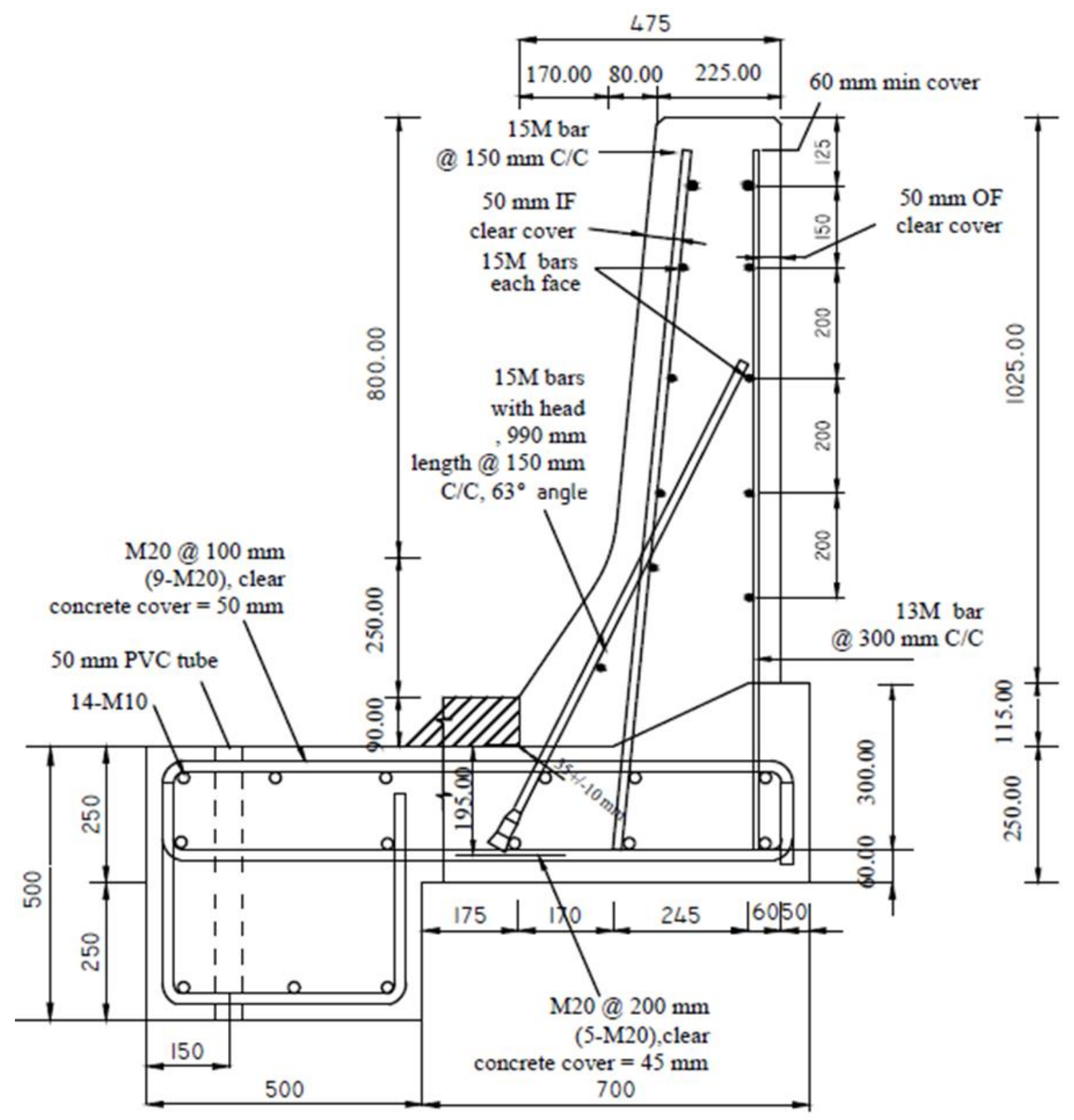

Figure 4.4: Barrier specimen B-4 details (Exterior Location - With Cantilever) 


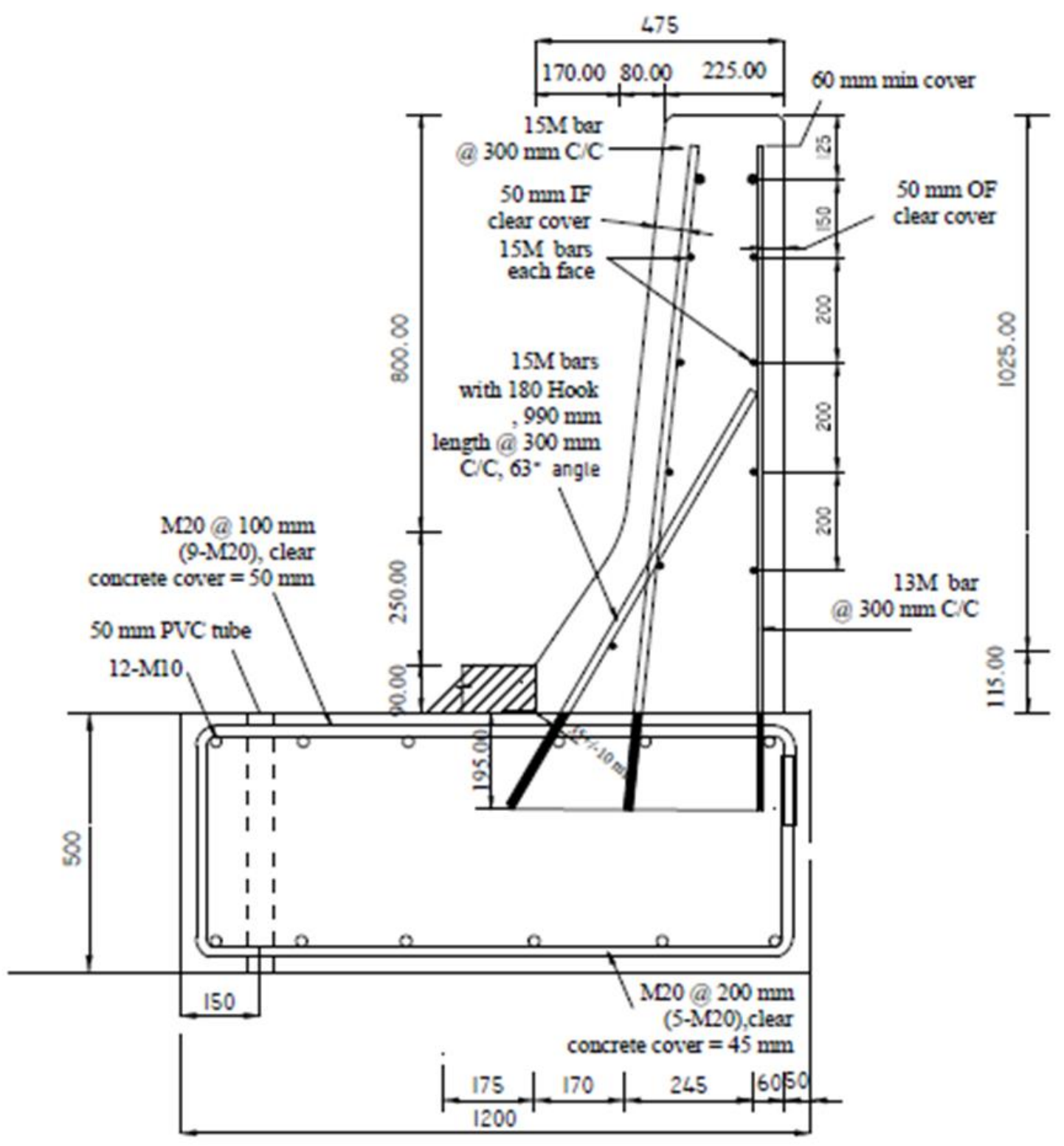

Figure 4.5: Barrier specimen B-5 details (Interior Location - No Cantilever - Post-Installed) 


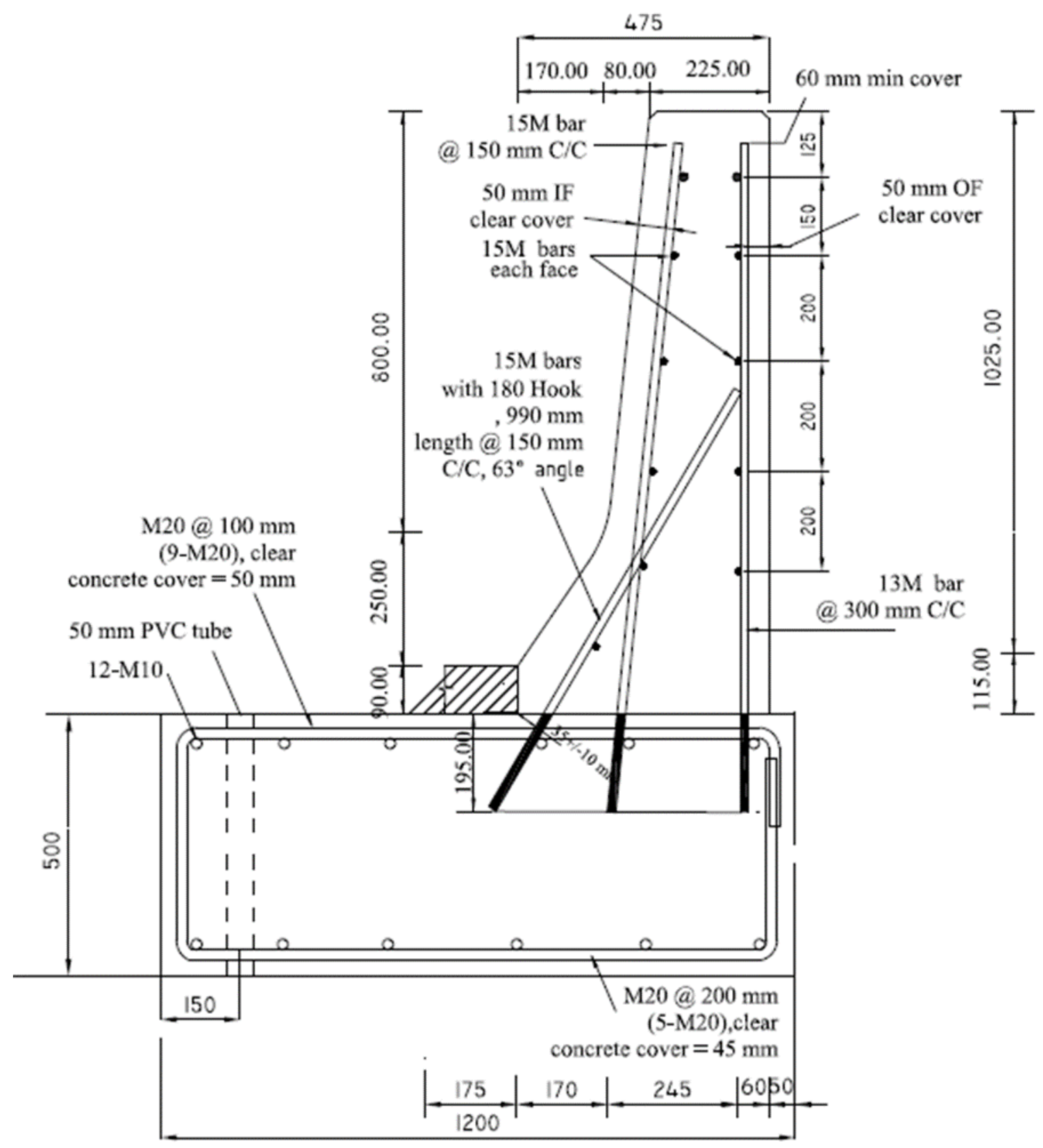

Figure 4.6: Barrier specimen B-6 details (Exterior Location - No Cantilever - Post-Installed)

\subsection{Material Properties}

The GFRP bars used to construct the barriers were manufactured elsewhere (B\&B FRP Manufacturing Inc., 2016). Tables 3.3 and 4.1 summarize the materials properties of these bars as supplied by the manufacturer. The $16 \mathrm{M}(\# 5)$ high-modulus (HM) GFRP bars of specified tensile 
strength of $1000 \mathrm{MPa}$, modulus of elasticity of $70 \mathrm{GPa}$, and strain at rupture of 1.5, as listed in the manufacturer's catalogue, were used as vertical bars in the barrier wall. The use of headedend GFRP bars was proposed in this research to allow for anchorage in concrete at lower cost than the bend bars. The head of the M15 bar is approximately $100 \mathrm{~mm}$ long. It begins with a wide disk which transfers a large portion of the load from the bar into the concrete. Beyond this disk, the head tapers in steps to the outer diameter of the bar. This geometry ensures optimal anchorage forces and minimal transverse splitting action in the vicinity of the head.

Table 4.1: Properties of GFRP Bar \#4 (B\&B FRP Manufacturing Inc., 2016)

\begin{tabular}{|c|c|c|c|c|c|c|}
\hline $\begin{array}{c}\text { Imperial } \\
\text { size }\end{array}$ & $\begin{array}{c}\text { Metric } \\
\text { size }(\mathrm{mm})\end{array}$ & $\begin{array}{c}\text { Ultimate tensile } \\
\text { strength (MPa) }\end{array}$ & $\begin{array}{c}\text { Young's modulus } \\
\text { of elasticity (MPa) }\end{array}$ & $\begin{array}{c}\text { Ultimate } \\
\text { strain } \\
(\%)\end{array}$ & $\begin{array}{c}\text { Bond } \\
\text { strength } \\
(\mathrm{MPa})\end{array}$ & $\begin{array}{c}\text { Weight } \\
(\mathrm{Kg} / \mathrm{m})\end{array}$ \\
\hline$\# 4$ & 13 & 1000 & 70,000 & $1.5 \%$ & 20 & 0.35 \\
\hline
\end{tabular}

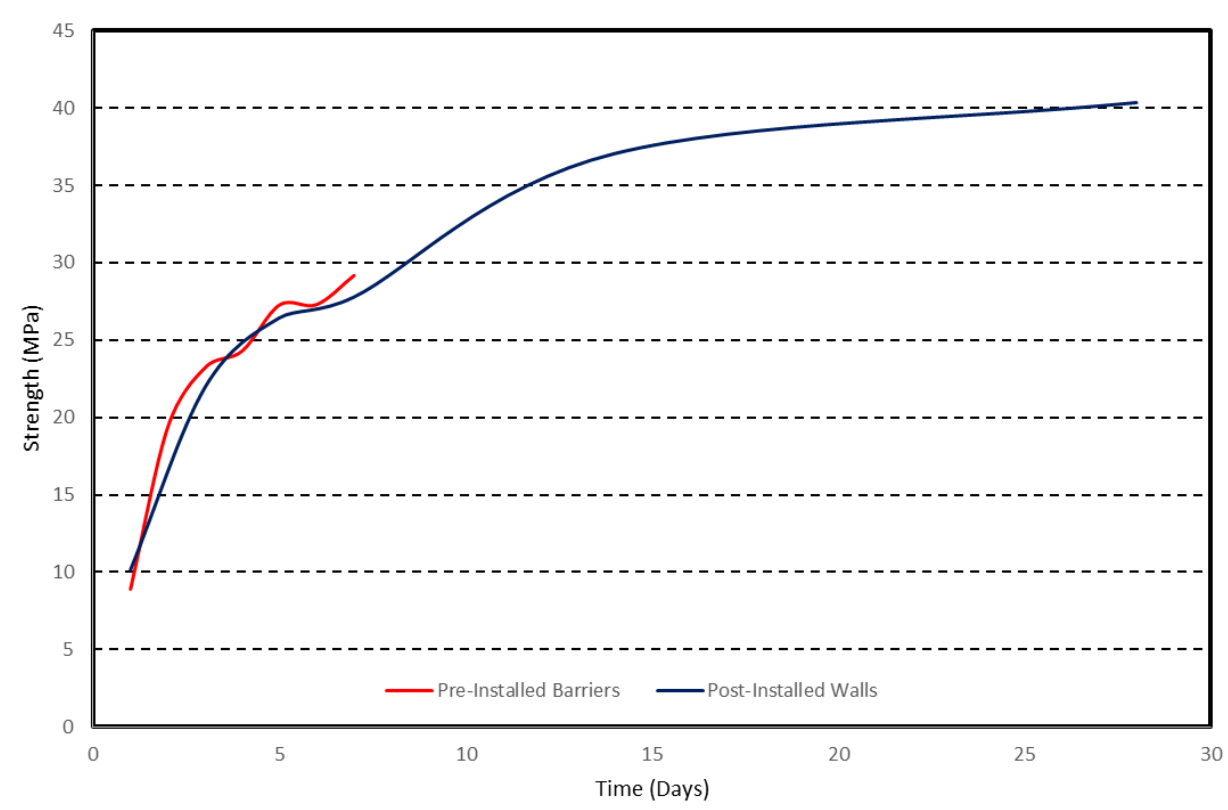

Figure 4.7: Strength development for the two different concrete batches

All specimens were cast using ready mix concrete with a target compressive strength of 35 $\mathrm{MPa}$. In order to determine the strength of the concrete, three $100 \times 200 \mathrm{~mm}$ concrete cylinders collected from the concrete used to cast each barrier were tested on the same day the barrier specimens were loaded to collapse. Concrete in this phase was ordered at three different points in time. The first batch was used for the four pre-installed TL-5 barriers, and the two slabs of the post-installed specimens. Then, the second batch was used for casting the slabs used to conduct 
the pullout tests described in chapter 3 . The third batch was used for the walls of the barrier with post-installed GFRP bars in the deck. For the post-installed barrier specimens, the ideal condition would have been to have concrete of the same strength at the time of testing for both the slab and wall. Cylinder testing data showed that the concrete strengths achieved between the two different segments was relatively close. Figure 4.7 and Tables 4.2 through 4.5 showcase these results.

Table 4.2: First concrete batch strength development for the pre-installed barriers and two slabs for the post-installed barrier walls

\begin{tabular}{|c|c|c|c|c|c|c|}
\hline $\begin{array}{l}\text { Time } \\
\text { (Days) }\end{array}$ & Specimen & $\begin{array}{c}\text { Strength } \\
\text { (MPa) }\end{array}$ & $\begin{array}{l}\text { Strength } \\
(\mathrm{kN})\end{array}$ & $\begin{array}{l}\text { Average strength } \\
\text { (MPa) }\end{array}$ & $\begin{array}{c}\text { Average } \\
\text { strength (kN) }\end{array}$ & $\begin{array}{c}\text { Characteristic } \\
\text { value (MPa) }\end{array}$ \\
\hline \multirow{3}{*}{1} & 1 & 11.94 & 93.71 & \multirow{3}{*}{10.97} & \multirow{3}{*}{86.11} & \multirow{3}{*}{8.90} \\
\hline & 2 & 10.36 & 81.35 & & & \\
\hline & 3 & 10.60 & 83.27 & & & \\
\hline \multirow{3}{*}{2} & 1 & 23.42 & 183.96 & \multirow{3}{*}{22.89} & \multirow{3}{*}{179.79} & \multirow{3}{*}{19.36} \\
\hline & 2 & 22.06 & 173.26 & & & \\
\hline & 3 & 23.19 & 182.15 & & & \\
\hline \multirow{3}{*}{3} & 1 & 27.39 & 215.06 & \multirow{3}{*}{27.20} & \multirow{3}{*}{213.64} & \multirow{3}{*}{23.22} \\
\hline & 2 & 26.78 & 210.30 & & & \\
\hline & 3 & 27.44 & 215.55 & & & \\
\hline \multirow{3}{*}{4} & 1 & 28.68 & 225.29 & \multirow{3}{*}{30.12} & \multirow{3}{*}{233.95} & \multirow{3}{*}{24.30} \\
\hline & 2 & 28.65 & 225.02 & & & \\
\hline & 3 & 33.03 & 251.53 & & & \\
\hline \multirow{3}{*}{5} & 1 & 30.98 & 243.31 & \multirow{3}{*}{32.41} & \multirow{3}{*}{254.58} & \multirow{3}{*}{27.27} \\
\hline & 2 & 33.36 & 261.99 & & & \\
\hline & 3 & 32.91 & 258.45 & & & \\
\hline \multirow{3}{*}{6} & 1 & 30.44 & 239.06 & \multirow{3}{*}{34.65} & \multirow{3}{*}{272.11} & \multirow{3}{*}{27.30} \\
\hline & 2 & 36.85 & 289.42 & & & \\
\hline & 3 & 36.65 & 287.84 & & & \\
\hline \multirow{3}{*}{7} & 1 & 38.02 & 298.61 & \multirow{3}{*}{36.11} & \multirow{3}{*}{283.57} & \multirow{3}{*}{29.17} \\
\hline & 2 & 37.62 & 295.44 & & & \\
\hline & 3 & 32.68 & 256.67 & & & \\
\hline
\end{tabular}


Table 4.3: Third concrete batch strength development for the two post installed walls

\begin{tabular}{|c|c|c|c|c|c|c|}
\hline $\begin{array}{l}\text { Time } \\
\text { (days) }\end{array}$ & Specimen & $\begin{array}{c}\text { Strength } \\
\text { (MPa) }\end{array}$ & $\begin{array}{l}\text { Strength } \\
(\mathrm{kN})\end{array}$ & $\begin{array}{l}\text { Average strength } \\
\text { (MPa) }\end{array}$ & $\begin{array}{c}\text { Average } \\
\text { strength (kN) }\end{array}$ & $\begin{array}{c}\text { Characteristic } \\
\text { value (MPa) }\end{array}$ \\
\hline \multirow{3}{*}{1} & 1 & 12.01 & 94.46 & \multirow{3}{*}{11.89} & \multirow{3}{*}{93.45} & \multirow{3}{*}{10.16} \\
\hline & 2 & 11.80 & 92.65 & & & \\
\hline & 3 & 11.87 & 93.23 & & & \\
\hline \multirow{3}{*}{3} & 1 & 25.70 & 202.20 & \multirow{3}{*}{25.80} & \multirow{3}{*}{202.90} & \multirow{3}{*}{21.95} \\
\hline & 2 & 26.40 & 207.60 & & & \\
\hline & 3 & 25.30 & 198.90 & & & \\
\hline \multirow{3}{*}{5} & 1 & 30.76 & 241.55 & \multirow{3}{*}{31.20} & \multirow{3}{*}{245.03} & \multirow{3}{*}{26.44} \\
\hline & 2 & 32.22 & 253.06 & & & \\
\hline & 3 & 30.62 & 240.47 & & & \\
\hline \multirow{3}{*}{7} & 1 & 35.88 & 281.82 & \multirow{3}{*}{34.02} & \multirow{3}{*}{267.16} & \multirow{3}{*}{27.79} \\
\hline & 2 & 34.92 & 274.26 & & & \\
\hline & 3 & 31.25 & 245.39 & & & \\
\hline \multirow{3}{*}{14} & 1 & 45.98 & 361.12 & \multirow{3}{*}{44.61} & \multirow{3}{*}{350.33} & \multirow{3}{*}{37.06} \\
\hline & 2 & 46.02 & 361.41 & & & \\
\hline & 3 & 41.82 & 328.46 & & & \\
\hline \multirow{3}{*}{28} & 1 & 48.27 & 379.12 & \multirow{3}{*}{47.91} & \multirow{3}{*}{376.28} & \multirow{3}{*}{40.35} \\
\hline & 2 & 49.51 & 388.84 & & & \\
\hline & 3 & 45.95 & 360.88 & & & \\
\hline
\end{tabular}


Table 4.4: Concrete strength at the time of testing (first batch)

\begin{tabular}{|c|c|c|c|c|c|c|c|}
\hline Barrier & Time & Specimen & $\begin{array}{c}\text { Strength } \\
(\mathrm{MPa})\end{array}$ & $\begin{array}{c}\text { Strength } \\
(\mathbf{k N})\end{array}$ & $\begin{array}{l}\text { Average } \\
\text { strength }\end{array}$ & $\begin{array}{l}\text { Average } \\
\text { strength }\end{array}$ & $\begin{array}{c}\text { Characteristic } \\
\text { value (MPa) }\end{array}$ \\
\hline \multirow{3}{*}{$\begin{array}{l}\text { Interior } \\
\text { Cantilever }\end{array}$} & \multirow{3}{*}{$\begin{array}{c}42 \\
\text { Days }\end{array}$} & 1 & 47.32 & 371.63 & \multirow{3}{*}{43.05} & \multirow{3}{*}{338.15} & \multirow{3}{*}{32.95} \\
\hline & & 2 & 36.72 & 288.38 & & & \\
\hline & & 3 & 45.13 & 354.43 & & & \\
\hline \multirow{3}{*}{$\begin{array}{l}\text { Exterior } \\
\text { Cantilever }\end{array}$} & \multirow{3}{*}{$\begin{array}{c}68 \\
\text { Days }\end{array}$} & 1 & 54.05 & 424.49 & \multirow{3}{*}{51.80} & \multirow{3}{*}{406.83} & \multirow{3}{*}{43.57} \\
\hline & & 2 & 51.26 & 402.63 & & & \\
\hline & & 3 & 50.09 & 393.38 & & & \\
\hline \multirow{3}{*}{$\begin{array}{c}\text { Interior } \\
\text { Fixed }\end{array}$} & \multirow{3}{*}{$\begin{array}{c}37 \\
\text { Days }\end{array}$} & 1 & 41.51 & 326.06 & \multirow{3}{*}{46.65} & \multirow{3}{*}{366.41} & \multirow{3}{*}{37.12} \\
\hline & & 2 & 48.56 & 381.37 & & & \\
\hline & & 3 & 49.88 & 391.80 & & & \\
\hline \multirow{3}{*}{$\begin{array}{c}\text { Exterior } \\
\text { Fixed }\end{array}$} & \multirow{3}{*}{$\begin{array}{c}58 \\
\text { Days }\end{array}$} & 1 & 48.94 & 384.39 & \multirow{3}{*}{52.46} & \multirow{3}{*}{412.04} & \multirow{3}{*}{43.27} \\
\hline & & 2 & 55.33 & 434.57 & & & \\
\hline & & 3 & 53.11 & 417.15 & & & \\
\hline \multirow{3}{*}{$\begin{array}{c}\text { Interior } \\
\text { Post-Install } \\
\text { Slab }\end{array}$} & \multirow{3}{*}{$\begin{array}{c}70 \\
\text { Days }\end{array}$} & 1 & 42.45 & 333.42 & \multirow{3}{*}{47.59} & \multirow{3}{*}{373.74} & \multirow{3}{*}{37.91} \\
\hline & & 2 & 51.04 & 400.88 & & & \\
\hline & & 3 & 49.26 & 386.93 & & & \\
\hline \multirow{3}{*}{$\begin{array}{c}\text { Exterior Post } \\
\text { Install Slab }\end{array}$} & \multirow{3}{*}{$\begin{array}{c}83 \\
\text { Days }\end{array}$} & 1 & 43.47 & 341.35 & \multirow{3}{*}{50.47} & \multirow{3}{*}{396.39} & \multirow{3}{*}{39.05} \\
\hline & & 2 & 53.37 & 419.11 & & & \\
\hline & & 3 & 54.59 & 428.71 & & & \\
\hline
\end{tabular}

Table 4.5: Concrete strength at the time of testing (second batch)

\begin{tabular}{|c|c|c|c|c|c|c|c|}
\hline Barrier & Time & Specimen & $\begin{array}{c}\text { Strength } \\
\text { (MPa) }\end{array}$ & $\begin{array}{l}\text { Strength } \\
\text { (kN) }\end{array}$ & $\begin{array}{l}\text { Average } \\
\text { strength }\end{array}$ & $\begin{array}{l}\text { Average } \\
\text { strength }\end{array}$ & $\begin{array}{l}\text { Characteristic } \\
\text { value (MPa) }\end{array}$ \\
\hline \multirow{3}{*}{$\begin{array}{l}\text { Interior Post- } \\
\text { Install Wall }\end{array}$} & \multirow{3}{*}{$\begin{array}{c}28 \\
\text { Days }\end{array}$} & 1 & 48.27 & 379.12 & \multirow{3}{*}{47.91} & \multirow{3}{*}{376.28} & \multirow{3}{*}{40.35} \\
\hline & & 2 & 49.51 & 388.84 & & & \\
\hline & & 3 & 45.95 & 360.88 & & & \\
\hline \multirow{3}{*}{$\begin{array}{c}\text { Exterior } \\
\text { Post-Install } \\
\text { Wall }\end{array}$} & \multirow{3}{*}{$\begin{array}{c}41 \\
\text { Days }\end{array}$} & 1 & 43.62 & 342.56 & \multirow{3}{*}{46.34} & \multirow{3}{*}{363.94} & \multirow{3}{*}{38.07} \\
\hline & & 2 & 49.64 & 389.91 & & & \\
\hline & & 3 & 45.75 & 359.37 & & & \\
\hline
\end{tabular}




\subsection{Phase Construction and Methodology}

\subsubsection{Barrier Construction}

This phase of the experiment consisted of 6 barrier specimens being built and tested in a laboratory environment, each barrier consisting of a different composition. Four of the barriers consisted of all materials being constructed and cast in concrete simultaneously. However, two of the six barrier specimens were constructed during two separate occurrences. The two occurrences were done in effort to achieve conditions to that of a bridge rehabilitation project. Approximately two months were allowed for the cast concrete properties to mature.

The formwork for the barriers was constructed out of wood materials, and connected with wood screws, as well as a series of bolts. The heavy reinforcement for the formwork was done to ensure no bulging or deformation of the concrete elements, which may impact experimental results and test setup. The forms consisted of three stud walls around the sides and the rear of the barrier. The front face of the barriers was constructed out of four separate sections which were bolted at the top to simulate a pivot point and could then be lifted and lowered manually while rotating at that point, they would best be described as overhead gates. The bottom section (one of the four separate sections) remained in place and did pivot as this was for the slab constructability. Figure 4.8 provides a clear image of the formwork construction. On the inside of the barriers, all joints were sealed with typical silicone based sealant via a caulking gun.

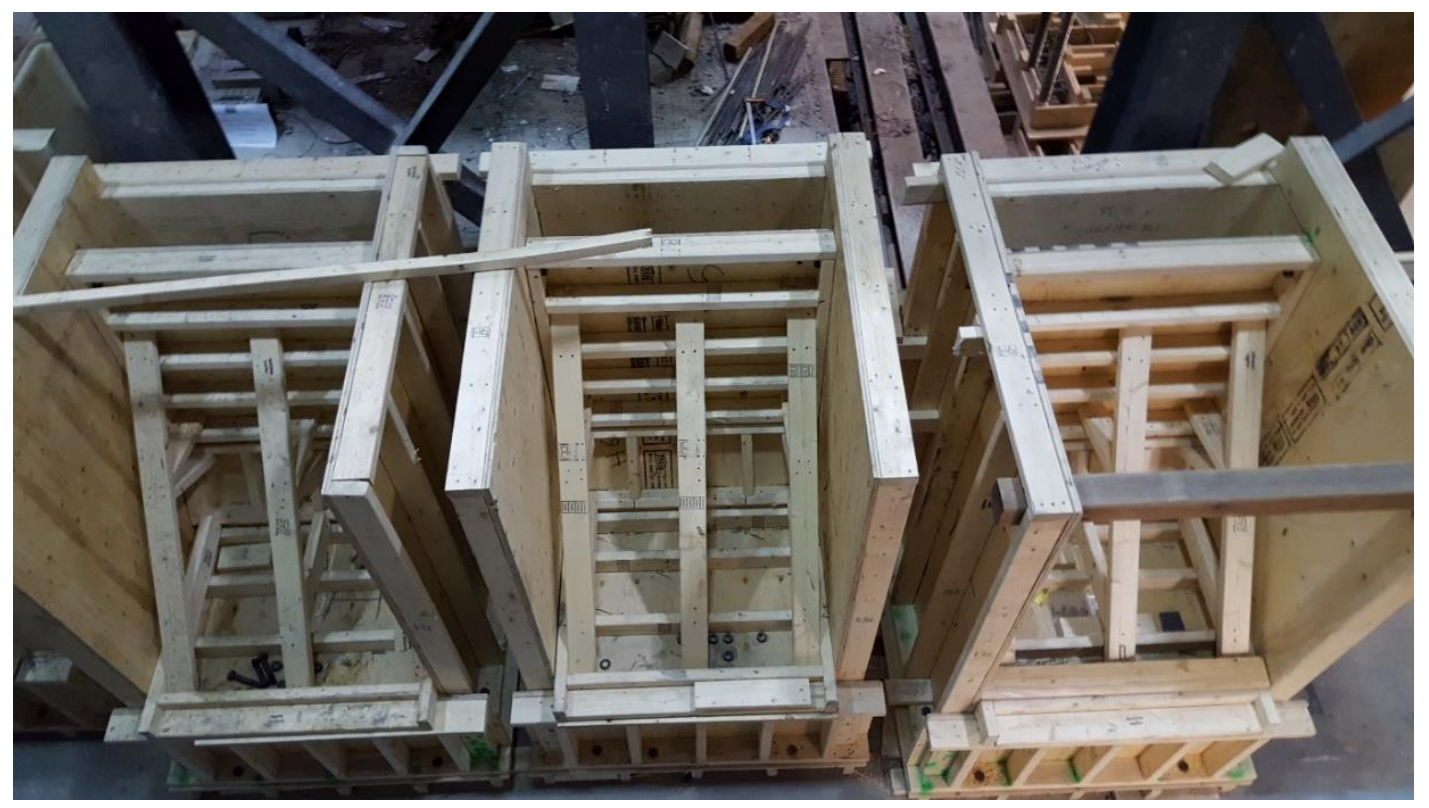

Figure 4.8: Typical formwork construction for TL-5 barriers in phase 2 
Once construction of the formwork was complete, two black $50 \mathrm{~mm}$ ABS pipes were cut and placed inside the barriers at precise locations $(600 \mathrm{~mm}$ center to center from one another, and $150 \mathrm{~mm}$ from the front face of the slab to the center of the pipe) to ensure correct anchoring of the barriers to the laboratory rigid concrete floor. The tolerance for this construction had to be zero, due to any misalignment resulting in the inability of the bolts to be installed. These pipes were secured in place by pre-drilling the wood forms in the correct place and sizing the holes to match the outer diameter of the pipes.

The steel cages for the slabs of the barriers were then constructed within the same laboratory. The steel cages were then built by welding the steel rebar as per drawing specifications, and then lifted with a crane and lowered into their respective barriers while maintaining their clear cover requirements using plastic spacers. Figure 4.9 depicts the placement of the steel cage into the barrier, which would be typical for all barriers. The clear cover requirements for the slab portion of the barriers, as per the drawing specifications were $50 \mathrm{~mm}$ at the top, and $45 \mathrm{~mm}$ at the bottom. Clear cover requirements pertaining to the barrier walls were $50 \mathrm{~mm}$ for both the front and rear faces, and $60 \mathrm{~mm}$ at the top surface.

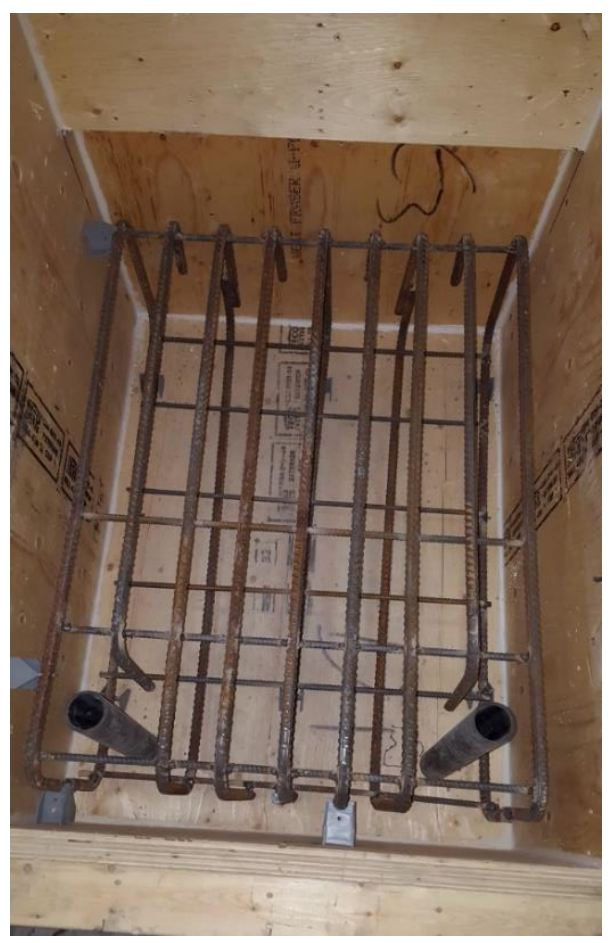

Figure 4.9: Slab steel reinforcement installation, and clear cover satisfaction 
Following construction and securing of the steel cages for the slabs, the GFRP bars were then included in the construction sequence. Firstly, all bars were cut to their correct lengths at the manufacturer's plant as per the drawing specifications. Precisely, the $63^{\circ}$ angled bars on the front face of the barrier wall were of interest thus required monitoring. These bars were the anchorheaded bars in the four pre-installed specimens and the regular straight GFRP bars for the postinstalled specimens. Ultimately, to monitor the stress level in these bars during the testing, strain gauges were installed on the GFRP bars at a height which was directly at the deck-wall junction. The GFRP profiled surface at that location was sanded down to be relatively flat for proper installation of the strain gauge. The gauges were installed on all $63^{\circ}$ angled bars at this location, all while following proper procedure and ensuring that the proper current was flowing. Figures 4.10 through 4.12 depict the locations of strain gauges on the GFRP bars while Figure 4.13 depicts the process of installing the strain gauges and covering them with protective tape.

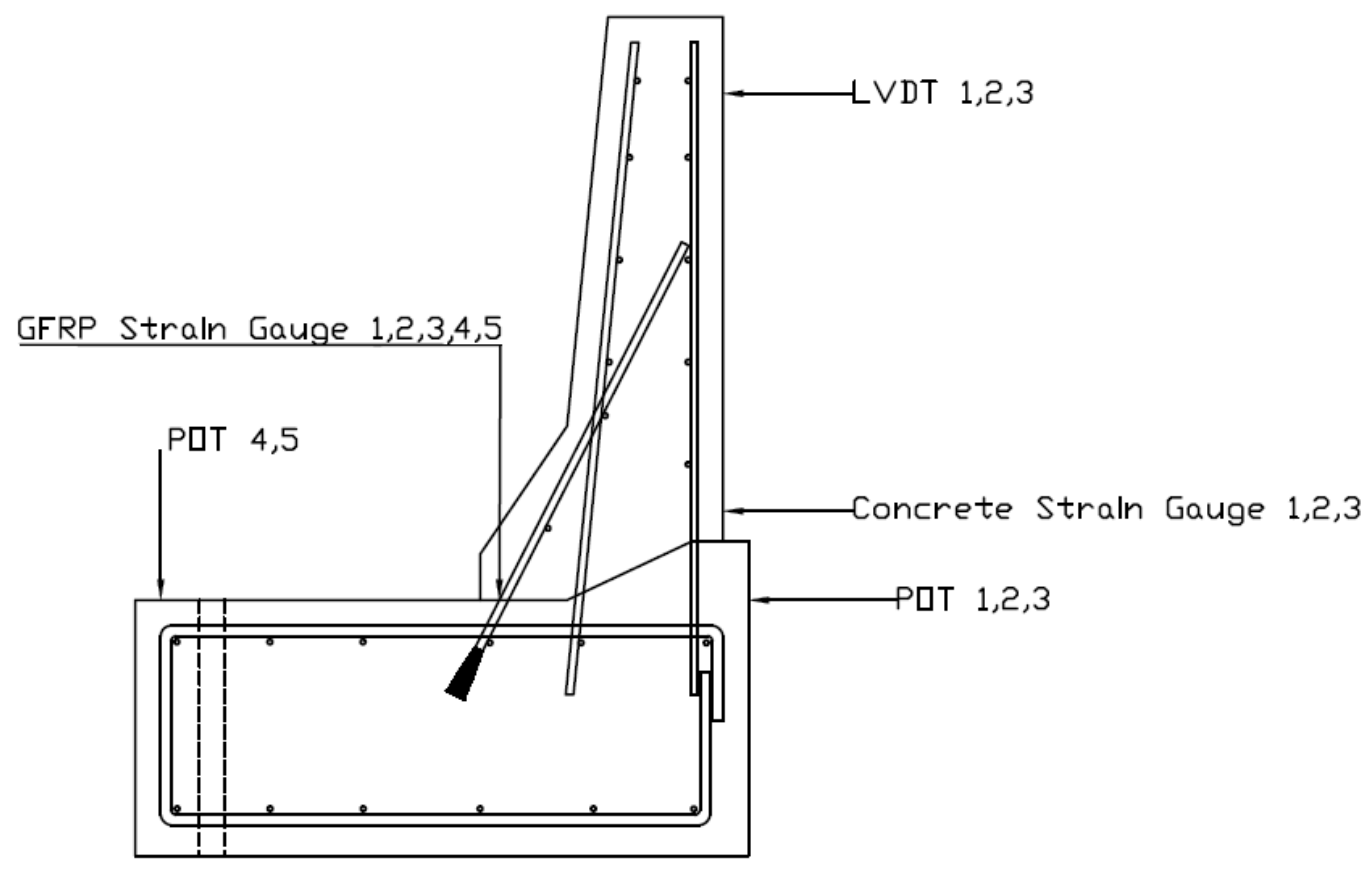

Figure 4.10: B-1 \& B-2 sensor placement (Note: B-1 only had 3 GFRP strain gauges) 


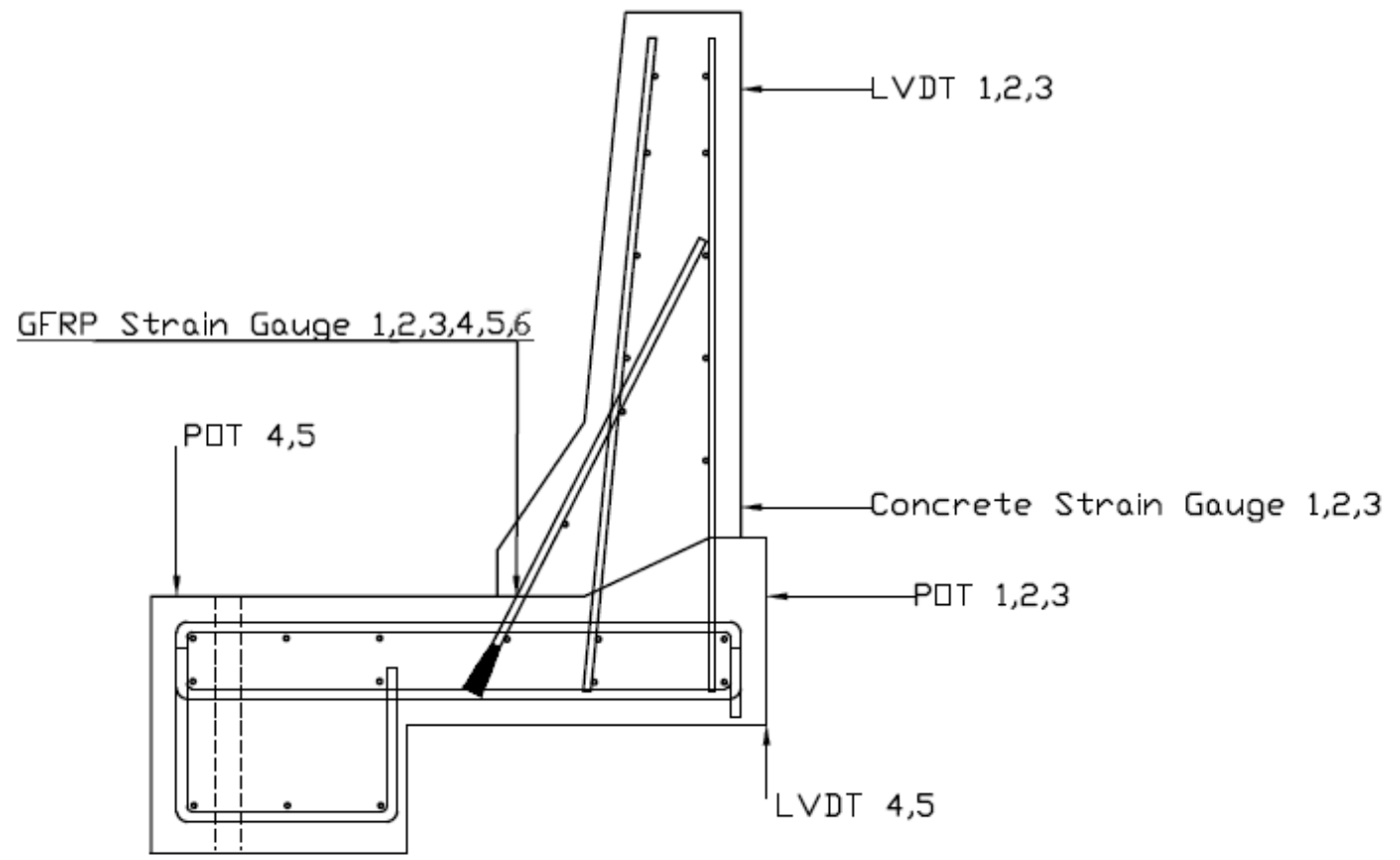

Figure 4.11: B-3 \& B-4 sensor placement (Note: B-3 only had 3 GFRP strain gauges)

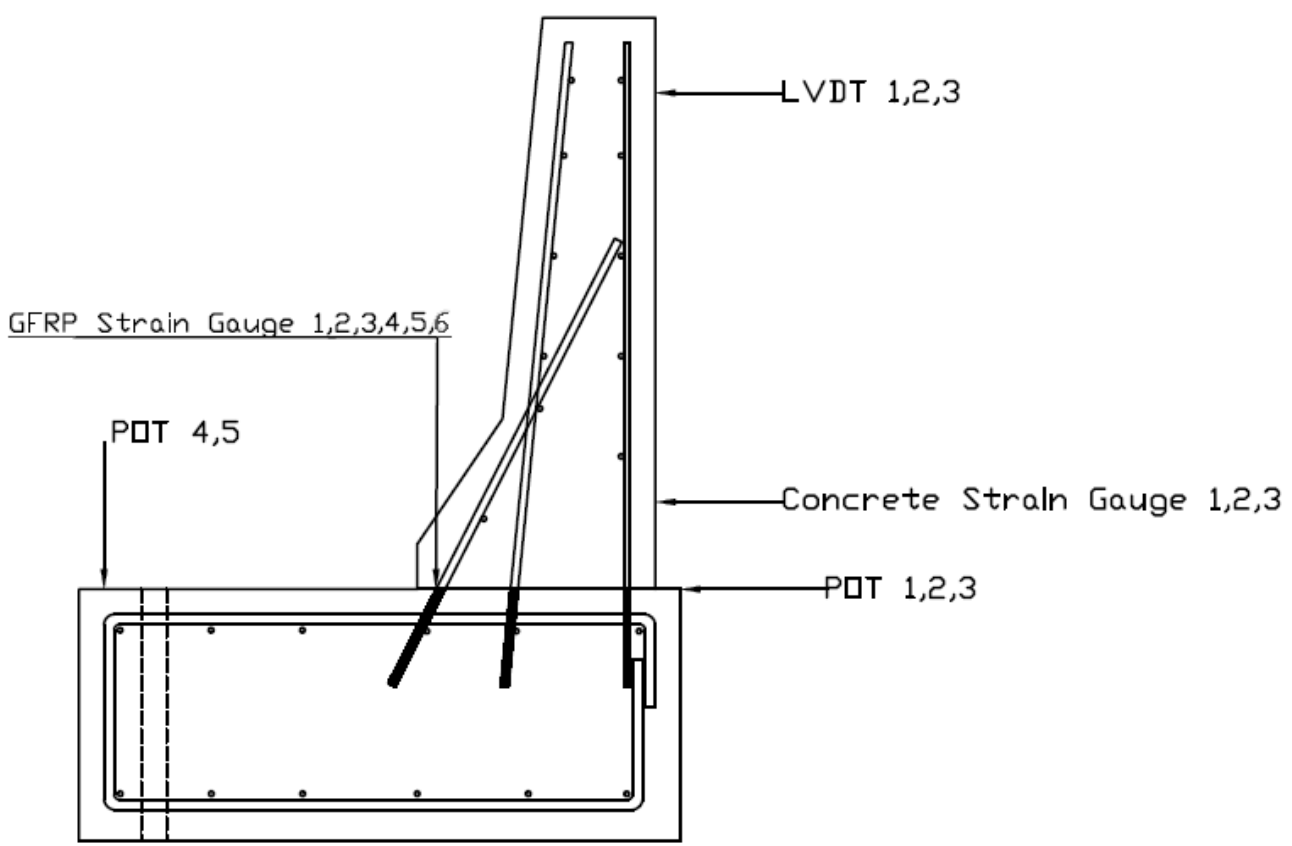

Figure 4.12: B-5 \& B-6 sensor placement (Note: B-5 only had 3 GFRP strain gauges) 


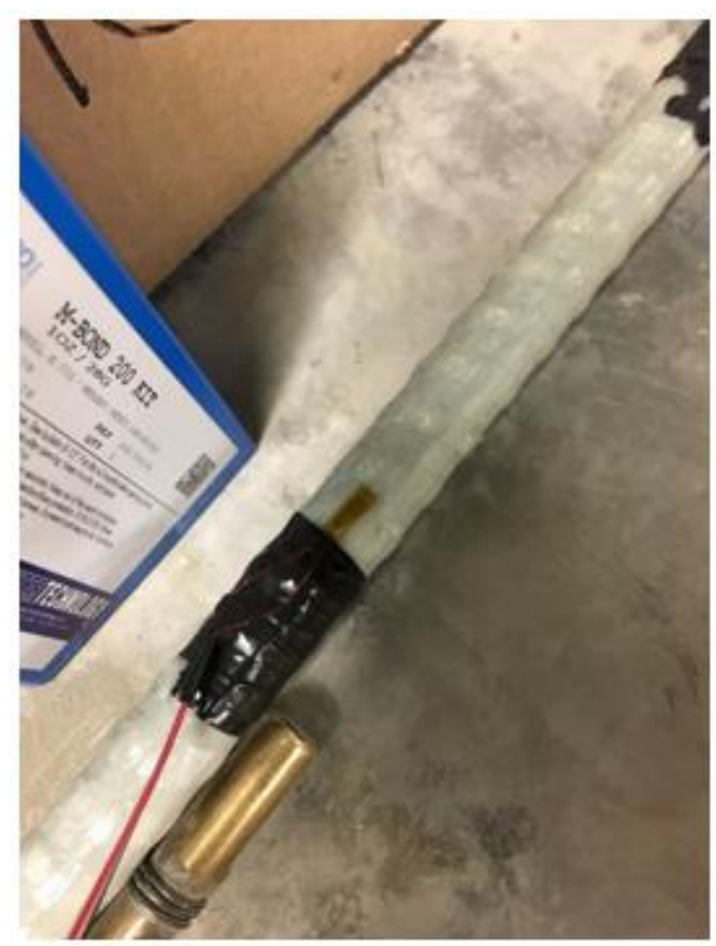

a) Exposed strain gauge

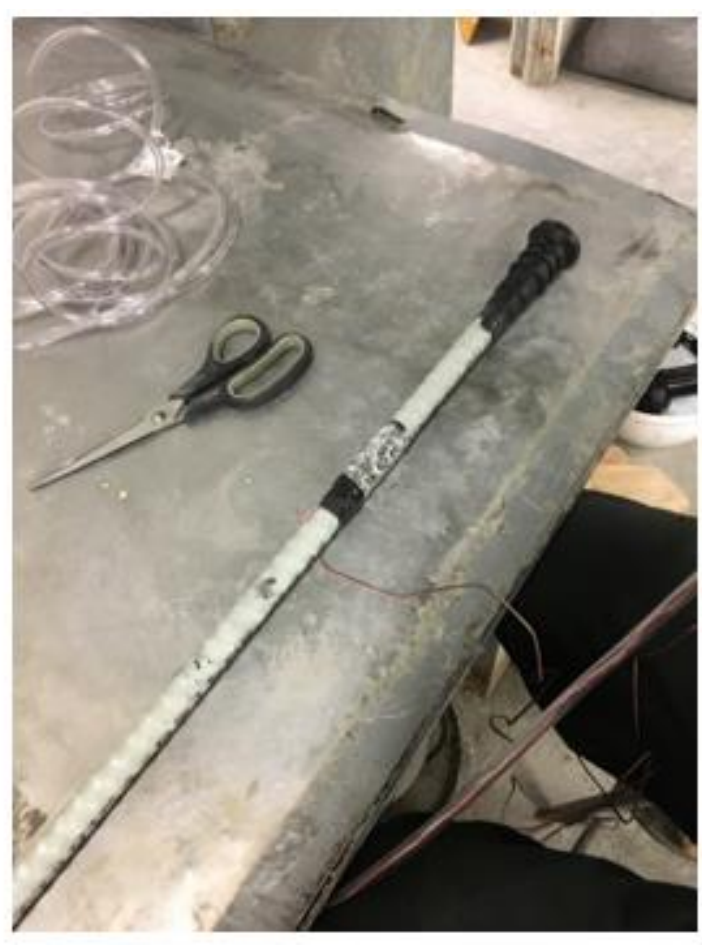

b) strain gauge covered with tape for protection

Figure 4.13: Application of the strain gauge on GFRP bars

After installing strain gauges on the GFRP bars, their placement inside the barrier proceeded. Four horizontal \#4 bars were cut longer than specified in the drawings to allow them to protrude from the barrier sides. This was done for constructability of the GFRP mesh in the barrier wall. These four bars allowed for the vertical bars and then the rest of the horizontal bars to be fastened and secured at their correct locations. Figure 4.14 shows a typical GFRP wall mesh layout for a barrier at its exterior location. The bars extend down into the slab as specified in the drawings. The $63^{\circ}$ angled bars at the front were installed with a digital level to ensure correct angle was achieved while ensuring that the strain gauge placement was exactly at the concrete deck-wall junction. A steel hook was also installed at the top of the wall in order to allow for crane maneuverability of the specimen. 


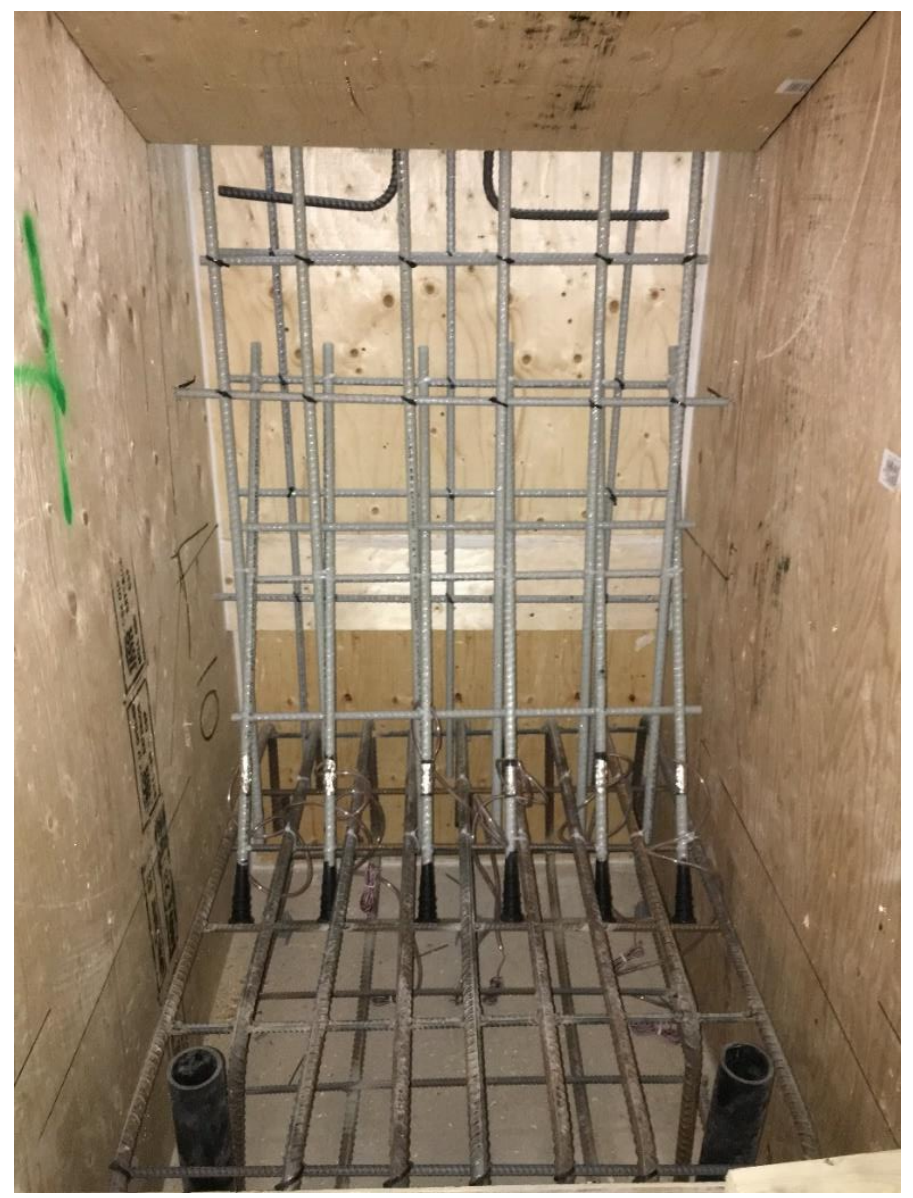

Figure 4.14: Typical GFRP wall mesh at exterior location

After complete installation of the reinforcing steel in the slab and GFRP bars in the wall, strain gauge wires were run through thin plastic tubing which would ideally act as an additional protective layer of the wire. These wires would sustain impact loads of the wet concrete at the time of casting, therefore the protective layer was deemed feasible for this construction. The cables were then fed through a drilled hole on the side of the barrier and covered with plastic. This portion would not be inside the concrete matrix, but would be the connection to the data acquisition system during testing. Once secured and protected, all barrier gates were then lifted up and awaited casting.

Casting of the barriers was done in a specific order. First, all six barrier slab portions were poured and given a small amount of extra concrete at the junction to achieve a slope at that section as specified in the drawings (with the exception of the post-installed barriers). The slabs were all vibrated to achieve proper compaction of the concrete in all areas. Once all slabs were poured and vibrated, the gates were manually lowered, and bolts were inserted and tightened, to avoid unwanted bulging or shifting of the barrier while pouring the walls. Only four of the 
barrier walls were poured during the first casting session; the casting of two post-installed barriers was halted after pouring their respective slabs. Each wall was poured in three sections, and vibrated three different times in effort to, once again, achieve proper compaction and distribution of the concrete elements.

All barrier formwork were secured with 8 large diameter bolts around the perimeter at the base to prevent shear failure of the wood screws. Each barrier was also secured with two of the same diameter bolts to create the pivot point for the gate opening and closing functionality. Four smaller diameter bolts were installed to maintain the connection between the rear wall and the two perpendicular side walls. The same bolts were also used to secure the gate position when lowered after pouring the slab portion. The gate had two bolts at the front and three on each side (two for each wall section composing the gate) for a total of eight. In total, approximately 22 bolts were used on each barrier formwork to maintain a strong seal.

The barriers were kept moist (only for the first four days) by applying water to all of the wood formwork, which concealed approximately the entire barrier exterior surface area. The barriers were not covered with any burlap or plastic, but were left to cure in normal conditions inside the laboratory at approximately $23^{\circ} \mathrm{C}$ and with a relative humidity of about $50 \%$ (the concrete cylinders were cured in the same manner). After approximately a week, the formwork for all barriers was removed. Figure 4.15 shows a typical cantilevered barrier in the process of the formwork being removed. There were no deficiencies noted upon removal of the forms, and no signs of "honeycombing" were visible. 


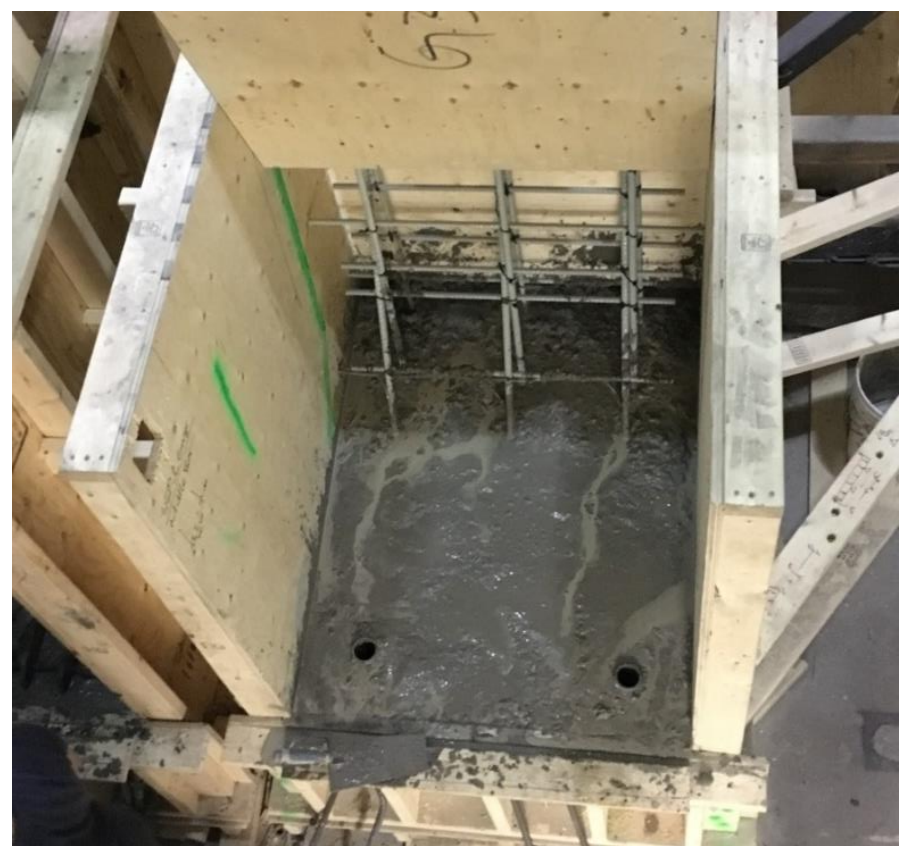

a) Pouring concrete over slab section

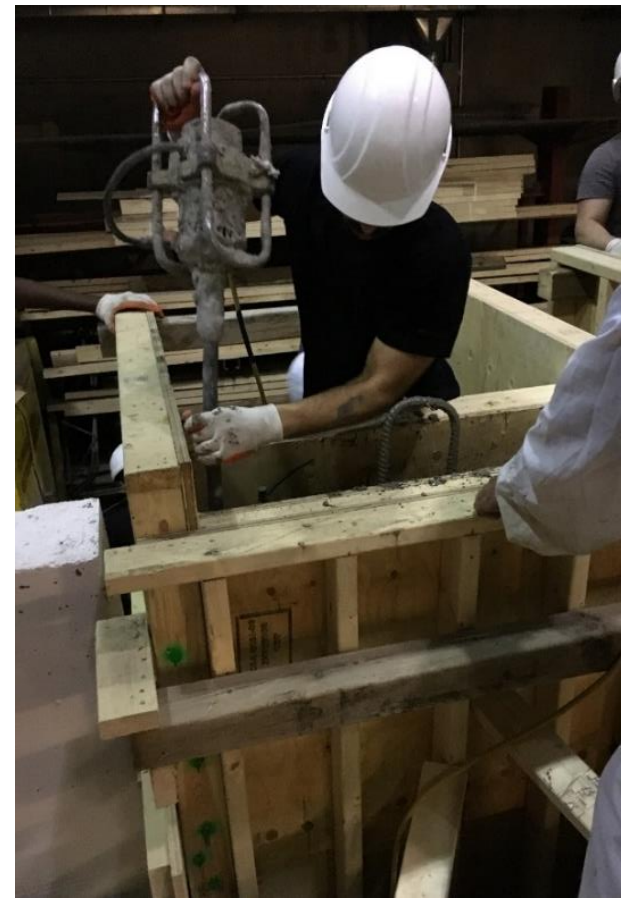

c) Vibrating poured concrete

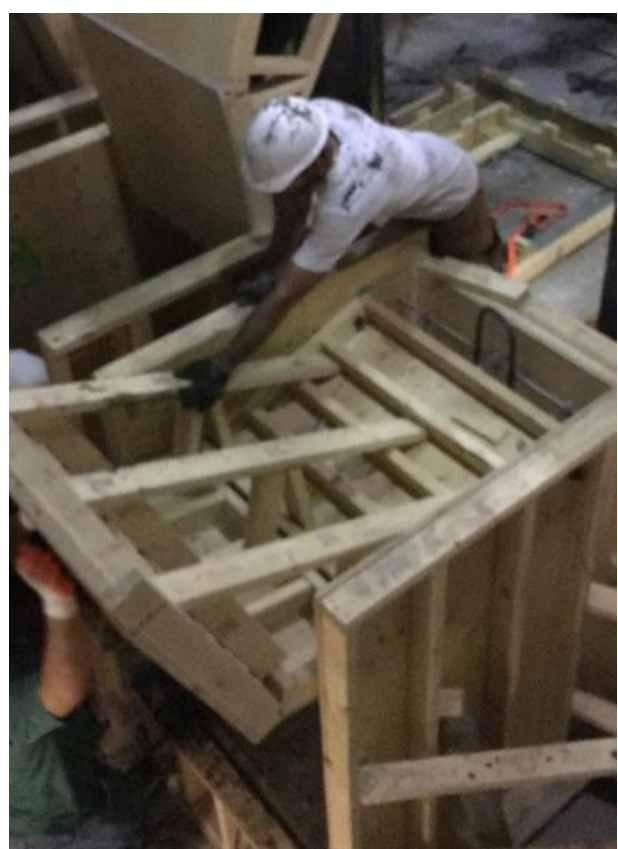

b) Lowering the timber side to cast the wall

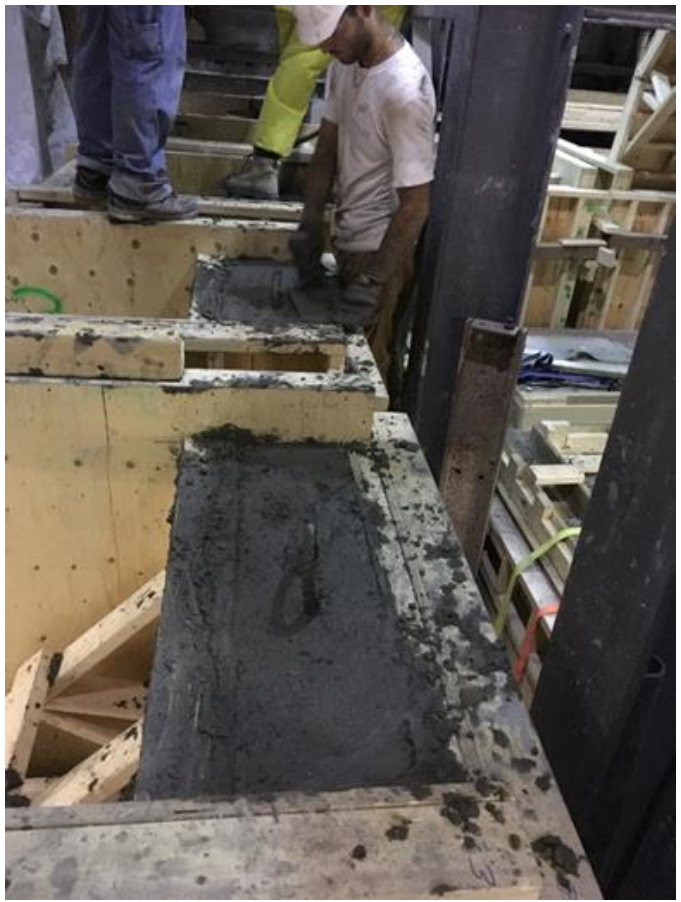

d) Smoothing concrete surface with a steel trowel 


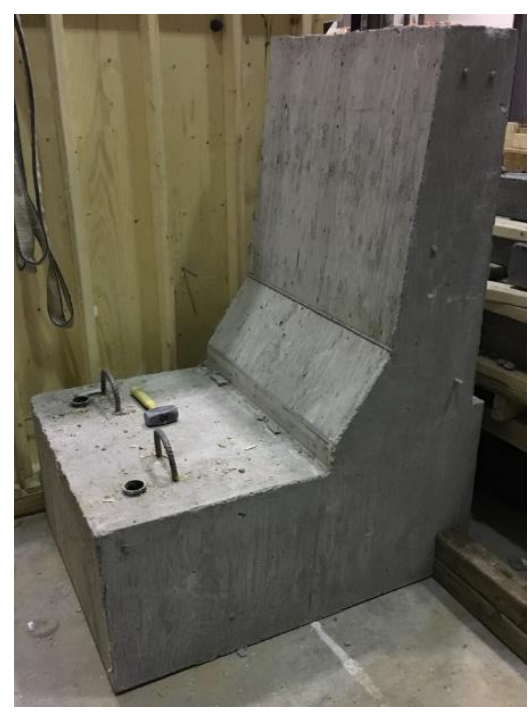

e) Barrier with rigid base

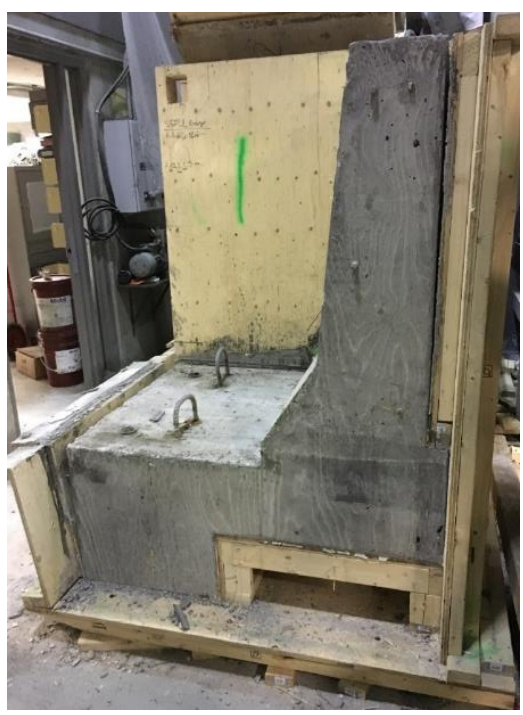

f) Barrier with deck cantilever

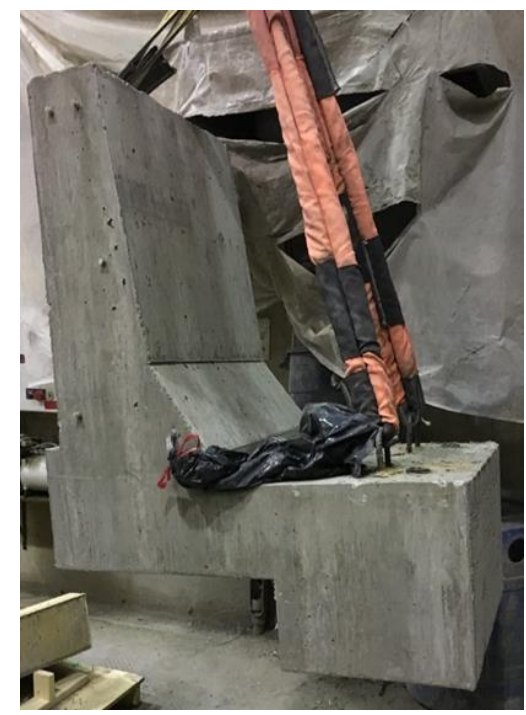

g) Barrier handling

Figure 4.15: Views of typical barriers after removal of formwork and while transporting it to the test rig

Approximately 2 months later, the two post-installed specimens were prepared for wall casting. The slab top surface, at the location of the wall that was to be cast, was roughened to allow for a better bond between the two separately cast concrete elements. A similar construction approach was considered in the installment of GFRP bars in the concrete slab as described in chapter 3 . The holes were first drilled to their specified depths with a concrete hammer drill using a marked (to see when the required embedment depth was reached) 1 - 1/16inch bit. Then, the holes were blown out using an air compressor to remove heavy debris and dust; afterwards. The hole was then scrubbed with a steel brush throughout its entire depth to remove excess remaining debris/ dust. The final two steps were repeated a total of 5 times. Hilti HIT-RE 500 V3 epoxy was then injected using the HDM 500 manual dispenser, also purchased from Hilti. Epoxy was injected at a slow rate to avoid improper consolidation, and the GFRP bars were installed slowly with a rotating motion about their vertical axis while being slowly pushed into the epoxy filled hole. When drilling for the $63^{\circ}$ and $84^{\circ}$ angled holes took place, the drill was held at the correct location with the aid of supporting wood and a digital level to maintain a straight anchor hole. It was also important to consider the clear cover requirements while drilling of these holes took place. The straight GFRP bars at the front face, which were angled at $63^{\circ}$, had their strain gauges installed prior to anchorage in the slab. Once all bars were installed, the strain gauges were then run through thin plastic tubing leading out of the formwork through a drilled hole, identical to the pre-installed barrier specimens. Upon installation of all bars, in both specimens, the gate was lowered into position and all bolts were inserted and tightened. Epoxy was left to cure for about a week, before casting of the wall section. The concrete was then 
poured in three separate layers and compacted three separate times for each wall. Cylinders were also cast at the same time, also in three separate layers whilst compacting with a metal rod as per ASTM standards. They were placed beside the barriers to allow for similar curing conditions. Concrete followed the same curing condition as the previous four barrier samples, and was then demolded about a week later.

\subsubsection{Barrier Methodology}

Each barrier consisted of a different viewpoint in analysis and construction. Every barrier had an alteration, either in its GFRP bar spacing or its general geometry of the concrete slab (cantilever or rigid base). The defining parameter of a TL-5 bridge barrier's GFRP bar spacing at the front face is the exterior or interior location of its placement along the bridge span. In total, the six barriers were divided into three sets. Each set consisted of an interior and exterior location analysis and construction of the respective barriers. One set of pre-installed TL-5 bridge barriers consisted of exterior and interior locations, constructed with rigid bases (no cantilever). The remaining set of pre-installed specimens consisted of both locations as well however, with a 500 $\mathrm{mm}$ cantilever overhang. The one set of post-installed specimens consisted of both locations and rigid bases.

All of the pre-installed barriers included anchor-headed GFRP bars, whereas the post-installed consisted of regular straight GFRP bars as mentioned in earlier sections. The location of the barrier being either interior or exterior resulted in double the quantity of bars at the front face of the wall for the exterior location. During placement of GFRP bars in the interior location specimens, bars at the front face were spaced at $300 \mathrm{~mm}$, center-to-center, while at the exterior location, the same bars were spaced at $150 \mathrm{~mm}$, center-to-center. The spacing of the bars were specified in the Ministry of Transportation of Ontario's (MTO) Standard Drawing SS110-92. The end (exterior) locations of the barriers included a greater amount of reinforcement due to the elevated moment intensity at the junction area in those sections. This phase included analysis of the crack patterns, ultimate load, strain relationships in the concrete and GFRP bars, and displacements of the barrier specimens at several locations. 
Table 4.6: Barrier Labeling Legend

\begin{tabular}{|c|c|}
\hline Name & Description \\
\hline B-1 & No cantilever; Interior location (300 mm spacing of front bars) \\
\hline B-2 & No cantilever; Exterior location (150 mm spacing of front bars) \\
\hline B-3 & Cantilever; Interior location (300 mm spacing of front bars) \\
\hline B-4 & Cantilever; Exterior location (150 $\mathrm{mm}$ spacing of front bars) \\
\hline B-5 & Post-Installed; No cantilever; Interior location (300 mm spacing of front bars) \\
\hline B-6 & Post-Installed; No cantilever; Exterior location (300 $\mathrm{mm}$ spacing of front bars) \\
\hline
\end{tabular}

\subsection{Test Setup and Procedure}

The test was setup in a lab environment under the conditions stated earlier in this chapter. All barriers consisted of a similar setup and procedure. Barriers were tested one at a time during different days due to duration and staff availability. Firstly, with an overhead crane the barriers were moved into place, on top of the laboratory rigid floor ( 1 meter thick concrete) and the front face of the barrier facing a rigid wall. The concrete deck of the barrier was anchored to the laboratory rigid floor with two 50-mm diameter threaded rods, which were spaced $600 \mathrm{~mm}$ center-to-center from each other. The threaded rods were tightened using specified nuts and half-inch thick plates acting as washers at the top and bottom of the rods. Above the bolted connection was a steel intensive setup consisting of W shapes, HSS sections, steel plates, and other custom shapes. All the steel members were acting as support for the load cell and hydraulic load jack. In front of the hydraulic load jack was a $W$ shape member reinforced with several stiffeners and had the strong axis located in the direction of the load. Behind the $W$ shape member was a piece of timber stud, cut to a trapezoidal shape, to fill the gaps between the vertical end of the loading system and the tapered surface of the front face of the barrier wall. This mechanism in front of the load jack was put in place to achieve a distributed load pattern. This set up was put at the correct height, which was $990 \mathrm{~mm}$ above the concrete deck. Lastly, behind the barrier was an anchored HSS section with steel plates wedged between the gap of the barrier and steel HSS. In the case of the barrier resting on the deck slab cantilever, the same HSS section was used but there was additional solid cylindrical steel sections placed beneath the barrier. These measures were put in place to prevent any sliding of the barriers under horizontal loading and to minimize errors in displacement readings.

Data acquisition of the barrier performance was done using a SYSTEM 6000 unit, which was available in the laboratory. All sensors connected to the unit and were zeroed with all resistance 
factors entered manually. A total of 10 displacement LVDTs and POTs were used in the case of a cantilevered barrier, and a total of 8 were used in case of the barrier resting over thick solid slab. Two POTs were used to measure the deck uplift displacement while three POTs were used to measure horizontal displacement of the deck slab at $500 \mathrm{~mm}$ from the top of the laboratory floor. Three LVDTs were used to measure displacement at a height of $1490 \mathrm{~mm}$ from the laboratory rigid floor level at the rear of the barrier wall as this was the location directly behind the applied load. This setup of displacement monitoring was present for all barriers, however barriers with a cantilevered portion had two extra LVDTs. These two extra LVDTs were installed in a position to measure the vertical deflection of the cantilevered portion of the deck slab. This was measured by installing two light steel angle sections at the edges of the cantilever with epoxy. The LVDTs would then use these angles as reference points during measurement. In order to keep all LVDTs and POTs in their correct placements throughout the duration of testing for each barrier, a wood structure was used for all sensors at the rear of the barrier, and the two POTs measuring uplift of the deck were mounted onto separate $2 \times 4$ timber studs which were ultimately mounted onto external W shape pedestals. Three standard concrete strain gauges were installed at the rear of the barrier wall at approximately a height of $625 \mathrm{~mm}$ above the rigid floor as depicted in Figures 4.10 through 4.12. Figure 4.16 shows schematics diagram of the test setup and locations of LVDTs AND POTs while Figures 4.17 through 4.19 shows photos of the test setup. Loading of the barriers was done in $10 \mathrm{kN}$ intervals, and was held for approximately 2-3 minutes to allow for crack monitoring and marking. The test stopped when the specimen could not take any increase in applied loading. 


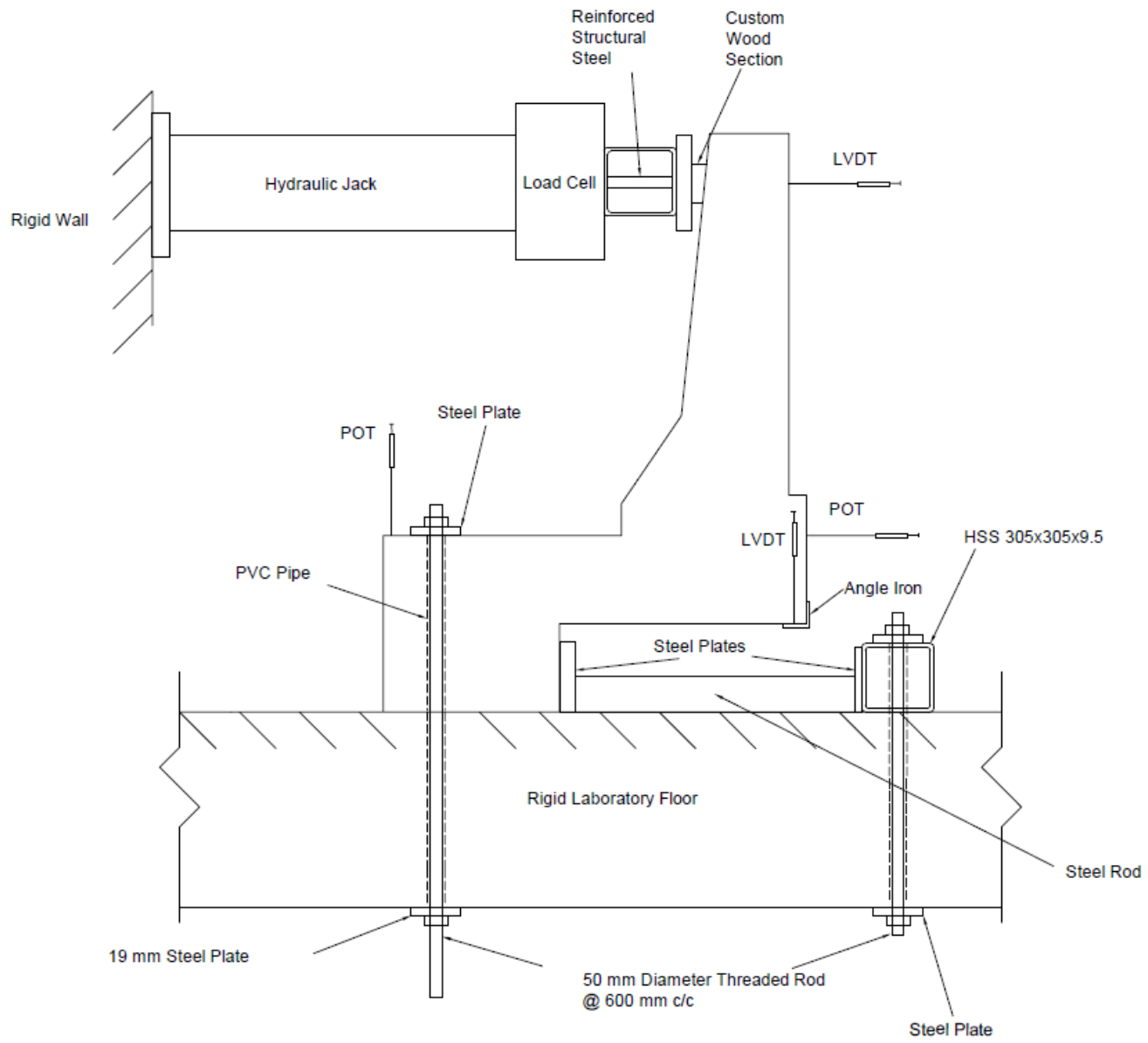

(a) Test setup showing the tie-down system to stabilize the deck slab during testing

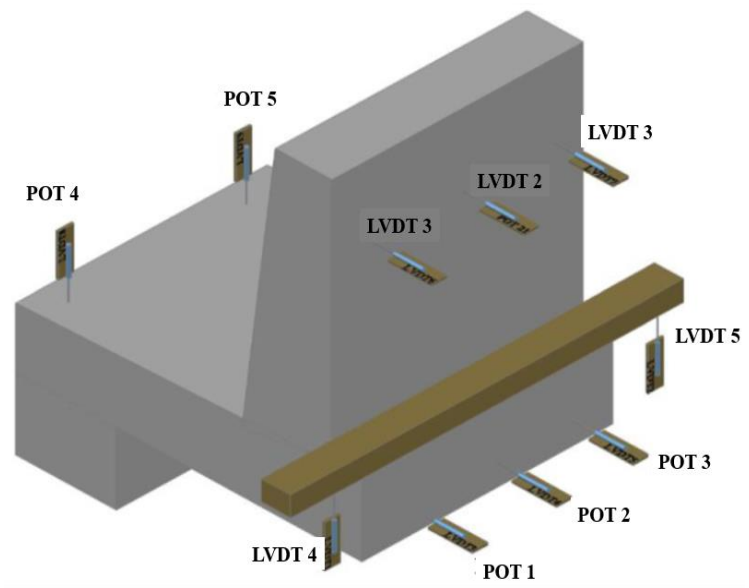

(b) Locations of potentiometers (POTs) to measure displacements

Figure 4.16: Test setup and LVDT and POT instrumentation 


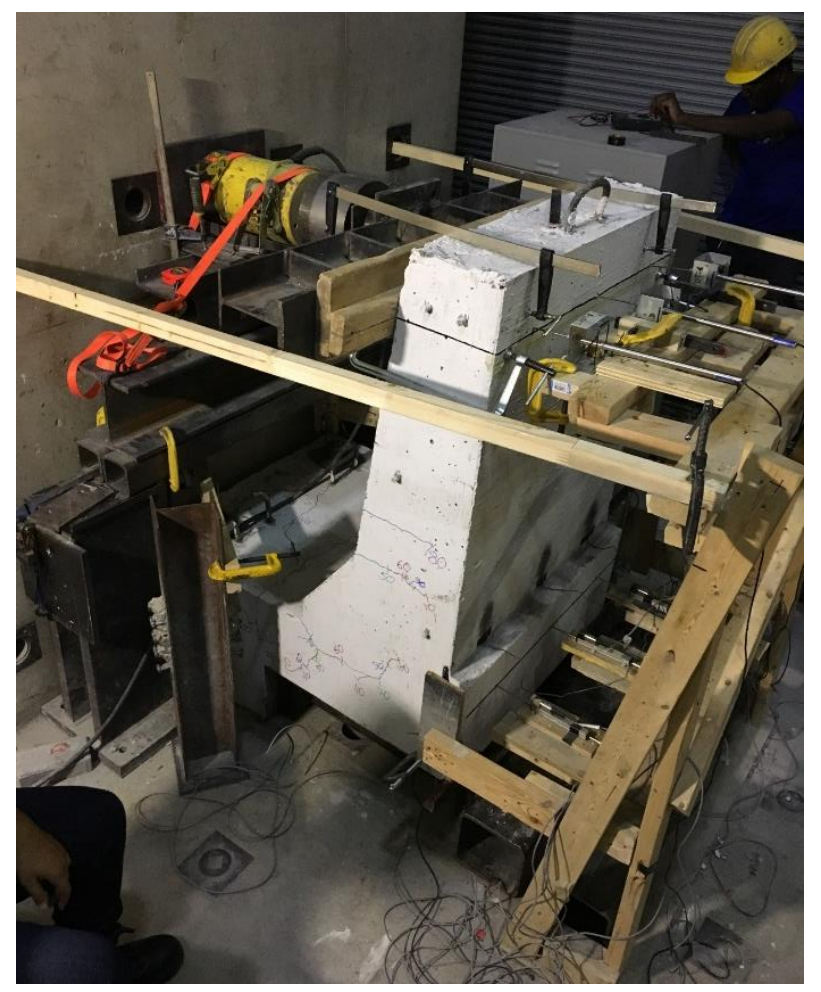

Figure 4.17: Typical test setup for a barrier resting over deck cantilever (test in progress in the photograph) 


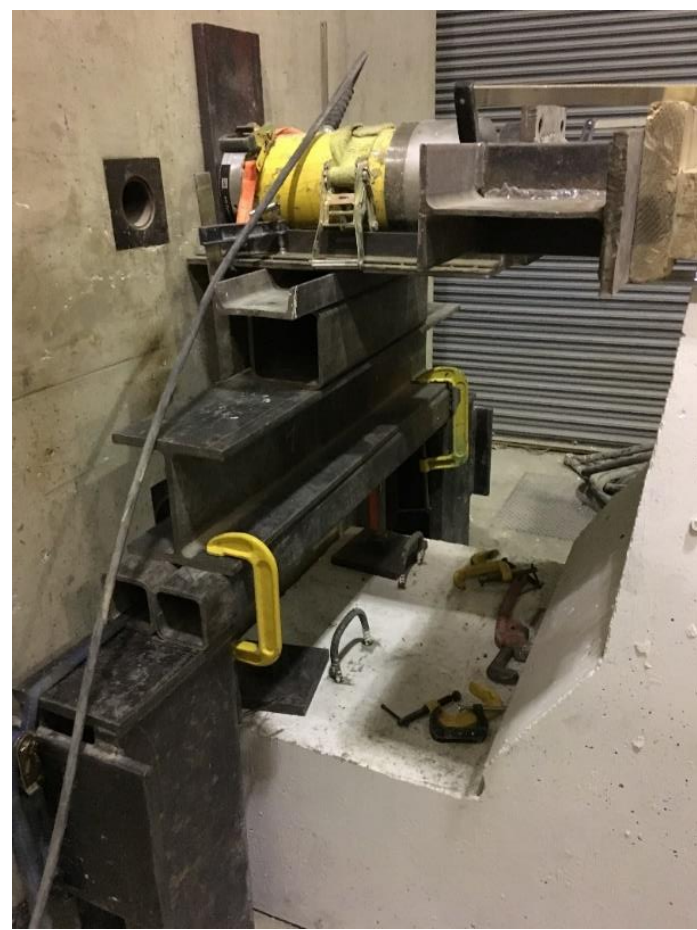

a) Setup for load application and tie-down anchors at back of deck slab

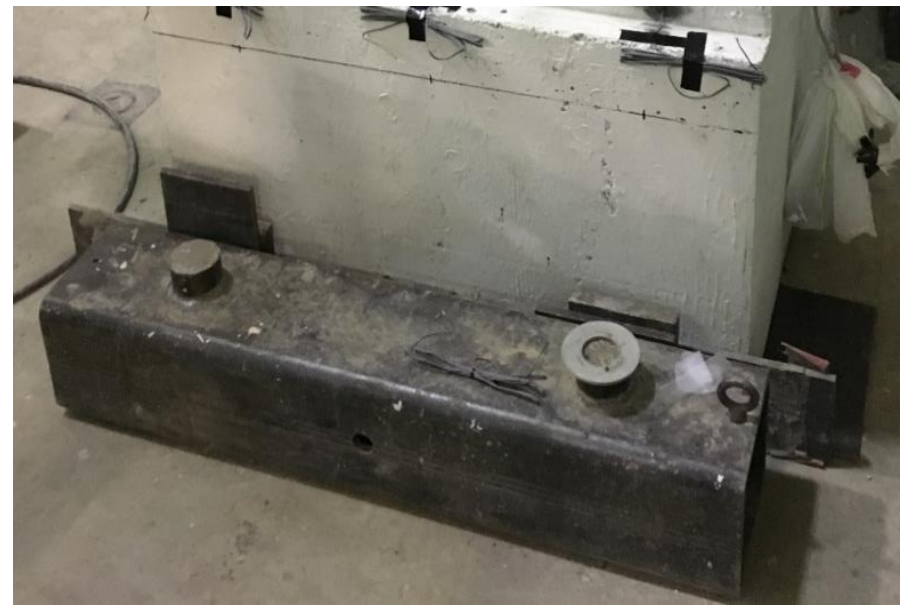

b) Steel HSS attached to barrier front side and tied-down to lab floor to prevent barrier sliding

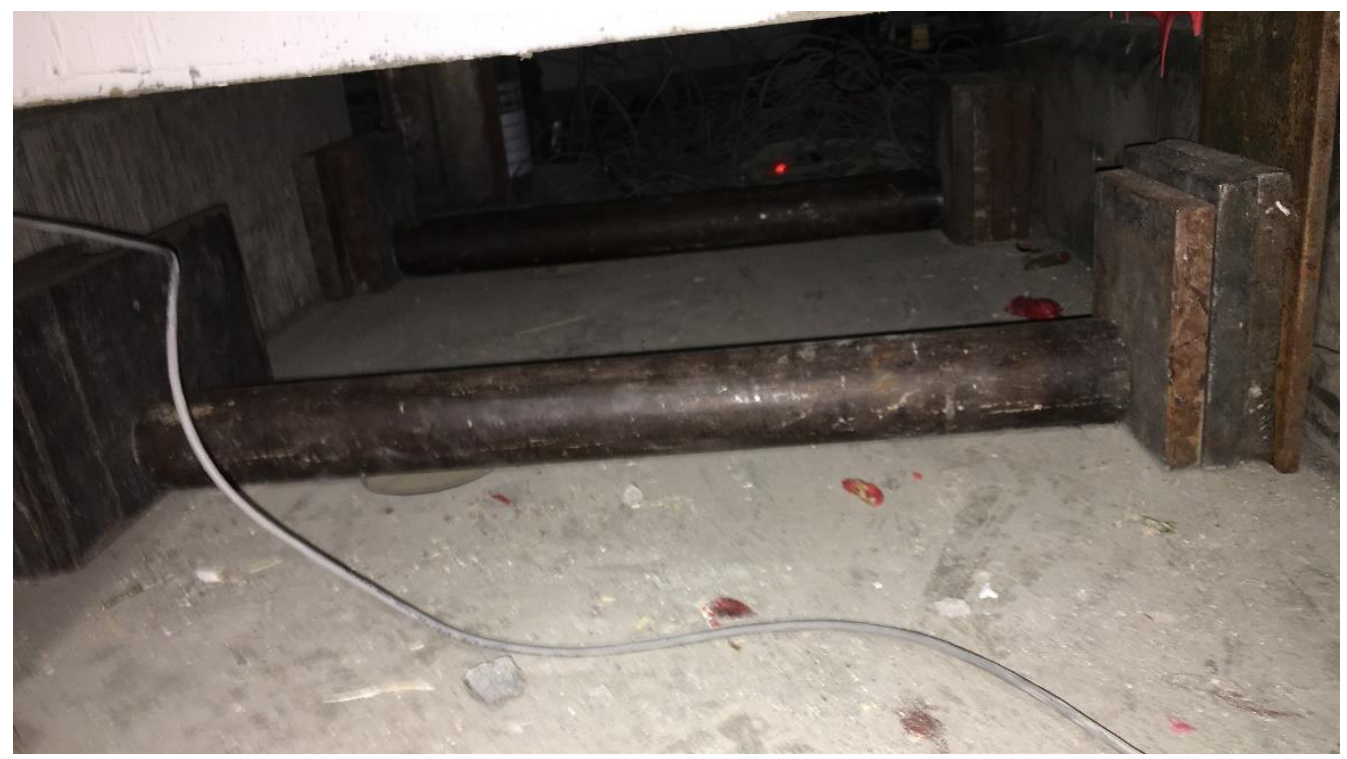

c) Setup underneath deck cantilever to prevent barrier sliding overlap floor under transerve loading

Figure 4.18: Additional details of the barrier test setup 


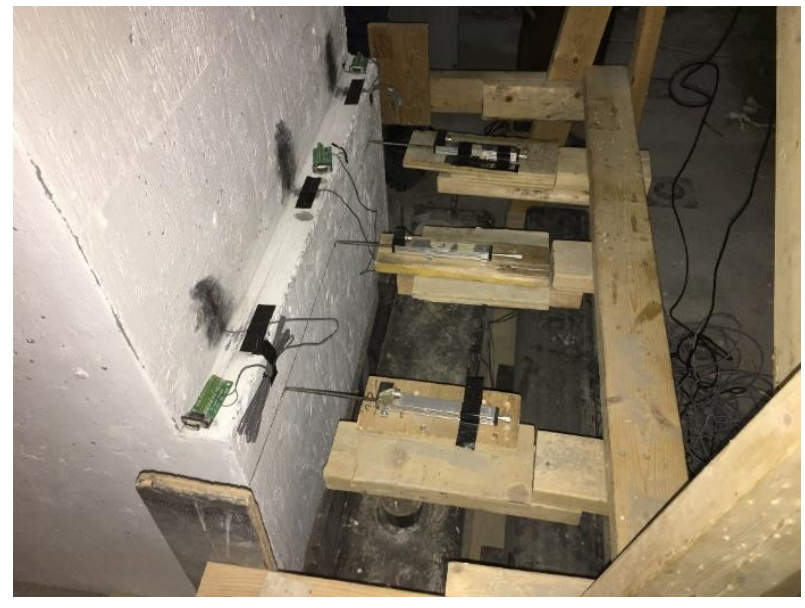

a) Locations of Pots at the level of the deck slab and concrete strain gauges to the side of the wall

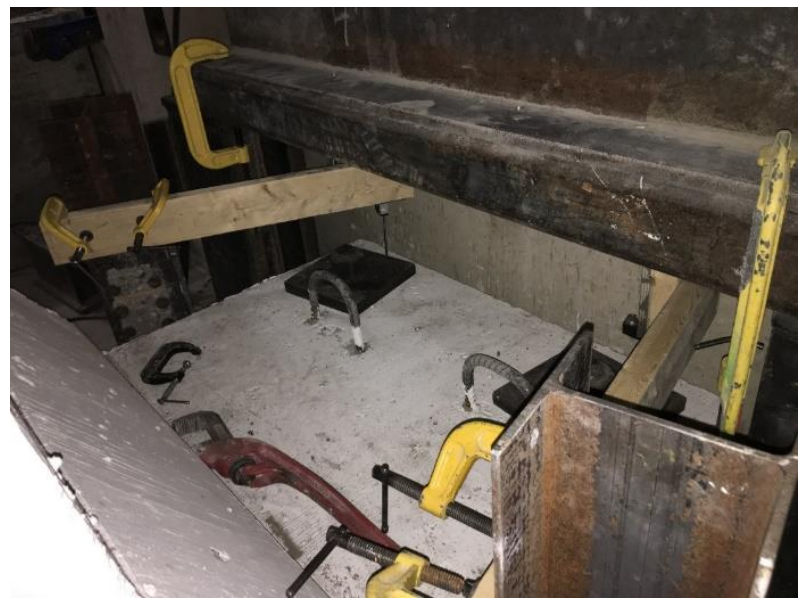

c) POT positioned at the deck uplift location

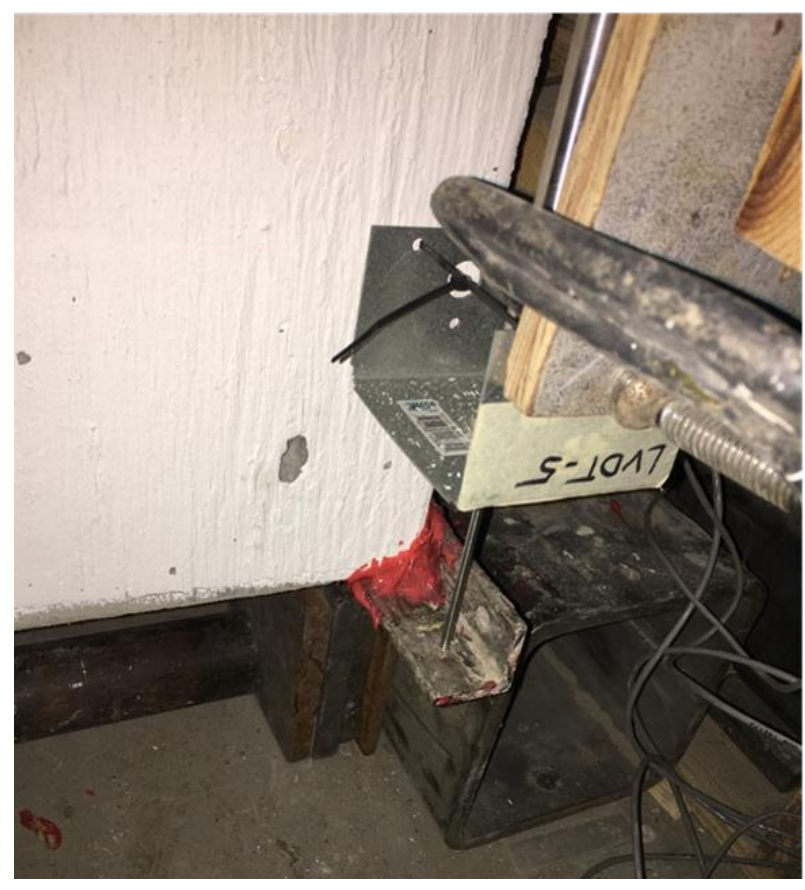

b) Location of Pot on the right side of the slab to measure barrier wall vertical deflection

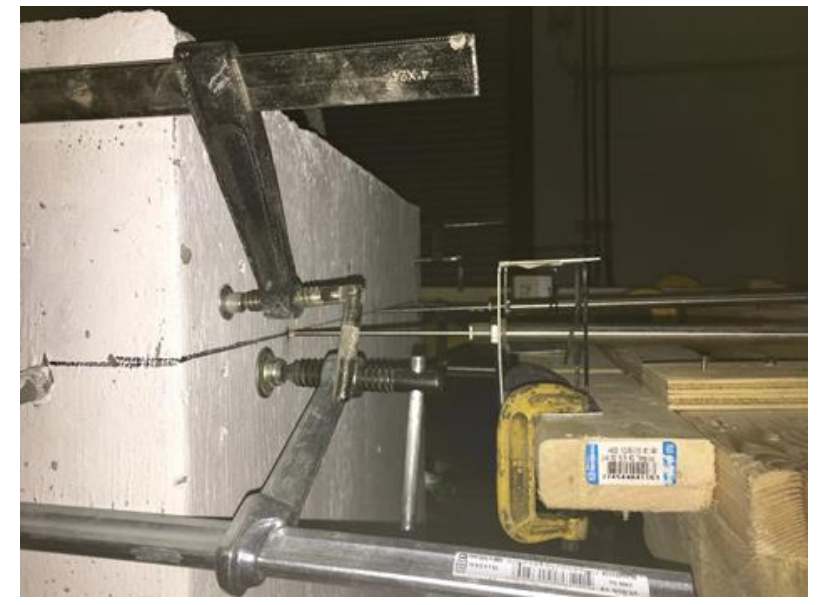

d) LVDTs positioned at the top back of the barrier wall to measure its lateral deflection

Figure 4.19: Views of typical sensor locations in tested specimens 


\subsection{Experimental Results}

\subsubsection{General}

While discussing results, cracks and failure mechanisms are described through dividing the barrier-deck specimen into 4 sections or regions as depicted in Figure 4.20 for visual understanding. Section 1 is classified as being the part of the deck slab anchored to the laboratory floor while Section 2 represented the deck slab-barrier wall junction. Section 3 represents the segment of the barrier wall over the height of the lower tapered portion on the traffic side. Section 4 represents the barrier segment along the height of the top tapered portion on the traffic side.

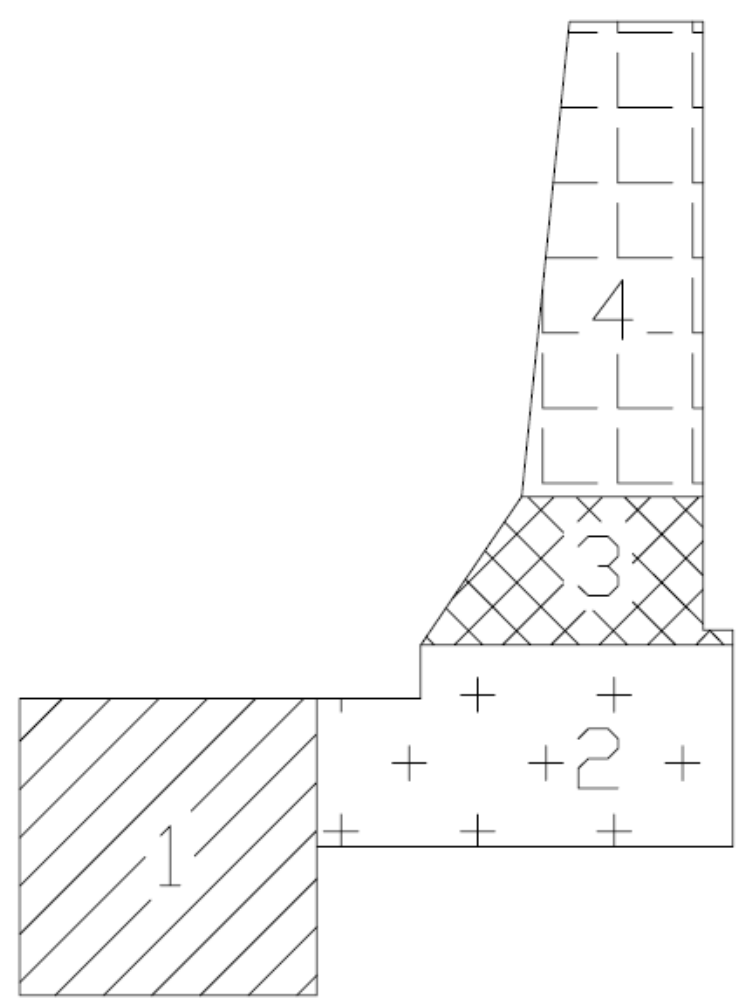

Figure 4.20: Sections to be used for crack location reference

\subsubsection{TL-5 Bridge Barrier Specimen B-1}

In barrier specimen B-1, the 500-mm thick deck slab base was completely rigid indicating that the barrier is resting on non-deformable slab bridge section. The front GFRP bars were spaced at $300 \mathrm{~mm}$ center-to-center to simulate vehicle impact at interior location. Detailing of the bar arrangement before concrete casting is shown in Figure 4.21. 


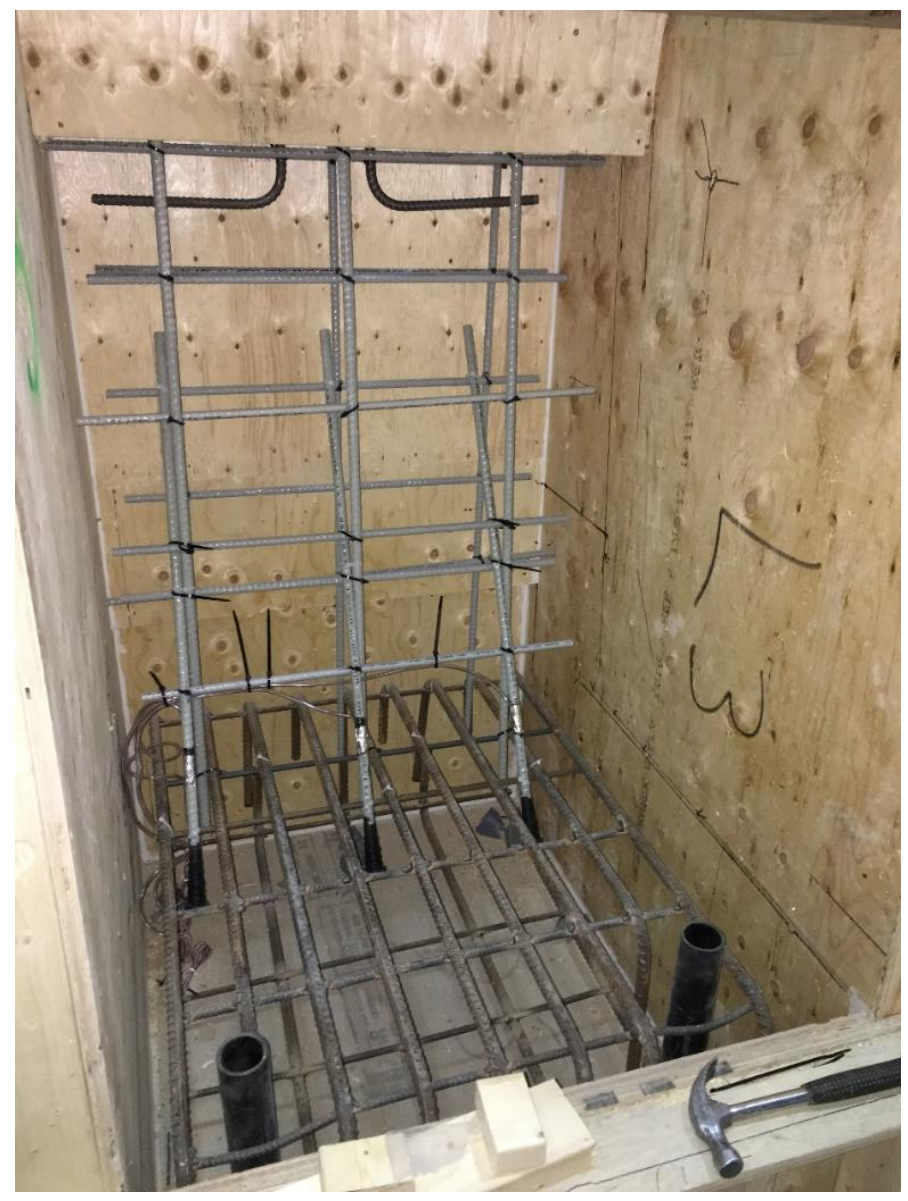

Figure 4.21: Barrier B-1 bar detailing prior to casting

Figures 4.22 through 4.25 show different views of the crack pattern of the tested barrier specimen. In this specimen, the first visible crack was observed in the front side of the barrier wall at barrier-deck junction at $60 \mathrm{kN}$ jacking load as depicted in Figure 4.22. Flexural crack appeared at the intersection just above the interface of the two tapered portions of the front side of the barrier wall at a jacking load of $85 \mathrm{kN}$. Flexural cracks started at the barrier-deck junction at a load of $100 \mathrm{kN}$. Although flexural cracks at the barrier-deck junction penetrated further into the barrier thickness at a higher load, sudden concrete breakout appeared approximately at the embedded GFRP bar headed end at a load of $140 \mathrm{kN}$ in each side of the barrier wall as depicted in Figure 4.23. These concrete breakout cracks extended towards the top surface of the solid slab and towards the back face of the barrier wall at higher loads till the barrier could not absorb jacking load beyond $168.63 \mathrm{kN}$. Given the width of the barrier of 900 $\mathrm{mm}$ and the height of the applied load over the top surface of the deck slab of $990 \mathrm{~mm}$, the experimental resisting moment is calculated as $185.49 \mathrm{kN} . \mathrm{m} / \mathrm{m}$. This experimental resisting moment at the barrier deck junction is greater than the CHBDC design value of $83 \mathrm{kN} . \mathrm{m} / \mathrm{m}$ at the 
barrier-deck slab junction (CSA, 2006). This leads to a factor of safety of 2.33 in the design of the proposed TL-5 barrier wall at interior location when it is rigidly connected to non-deformable concrete deck slab as listed in Table 4.14. Figure 4.24 shows the deck slab of the specimen after testing. The concrete around the outer headed bar was removed by drill hammer as shown in Figure 4.24(b) to examine the damage in the bar head. Figure 4.25 depicts the bar head with broken part at its largest desk.

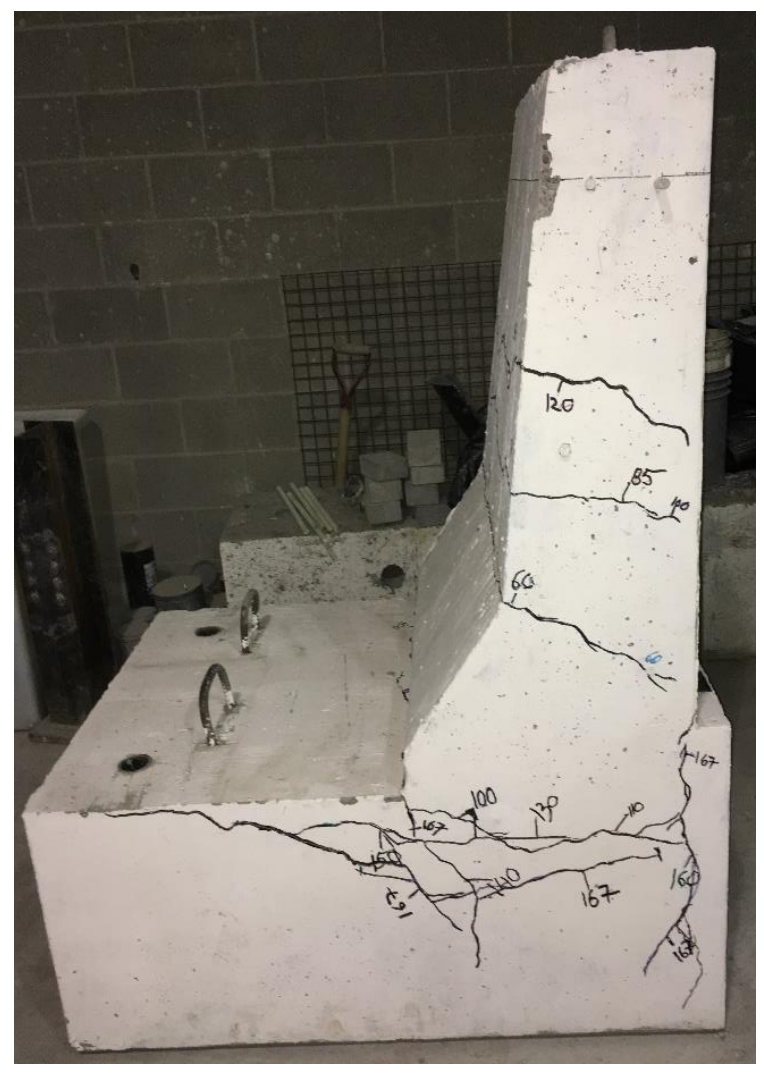

(a) Right side

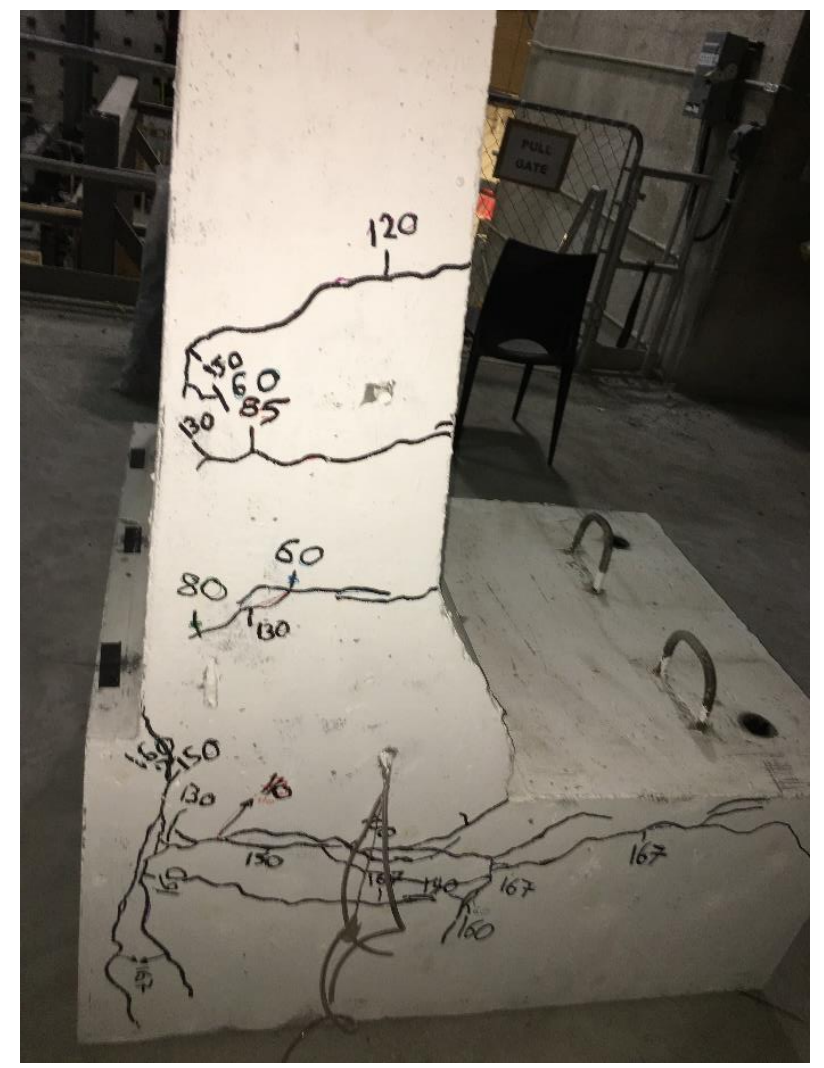

(b) Left side

Figure 4.22: View of crack pattern after failure of the tested specimen B-1 

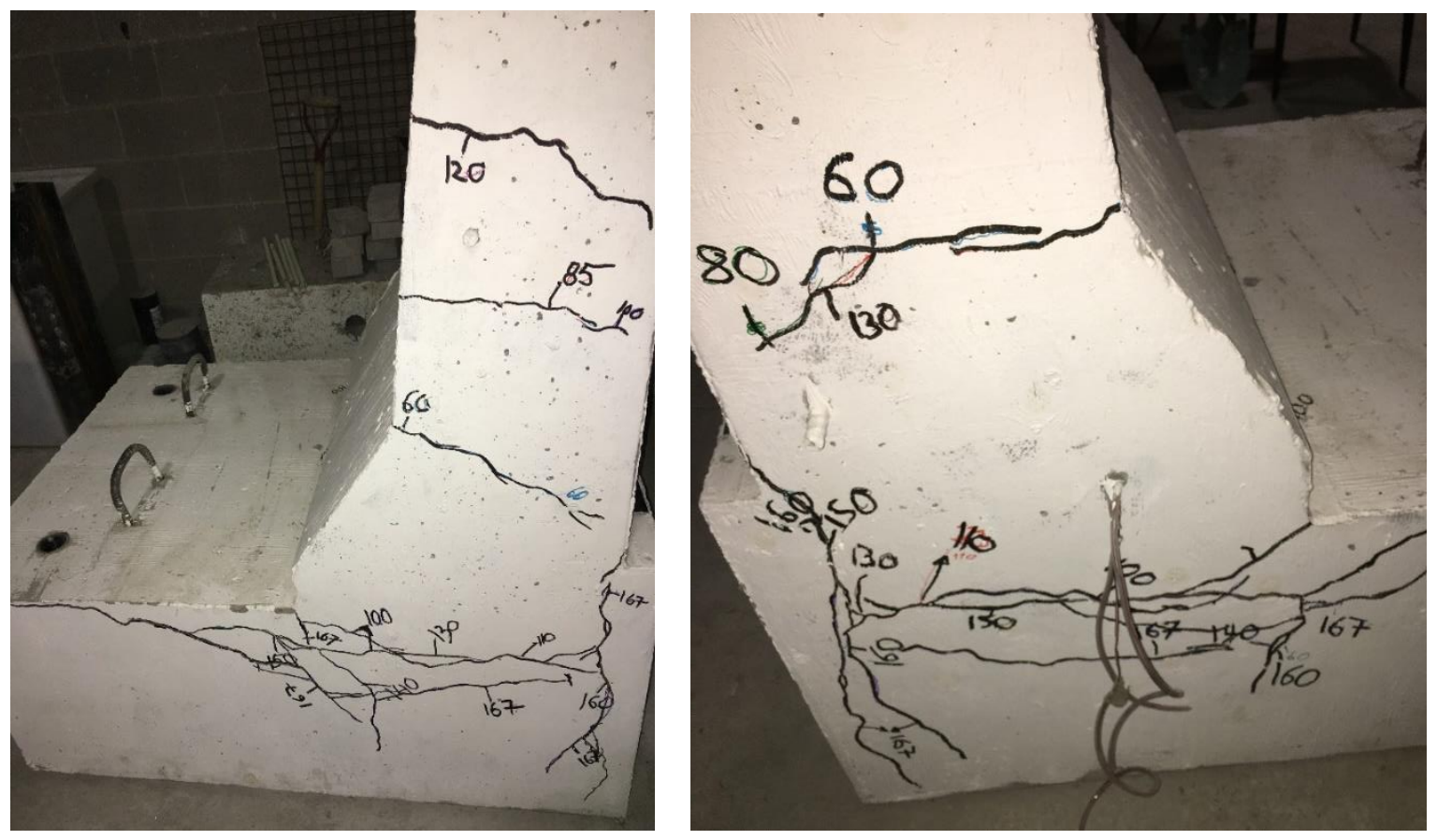

Figure 4.23: Close up view of crack pattern after failure of specimen B-1

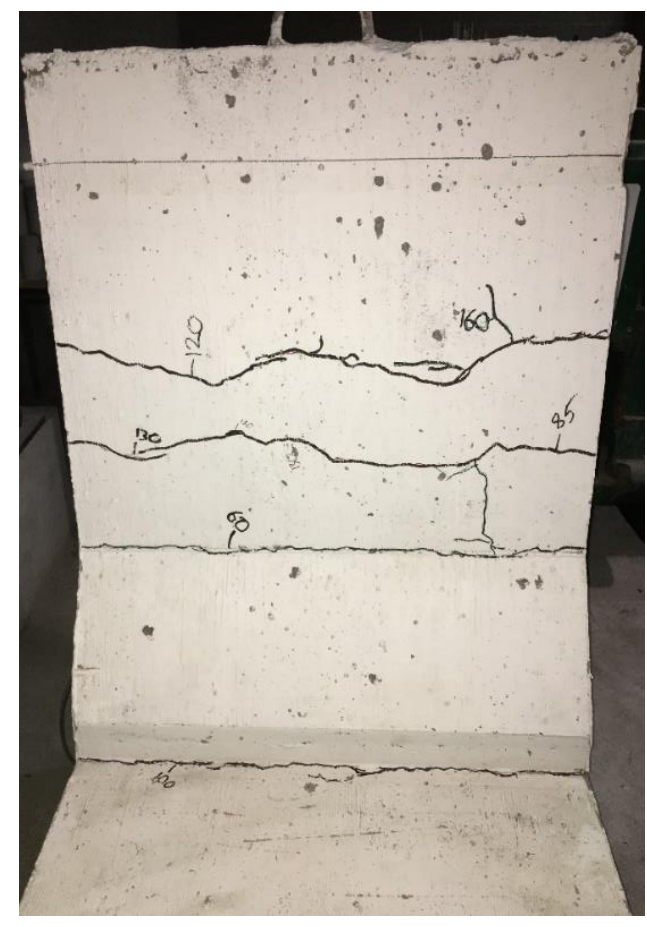

(a) Before jackhammering

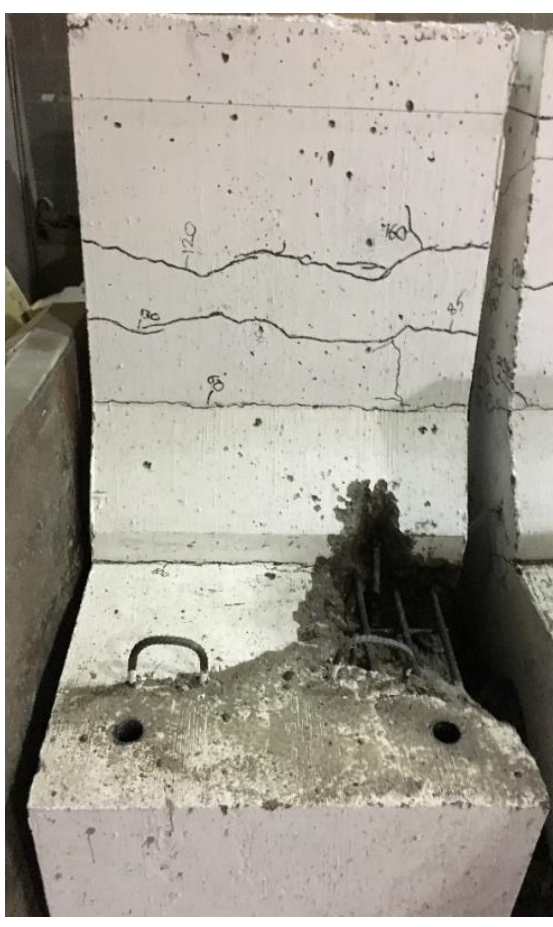

(b) After Jackhammering

Figure 4.24: View of cracks at front side of specimen B-1 

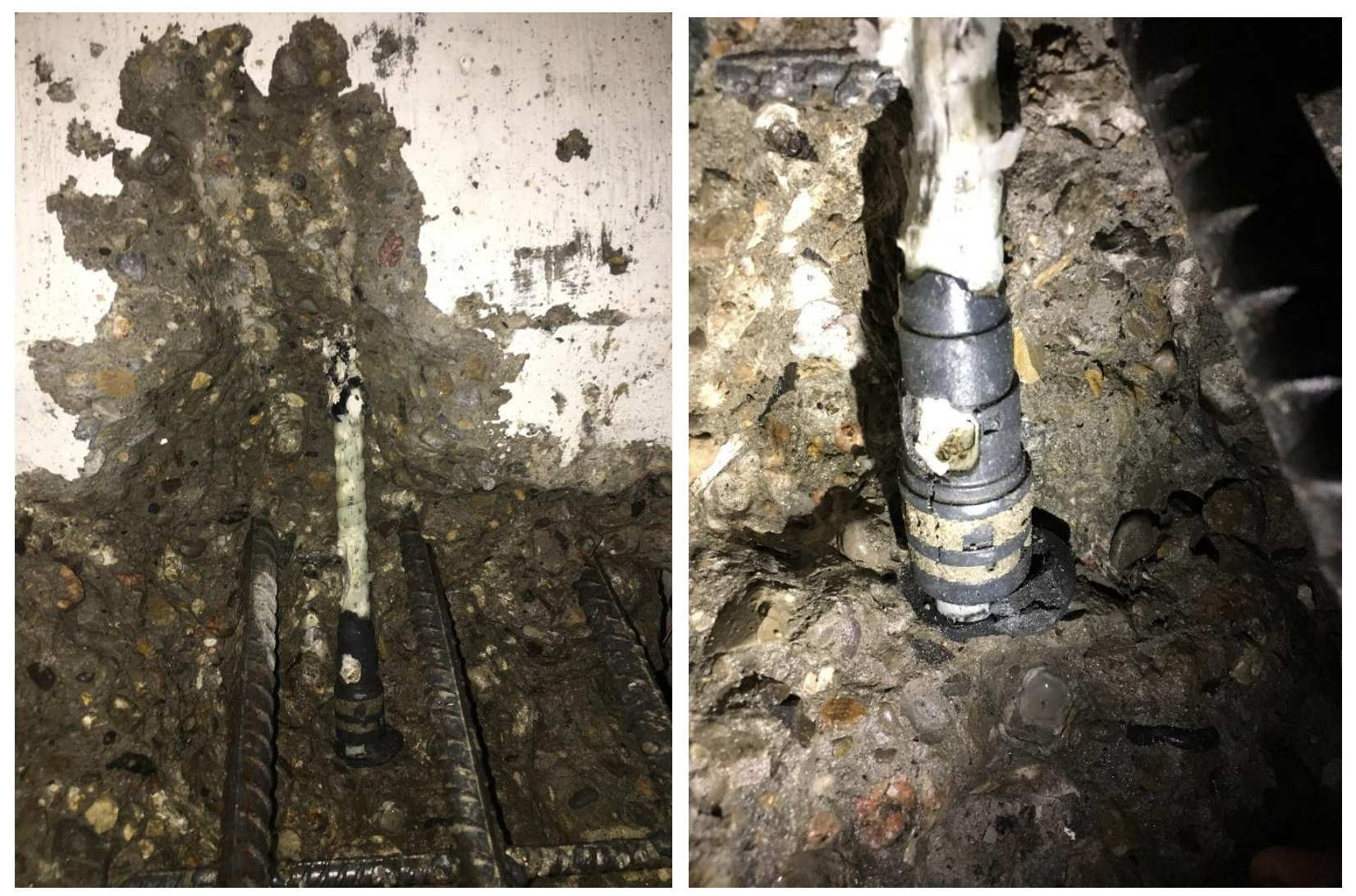

Figure 4.25: Close up of failed headed GFRP bar in specimen B-1 after jack hammering concrete at barrier-deck junction

\subsubsection{TL-5 Bridge Barrier Specimen B-2}

Specimen B-2 represents a barrier wall connected to non-deformable concrete slab at exterior location. The amount of vertical reinforcement at the front face represents the case of exterior segment of the barrier wall. Figure 4.26 shows view of the reinforcement for specimen B-4 before concrete casting. Figures 4.27 through 4.29 show different views of the crack pattern of the tested barrier specimen. The first flexural crack appeared in the front side of the barrier wall at barrier-deck junction at $60 \mathrm{kN}$ jacking load. Other flexural crack appeared above the intersection of the tapered portions of the front side of the barrier wall at a jacking load of $80 \mathrm{kN}$. Other extensive flexural cracks appeared in the tapered portion of the barrier at higher loads as depicted in Figure 4.27. Although flexural cracks at the barrier-deck junction at $140 \mathrm{kN}$ penetrated further into the barrier thickness at a higher load giving the signed of flexural failure, sudden concrete diagonal shear failure appeared in the top tapered portion of the barrier wall, starting from the applied load location, at a jacking load of $170 \mathrm{kN}$ in each side of the barrier wall as depicted in Figure 4.27. The barrier continued to pick up loading up to $182.63 \mathrm{kN}$. Given the 
width of the barrier of $900 \mathrm{~mm}$ and the height of the applied load over the top surface of the deck slab of $990 \mathrm{~mm}$, the experimental resisting moment is calculated as $200.89 \mathrm{kN} . \mathrm{m} / \mathrm{m}$. This experimental resisting moment at the barrier deck junction is greater than the CHBDC design value of $102 \mathrm{kN} . \mathrm{m} / \mathrm{m}$ at the barrier-deck slab junction (CSA, 2006). This leads to a factor of safety of 1.97 in the design of the TL-5 barrier wall at exterior location when it is rigidly connected to non-deformable concrete deck slab as listed in Table 4.14. It should be noted that the diagonal shear crack propagated through the barrier thickness to the back side of the barrier causing concrete plugging and spalling as depicted in Figure 4.29.

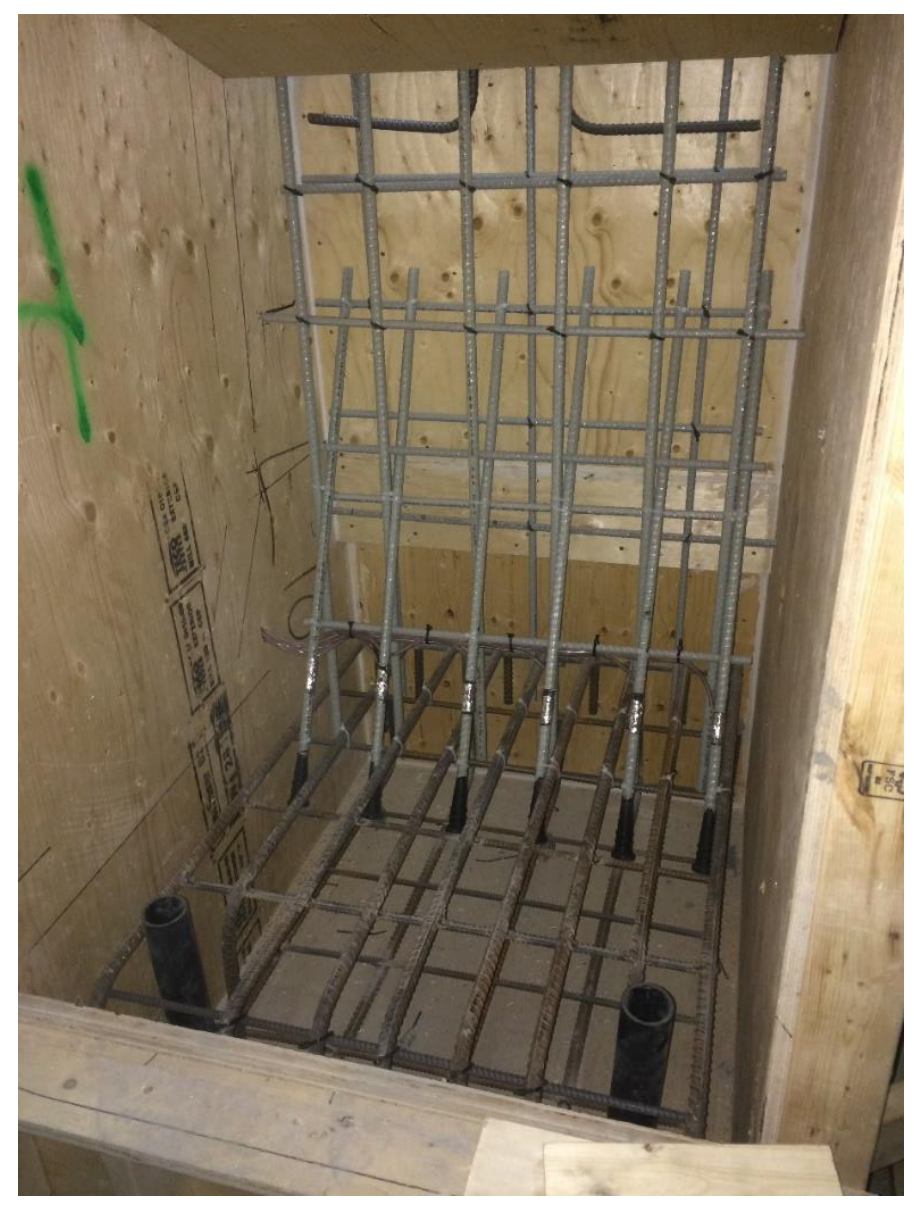

Figure 4.26: Barrier B-2 bar detailing prior to casting 


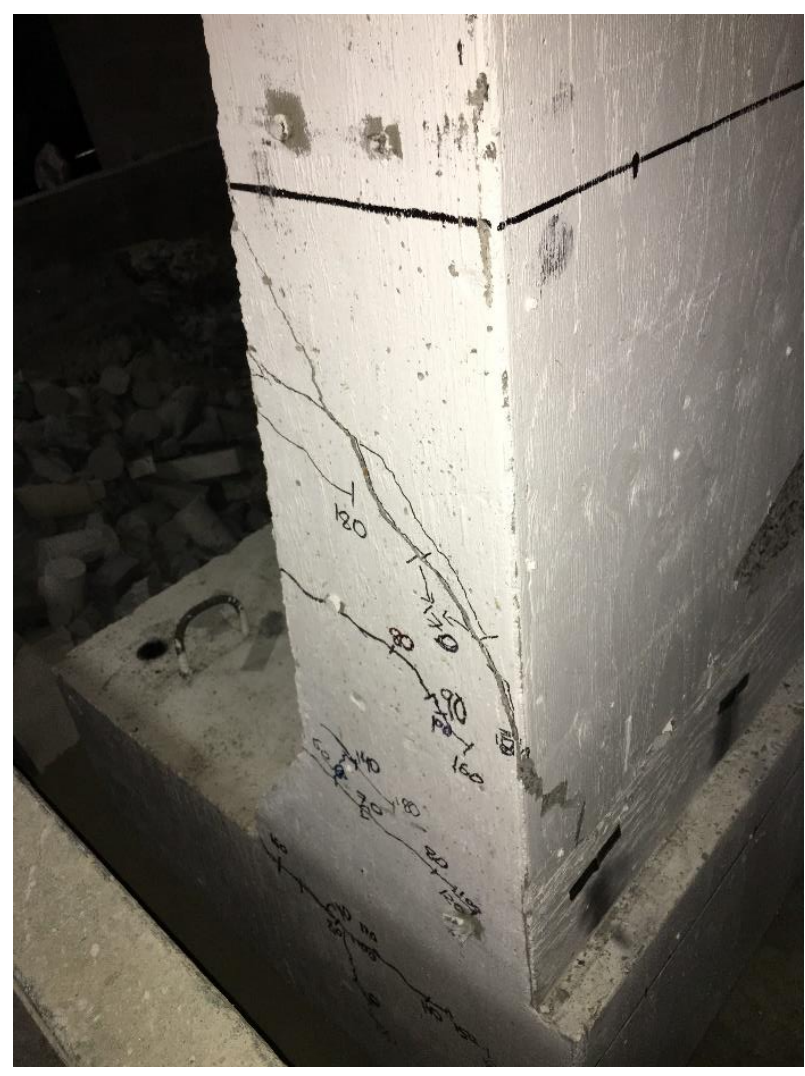

(a) Right side

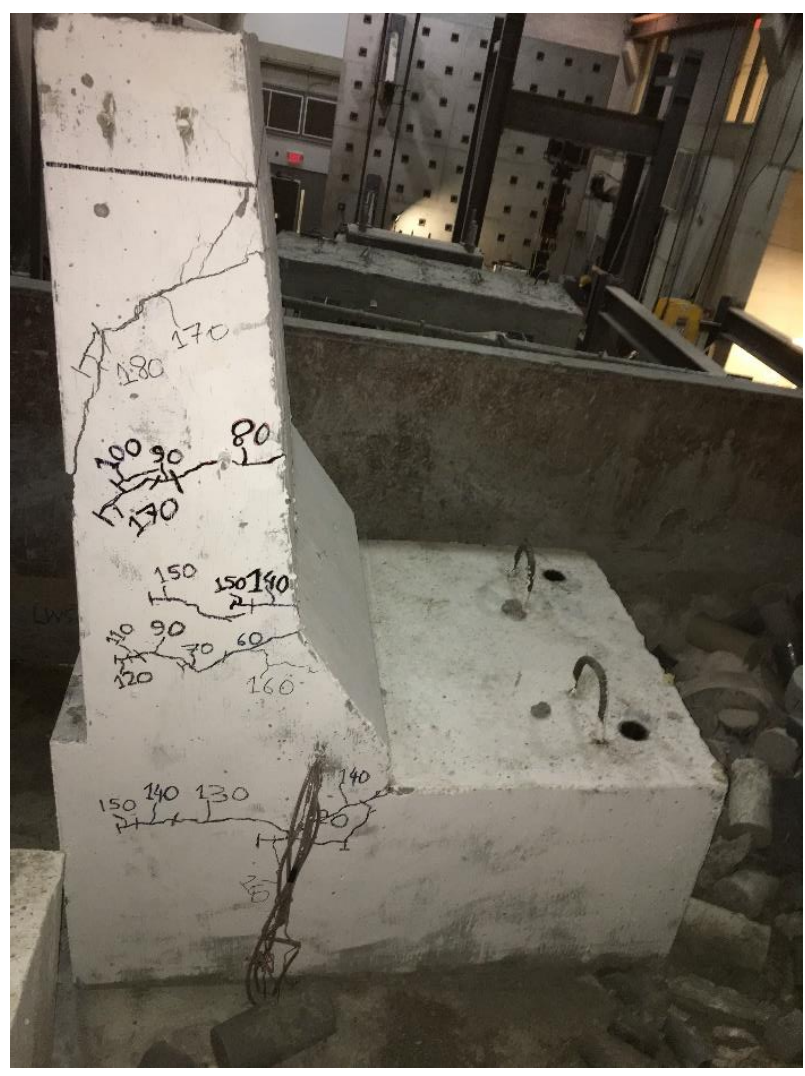

(b) Left side

Figure 4.27: View of crack pattern after failure of the tested specimen B-2 

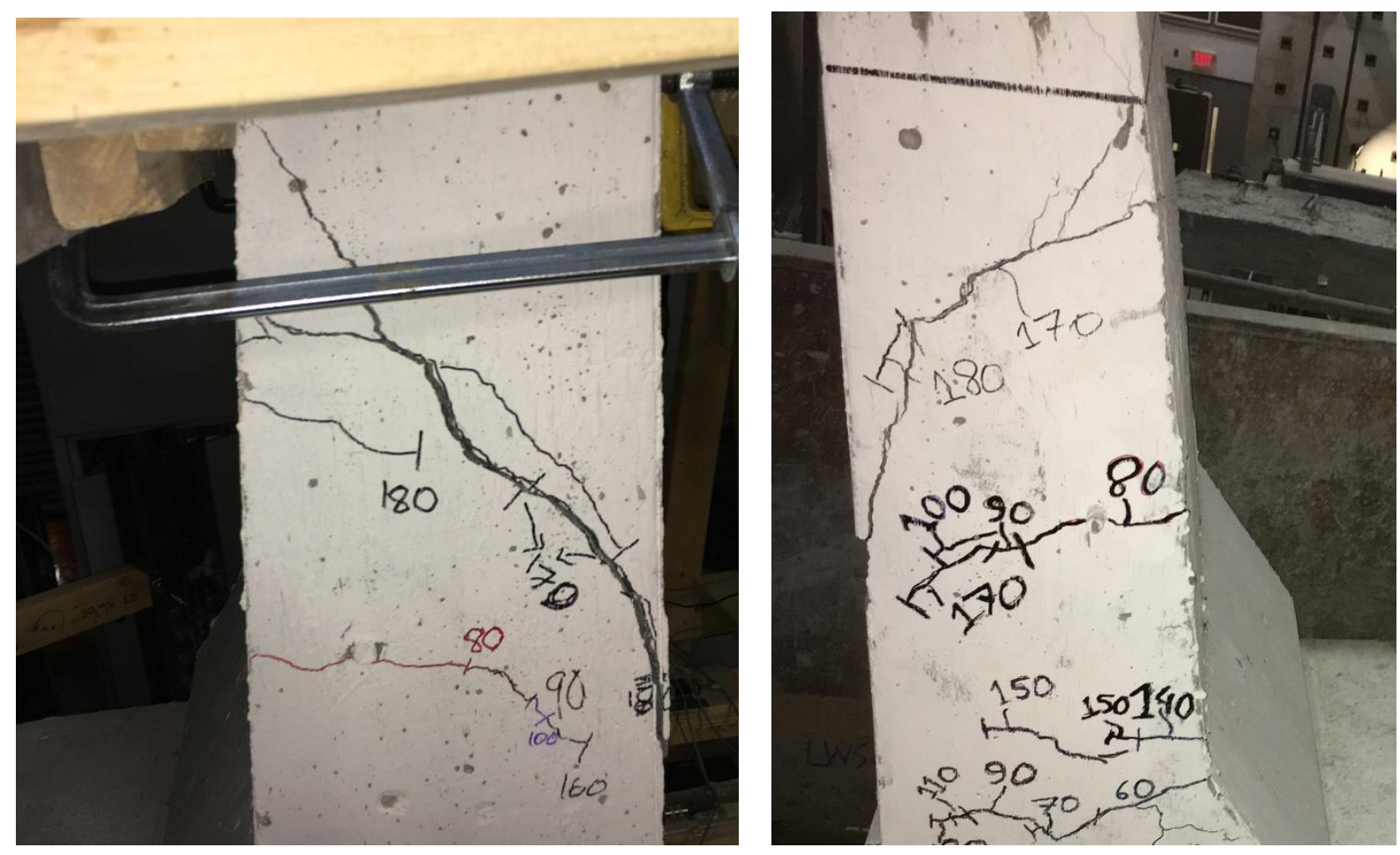

Figure 4.28: Close up view of crack pattern afterfailure of specimen B-2

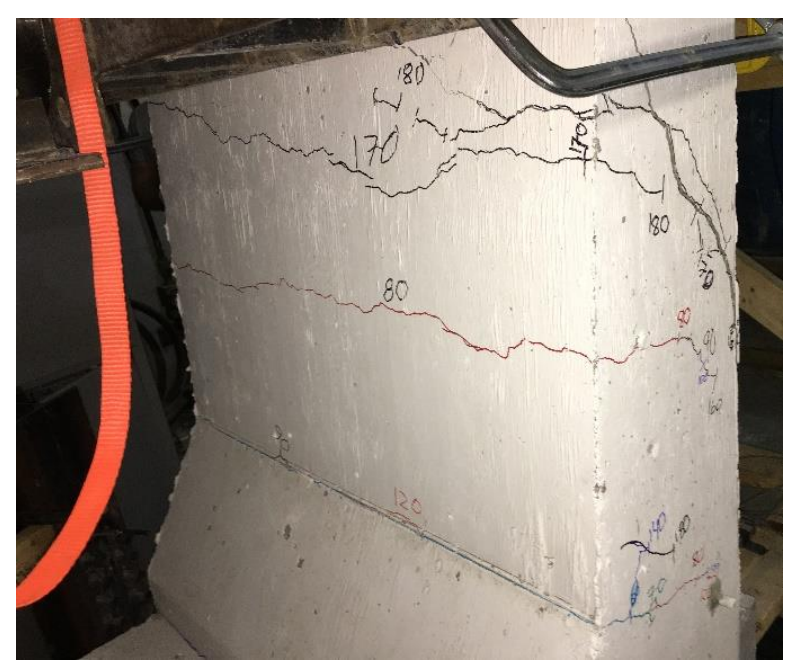

(a) Front side

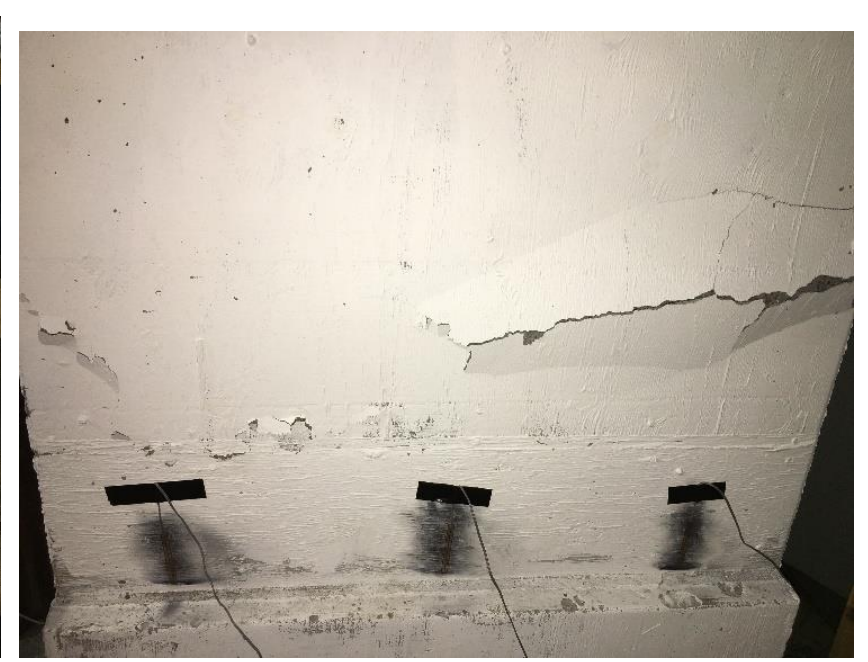

(b) Rear side

Figure 4.29: View of cracks at front and rear sides of specimen B-2 


\subsubsection{TL-5 Bridge Barrier Specimen B-3}

Figure 4.30 shows the arrangement of reinforcement in the barrier specimen B-3 before casting. Figures 4.31 through 4.33 show different views of the crack pattern of the tested barrier specimen. In this specimen, the first visible flexural crack was observed at the intersection of the tapered portions of the front side of the barrier wall as well as at the barrier-deck junction and at the deck slab fixed end at $80 \mathrm{kN}$ and $60 \mathrm{kN}$ jacking load, respectively. These flexural cracks penetrated further at a higher load, along with other flexural cracks in the deck slab as appeared in Figure 4.31. Although flexural cracks appeared in the barrier wall and the deck slab portion, a sudden diagonal tension crack appeared in the deck slab at a jacking load of $90 \mathrm{kN}$, respectively. These cracks propagated further till the barrier could not take a jacking load beyond $129.64 \mathrm{kN}$. Given the width of the barrier of $900 \mathrm{~mm}$ and the height of the applied load over the top surface of the deck slab of $990 \mathrm{~mm}$, the experimental resisting moment is calculated as $142.6 \mathrm{kN} . \mathrm{m} / \mathrm{m}$. This experimental resisting moment at the barrier deck junction is greater than the CHBDC design value of $83 \mathrm{kN} . \mathrm{m} / \mathrm{m}$ at the barrier-deck slab junction. This leads to a factor of safety of 1.72 in the design of the TL-5 barrier wall at interior location as listed in Table 4.14.

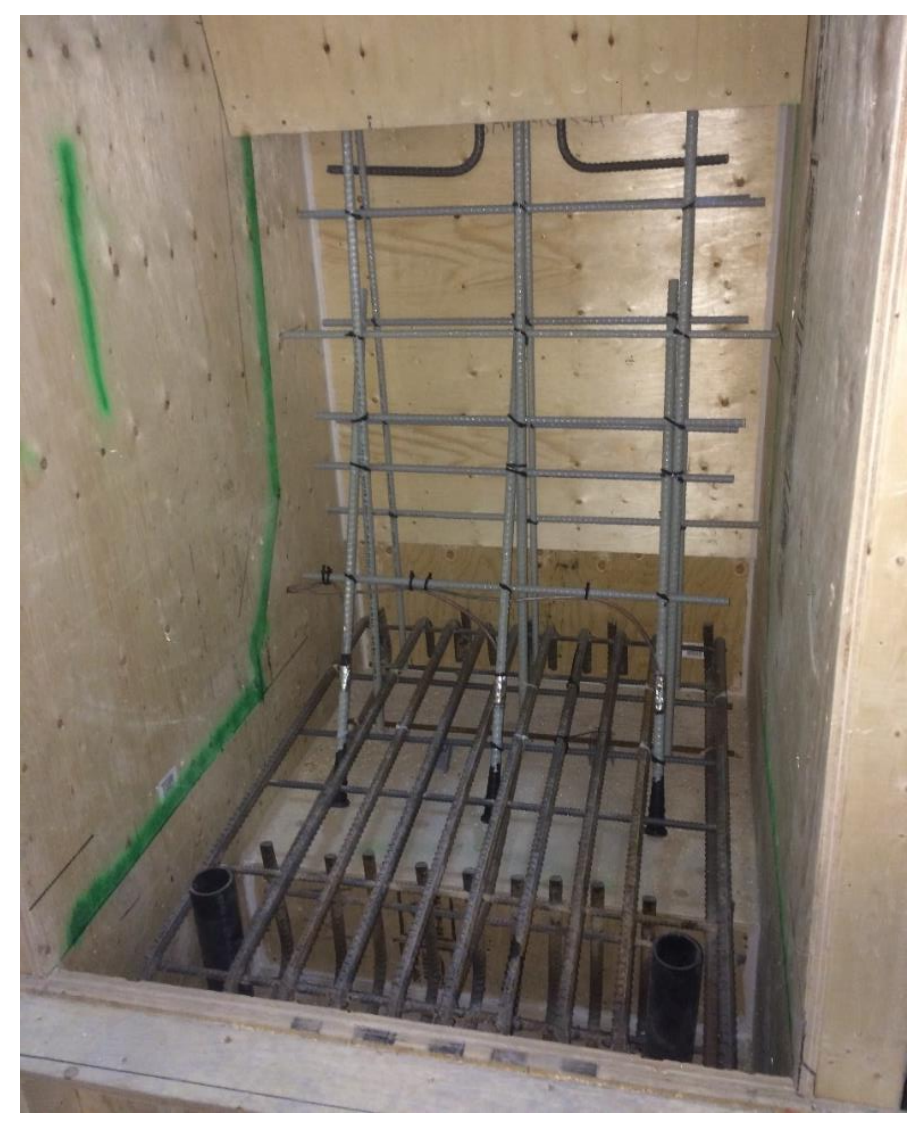

Figure 4.30: Barrier B-3 bar detailing prior to casting 


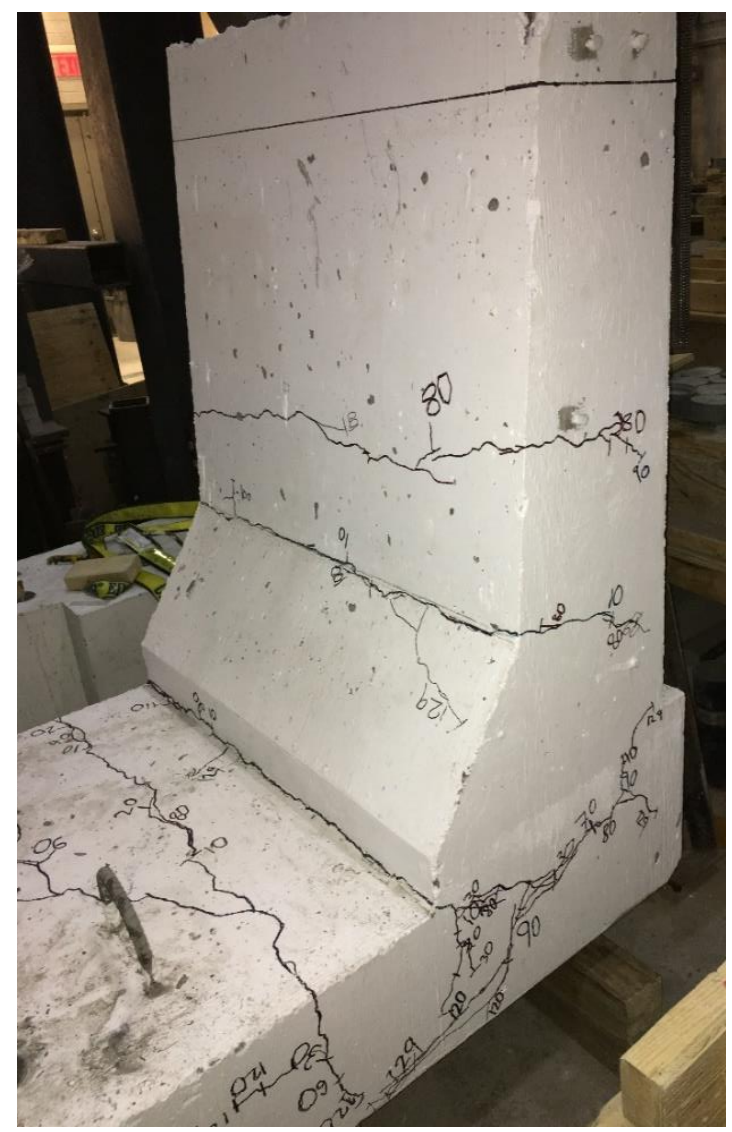

(a) Right side

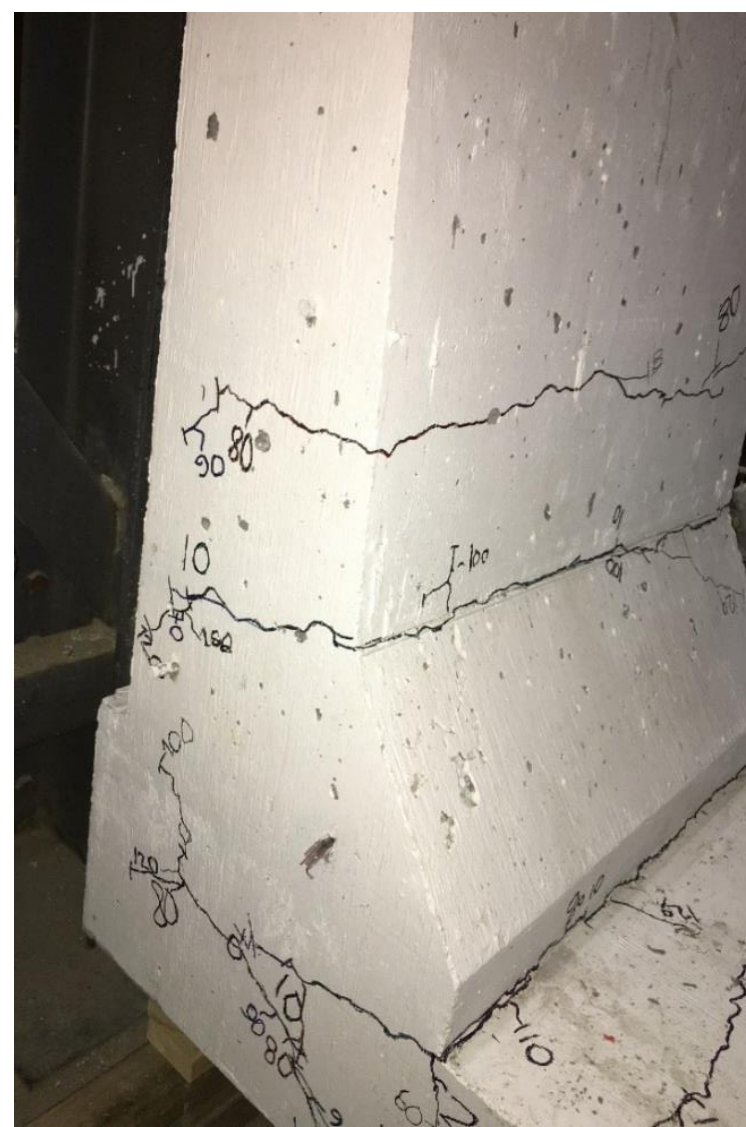

(b) Left side

Figure 4.31: View of crack pattern after failure of the tested specimen B-3
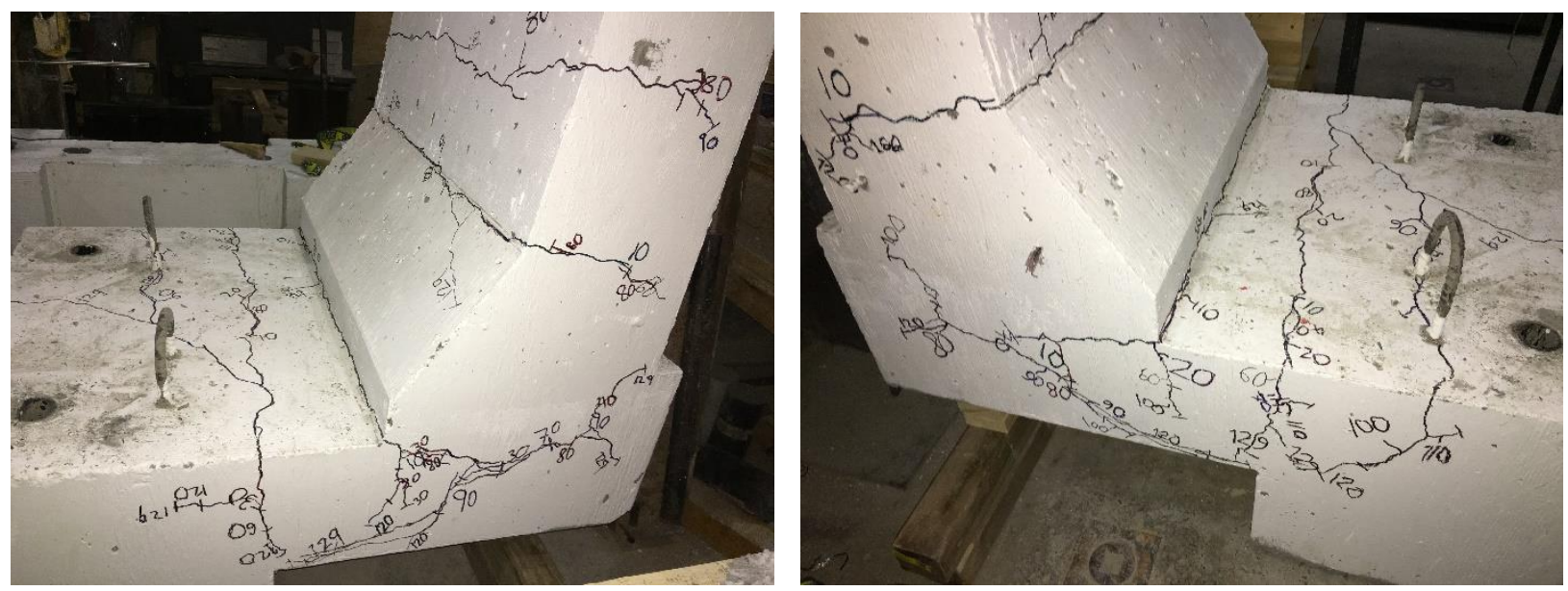

Figure 4.32: Close up view of crack pattern after failure of specimen B-2 


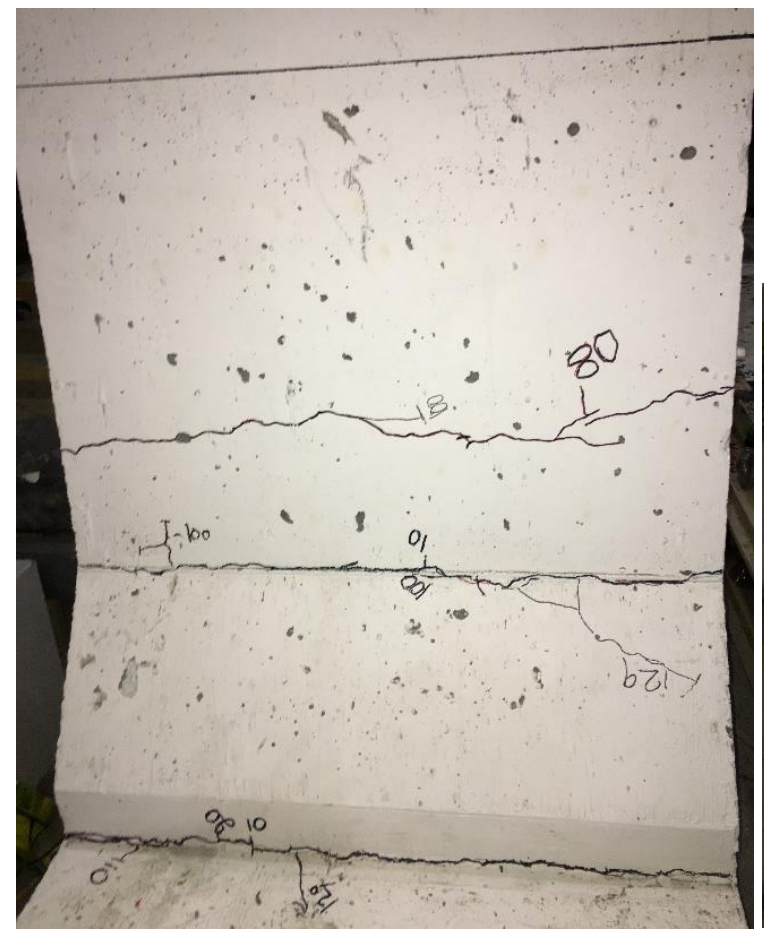

(a) Front face

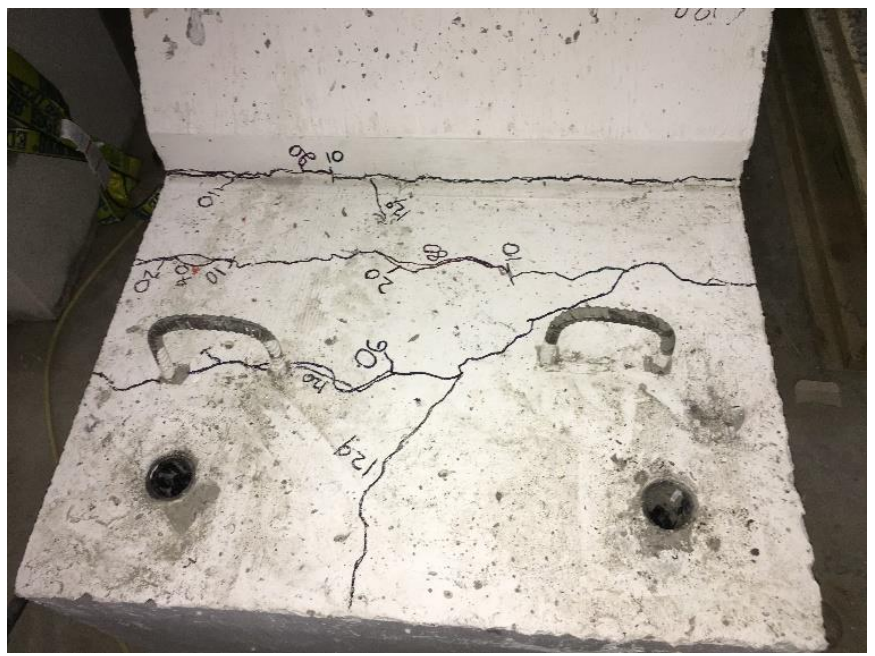

(b) Deck area

Figure 4.33: View of cracks at front face and deck area of specimen B-3

\subsubsection{TL-5 Bridge Barrier Specimen B-4}

Specimen B-4 represented barrier wall supported over deck slab cantilever at exterior location. Figure 4.4 shows the arrangement of reinforcement in the barrier specimen B-4 before casting. Figures 4.35 through 4.37 show different views of the crack pattern of the tested barrier specimen. In this specimen, the first visible flexural crack was observed at the intersection of the tapered portions of the front side of the barrier wall as well as at the barrier-deck junction and at the deck slab fixed end at $50 \mathrm{kN}$. These flexural cracks penetrated further at a higher load, along with other flexural cracks in the deck slab as appeared in Figure 4.35. Although flexural cracks appeared in the barrier wall and the deck slab portion, a sudden diagonal tension crack appeared in the deck slab at a jacking load of $90 \mathrm{kN}$, respectively. These cracks propagated further till the barrier could not take a jacking load beyond $163.41 \mathrm{kN}$. Given the width of the barrier of $900 \mathrm{~mm}$ and the height of the applied load over the top surface of the deck slab of $990 \mathrm{~mm}$, the experimental resisting moment is calculated as $179.75 \mathrm{kN} . \mathrm{m} / \mathrm{m}$. This experimental resisting moment at the barrier deck junction is greater than the CHBDC design value of $83 \mathrm{kN} \cdot \mathrm{m} / \mathrm{m}$ at the barrier-deck slab junction. This leads to a factor of safety of 1.76 in the design of the TL-5 barrier wall at interior location as listed in Table 4.14. 


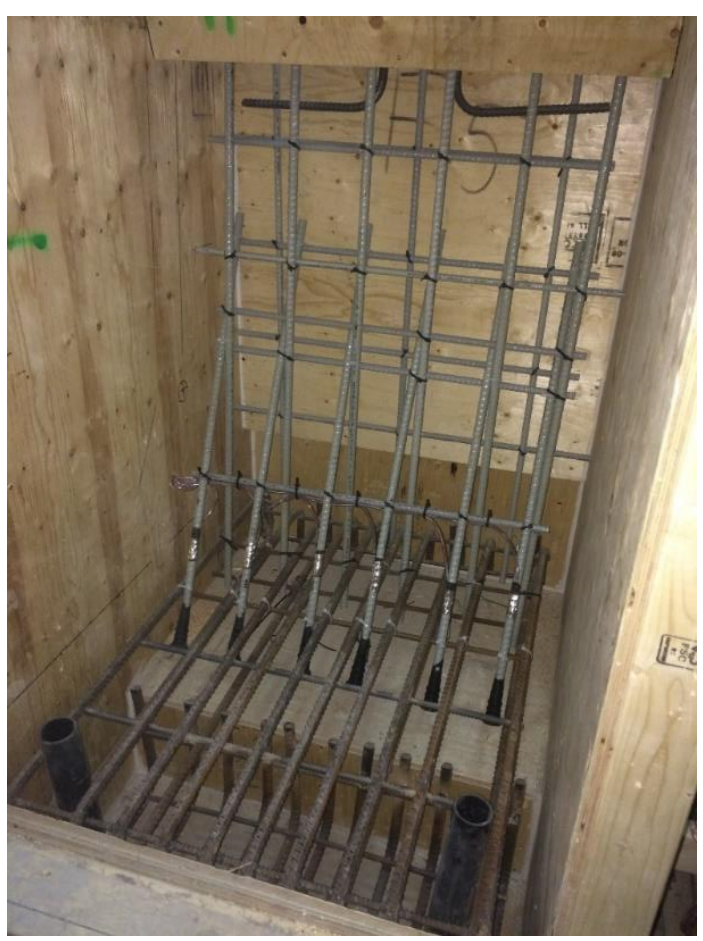

Figure 4.34: Barrier B-4 bar detailing prior to casting

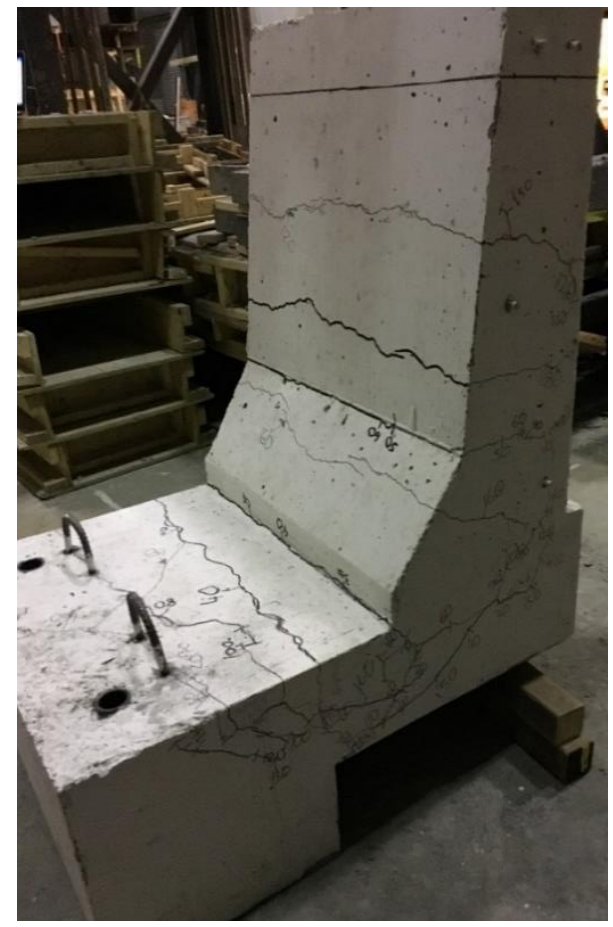

(a) Right side

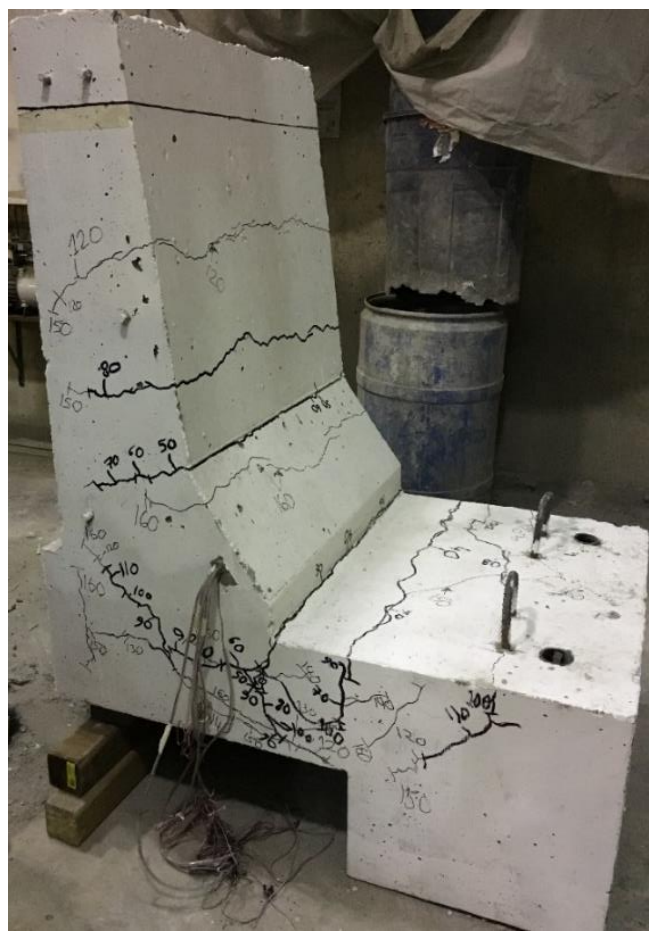

(b) Left side

Figure 4.35: View of crack pattern after failure of the tested specimen B-4 

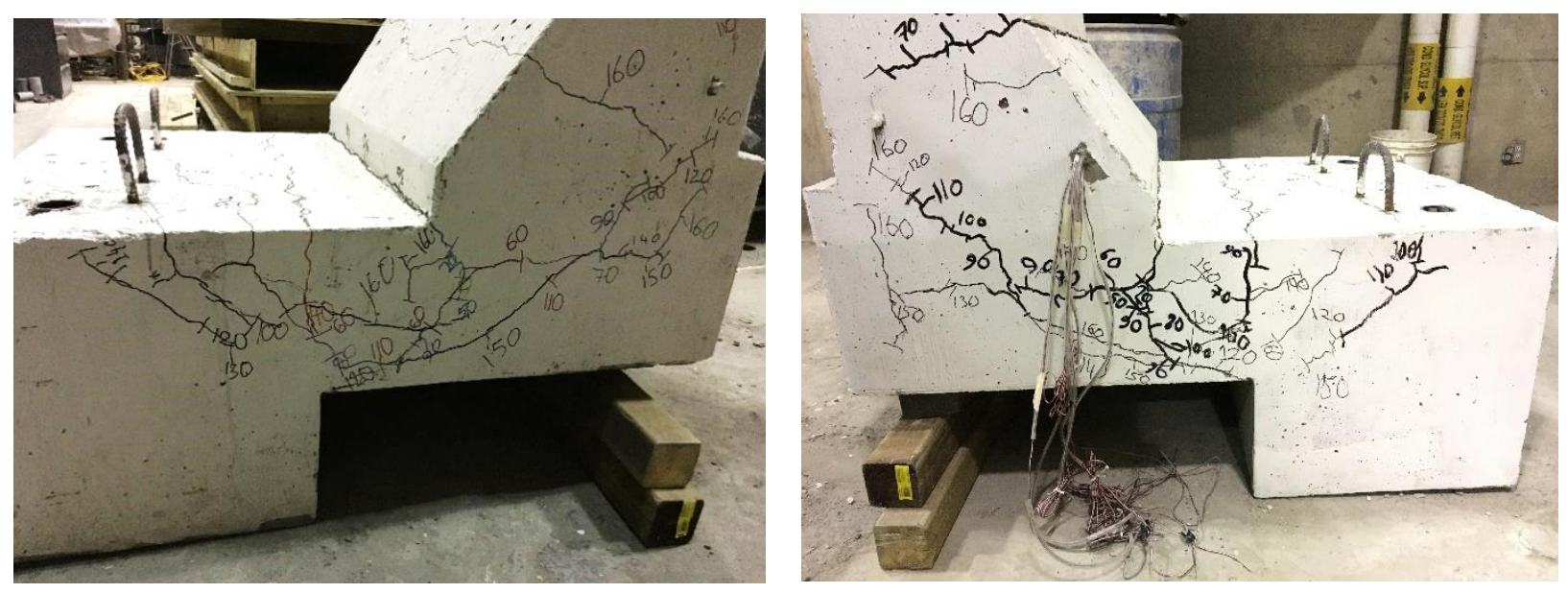

Figure 4.36: Close up view of crack pattern after failure of specimen B-4

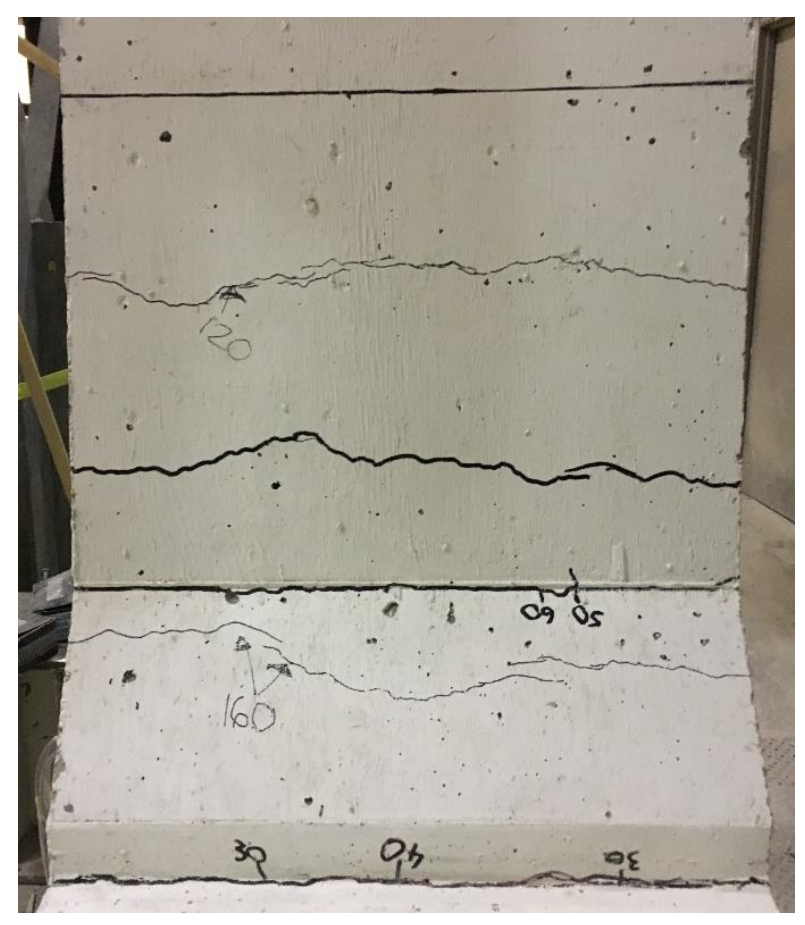

(a) Front face

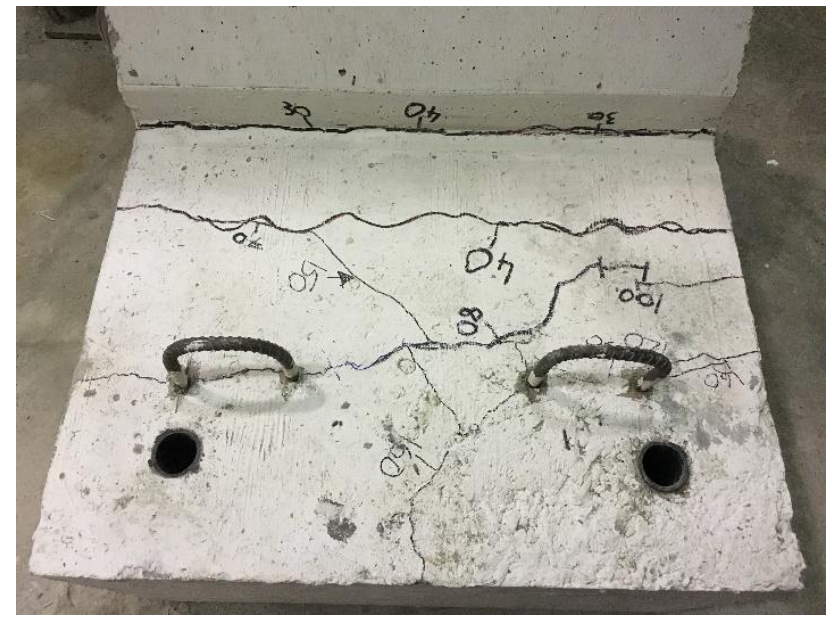

(b) Deck area

Figure 4.37: View of cracks at front face and deck area of specimen B-4

\subsubsection{TL-5 Bridge Barrier Specimen B-5}

Specimen B-5 represents a barrier wall connected to non-deformable concrete slab using postinstalled, straight-end, GFRP bars. The amount of vertical reinforcement at the front face 
represents the case of interior segment of the barrier wall. Figure 4.38 shows the reinforcement details in the barrier and deck before casting. Figures 4.39 through 4.41 show different views of the crack pattern of the tested barrier specimen. In this specimen, the first visible crack was observed in the front side of the barrier wall at barrier-deck junction at $30 \mathrm{kN}$ jacking load, followed by flexural crack at intersection of the two tapered portions of the front face of the barrier wall at $70 \mathrm{kN}$ jacking load. These flexural cracks penetrated through the barrier thickness with increase in the jacking load. However, sudden concrete vertical splitting appeared approximately at the embedded GFRP bar location at a load of $140 \mathrm{kN}$, followed by signs of concrete breakout close to the end of the embedded bar in the slab at a load of $159 \mathrm{kN}$. These concrete breakout cracks extended laterally in the slab and towards the back face of the barrier wall at higher loads till the barrier could not absorb jacking load beyond $159.74 \mathrm{kN}$. Given the width of the barrier of $900 \mathrm{~mm}$ and the height of the applied load over the top surface of the deck slab of $990 \mathrm{~mm}$, the experimental resisting moment is calculated as $175.71 \mathrm{kN} . \mathrm{m} / \mathrm{m}$. This experimental resisting moment at the barrier deck junction is greater than the CHBDC design value of $83 \mathrm{kN} . \mathrm{m} / \mathrm{m}$ at the barrier-deck slab. This leads to a factor of safety of 2.12 in the design of the TL-5 barrier wall at interior location when it is rigidly connected to non-deformable concrete deck slab using post-installed, straight-end, GFRP bars as listed in Table 4.14.

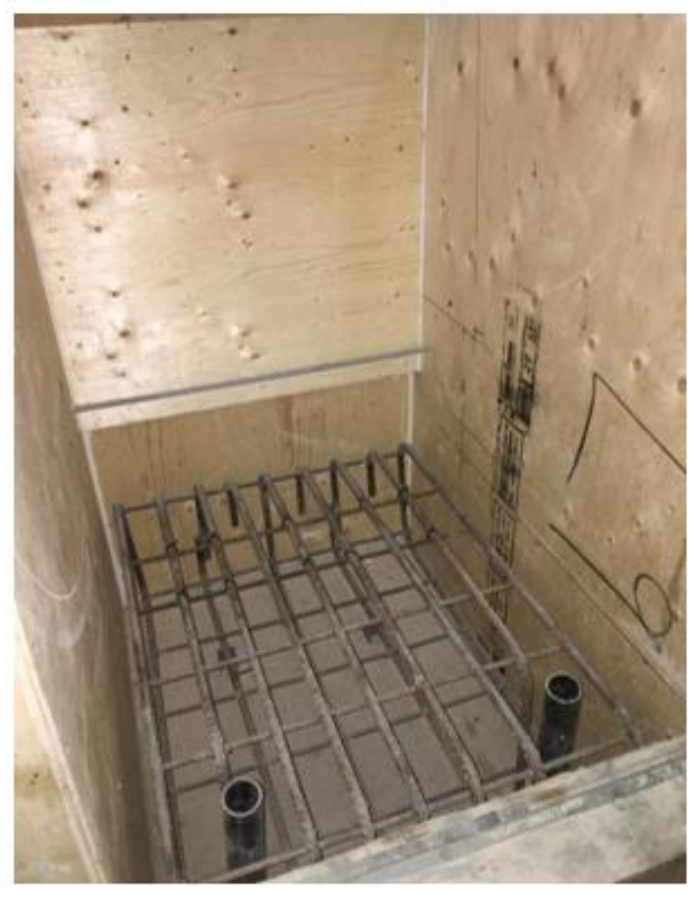

a) Slab prior to casting

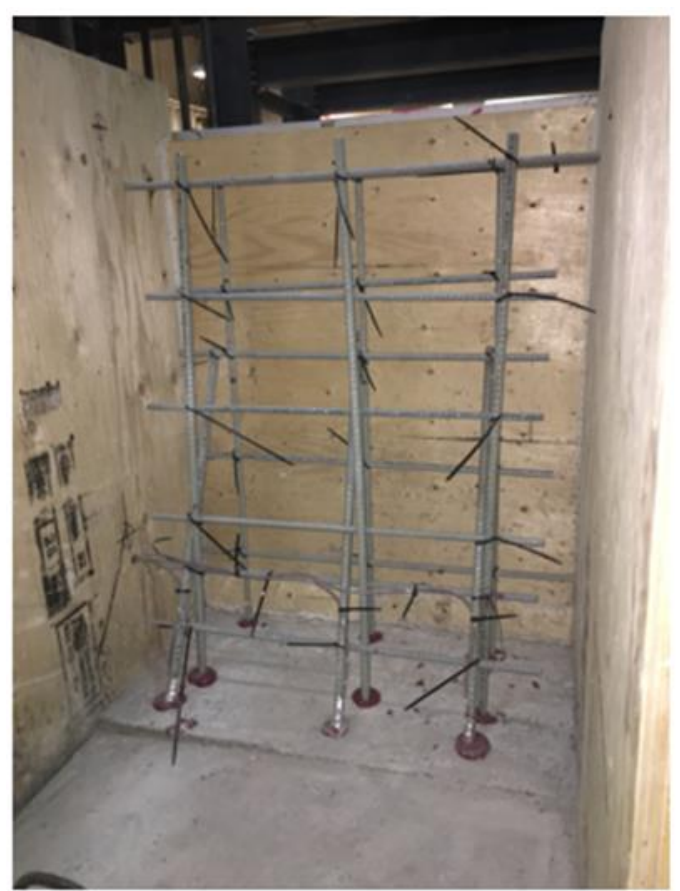

b) Post-installed wall prior to casting

Figure 4.38: Barrier B-5 bar detailing 


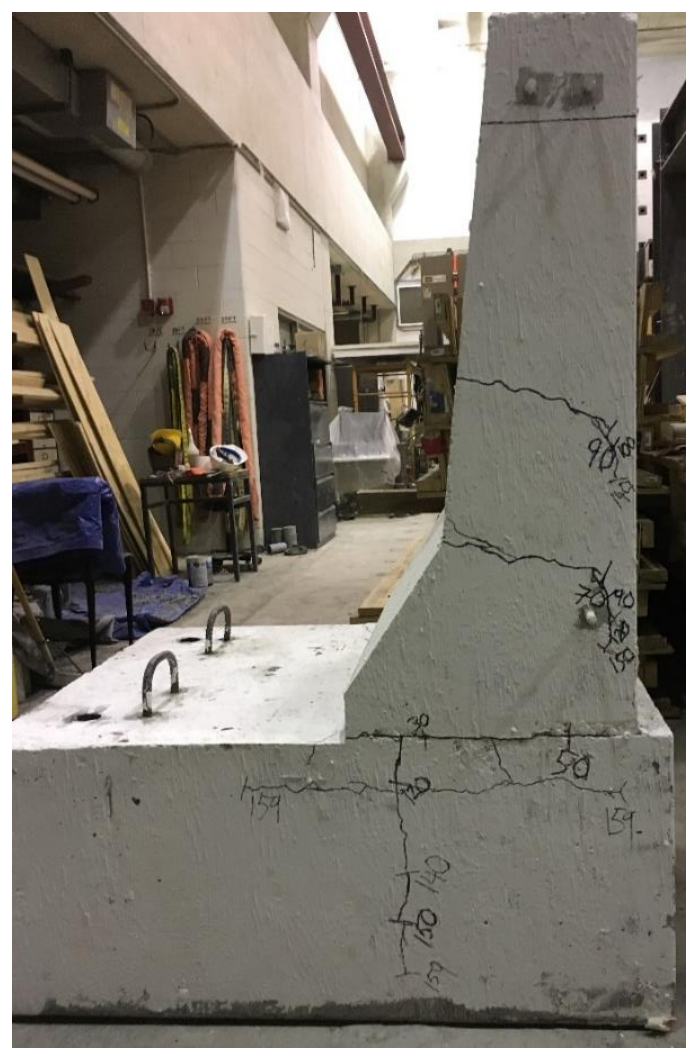

(a) Right side

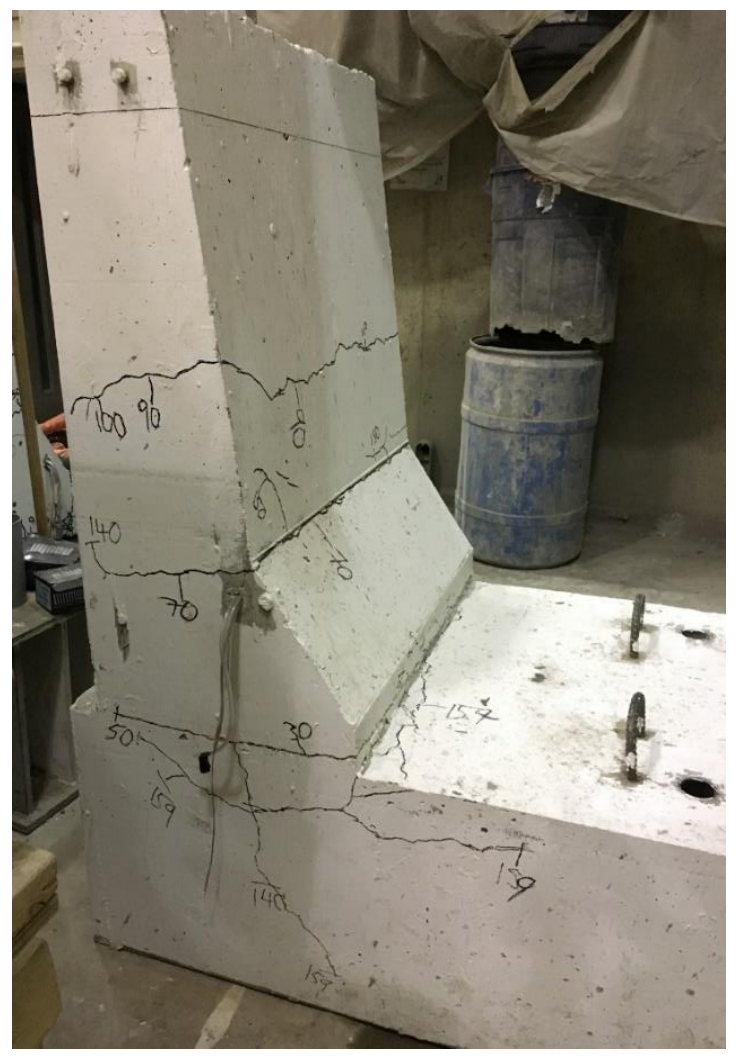

(b) Left side

Figure 4.39: View of crack pattern after failure of the tested specimen B-5
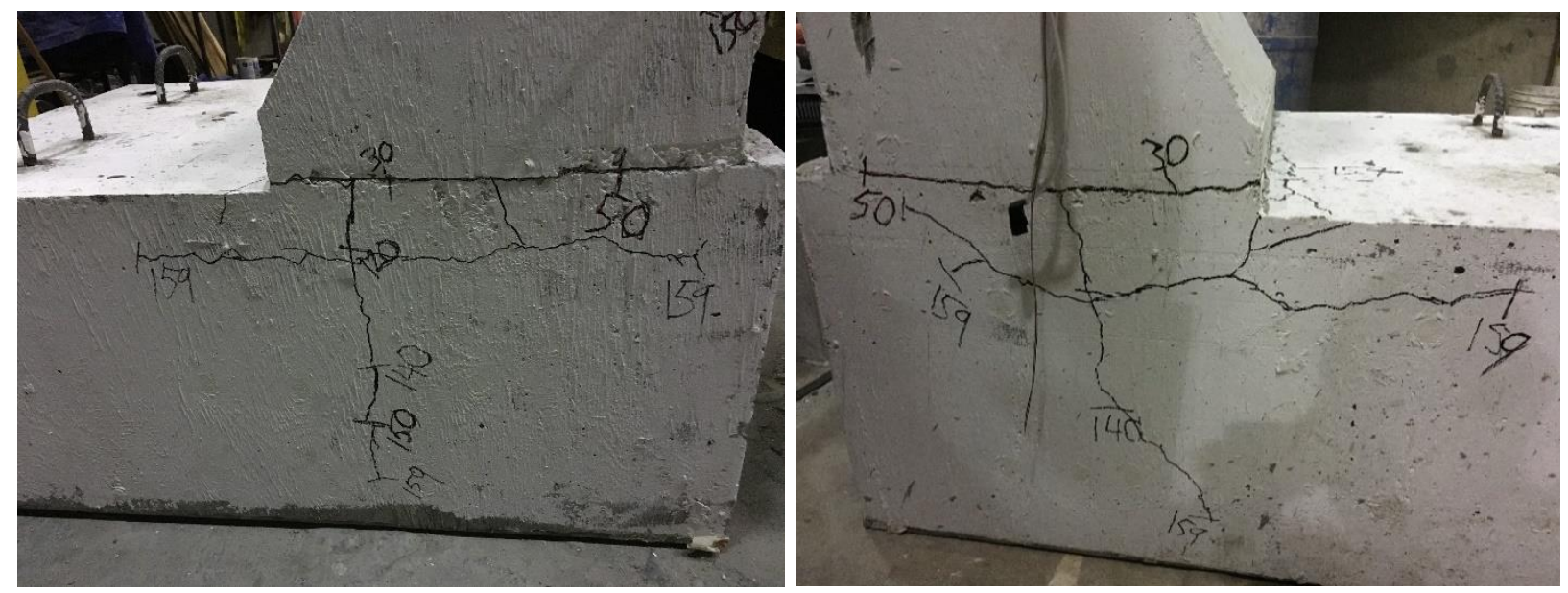

Figure 4.40: Close up view of crack pattern after failure of specimen B-5 


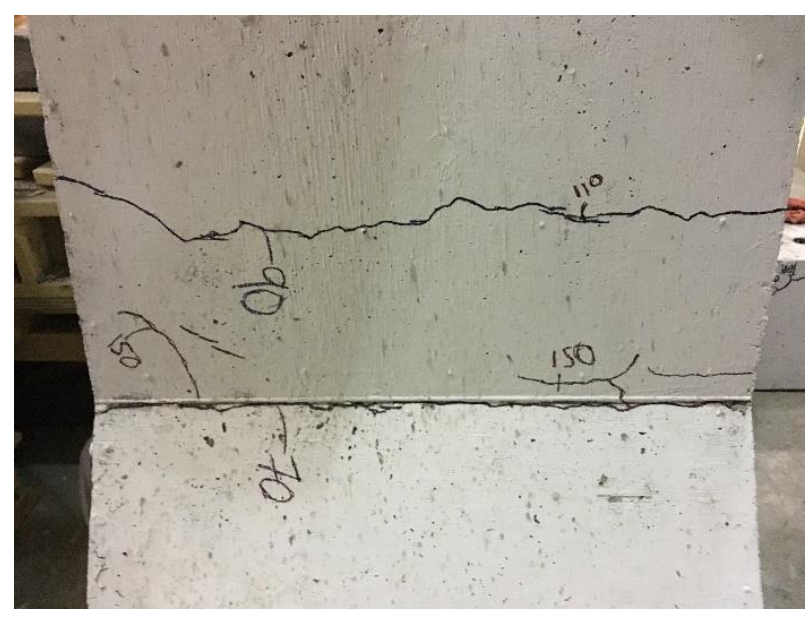

(a) Front face

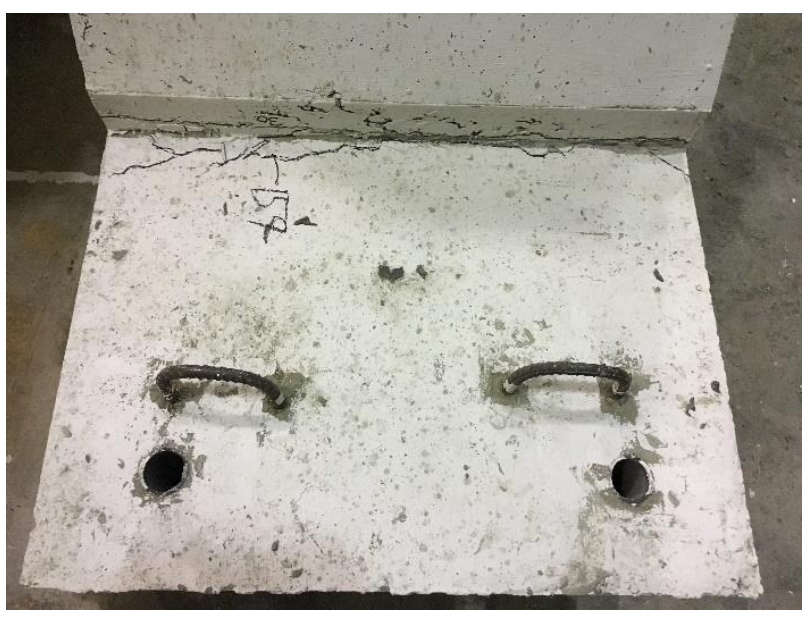

(b) Deck area

Figure 4.41: View of cracks at front face and deck area of specimen B-5

\subsubsection{TL-5 Bridge Barrier Specimen B-6}

Specimen B-6 represents a barrier wall connected to non-deformable concrete slab using postinstalled, straight-end, GFRP bars. The amount of vertical reinforcement at the front face represents the case of exterior segment of the barrier wall. Figure 4.42 shows the reinforcement details in the barrier and deck before casting. Figures 4.43 through 4.45 show different views of the crack pattern of the tested barrier specimen. In this specimen, the first visible crack was observed in the front side of the barrier wall at barrier-deck junction at $20 \mathrm{kN}$ jacking load, followed by flexural crack at intersection of the two tapered portions of the front face of the barrier wall at $60 \mathrm{kN}$ jacking load. These flexural cracks penetrated through the barrier thickness with increase in the jacking load. However, sudden shear crack appeared at the middle of top tapered portion of the barrier wall at a load of $180 \mathrm{kN}$ and the specimens could not absorb jacking load beyond $186.74 \mathrm{kN}$. Given the width of the barrier of $900 \mathrm{~mm}$ and the height of the applied load over the top surface of the deck slab of $990 \mathrm{~mm}$, the experimental resisting moment is calculated as $205.41 \mathrm{kN} . \mathrm{m} / \mathrm{m}$. This experimental resisting moment at the barrier deck junction is greater than the CHBDC design value of $83 \mathrm{kN} . \mathrm{m} / \mathrm{m}$ at the barrier-deck slab. This leads to a factor of safety of 2.01 in the design of the TL-5 barrier wall at interior location when it is rigidly connected to non-deformable concrete deck slab using post-installed, straight-end, GFRP bars as listed in Table 4.14. 


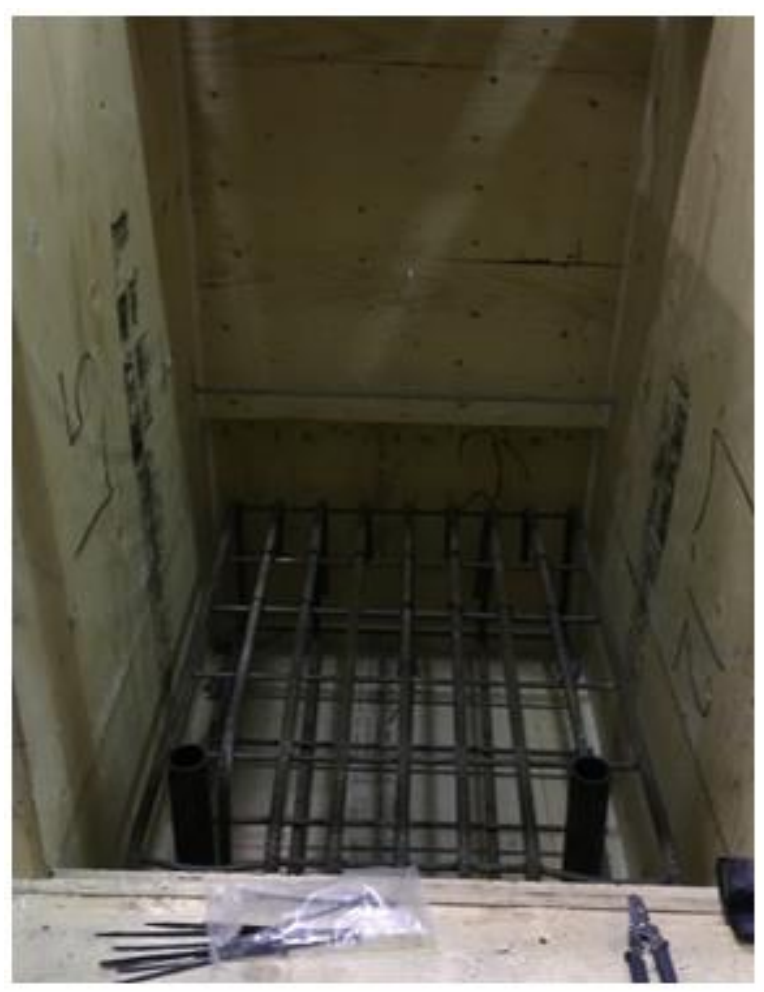

a) Slab reinforcement

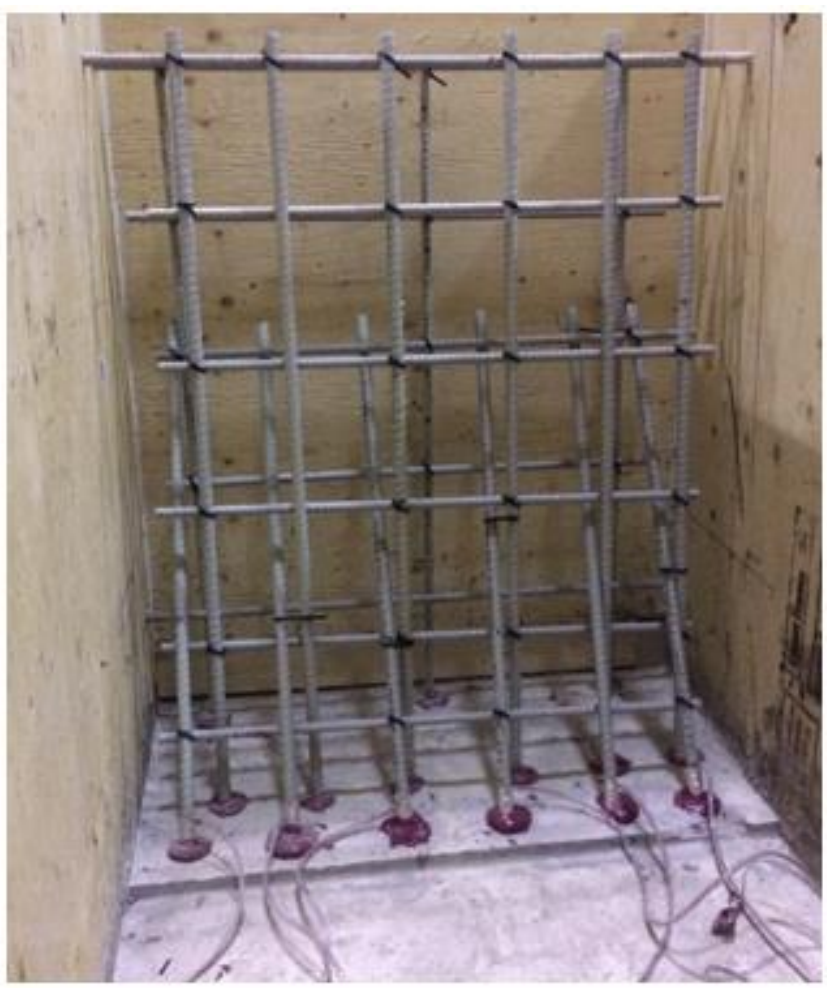

b) Post-installed bars in wall prior to casting

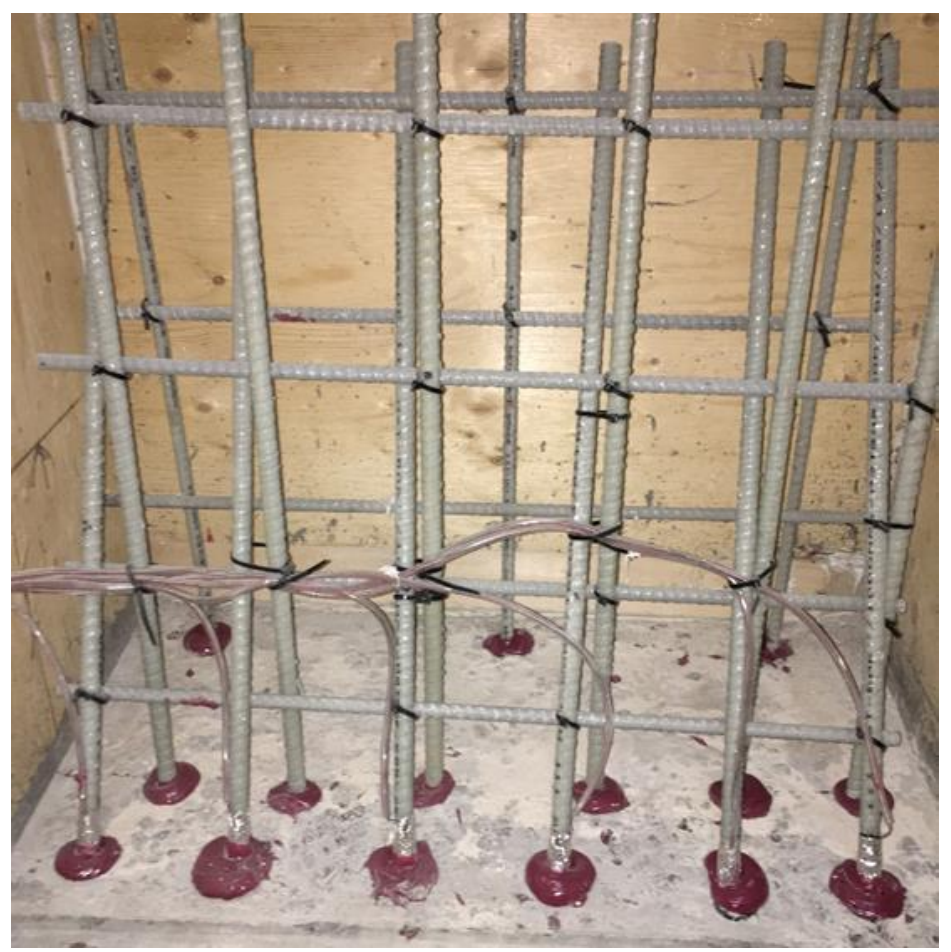

c) Close-up view of final set of pre-installed GFRP bars

Figure 4.42: Barrier B-6 bar detailing 


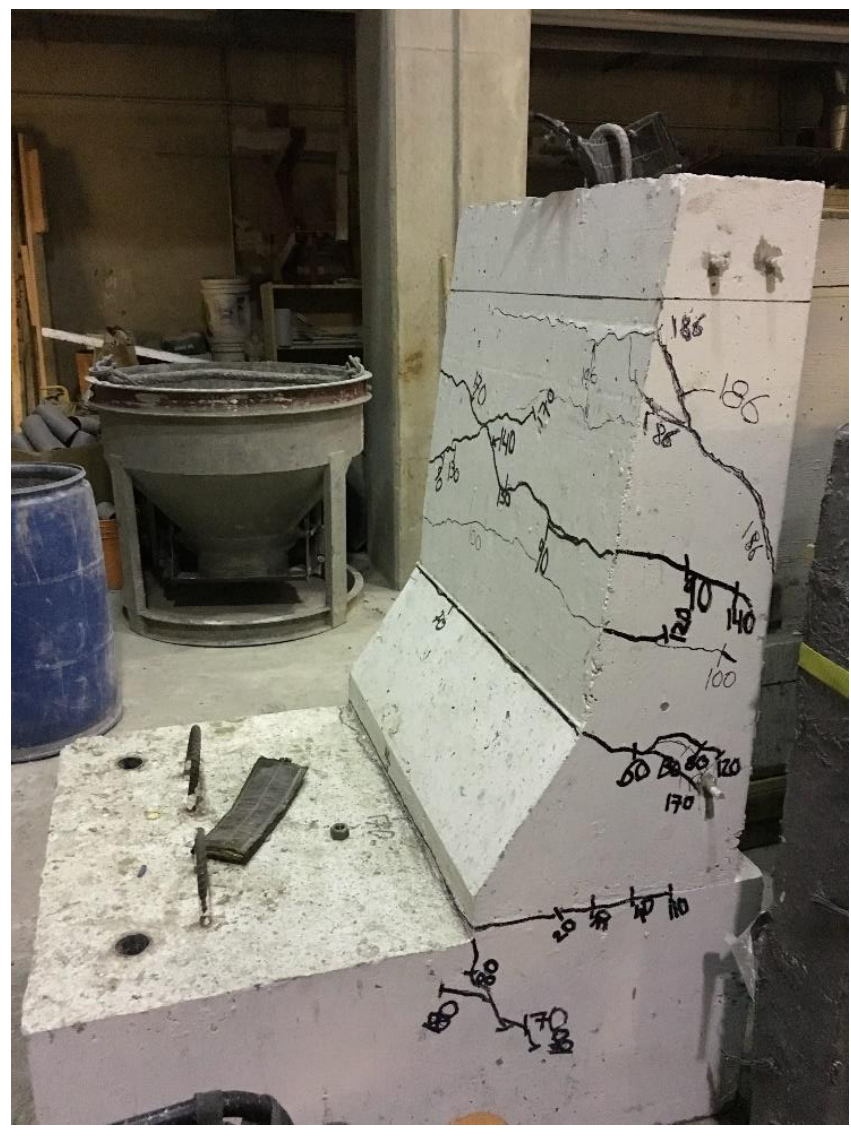

(a) Right side

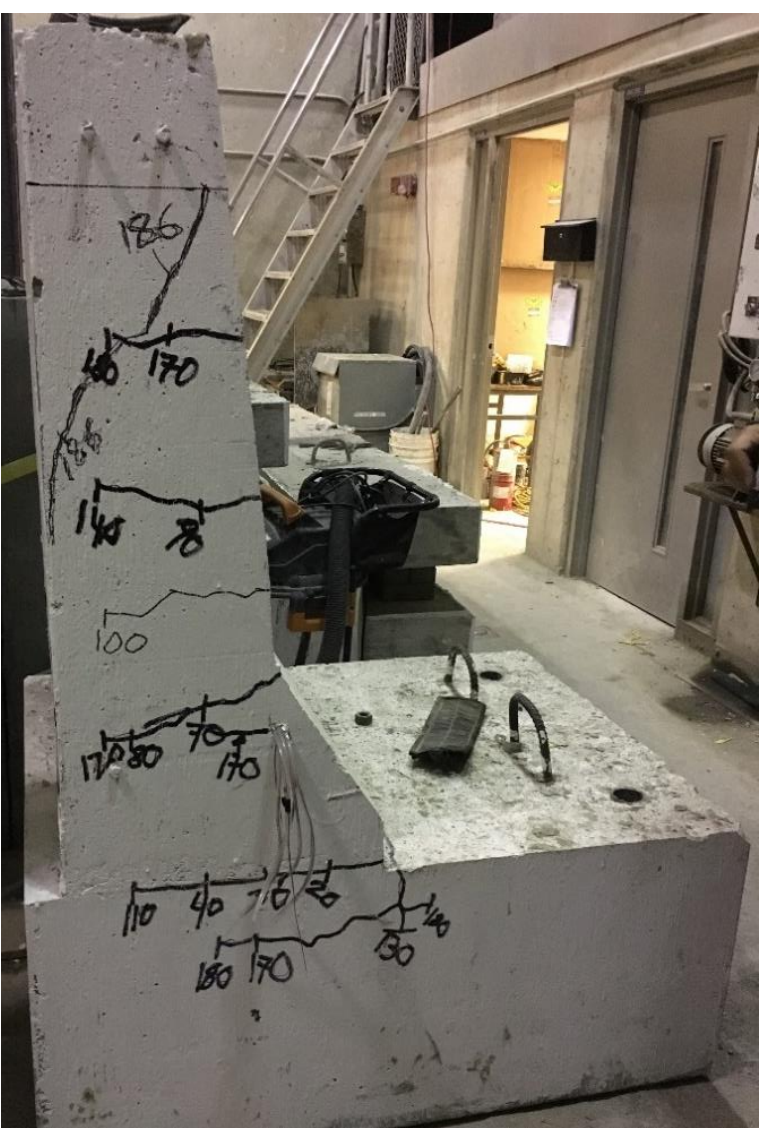

(b) Left side

Figure 4.43: View of crack pattern after failure of the tested specimen B-6 

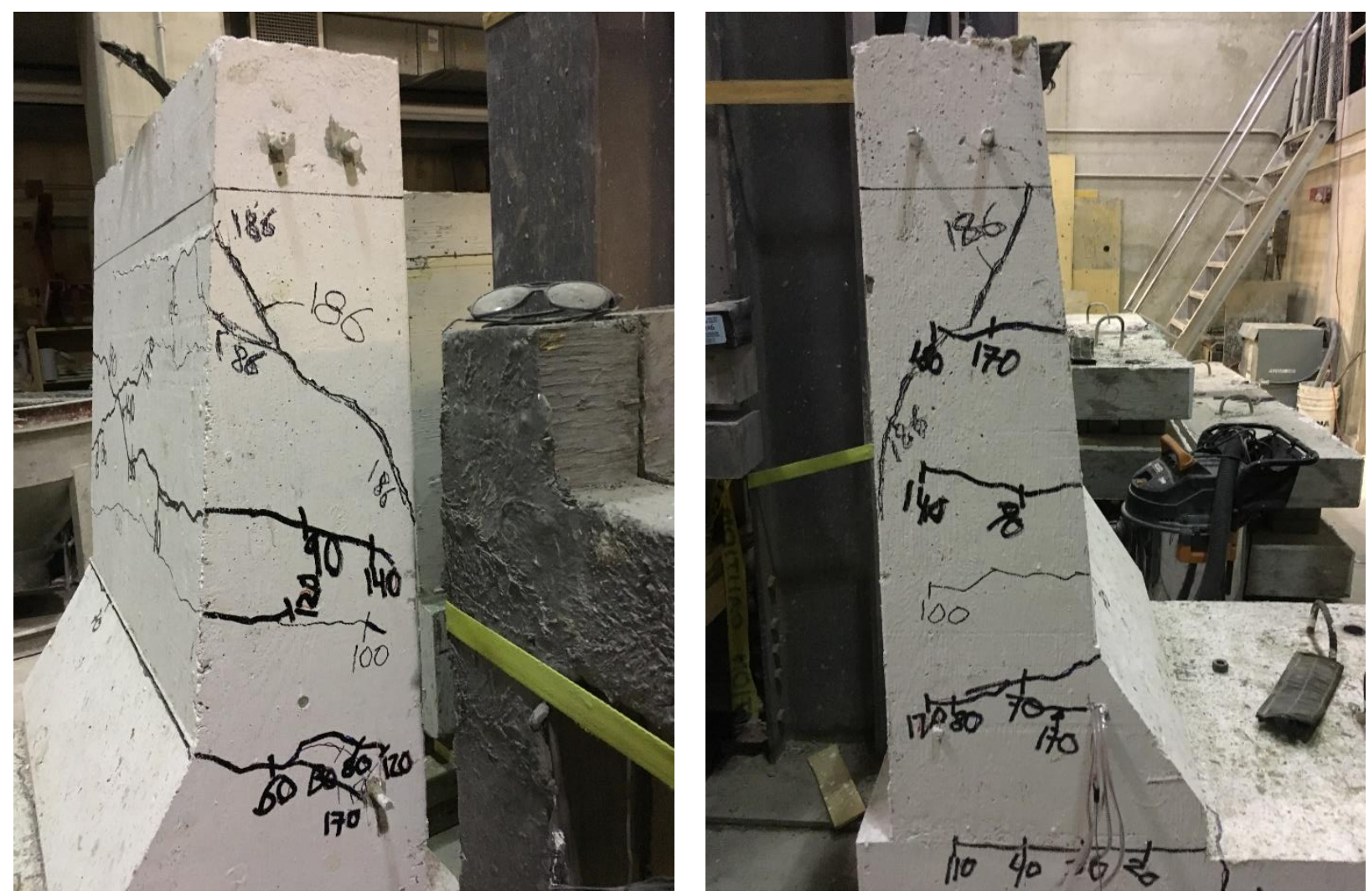

Figure 4.44: Close up view of crack pattern after failure of specimen B-6

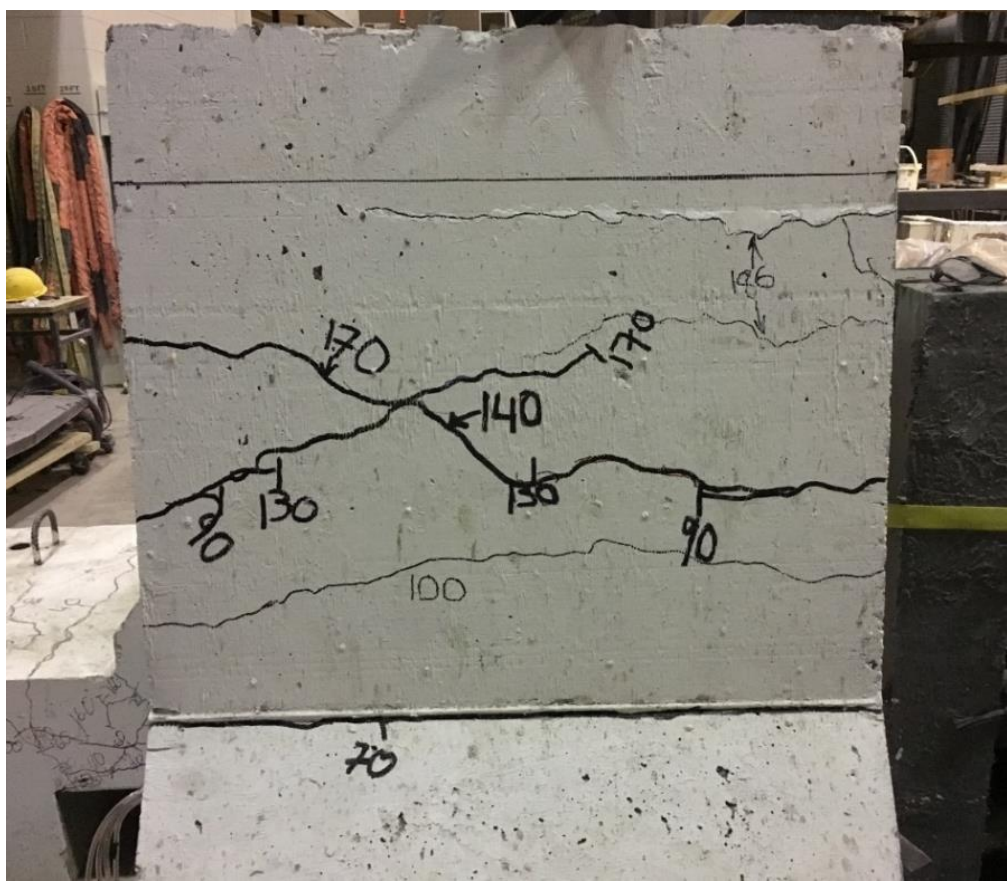

Figure 4.45: View of cracks at front face of specimen B-6 


\subsection{Analysis of data obtained from sensors}

When analyzing the data sets, three different sets of graphs were created for each barrier specimen. The first type of graphs showcases the displacement of the barrier at various locations with the increase in applied load, while the second graph type shows the GFRP bar strain response at the barrier-deck junction with load increase. The third graph type outlines the strain response of concrete at the rear of the wall close to the barrier-deck junction.

\subsubsection{TL-5 Bridge Barrier Specimen B-1}

Figure 4.46 depicts the applied load-displacement relationship for specimen B-1. It can be observed that the average deck slab uplift and the horizontal movement at failure were 0.39 and $3.81 \mathrm{~mm}$, respectively. These values are considered acceptable and do not significantly affect the structural response of the barrier wall. It can be observed that the maximum lateral deflection of the barrier wall at failure is $26.32 \mathrm{~mm}$ which is quite small given the presence of non-deformable deck slab.

Table 4.7: Specimen B-1 averages of maximums

\begin{tabular}{|c|c|c|}
\hline Element & Value & Average \\
\hline \multirow{3}{*}{ Top displacement (mm) } & 26.38 & \multirow{3}{*}{26.32} \\
\hline & 25.84 & \\
\hline & 26.74 & \\
\hline \multirow{3}{*}{$\begin{array}{l}\text { Bottom displacement } \\
\text { (mm) }\end{array}$} & 3.73 & \multirow{3}{*}{3.81} \\
\hline & 3.80 & \\
\hline & 3.91 & \\
\hline \multirow{2}{*}{ Front uplift (mm) } & 0.43 & \multirow{2}{*}{0.39} \\
\hline & 0.35 & \\
\hline \multirow{3}{*}{ Concrete strain $(\mu \varepsilon)$} & -926.00 & \multirow{3}{*}{-818.33} \\
\hline & -737.00 & \\
\hline & -792.00 & \\
\hline \multirow{3}{*}{ GFRP strain $(\mu \varepsilon)$} & 5203.00 & \multirow{3}{*}{6503.93} \\
\hline & 6400.00 & \\
\hline & 7908.78 & \\
\hline Maximum load (kN) & \multicolumn{2}{|c|}{168.63} \\
\hline
\end{tabular}


Figure 4.47 depicts the tensile strains in the diagonal GFRP bars at the front face of the barrier. The strain gauges were located just at top surface of the deck at the barrier-deck junction. It can be observed that the average strain in the GFRP bars was $6503.93 \mu \varepsilon$ while the ultimate strain of the GFRP bars per the manufacturer's certification sheet is $15,000 \mu \varepsilon$. Figure 4.48 shows the loadconcrete strain relationship close to the barrier-deck junction. The concrete strain gauges were located just $115 \mathrm{~mm}$ above the top surface of the deck cantilever and at the front face of the barrier wall. It can be observed that the average concrete compressive strain at failure was $818.33 \mu \varepsilon$ which is far below the ultimate concrete strain at failure of $3500 \mu \varepsilon$. The low GFRP and concrete strain values are attributed to the fact that the failure of the barrier-deck junction is due to GFRP bar-concrete anchorage. Table 4.7 summarizes the critical experimental findings obtained from sensors.

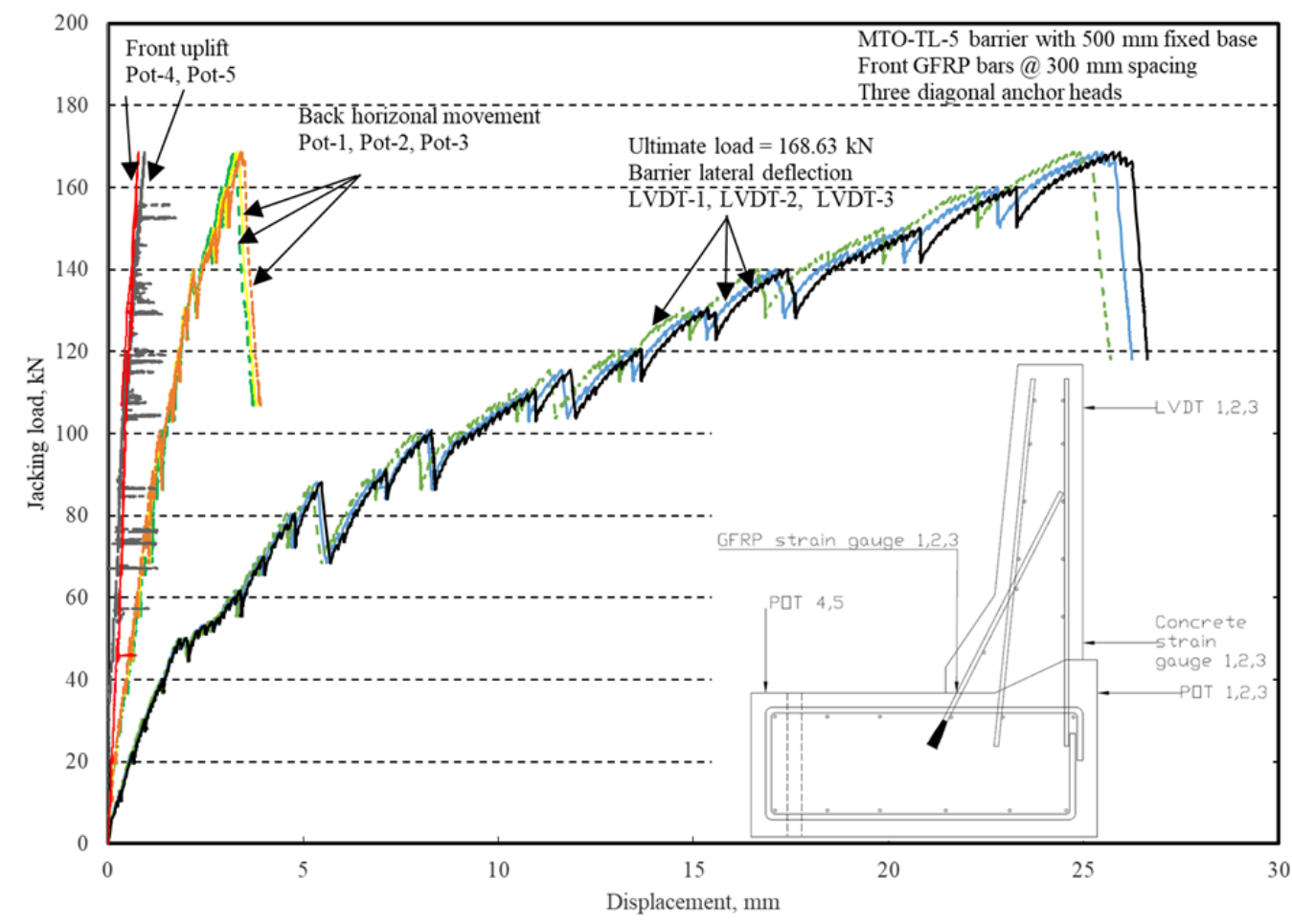

Figure 4.46: Displacement response of Barrier B-1 to increase in static load 


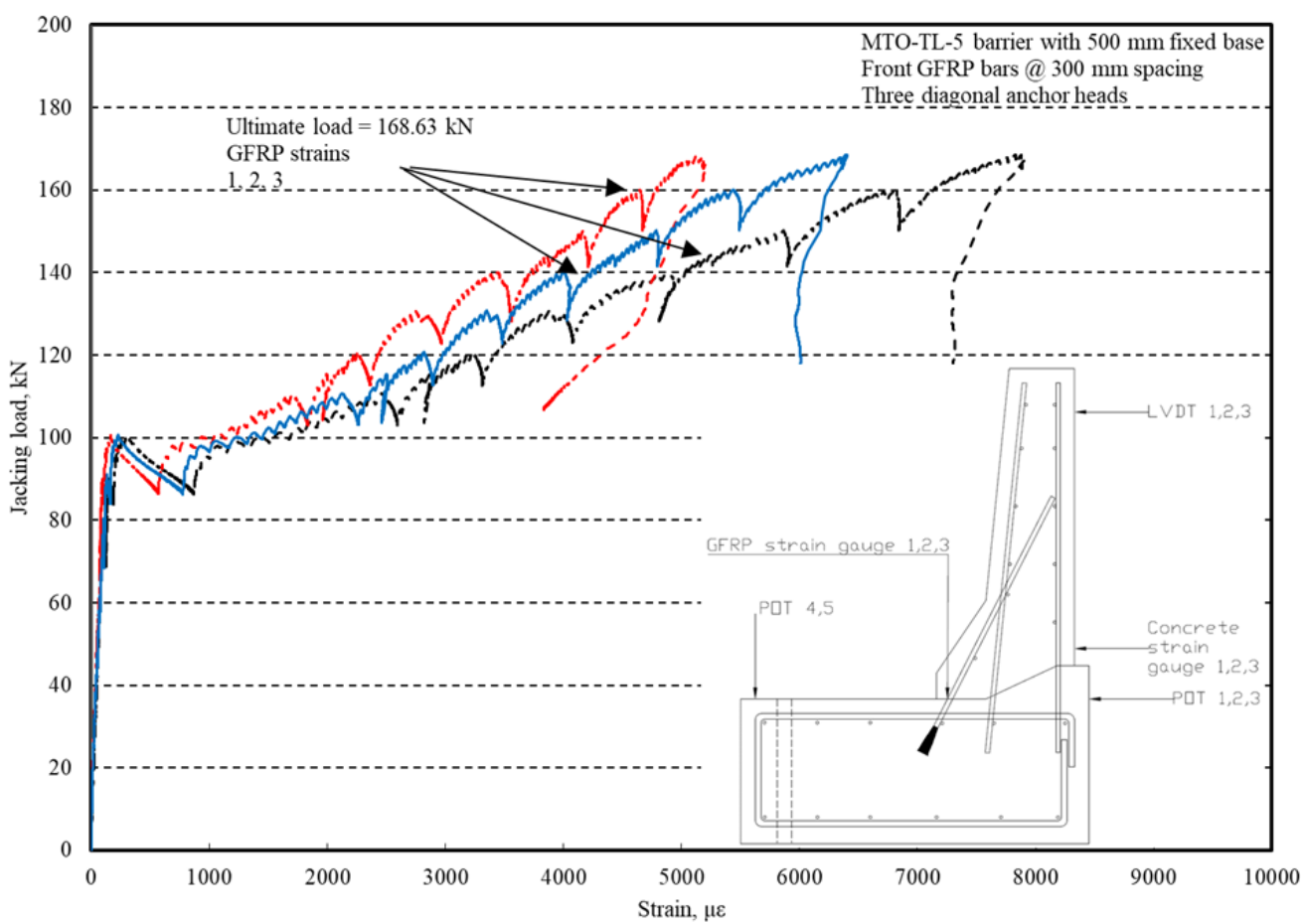

Figure 4.47: GFRP strain response of Barrier B-1 to increase in static load

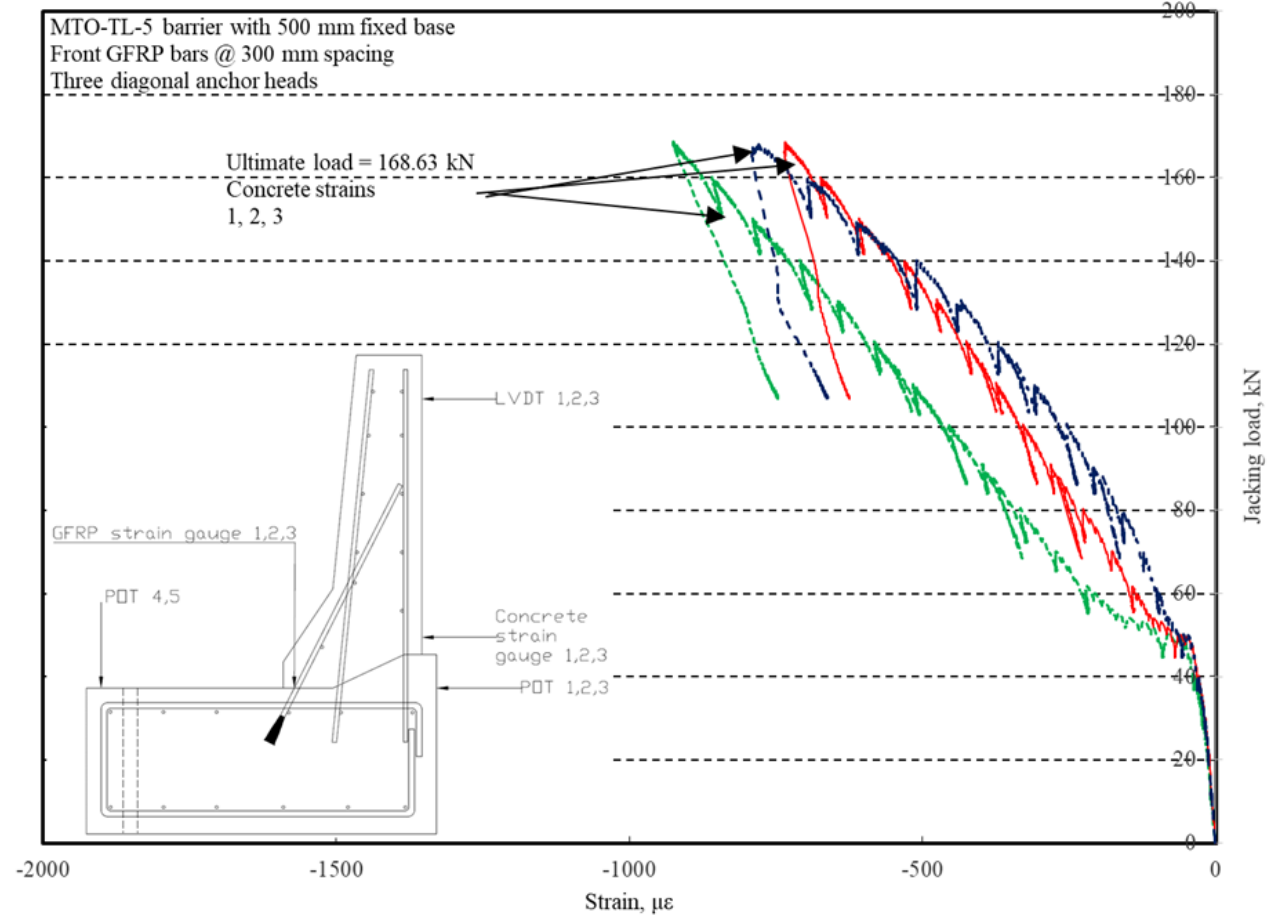

Figure 4.48: Concrete strain response of Barrier B-1 to increase in static load 


\subsubsection{TL-5 Bridge Barrier Specimen B-2}

Figure 4.49 depicts the applied load-displacement relationship for specimen B-2. It can be observed that the average deck slab uplift and the horizontal movement at failure were 1.62 and $4.27 \mathrm{~mm}$, respectively. These values are considered acceptable and do not significantly affect the structural response of the barrier wall. It can be observed that the maximum lateral deflection of the barrier wall at failure is $23.74 \mathrm{~mm}$ which is quite small given the presence of non-deformable deck slab. Figure 4.50 depicts the tensile strains in the diagonal GFRP bars at the front face of the barrier. It can be observed that the average strain in the GFRP bars was $3914.8 \mu \varepsilon$ while the ultimate strain of the GFRP bars per the manufacturer's certification sheet is $15,000 \mu \varepsilon$. Figure 4.51 shows the load-concrete strain relationship close to the barrier-deck junction. It can be observed that the average concrete compressive strain at failure was $868 \mu \varepsilon$ which is far below the ultimate concrete strain at failure of $3500 \mu \varepsilon$. The low GFRP and concrete strain values are attributed to the fact that the sudden diagonal shear crack in the barrier wall. Table 4.8 summarizes the critical experimental findings obtained from sensors.

Table 4.8: Specimen B-2 averages of maximums

\begin{tabular}{|c|c|c|}
\hline Element & Value & Average \\
\hline \multirow{3}{*}{ Top displacement (mm) } & 23.50 & \multirow{3}{*}{23.74} \\
\hline & 23.15 & \\
\hline & 24.56 & \\
\hline \multirow{3}{*}{ Bottom displacement (mm) } & 4.41 & \multirow{3}{*}{4.27} \\
\hline & 4.32 & \\
\hline & 4.09 & \\
\hline \multirow{2}{*}{ Front uplift (mm) } & 1.04 & \multirow{2}{*}{1.62} \\
\hline & 2.20 & \\
\hline \multirow{3}{*}{ Concrete strain $(\mu \varepsilon)$} & -1023.00 & \multirow{3}{*}{-868.00} \\
\hline & -924.00 & \\
\hline & -657.00 & \\
\hline \multirow{5}{*}{ GFRP strain $(\mu \varepsilon)$} & 3396.00 & \multirow{5}{*}{3914.80} \\
\hline & 3144.00 & \\
\hline & 4648.00 & \\
\hline & 3556.00 & \\
\hline & 4830.00 & \\
\hline Maximum load (kN) & \multicolumn{2}{|c|}{182.63} \\
\hline
\end{tabular}




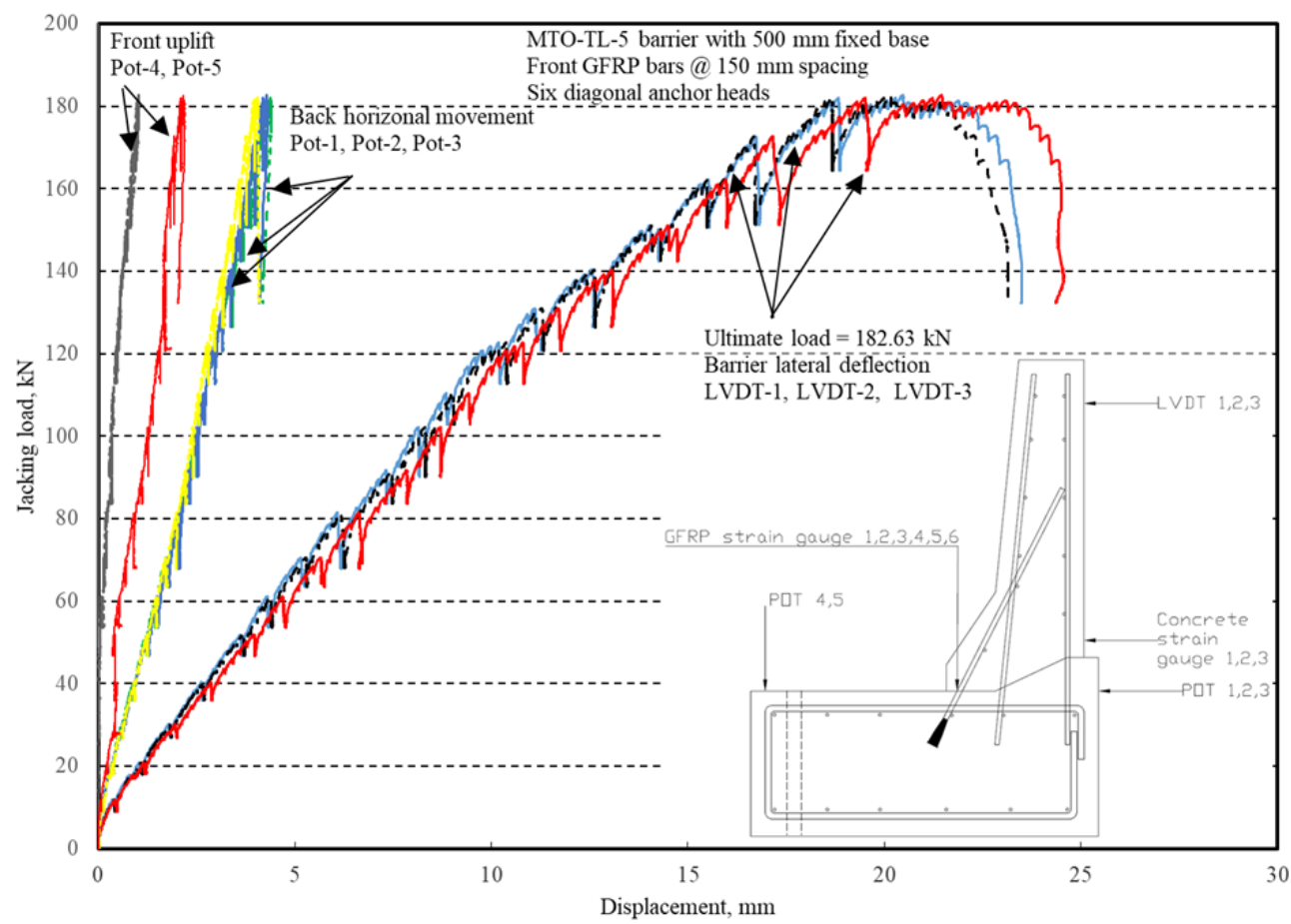

Figure 4.49: Displacement response of Barrier B-2 to increase in static load

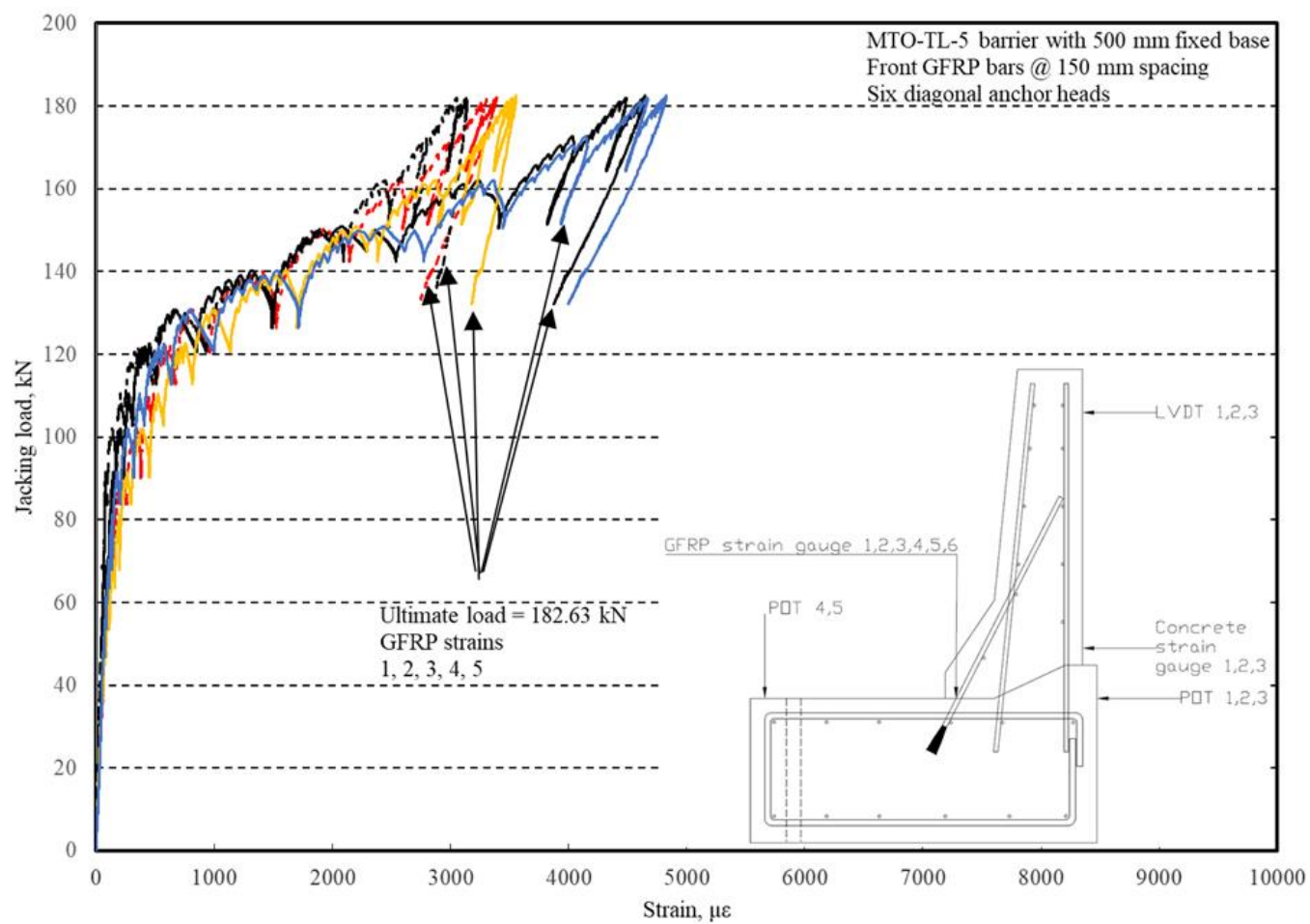

Figure 4.50: GFRP strain response of Barrier B-2 to increase in static load 


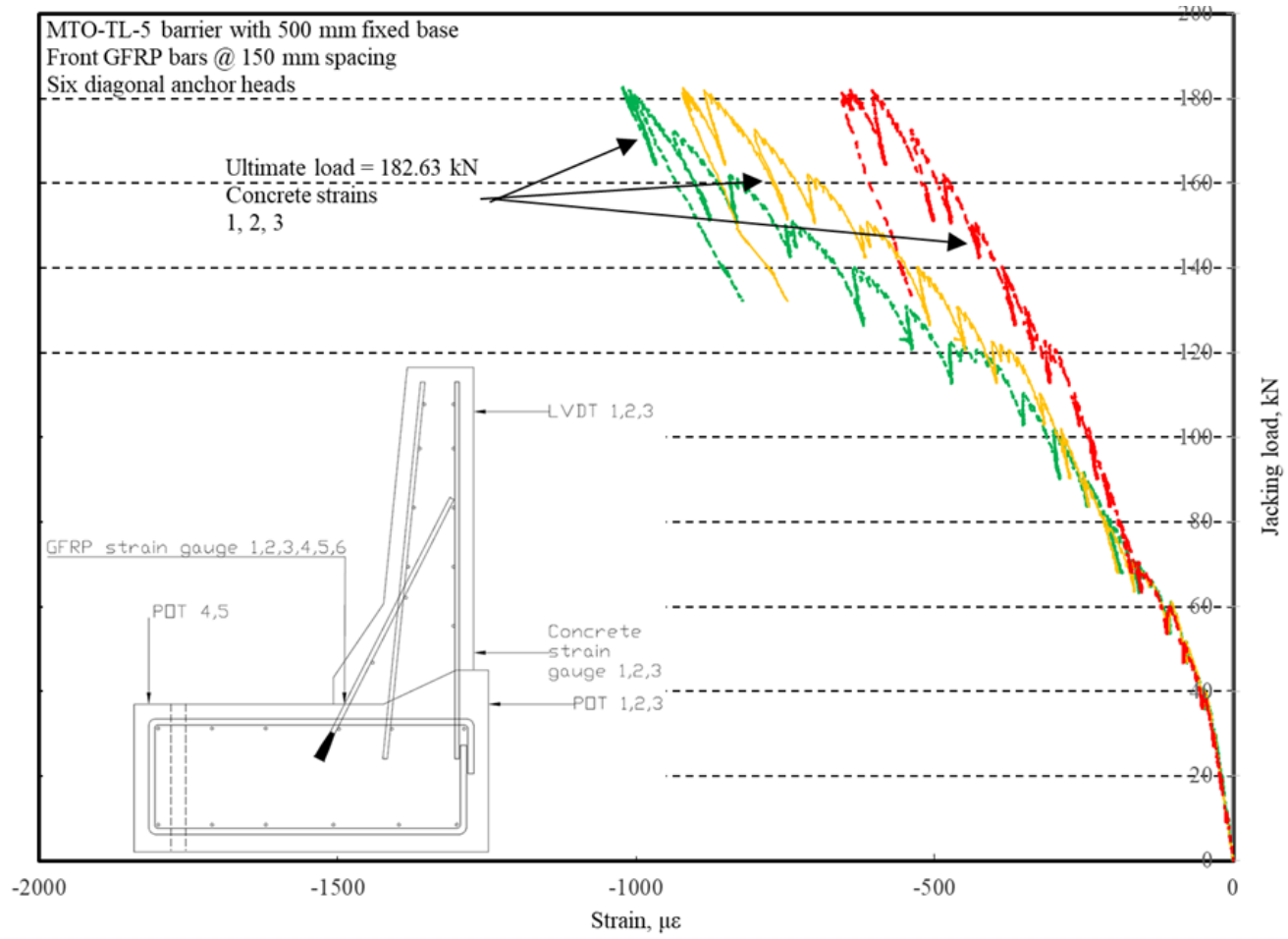

Figure 4.51: Concrete strain response of Barrier B-2 to increase in static load

\subsubsection{TL-5 Bridge Barrier Specimen B-3}

Figure 4.52 depicts the applied load-displacement relationship for specimen B-3 at interior location for a barrier-deck slab cantilever system. It can be observed that the average deck slab uplift and the horizontal movement at failure were 3.66 and $8.43 \mathrm{~mm}$, respectively. These values are greater than those recorded for other specimens as the threaded rod tightening was not as that for specimens B-1 and B-2. However, these values can be used at a later stage to obtain the net barrier lateral deflection. It can be observed that the maximum lateral deflection of the barrier wall at failure is $44.75 \mathrm{~mm}$ while the maximum vertical deflection of the deck slab cantilever is $17.57 \mathrm{~mm}$. Figure 4.53 depicts the tensile strains in the diagonal GFRP bars at the front face of the barrier. It can be observed that the average strain in the GFRP bars was 7198.86 $\mu \varepsilon$ while the ultimate strain of the GFRP bars per the manufacturer's certification sheet is 15,000 $\mu \varepsilon$. Figure 4.54 shows the load-concrete strain relationship close to the barrier-deck junction. It can be observed that the average concrete compressive strain at failure was $784.67 \mu \varepsilon$ which is far below the ultimate concrete strain at failure of $3500 \mu \varepsilon$. The low GFRP and concrete strain values are attributed to the fact that GFRP-concrete anchorage failure occurred. Table 4.9 summarizes the critical experimental findings obtained from sensors. 
Table 4.9: Specimen B-3 averages of maximums

\begin{tabular}{|c|c|c|}
\hline Element & Value & Average \\
\hline \multirow{3}{*}{ Top displacement (mm) } & 44.49 & \multirow{3}{*}{44.75} \\
\hline & 44.81 & \\
\hline & 44.94 & \\
\hline \multirow{3}{*}{$\begin{array}{l}\text { Bottom displacement } \\
(\mathrm{mm})\end{array}$} & 8.76 & \multirow{3}{*}{8.43} \\
\hline & 8.61 & \\
\hline & 7.92 & \\
\hline \multirow{2}{*}{ Overhang (mm) } & 18.00 & \multirow{2}{*}{17.57} \\
\hline & 17.15 & \\
\hline \multirow{2}{*}{ Front uplift (mm) } & 2.51 & \multirow{2}{*}{3.66} \\
\hline & 4.80 & \\
\hline \multirow{3}{*}{ Concrete strain $(\mu \varepsilon)$} & -665.00 & \multirow{3}{*}{-784.67} \\
\hline & -820.00 & \\
\hline & -869.00 & \\
\hline \multirow{3}{*}{ GFRP strain $(\mu \varepsilon)$} & 8008.00 & \multirow{3}{*}{7198.86} \\
\hline & 6643.00 & \\
\hline & 6945.58 & \\
\hline Maximum load (kN) & & 64 \\
\hline
\end{tabular}




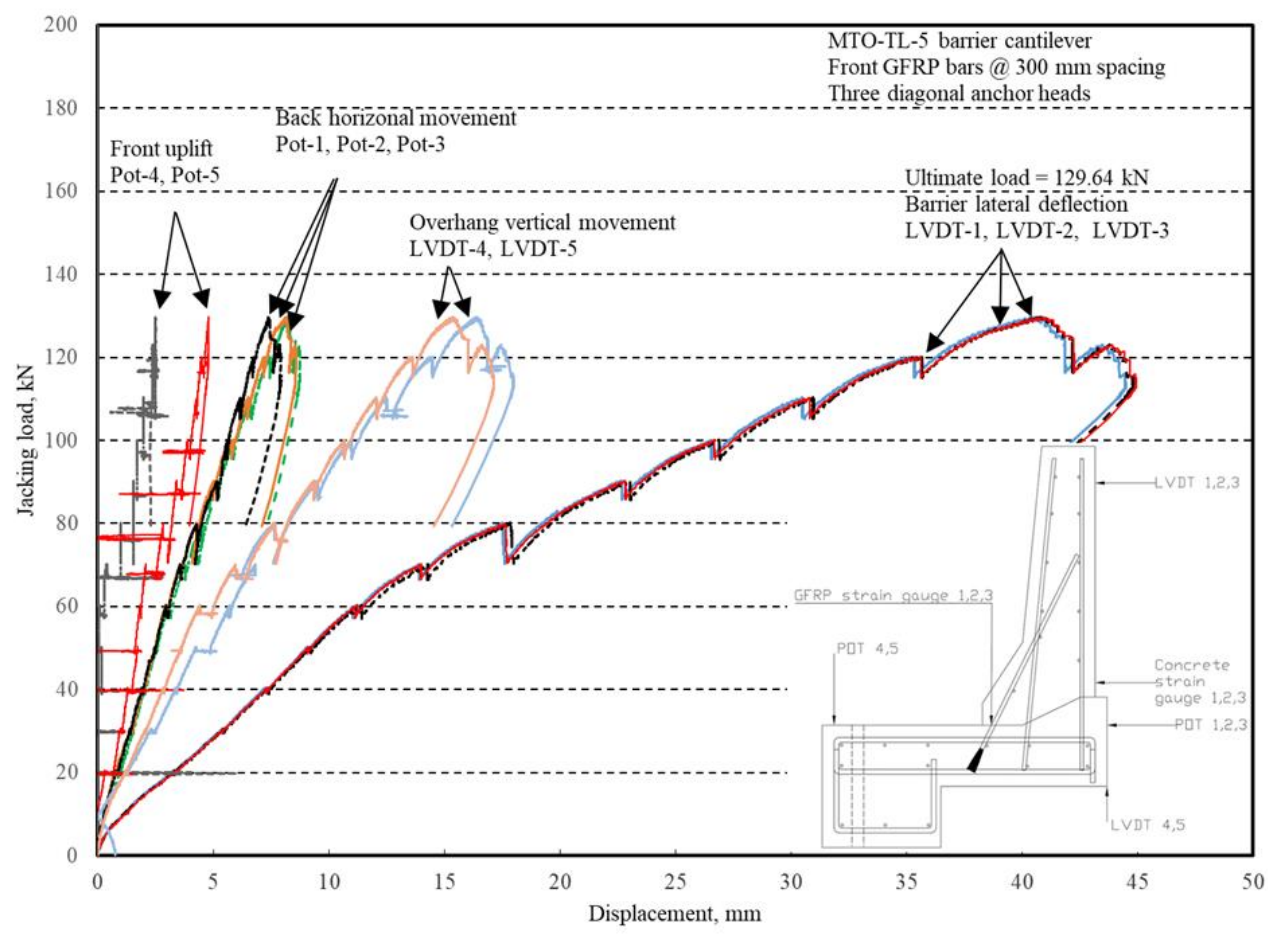

Figure 4.52: Displacement response of Barrier B-3 to increase in static load

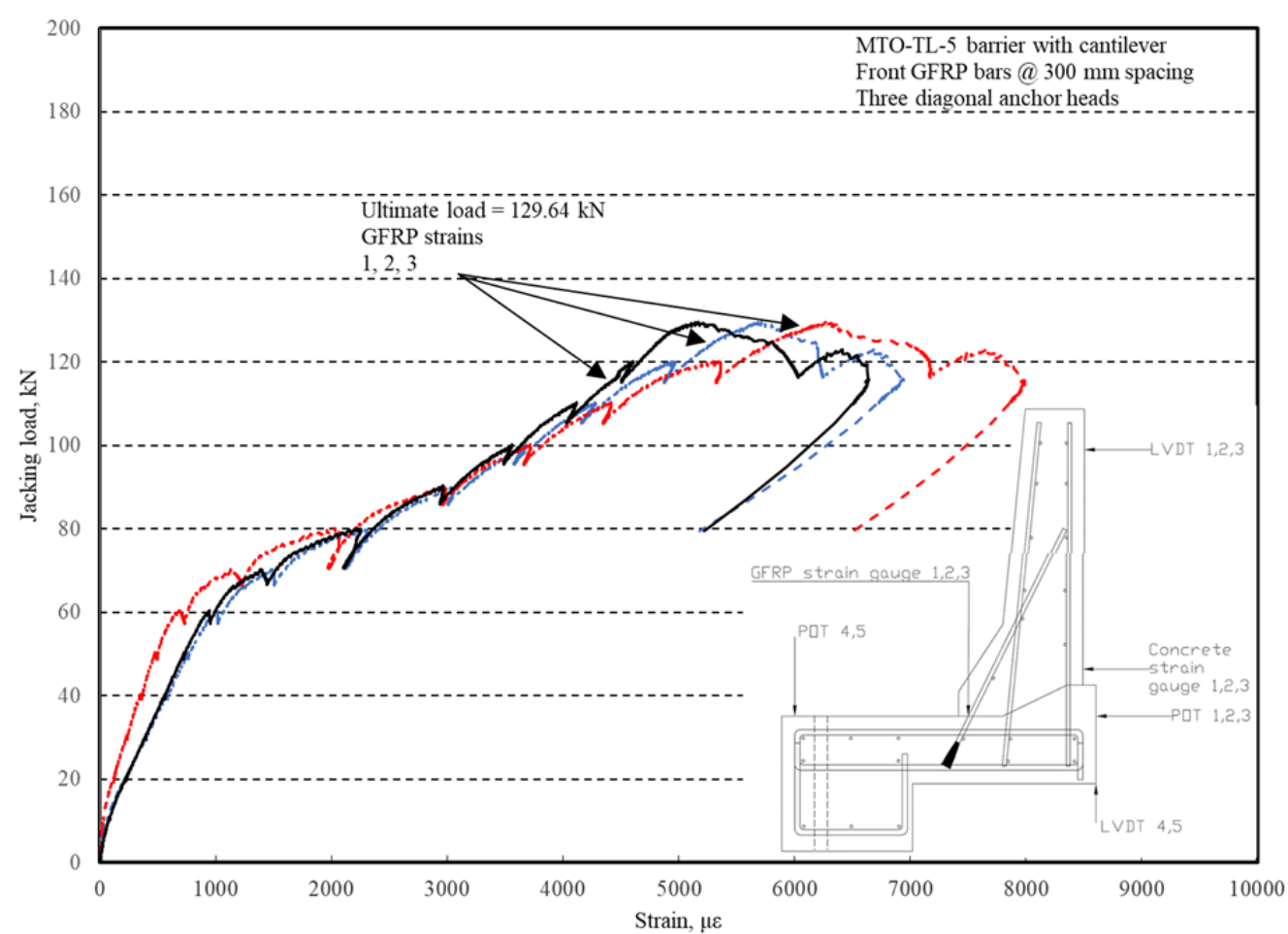

Figure 4.53: GFRP strain response of Barrier B-3 to increase in static load 


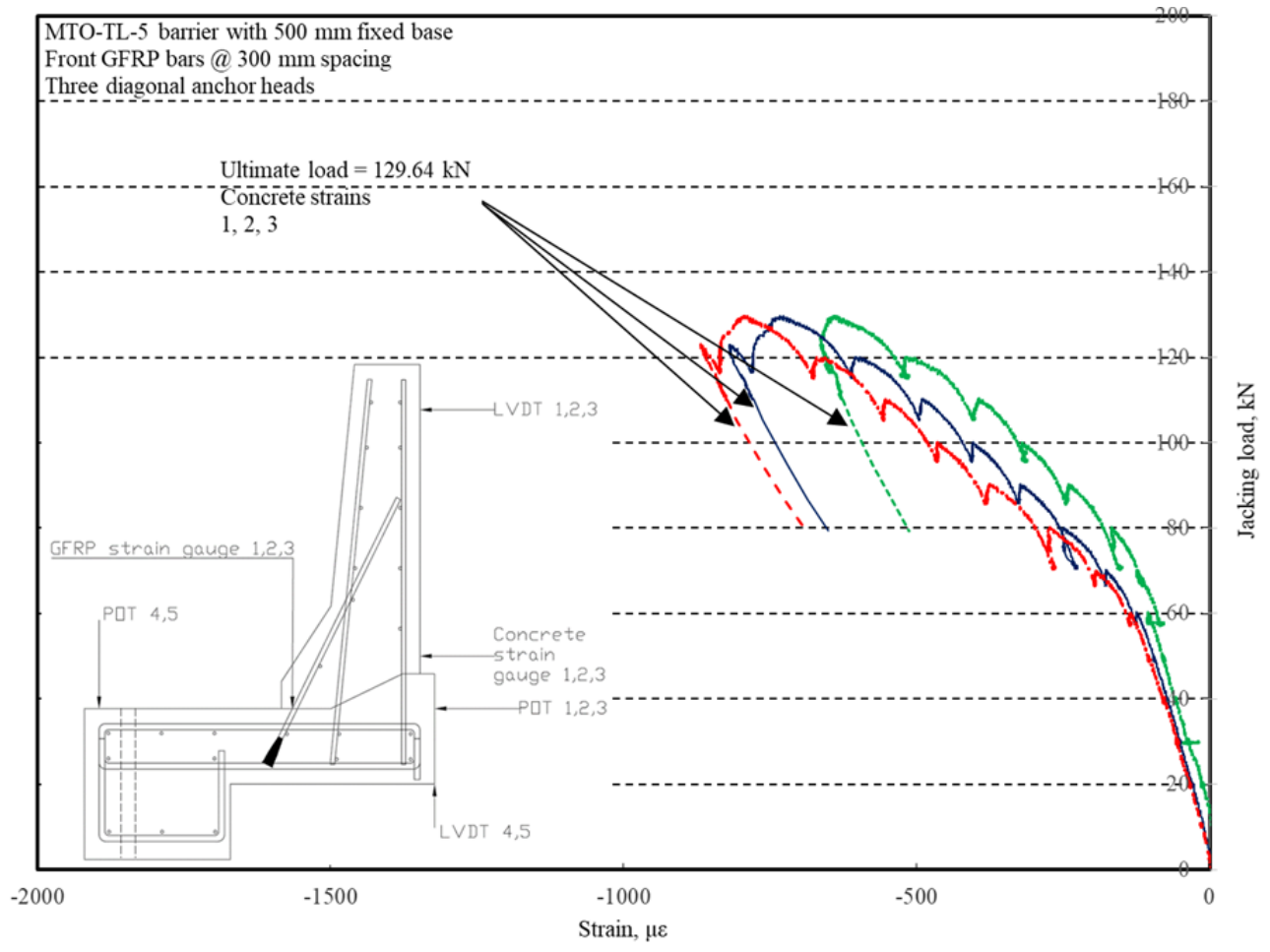

Figure 4.54: Concrete strain response of Barrier B-3 to increase in static load

\subsubsection{TL-5 Bridge Barrier Specimen B-4}

Figure 4.55 depicts the applied load-displacement relationship for specimen B-4 at exterior location. It can be observed that the average deck slab uplift and the horizontal movement at failure were 5.3 and $13.42 \mathrm{~mm}$, respectively. These values are greater than those recorded for other specimens as the threaded rod tightening was not as that for specimens B-1 and B-2. However, these values can be used at a later stage to obtain the net barrier lateral deflection. 
Table 4.10: Specimen B-4 averages of maximums

\begin{tabular}{|c|c|c|}
\hline Element & Value & Average \\
\hline \multirow{3}{*}{ Top displacement (mm) } & 70.97 & \multirow{3}{*}{66.76} \\
\hline & 66.03 & \\
\hline & 63.28 & \\
\hline \multirow{3}{*}{ Bottom displacement (mm) } & 13.48 & \multirow{3}{*}{13.42} \\
\hline & 13.38 & \\
\hline & 13.38 & \\
\hline \multirow{2}{*}{ Overhang (mm) } & 28.17 & \multirow{2}{*}{27.88} \\
\hline & 27.58 & \\
\hline \multirow{2}{*}{ Front uplift (mm) } & 5.48 & \multirow{2}{*}{5.30} \\
\hline & 5.13 & \\
\hline \multirow{2}{*}{ Concrete strain $(\mu \varepsilon)$} & -1060.00 & \multirow{2}{*}{-1083.00} \\
\hline & -1106.00 & \\
\hline \multirow{5}{*}{ GFRP strain $(\mu \varepsilon)$} & 6323.15 & \multirow{5}{*}{6116.32} \\
\hline & 5985.60 & \\
\hline & 7191.75 & \\
\hline & 5266.43 & \\
\hline & 5814.68 & \\
\hline Maximum load (kN) & \multicolumn{2}{|c|}{163.41} \\
\hline
\end{tabular}

It can be observed that the maximum lateral deflection of the barrier wall at failure is 66.76 $\mathrm{mm}$ while the vertical deflection of the deck slab cantilever is $27.88 \mathrm{~mm}$. Figure 4.56 depicts the tensile strains in the diagonal GFRP bars at the front face of the barrier. It can be observed that the average strain in the GFRP bars was $6116.32 \mu \varepsilon$ while the ultimate strain of the GFRP bars per the manufacturer's certification sheet is $15,000 \mu \varepsilon$. Figure 4.57 shows the load-concrete strain relationship close to the barrier-deck junction. It can be observed that the average concrete compressive strain at failure was $1083 \mu \varepsilon$ which is far below the ultimate concrete strain at failure of $3500 \mu \varepsilon$. The low GFRP and concrete strain values are attributed to the fact that GFRP-concrete anchorage failure occurred. Table 4.10 summarizes the critical experimental findings obtained from sensors. 


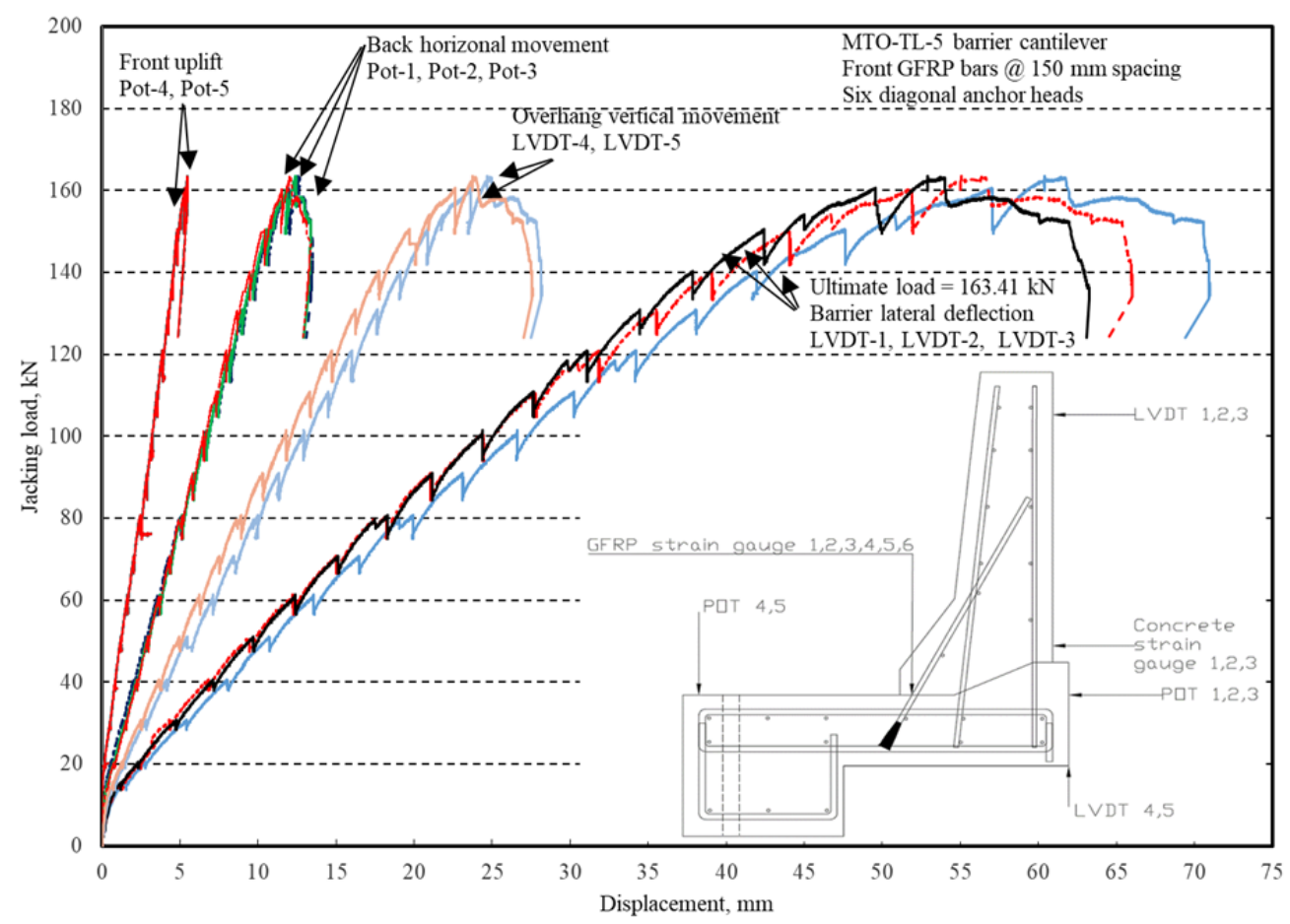

Figure 4.55: Displacement response of Barrier B-4 to increase in static load

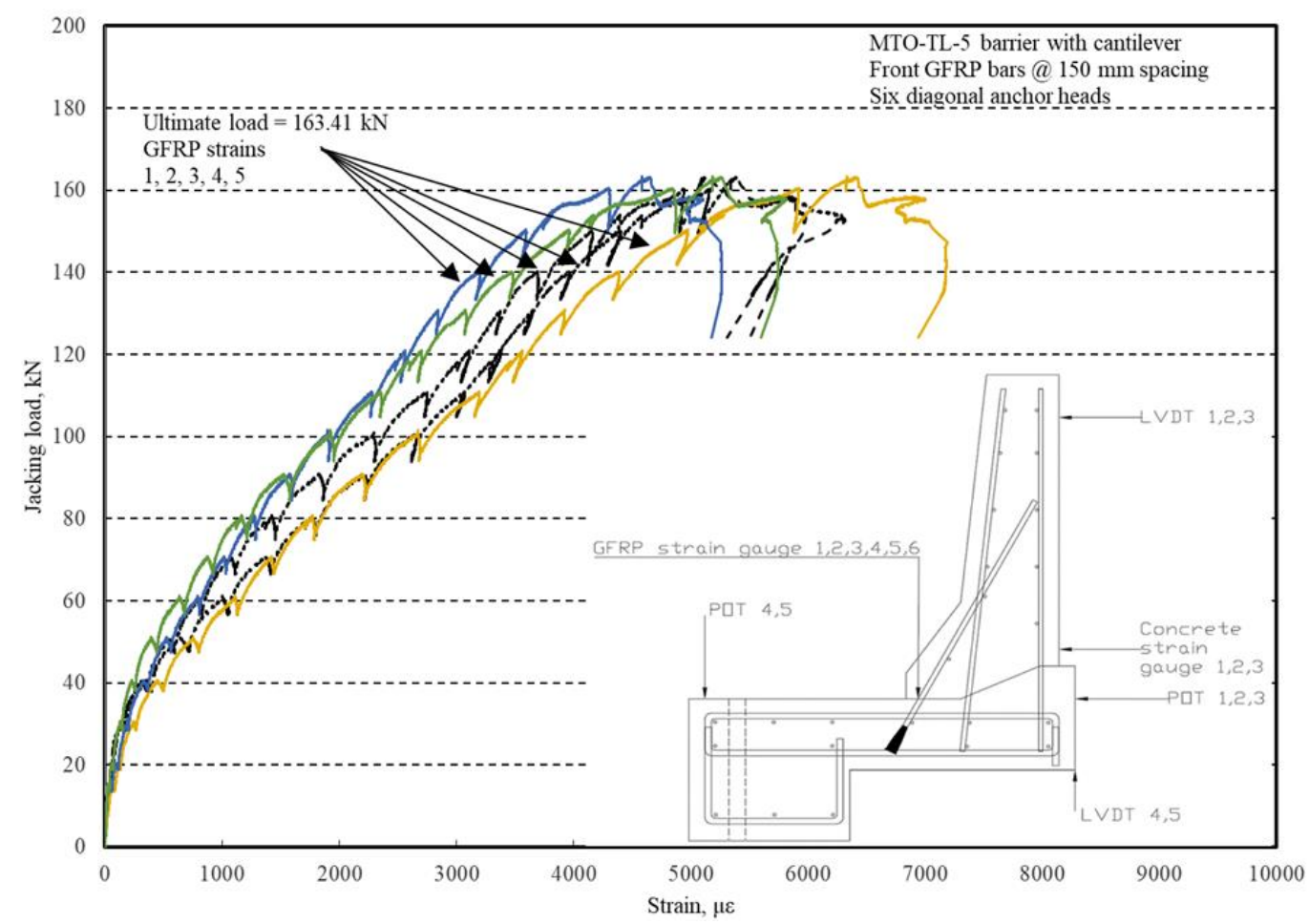

Figure 4.56: GFRP strain response of Barrier B-4 to increase in static load 


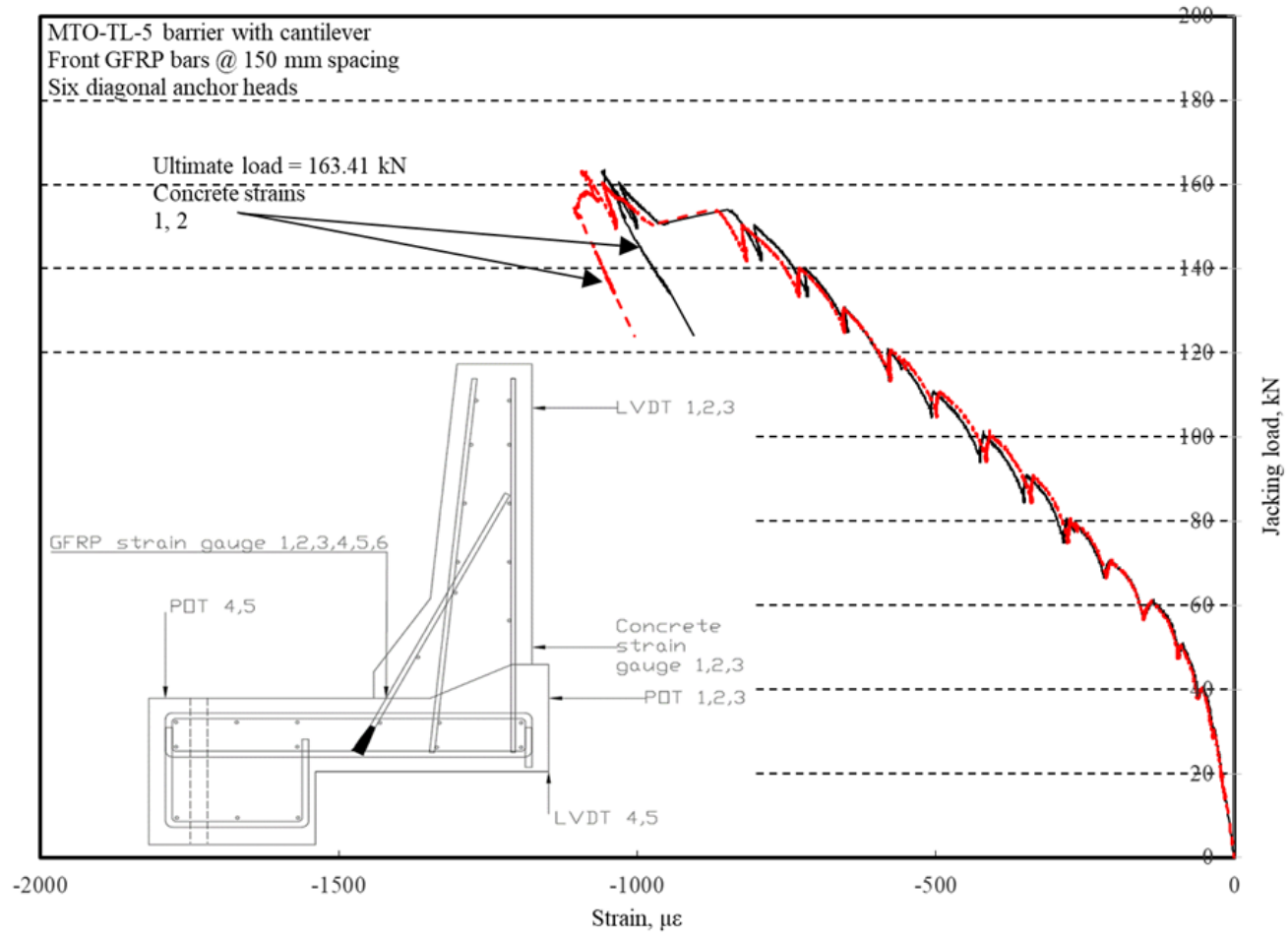

Figure 4.57: Concrete strain response of Barrier B-4 to increase in static load

\subsubsection{TL-5 Bridge Barrier Specimen B-5}

Figure 4.58 depicts the applied load-displacement relationship for specimen B-5 at interior location. It can be observed that the average deck slab uplift and the horizontal movement at failure were 0.97 and $0.73 \mathrm{~mm}$, respectively, which are considered very small. Also, it can be observed that the maximum lateral deflection of the barrier wall at failure is $8.92 \mathrm{~mm}$. Figure 4.59 depicts the tensile strains in the diagonal GFRP bars at the front face of the barrier. It can be observed that the average strain in the GFRP bars was $16,269 \mu \varepsilon$ while the ultimate strain of the GFRP bars per the manufacturer's certification sheet is $15,000 \mu \varepsilon$. Although the experimental ultimate strain is more than the designated GFRP bar ultimate strain in the manufacturer's data sheet, tensile rupture in the GFRP did not occur since design values specified by the manufacturer are based on statistical data that makes the bar characteristic tensile strength less than the mean value. Figure 4.60 shows the load-concrete strain relationship close to the barrier-deck junction. It can be observed that the average concrete compressive strain at failure was $893.33 \mu \varepsilon$ which is far below the ultimate concrete strain at failure of $3500 \mu \varepsilon$. The low GFRP and concrete strain values are attributed to concrete breakout and splitting close to the embedded bar location. Table 4.11 summarizes the critical experimental findings obtained from sensors. 
Table 4.11: Specimen B-5 averages of maximums

\begin{tabular}{|c|c|c|}
\hline Element & Value & Average \\
\hline \multirow{3}{*}{ Top displacement (mm) } & 9.536 & \multirow{3}{*}{8.92} \\
\hline & 15.9426 & \\
\hline & 1.2787 & \\
\hline \multirow{3}{*}{$\begin{array}{l}\text { Bottom displacement } \\
(\mathrm{mm})\end{array}$} & 1.3068 & \multirow{3}{*}{0.73} \\
\hline & 0.6212 & \\
\hline & 0.2567 & \\
\hline \multirow{2}{*}{ Front uplift (mm) } & 1.0796 & \multirow{2}{*}{0.97} \\
\hline & 0.8559 & \\
\hline \multirow{3}{*}{ Concrete strain $(\mu \varepsilon)$} & -1070 & \multirow{3}{*}{-893.33} \\
\hline & -961 & \\
\hline & -649 & \\
\hline \multirow{3}{*}{ GFRP strain $(\mu \varepsilon)$} & 17585.925 & \multirow{3}{*}{16268} \\
\hline & 16475.45 & \\
\hline & 14744.7 & \\
\hline Maximum load (kN) & \multicolumn{2}{|c|}{159.74} \\
\hline
\end{tabular}

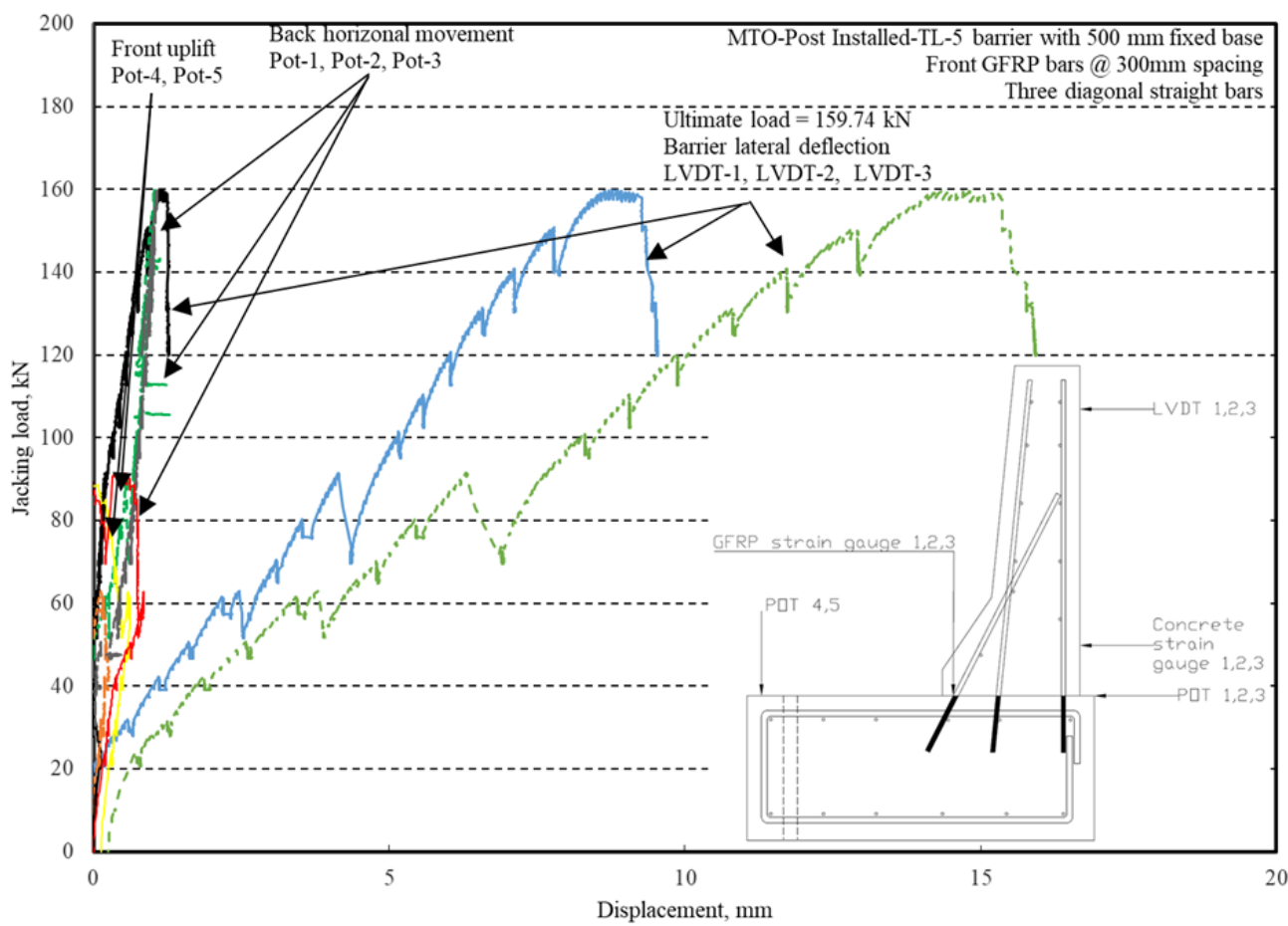

Figure 4.58: Displacement response of Barrier B-5 to increase in static load 


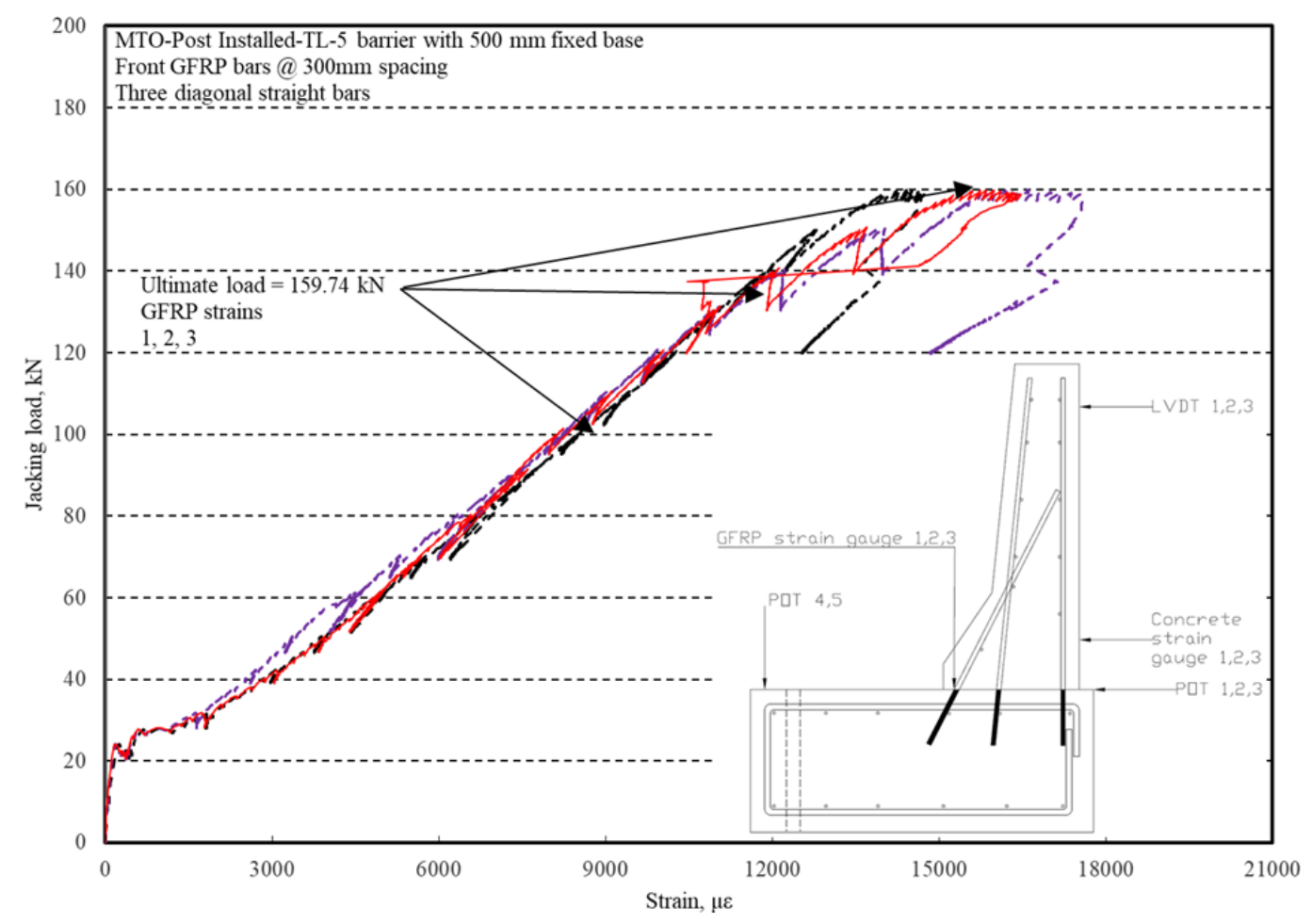

Figure 4.59: GFRP strain response of Barrier B-5 to increase in static load

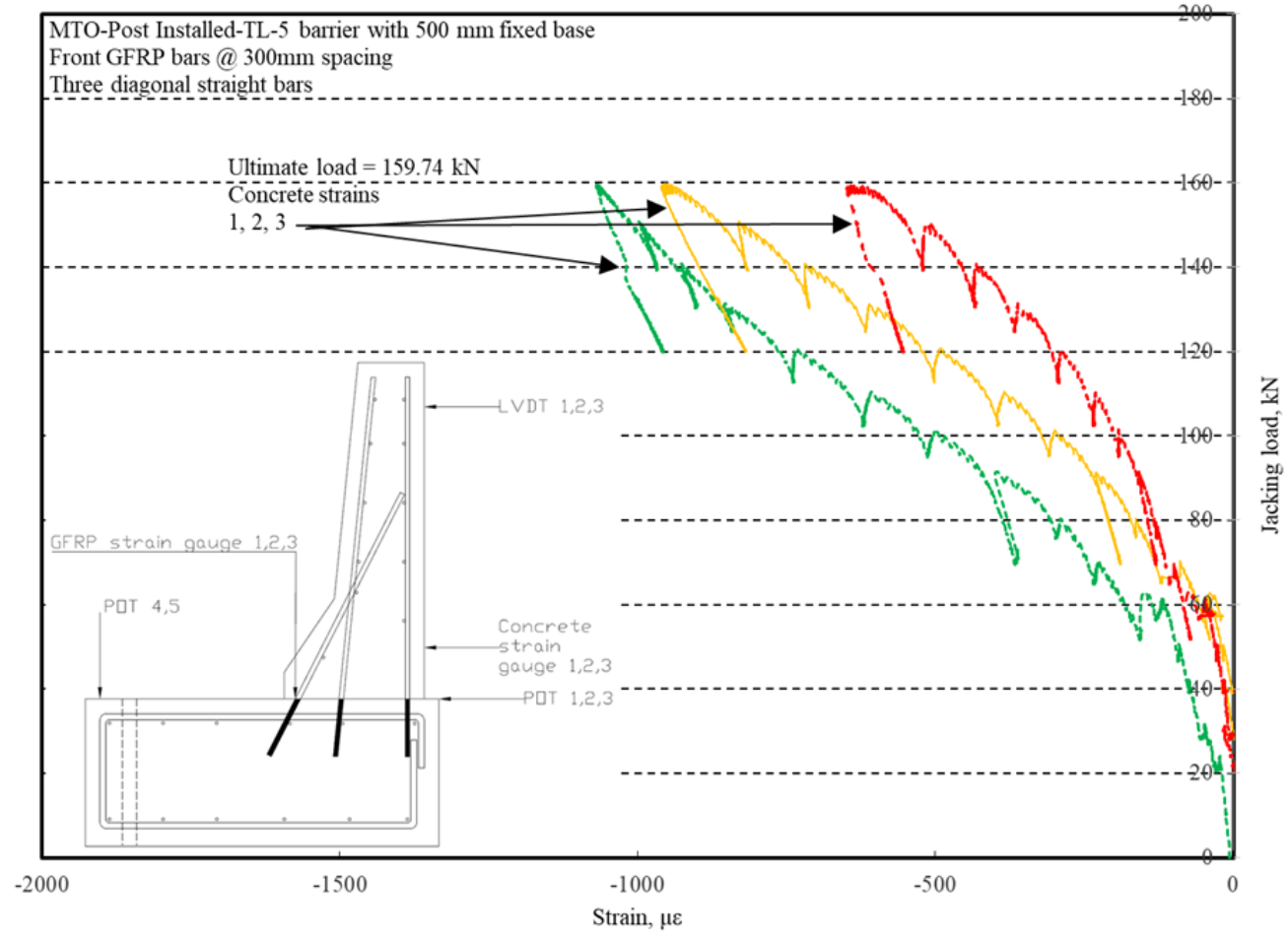

Figure 4.60: Concrete strain response of Barrier B-5 to increase in static load 


\subsubsection{TL-5 Bridge Barrier Specimen B-6}

Figure 4.61 depicts the applied load-displacement relationship for specimen B-6 at exterior location. It can be observed that the average deck slab uplift and the horizontal movement at failure were 0.96 and $3.46 \mathrm{~mm}$, respectively, which are considered very small. Also, it can be observed that the maximum lateral deflection of the barrier wall at failure is $11.28 \mathrm{~mm}$. Figure 4.62 depicts the tensile strains in the diagonal GFRP bars at the front face of the barrier. It can be observed that the average strain in the GFRP bars was $7225.97 \mu \varepsilon$ while the ultimate strain of the GFRP bars per the manufacturer's certification sheet is 15,000 $\mu \varepsilon$. Figure 4.63 shows the loadconcrete strain relationship close to the barrier-deck junction. It can be observed that the average concrete compressive strain at failure was $701.33 \mu \varepsilon$ which is far below the ultimate concrete strain at failure of $3500 \mu \varepsilon$.

Table 4.12: Specimen B-6 averages of maximums

\begin{tabular}{|c|c|c|}
\hline Element & Value & Average \\
\hline \multirow{3}{*}{ Top displacement $(\mathrm{mm})$} & 11.69 & \multirow{3}{*}{11.28} \\
\hline & 7.43 & \\
\hline & 14.72 & \\
\hline \multirow{3}{*}{$\begin{array}{l}\text { Bottom displacement } \\
(\mathrm{mm})\end{array}$} & 5.58 & \multirow{3}{*}{3.46} \\
\hline & 1.70 & \\
\hline & 3.09 & \\
\hline \multirow{2}{*}{ Front uplift (mm) } & 0.10 & \multirow{2}{*}{0.96} \\
\hline & 1.81 & \\
\hline \multirow{3}{*}{ Concrete strain $(\mu \varepsilon)$} & -719.00 & \multirow{3}{*}{-701.33} \\
\hline & -900.00 & \\
\hline & -485.00 & \\
\hline \multirow{6}{*}{ GFRP strain $(\mu \varepsilon)$} & 9482.58 & \multirow{6}{*}{7225.97} \\
\hline & 6167.28 & \\
\hline & 6385.50 & \\
\hline & 6685.43 & \\
\hline & 8483.90 & \\
\hline & 6151.15 & \\
\hline Maximum load (kN) & \multicolumn{2}{|c|}{186.74} \\
\hline
\end{tabular}




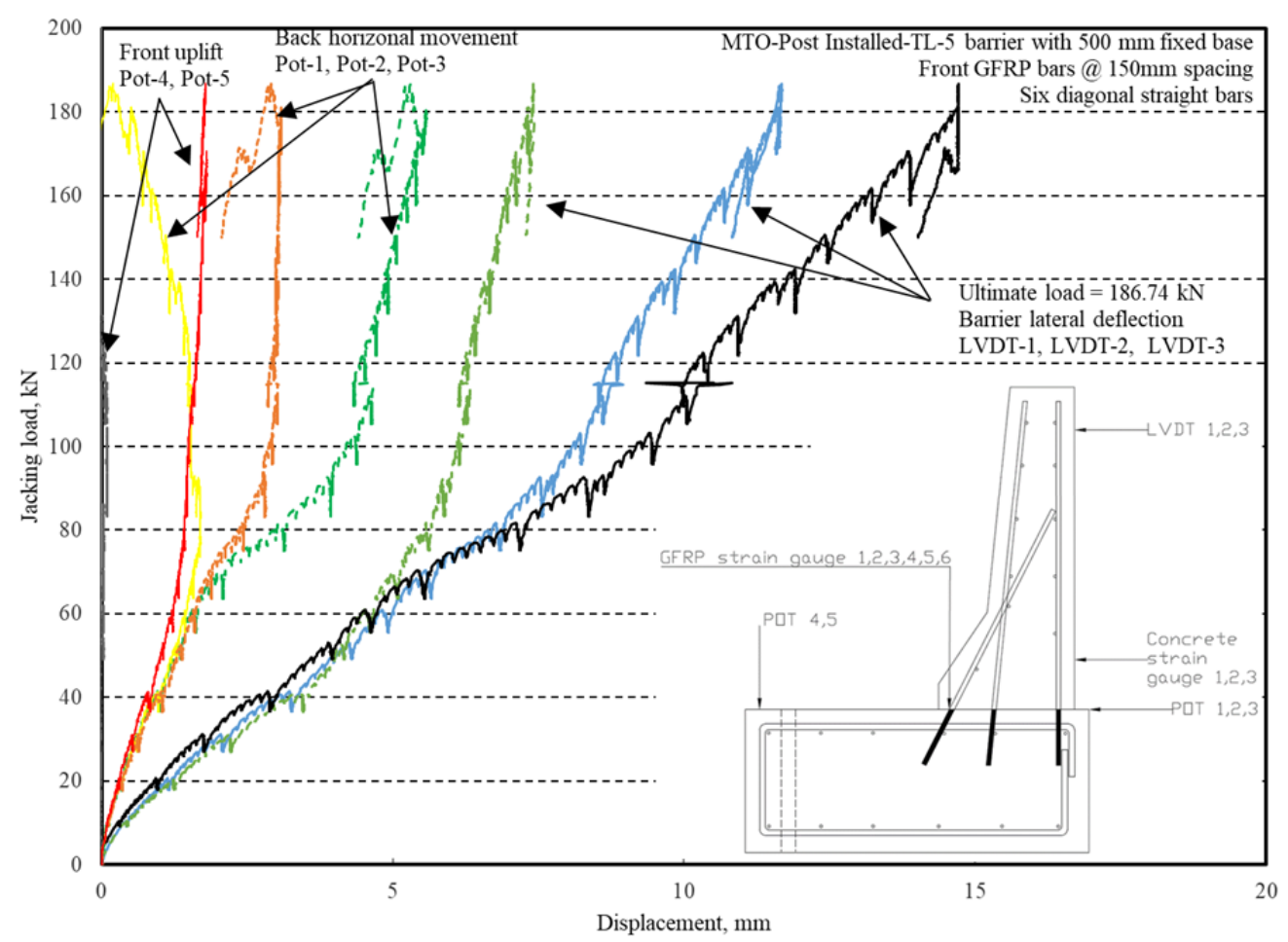

Figure 4.61: Displacement response of Barrier B-6 to increase in static load

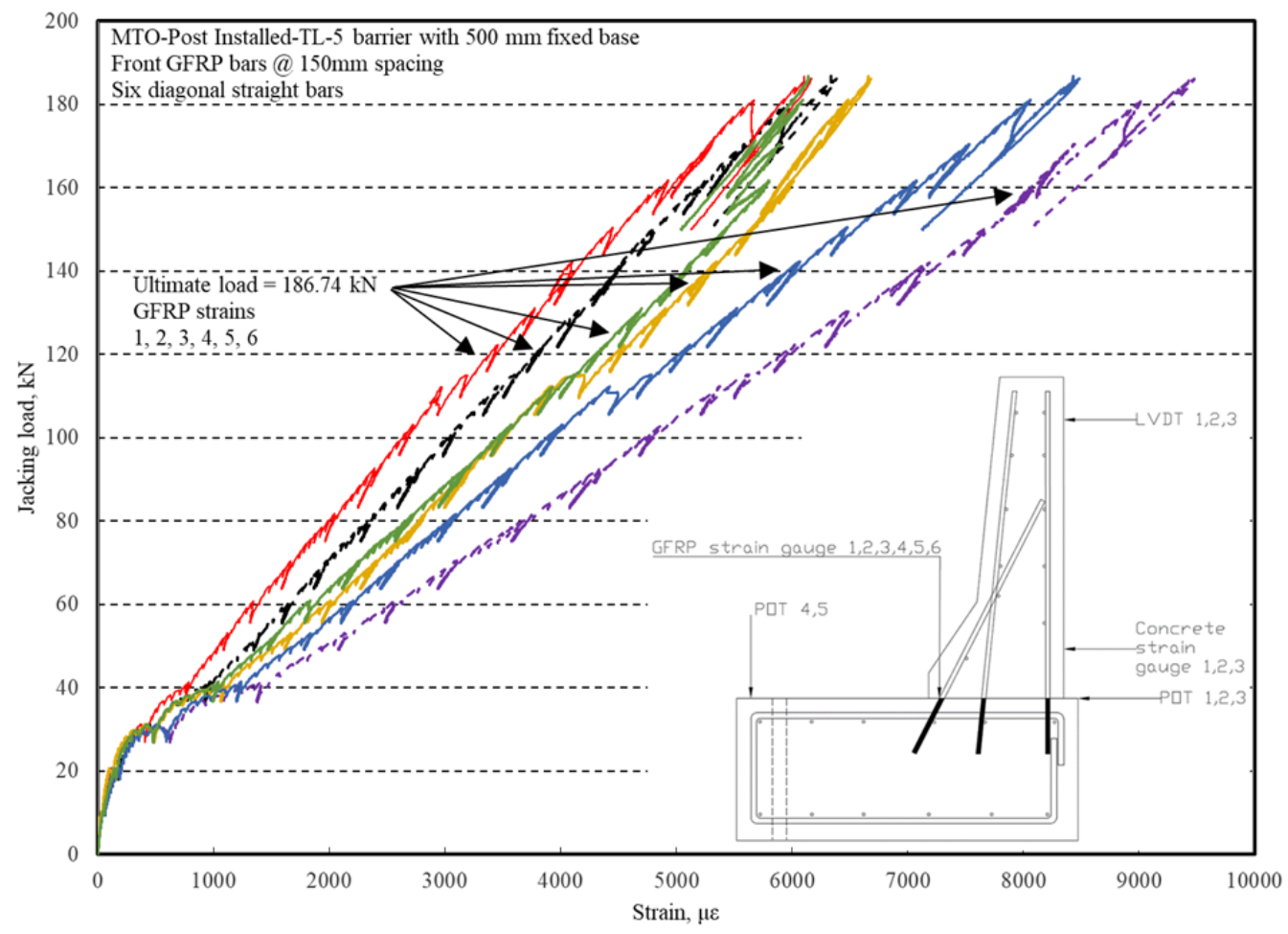

Figure 4.62: GFRP strain response of Barrier B-6 to increase in static load 


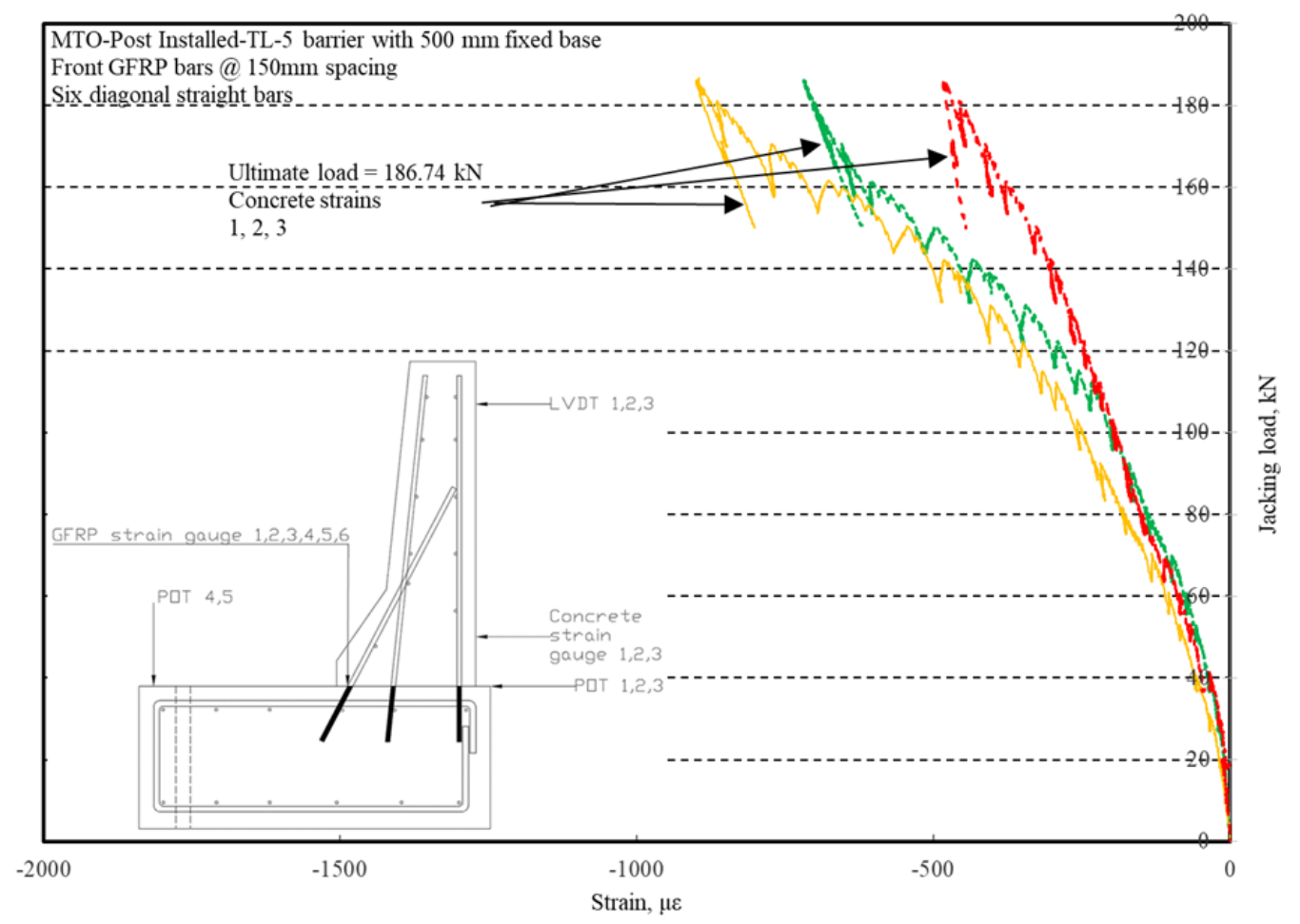

Figure 4.63: Concrete strain response of Barrier B-6 to increase in static load

\subsubsection{Barrier Maximum Moment Associated with Diagonal Tension Crack in Deck Cantilever}

Khederzadeh (2014) conducted cross-sectional analysis of cantilevered barrier specimens to develop formulas to better predict failure of the barrier specimens due to diagonal tension crack in the deck slab cantilever at the barrier-deck junction. The utilized methodology was adopted from Matta and Nanni's research (2009). Khederzadeh (2014) introduced new formulas to eliminate the iterative process proposed by Matta and Nanni while maintaining good correlation between the experimental and analytical results. Khederzadeh (2014) analyzed the internal forces and used diagonal tension crack length and angle data collected from experimental finding to develop the formulas. Figure 4.64 outlines the internal forces that are present in the barrier wall-deck junction. Subsequent to the figure are the formulas used in Khederzadeh (2014) derivation for the new cracking moment to predict failure of the barriers. 


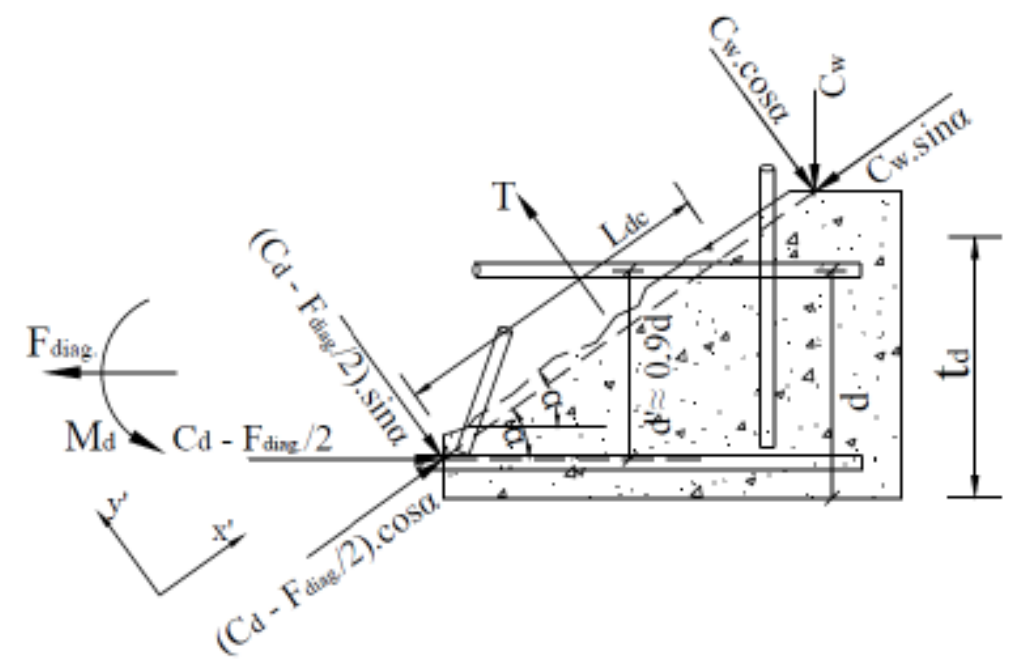

Figure 4.64: Internal forces in the barrier deck-wall junction (Khederzadeh, 2014)

Khederzadeh (2014) derived the cracking moment formula as follows.

$$
\begin{array}{ll}
f_{r}=0.6 \lambda \sqrt{f_{c}^{\prime}} & f_{r}=\text { concrete modulus of rupture } \\
& \lambda=\text { concrete density factor } \\
T=\frac{2}{3} f_{r} \cdot b \cdot L_{d c} & f^{\prime}{ }_{c}=\text { concrete compressive strength } \\
& T=\text { perpendicular tensile force on the crack } \\
& b=\text { longitudinal width of barrier wall } \\
F_{\text {diag }}=\frac{T \cdot \sin \alpha}{A-0.5} & L_{d c}=\text { diagonal tension crack length } \\
& F_{\text {diag }}=\text { applied transverse load on wall } \\
A=\frac{H_{e}+0.5 t_{d}+0.5 d^{\prime}}{d^{\prime}{ }_{d}} & \alpha=\text { inclination of diagonal tension crack } \\
& A=\text { a constant value } \\
C_{d}=F_{\text {diag }} \cdot A & H_{e}=\text { height of transverse load from the deck } \\
& t_{d}=\text { deck thickness } \\
C_{w}=\frac{F_{\text {diag }}(A-0.5)}{\tan \alpha} & d_{d}=\text { effective depth of deck } \\
& d_{d}^{\prime}=\text { distance between tension and } \\
& \text { compression reinforcement }\left(\approx 0.9 d_{d}\right) \\
M_{d, c r}=0.6 \cdot f_{r} \cdot b \cdot L_{d c} \cdot d_{d} \cdot \sin \alpha & C_{d}=\text { compression force in the deck } \\
& C_{w}=\text { compression force in the wall } \\
& M_{d, c r}=\text { cracking moment in the deck } \\
&
\end{array}
$$


When Khederzadeh (2014) calculated the cracking moment, he considered a crack length between the straight vertical bars (on the front face) to the top right corner of longitudinal and vertical bar intersection in the deck, as shown in Figure 4.64. When comparing experimental results achieved in this research, results appear to indicate a crack length propagating from the top right concrete construction joint which extends down to the bottom left, where the anchorheaded bar ends. The experimental crack results are shown in Figures 4.65 and 4.66. Khederzadeh (2014) derivation was used in experimental results obtained in this phase to analyze correlation between the analytical methods vs. experimental. However, crack length and angle was determined analytically without measuring from the tested sample. It should be noted that the angle and crack length were taken from the end of the anchor-headed GFRP bar to the concrete construction joint. This is showcased in Figure 4.68 and 4.69 .

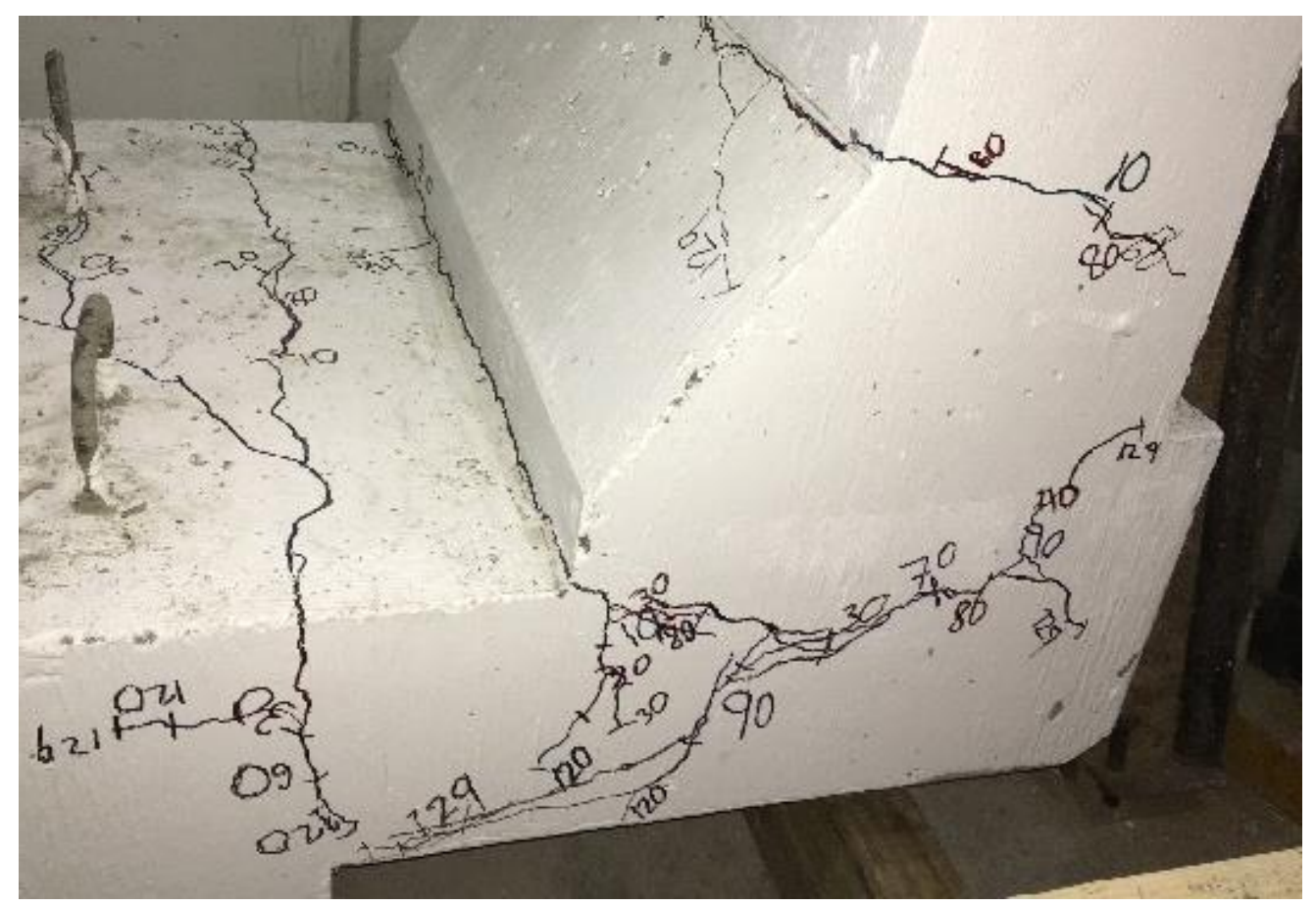

Figure 4.65: Barrier B-3- Interior location cantilever; diagonal cracking is evident in areas and lengths mentioned above 


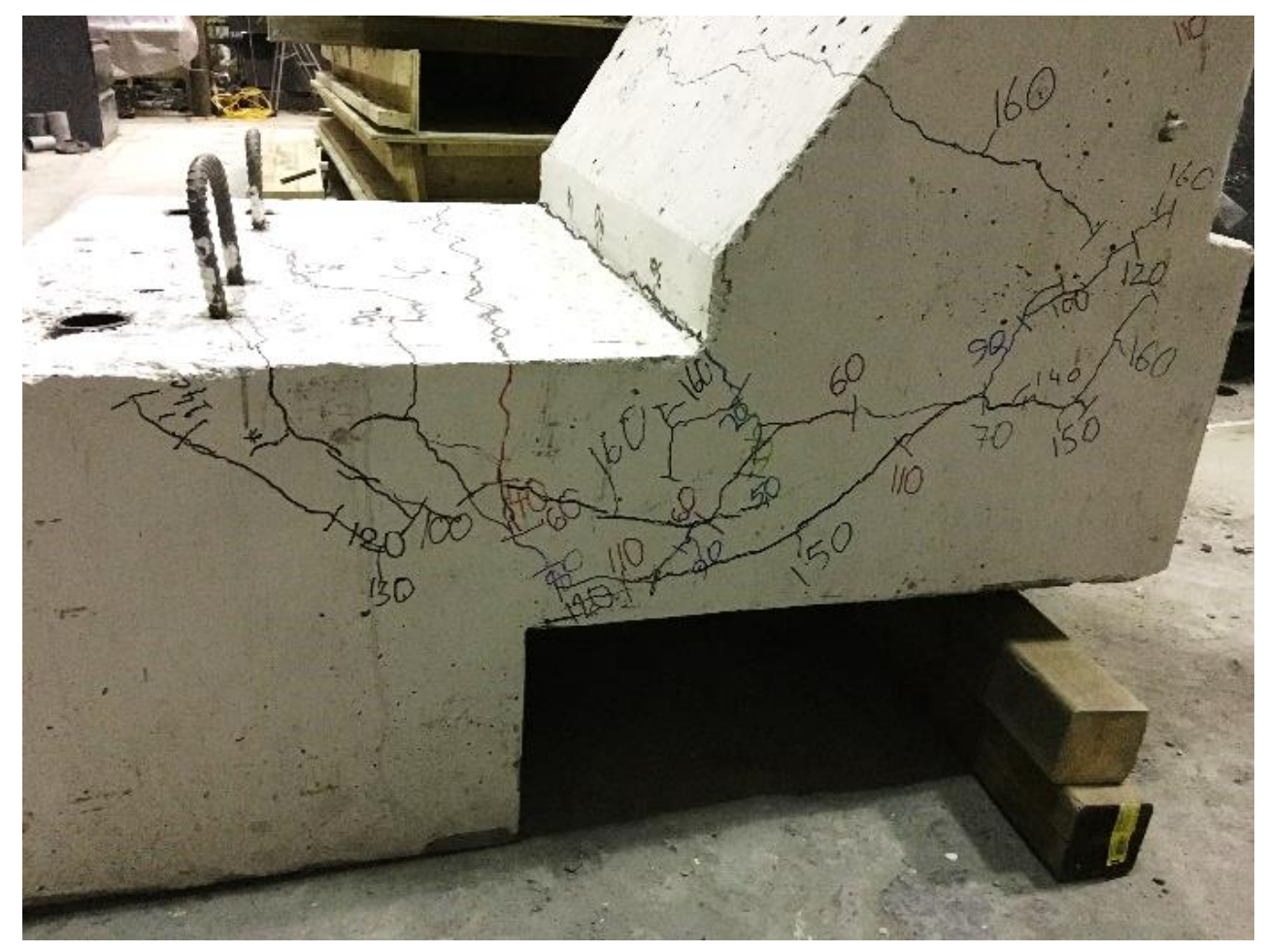

Figure 4.66: Barrier B-4 exterior location; similar diagonal cracking is visible 


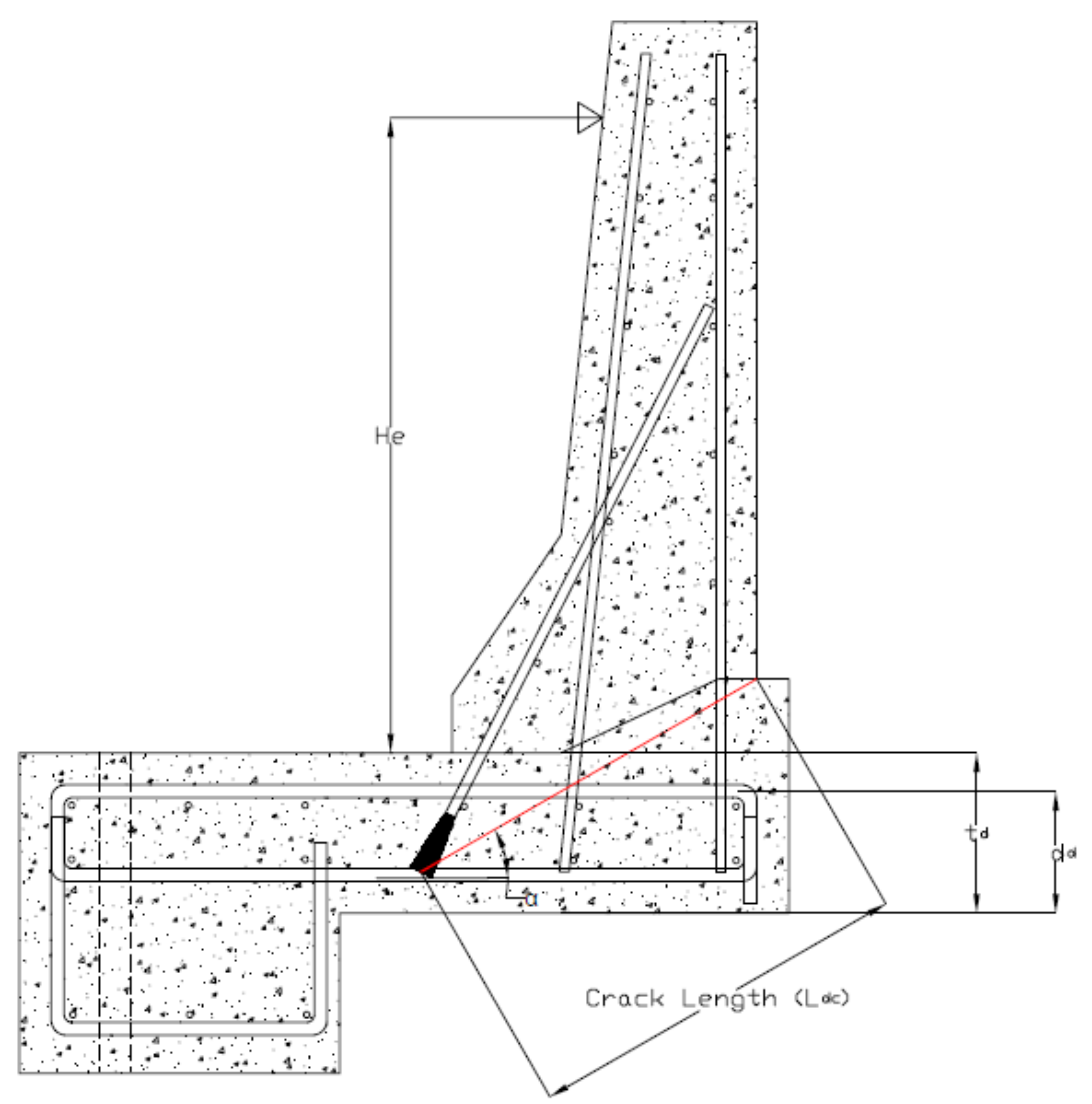

Figure 4.67: Red line outlines the crack length to be used in analysis for this research

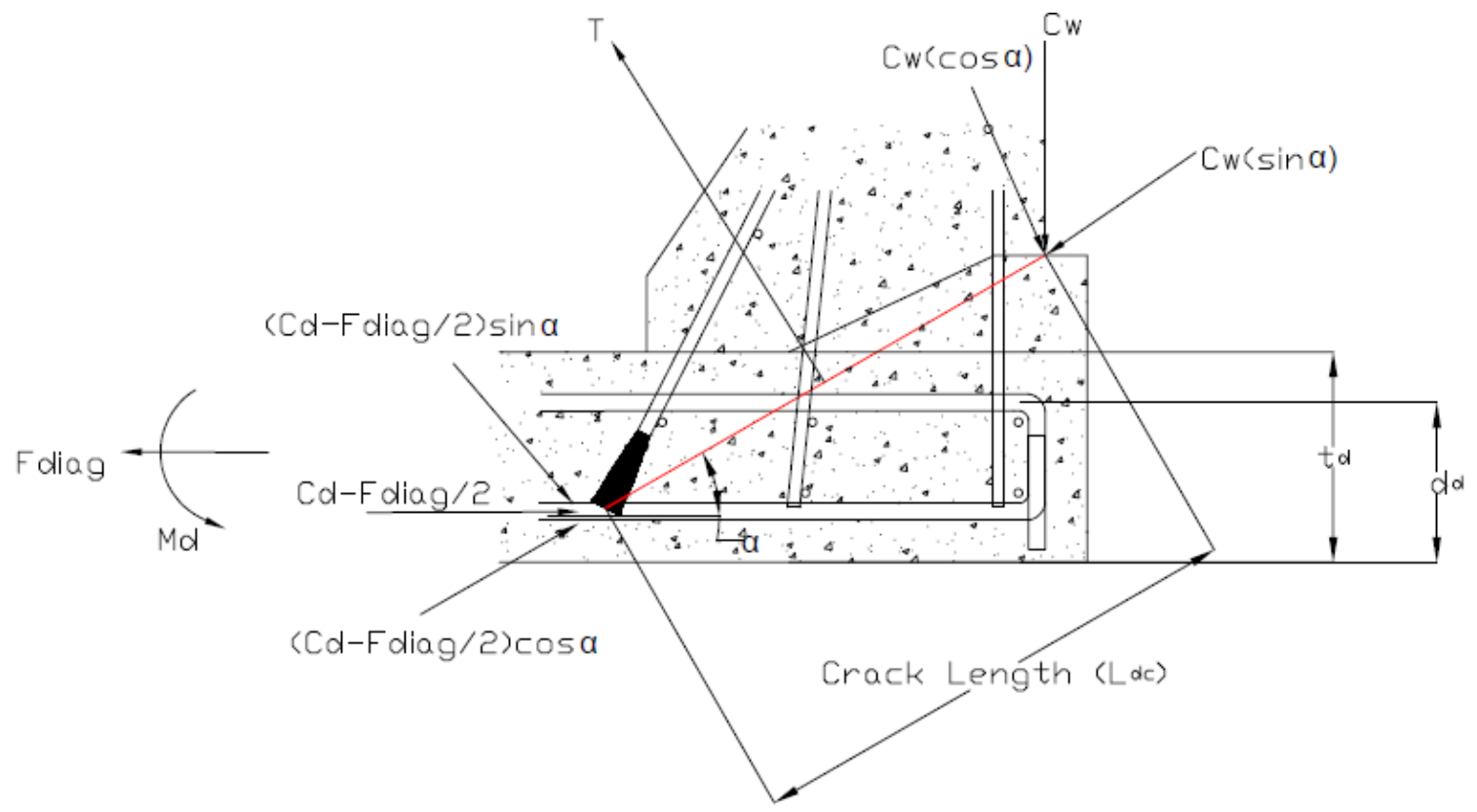

Figure 4.68: A close up of the deck-wall junction along with internal forces 


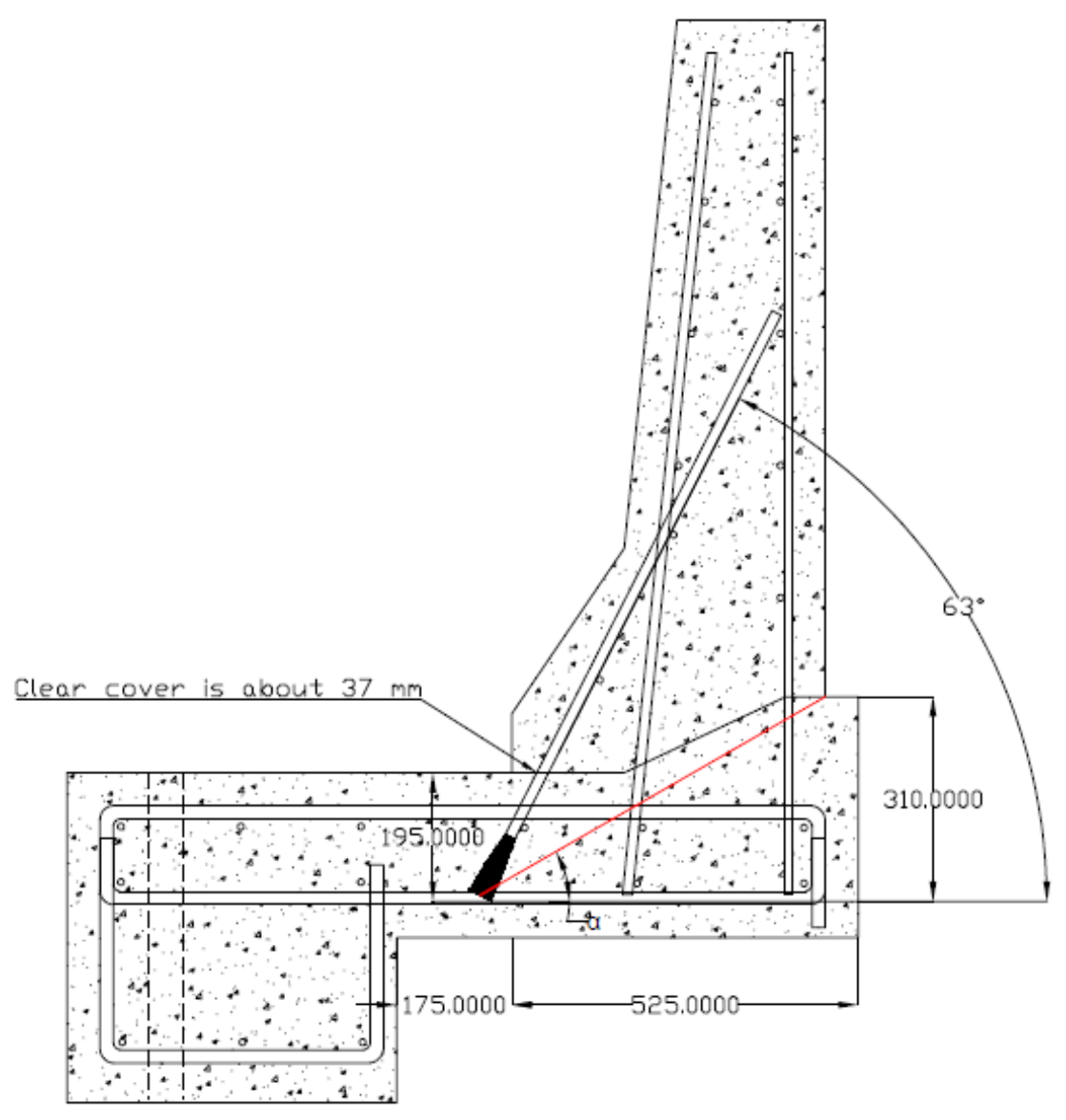

Figure 4.69: Dimensions necessary for crack length calculation

Without using experimental data for crack length and angle information, the following calculations must first be conducted. Preliminary information is already provided in barrier specs. Figure 4.69 showcases some of the factors needed for these calculations.

Firstly, the horizontal length between the anchor head and the point at which the bar enters the deck section should be determined (point where development length begins to occur). Using simple trigonometric ratios, this distance is $99.36 \mathrm{~mm}$.

$$
\text { horizontal length in embedment depth of headed bar }=\frac{195}{\tan 63}=99.36 \mathrm{~mm}
$$

Knowing that the rear step protruding at the back of the barrier wall is $50 \mathrm{~mm}$, and the clear cover of the headed GFRP bar at the deck-wall junction being about $37 \mathrm{~mm}$, the vertical length (rise) of the crack is about $310 \mathrm{~mm}$, the horizontal length (run) of the crack is about:

Horizontal length of diagonal tension crack $=525-50+(99.36-37)=537.36 \mathrm{~mm}$ 
Using trigonometric ratios once again, the angle and crack length of interest may now be found.

$$
\begin{gathered}
\alpha=\tan ^{-1}\left(\frac{310}{537.36}\right)=29.98^{\circ} \cong 30^{\circ} \\
L_{d c}=\frac{310}{\sin 30}=620 \mathrm{~mm}
\end{gathered}
$$

Having determined the two primary constants for the analysis, the formulas from the CHBDC, AASHTO LRFD (2014), and Khederzadeh (2014) may now be applied to see the correlation between the analytical prediction of failure force and moment versus the experimental.

$$
\begin{aligned}
& \alpha=30^{\circ} \\
& L_{d c}=620 \mathrm{~mm} \\
& b=900 \mathrm{~mm} \\
& H_{e}=990 \mathrm{~mm} \\
& t_{d}=250 \\
& d_{d}^{\prime}=0.9 d_{d}=171 \mathrm{~mm} \\
& =250 \text { (deck thickness) } \\
& \text { - } 10 \text { (half of the bar diameter) } \\
& \lambda=1 \\
& {f^{\prime}}^{\prime}{ }_{, B-3}=32.95 \mathrm{MPa} \\
& f^{\prime}{ }_{C, B-4}=43.57 \mathrm{MPa}
\end{aligned}
$$$$
d_{d}
$$$$
\text { - } 50 \text { (clear cover) }
$$$$
=190 \mathrm{~mm}
$$

*Subscripts B-3 and B-4 indicate the barrier specimen the result pertains to.

(1)

$f_{r}=0.6 \lambda \sqrt{f^{\prime}}$

$f_{r, B-3}=0.6(1) \sqrt{32.95}=3.44$

$f_{r, B-4}=0.6(1) \sqrt{43.57}=3.96$

(2)

$T=\frac{2}{3} f_{r} \cdot b \cdot L_{d c}$

$T_{B-3}=\frac{2}{3}(3.44) \cdot(900) \cdot(620)=1,279,680 \mathrm{~N}$

$T_{B-4}=\frac{2}{3}(3.96) \cdot(900) \cdot(620)=1,473,120 \mathrm{~N}$

(3) 


$$
\begin{aligned}
& A=\frac{H_{e}+0.5 t_{d}+0.5{d^{\prime}}_{d}}{d_{d}^{\prime}} \\
& A=\frac{990+0.5(250)+0.5(171)}{171}=7.02
\end{aligned}
$$

(4)

$$
\begin{aligned}
& F_{\text {diag }}=\frac{T \cdot \sin \alpha}{A-0.5} \\
& F_{\text {diag }, B-3}=\frac{(1,279,680) \cdot \sin 30}{7.02-0.5}=98,134.97 \mathrm{~N} \\
& F_{\text {diag }, B-4}=\frac{(1,473,120) \cdot \sin 30}{7.02-0.5}=112,969.33 \mathrm{~N}
\end{aligned}
$$

(5)

$$
\begin{aligned}
& C_{d}=F_{d i a g} \cdot A \\
& C_{d, B-3}=(98,134.97) \cdot(7.02)=688,907.49 N \\
& C_{d, B-4}=(112,969.33) \cdot(7.02)=793,044.70 \mathrm{~N}
\end{aligned}
$$

(6)

$$
\begin{aligned}
& C_{w}=\frac{F_{\text {diag }}(A-0.5)}{\tan \alpha} \\
& C_{w, B-3}=\frac{(98,134.97)(7.02-0.5)}{\tan 30}=1,108,235.40 \mathrm{~N} \\
& C_{w, B-4}=\frac{(112,969.33)(A-0.5)}{\tan 30}=1,275,759.40 \mathrm{~N}
\end{aligned}
$$

(7)

$$
\begin{aligned}
& M_{d, c r}=0.6 \cdot f_{r} \cdot b \cdot L_{d c} \cdot d_{d} \cdot \sin \alpha \\
& M_{d, c r, B-3}=0.6 \cdot(3.44) \cdot(900) \cdot(620) \cdot(190) \cdot \sin 30=109,412,640 \mathrm{~N} . \mathrm{mm} \\
& M_{d, c r, B-4}=0.6 \cdot(3.96) \cdot(900) \cdot(620) \cdot(190) \cdot \sin 30=125,951,760 \mathrm{~N} . \mathrm{mm}
\end{aligned}
$$

Table 4.13 provides a summary of all the results calculated above as well as correlation between these results and the experimental findings. The last column in the table provides the ratio between the maximum moment reached experimentally at the barrier-deck junction and the maximum moment that causes diagonal tension crack in the deck. A ratio or 1 or more than 1 would indicates that the analytical method is a good tool for estimating the maximum moment 
that can be carried by the barrier-deck junction to prevent diagonal tension crack in the deck at the same location. It should be noted that the analytical method was done using characteristic values of concrete strength. The characteristic values are slightly lower than the simple average of the compressive strength obtained by testing concrete cylinders. By using non-characteristic values, the results would correlate better due to increased strength analytically.

Table 4.13: Summary of results and comparing with experimental findings

\begin{tabular}{|l|l|l|l|l|l|l|l|l|l|}
\hline $\begin{array}{l}\text { Barrier } \\
\text { specimen }\end{array}$ & $\mathrm{T}(\mathrm{kN})$ & $\begin{array}{l}\mathrm{F}_{\text {diag }} \\
(\mathrm{kN})\end{array}$ & $\mathrm{C}_{\mathrm{d}}(\mathrm{kN})$ & $\mathrm{C}_{\mathrm{w}}(\mathrm{kN})$ & $\begin{array}{l}\mathrm{M}_{\mathrm{d}, \mathrm{cr}} \\
(\mathrm{kNm})\end{array}$ & $\begin{array}{l}\mathrm{F}_{\exp } \\
(\mathrm{kN})\end{array}$ & $\begin{array}{l}\mathrm{M}_{\mathrm{d}, \exp } \\
(\mathrm{kNm})\end{array}$ & $\begin{array}{l}\mathrm{F}_{\text {exp }} / \\
\mathrm{F}_{\text {diag }}\end{array}$ & $\begin{array}{l}\mathrm{M}_{\mathrm{d}, \exp } / \\
\mathrm{M}_{\mathrm{d}, \mathrm{cr}}\end{array}$ \\
\hline $\mathrm{B}-3$ & $1,279.68$ & 98.13 & 688.91 & $1,108.24$ & 109.41 & 144.04 & 142.60 & 1.46 & 1.30 \\
\hline $\mathrm{B}-4$ & $1,473.12$ & 112.97 & 793.04 & $1,275.76$ & 125.95 & 181.57 & 179.75 & 1.60 & 1.42 \\
\hline
\end{tabular}

\subsection{Discussion of the Load Carrying Capacity of the Studied Barrier-Deck System in Phase 2}

Table 4.14 summarizes the experimental findings including the factor of safety in design of such barrier-deck junction. This factor of safety represents the ratio between the experimental failure moment to the design moment specified in CHBDC Commentaries of 2006. However, CHBDC (CSA, 2014) specifies that the designer shall consider the environmental conditions and deterioration mechanisms for the FRP reinforcement. Thus, a 0.75 resistance factor for design is proposed herein to apply to the experimental findings as given in CHBDC Commentaries. Table 4.14 provides a revised set of the factor of safety in design of these barrier specimens by applying a resistance factor of 0.75 . Still, all factors of safety are more than 1 which indicates a successful design of the barrier-deck junction based on experimental testing. 
Table 4.14: Experimental results benchmarked against CHBDC requirements and safety factors

\begin{tabular}{|c|c|c|c|c|c|c|}
\hline \multirow{3}{*}{ Criteria } & \multicolumn{6}{|c|}{ Specimen } \\
\hline & $\begin{array}{l}\text { Fixed base } \\
\text { - interior }\end{array}$ & $\begin{array}{l}\text { Fixed base } \\
\text { - exterior }\end{array}$ & $\begin{array}{l}\text { Cantilever } \\
\text { - interior }\end{array}$ & $\begin{array}{l}\text { Cantilever } \\
\text { - exterior }\end{array}$ & $\begin{array}{c}\text { Post- } \\
\text { installed } \\
\text {-interior }\end{array}$ & $\begin{array}{l}\text { Post- } \\
\text { installed - } \\
\text { exterior }\end{array}$ \\
\hline & B-1 & B-2 & B-3 & B-4 & B-5 & B-6 \\
\hline $\begin{array}{c}\text { Experimental failure } \\
\text { load }(\mathrm{kN})\end{array}$ & 168.63 & 182.63 & 129.64 & 163.41 & 159.74 & 186.74 \\
\hline $\begin{array}{l}\text { Experimental failure } \\
\text { load }(\mathrm{kN} / \mathrm{m})\end{array}$ & 187.37 & 202.92 & 144.04 & 181.57 & 177.49 & 207.49 \\
\hline $\begin{array}{l}\text { Experimental } \\
\text { resisting moment } \\
(\mathrm{kN} . \mathrm{m} / \mathrm{m})\end{array}$ & 185.49 & 200.89 & 142.60 & 179.75 & 175.71 & 205.41 \\
\hline $\begin{array}{l}2006 \text { CHBDC design } \\
\text { moment (kN.m/m) }\end{array}$ & 83.00 & 102.00 & 83.00 & 102.00 & 83.00 & 102.00 \\
\hline $\begin{array}{c}\text { Factor of safety } \\
\text { (experimental failure } \\
\text { moment/ CHBDC } \\
\text { design moment) }\end{array}$ & 2.23 & 1.97 & 1.72 & 1.76 & 2.12 & 2.01 \\
\hline $\begin{array}{c}\text { Factor of safety } \\
\text { (experimental failure } \\
\text { moment/ CHBDC } \\
\text { design moment) } \\
\text { with } 0.75 \text { durability } \\
\text { factor }\end{array}$ & 1.68 & 1.48 & 1.29 & 1.32 & 1.59 & 1.51 \\
\hline $\begin{array}{c}\text { Top front } \\
\text { displacement }(\mathrm{mm})\end{array}$ & 26.32 & 23.74 & 44.75 & 66.76 & 8.92 & 11.28 \\
\hline $\begin{array}{c}\text { Bottom back } \\
\text { displacement }(\mathrm{mm})\end{array}$ & 3.81 & 4.27 & 8.43 & 13.42 & 0.73 & 3.46 \\
\hline Overhang (mm) & - & - & 17.57 & 27.88 & - & - \\
\hline Front uplift (mm) & 0.39 & 1.62 & 3.66 & 5.30 & 0.97 & 0.96 \\
\hline GFRP micro strain & 6503.93 & 3914.80 & 7198.86 & 5494.50 & 16268.69 & 7225.97 \\
\hline $\begin{array}{l}\text { Concrete micro } \\
\text { strain }\end{array}$ & -818.33 & -868.00 & -784.67 & -1735.00 & -893.33 & -701.33 \\
\hline $\begin{array}{l}\text { Observed failure } \\
\text { mechanism }\end{array}$ & $\begin{array}{c}\text { GFRP- } \\
\text { concrete } \\
\text { anchorage }\end{array}$ & $\begin{array}{l}\text { Diagonal } \\
\text { shear in } \\
\text { the wall }\end{array}$ & $\begin{array}{c}\text { GFRP- } \\
\text { concrete } \\
\text { anchorage }\end{array}$ & $\begin{array}{c}\text { GFRP- } \\
\text { concrete } \\
\text { anchorage }\end{array}$ & $\begin{array}{l}\text { Concrete } \\
\text { breakout }\end{array}$ & $\begin{array}{l}\text { Diagonal } \\
\text { shear in } \\
\text { the wall }\end{array}$ \\
\hline
\end{tabular}




\subsection{Experimental Versus Numerical}

Literature search showed that factored applied moments specified in CHBDC Commentaries of 2006 are limited to specific deck slab cantilever length and slab thickness. Also, these moment values do not take into account the length of the barrier in the direction of traffic. As such, Finite element analysis (FEA), using SAP2000 software, on TL-5 bridge barriers was conducted by Azimi et al. (2014) to determine forces and moments acting at the deck-wall junction and to improve design practices. The parametric study took into account several variables associated with various construction types of the barriers. The parameters investigated were barrier length, cantilever overhang length, and deck thickness. As a result of the analysis, formulas were developed to determine the moment acting at the anchorage zone based on the subject barrier dimensions as shown in Table 4.15.

Table 4.15: Formulas developed from FEA (Azimi et al., 2014)

\begin{tabular}{|c|c|c|}
\hline \multicolumn{2}{|c|}{ Lateral load, $P_{t}(\mathrm{kN})$} & 210 \\
\hline \multicolumn{2}{|c|}{ Factored lateral load $(\mathrm{kN})$} & 357 \\
\hline \multicolumn{2}{|c|}{ Length of lateral load (mm) } & 2400 \\
\hline \multicolumn{2}{|c|}{ Height of lateral load, $\mathrm{H}(\mathrm{mm})$} & 990 \\
\hline \multirow[b]{2}{*}{$M_{\text {inner }}$ (kN.m) } & Fixed base & 132 \\
\hline & $\begin{array}{l}\text { Cantilever } \\
\text { deck slab }\end{array}$ & $\begin{array}{c}100\left(L_{b}+2.3 t_{s}\right)^{-1}+2.83 t_{s}^{0.2}\left(L_{b}-1\right)^{0.7} L_{c}{ }^{-0.8} \\
+143 t_{s}+23\end{array}$ \\
\hline \multirow[b]{2}{*}{$M_{\text {end }}$ (kN.m) } & Fixed base & 148 \\
\hline & $\begin{array}{l}\text { Cantilever } \\
\text { deck slab }\end{array}$ & $\begin{aligned} 14 t_{s}\left(L_{b}+2.3\right. & \left.t_{s}-2\right)^{-1} \\
& +2.83 t_{s}^{0.2}\left(L_{b}-1\right)^{0.7} L_{c}{ }^{-0.7}+240 t_{s} \\
& +25\end{aligned}$ \\
\hline
\end{tabular}

Notes: $L_{b}$ - Barrier length $(m), t_{s}$-Slab thickness $(m), L_{c}$ - Cantilever overhang length $(m)$ The formulas are best applicable to the following conditions:

- The deck slab thickness $\left(t_{s}\right)$ for a cantilever barrier is between 175 and $350 \mathrm{~mm}$.

- The cantilever overhang length $\left(L_{c}\right)$ is between 0 and 2 meters.

- The barrier length $\left(L_{b}\right)$ is greater than 3 meters.

The formulas derived were then used to benchmark data collected throughout the experimental program of this research. By comparing the experimental data to the FEA modeling 
one may be able to further verify the safety of implementing the proposed barrier-deck junction details in this research. The experimental results were introduced as a ratio over the FEA values obtained from the empirical equation in Table 4.15 to determine whether the ratio is more than or equal to 1 for safe design. It should be noted that a GFRP-concrete durability factor of 0.75 was applied to add to the safety of the barrier design. These results are shown in graphical and table format in Figures 4.70 and 4.71, and Table 4.16. Results show that all factors of safety for design of the barrier-deck junction in this research are more than 1 irrespective of the barrier length. So, it is recommended to use this design for TL-5 barriers. It should be noted that barrier lengths considered in this study were of $3 \mathrm{~m}$ or more.

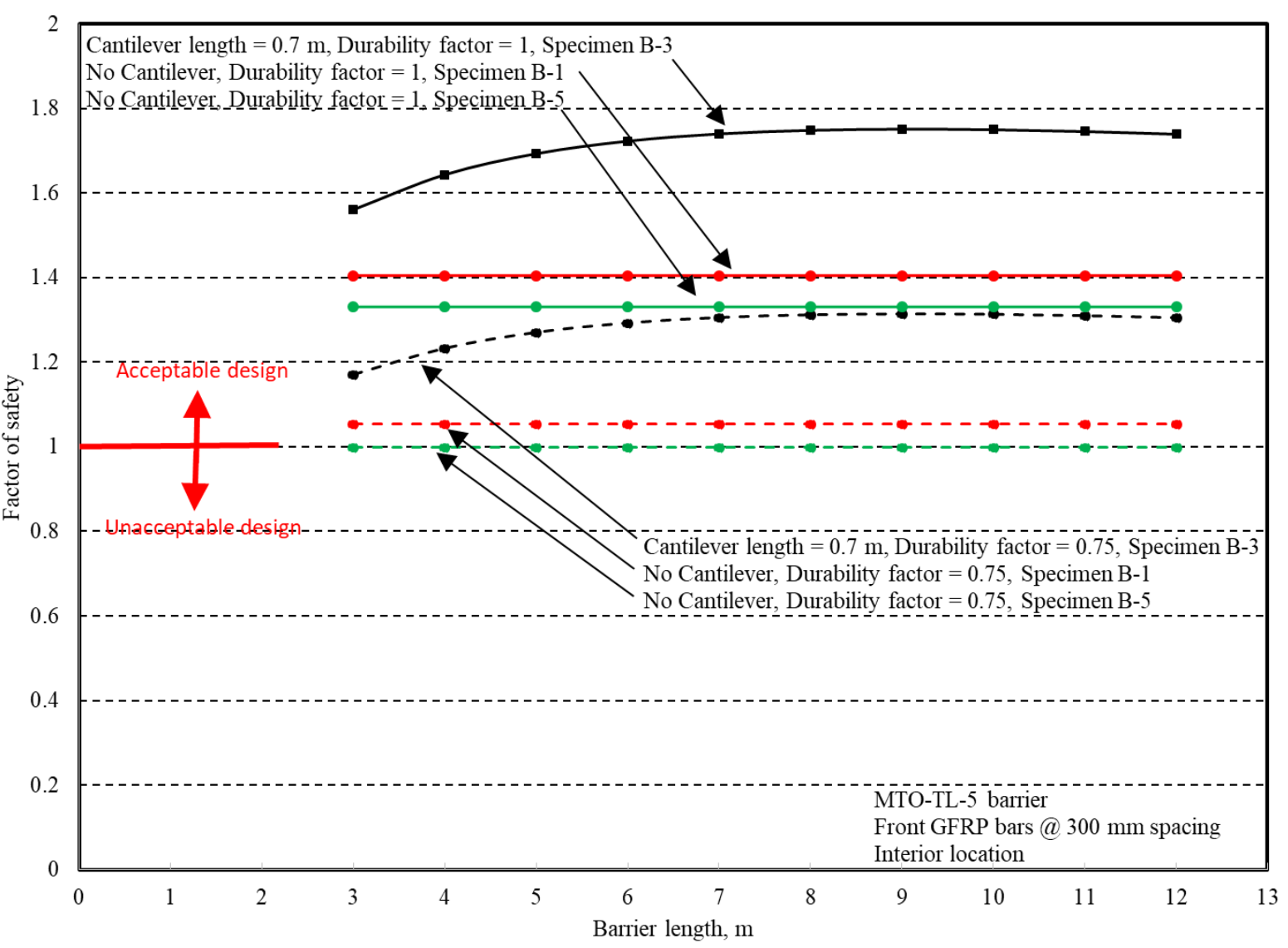

Figure 4.70: Interior loaded barriers factor of safety representation 


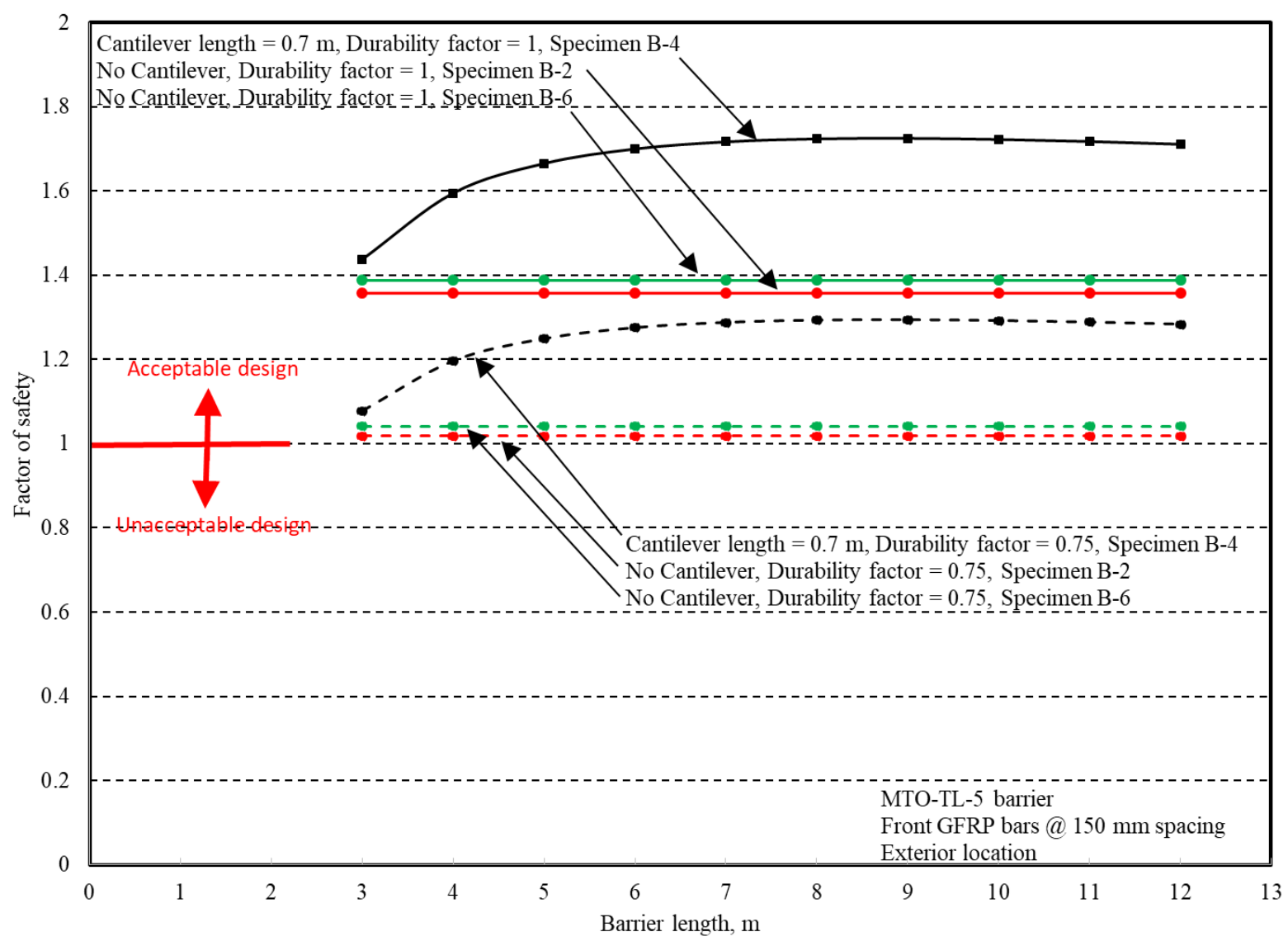

Figure 4.71: Exterior loaded barriers factor of safety representation 
Table 4.16: Data comparison using formulas by Azimi et al. (2014)

\begin{tabular}{|c|c|c|c|c|c|c|c|c|}
\hline Barrier & $\begin{array}{c}t_{s} \\
(\mathrm{~m})\end{array}$ & $\begin{array}{l}L_{c} \\
(\mathrm{~m})\end{array}$ & $\begin{array}{c}L_{b} \\
(\mathrm{~m})\end{array}$ & $\begin{array}{c}\text { Load } \\
\text { location }\end{array}$ & $\begin{array}{c}\text { FEA result } \\
\text { (kN.m) }\end{array}$ & $\begin{array}{l}\text { Experimental } \\
\text { result (kN.m) }\end{array}$ & $\begin{array}{c}\text { Factor of } \\
\text { safety }\end{array}$ & $\begin{array}{c}0.75 \times \text { Factor } \\
\text { of safety }\end{array}$ \\
\hline B-1 & 0.5 & 0 & $\mathrm{~N} / \mathrm{A}$ & Interior & 132 & 185.49 & 1.41 & 1.05 \\
\hline B-2 & 0.5 & 0 & $\mathrm{~N} / \mathrm{A}$ & Exterior & 148 & 200.89 & 1.36 & 1.02 \\
\hline \multirow{10}{*}{ B-3 } & \multirow{10}{*}{0.25} & \multirow{10}{*}{0.7} & 3 & \multirow{10}{*}{ Interior } & 91.36 & 142.60 & 1.56 & 1.17 \\
\hline & & & 4 & & 86.76 & 142.60 & 1.64 & 1.23 \\
\hline & & & 5 & & 84.22 & 142.60 & 1.69 & 1.27 \\
\hline & & & 6 & & 82.76 & 142.60 & 1.72 & 1.29 \\
\hline & & & 7 & & 81.95 & 142.60 & 1.74 & 1.31 \\
\hline & & & 8 & & 81.55 & 142.60 & 1.75 & 1.31 \\
\hline & & & 9 & & 81.43 & 142.60 & 1.75 & 1.31 \\
\hline & & & 10 & & 81.49 & 142.60 & 1.75 & 1.31 \\
\hline & & & 11 & & 81.69 & 142.60 & 1.75 & 1.31 \\
\hline & & & 12 & & 81.99 & 142.60 & 1.74 & 1.30 \\
\hline \multirow{10}{*}{ B-4 } & \multirow{10}{*}{0.25} & \multirow{10}{*}{0.7} & 3 & \multirow{10}{*}{ Exterior } & 125.03 & 179.75 & 1.44 & 1.08 \\
\hline & & & 4 & & 112.69 & 179.75 & 1.60 & 1.20 \\
\hline & & & 5 & & 107.93 & 179.75 & 1.67 & 1.25 \\
\hline & & & 6 & & 105.73 & 179.75 & 1.70 & 1.28 \\
\hline & & & 7 & & 104.69 & 179.75 & 1.72 & 1.29 \\
\hline & & & 8 & & 104.27 & 179.75 & 1.72 & 1.29 \\
\hline & & & 9 & & 104.20 & 179.75 & 1.73 & 1.29 \\
\hline & & & 10 & & 104.35 & 179.75 & 1.72 & 1.29 \\
\hline & & & 11 & & 104.65 & 179.75 & 1.72 & 1.29 \\
\hline & & & 12 & & 105.05 & 179.75 & 1.71 & 1.28 \\
\hline B-5 & 0.5 & 0 & $\mathrm{~N} / \mathrm{A}$ & Interior & 132 & 175.71 & 1.33 & 1.00 \\
\hline B-6 & 0.5 & 0 & $\mathrm{~N} / \mathrm{A}$ & Exterior & 148 & 205.41 & 1.39 & 1.041 \\
\hline
\end{tabular}




\section{Chapter 5: Conclusions}

\subsection{General}

The use of steel reinforcement has dominated the infrastructure of our world, and has proven exceptional performance in many aspects. It has been the driving economic force behind certain markets, and has improved employment amongst many countries. Traditional steel reinforcement faces one fundamental problem in our modern world. Corrosion of rebar in cold climates is the root cause behind large capital expenditures in maintenance and rehabilitation of today's infrastructure. The use of deicing salts has accelerated deterioration rates of our concrete structures, and the need for innovation is amplified. Glass fibre reinforcement polymers (GFRP) were introduced in the past and have been recommended for use in concrete. GFRP possesses many notorious specifications which steel lacks. GFRP provides exceptionally high tensile strengths, is non-corrosive and is not a conductor and is a substantially light-weight material. GFRP is currently implemented in new and rehabilitation projects as extensive research has been conducted on the subject matter. It is continuously gaining confidence and trust in the construction and sustainability markets.

A newly developed high modulus (HM) GFRP bar has now emerged into the market. The new bar offers a re-engineered anchor head, which is believed to possess a greater pullout capacity, ultimately offering a more competitive performance to dollar ratio. The new HM anchor head is studied in various aspects through this research. Tests to determine the pullout capacity of the bars were conducted prior to proceeding with static load testing on actual-size TL-5 bridge barriers. The findings were benchmarked against the current CHBDC and Ministry requirements, along with applicable durability factors. The sub-sections below provide a summary of the findings, and recommendations for future research opportunities.

It will be noticed that the new HM Anchor-Headed GFRP bars satisfied all code requirements as well as Ministry of Transportation of Ontario standards, in terms of pullout capacity and static load testing of TL-5 bridge barriers. These conclusions were drawn from an extensive experimental program consisting of two separate phases. Phase 1 of this research analyzed the pullout capacity of the bars for pre- and post-installed applications. Phase 2 of this research was geared towards studying the ultimate load carrying capacity of the barrier-deck junction in the developed barrier-deck system. Six barrier segments were tested in total, 4 being pre-installed and 2 being post installed. The need for full-scale vehicle crash testing of the barrier wall currently remains. 


\subsection{Pullout Testing Takeaways}

The pullout capacity testing was considered to be phase 1 of the experimental program of the research. Three, $1.3 \mathrm{~m}$ wide $\times 2.5 \mathrm{~m}$ long $\times 0.3 \mathrm{~m}$ deep, steel reinforced concrete slabs were constructed. In each slab, 5 pre-installed GFRP bars protruding upwards from the slab were present for a total of 15 pre-installed GFRP bars. The 15 bars were divided in three groups with different objectives. One group consisted of fully bonded, straight 15M bars; the other group consisted of fully bonded, anchor-headed 15M bars; and the last group consisted of anchorheaded, partially bonded (only anchor-head), 15M bars. The following conclusions can be drawn.

1- The pullout capacity of the pre-installed straight bars, $145.48 \mathrm{kN}$, yielded a bond strength of 14.85 MPa for $195 \mathrm{~mm}$ embedment length. Given the failure mode of bar crushing at the grip, the bar can still carry more tensile force to be pulled out of concrete. Similar observation can be drawn for the post-installed bar with $200 \mathrm{~mm}$ embedment length that reached a pullout capacity of $144.83 \mathrm{kN}$ with mixed failure modes in the tested samples. These mixed failure modes include (i) bar slip, (ii) bar slip combined with concrete conical failure, and (iii) bar crushing at grip.

2- The capacity of the GFRP bar to break its anchorage with the 100-mm length cast headed end was $128.63 \mathrm{kN}$ while the capacity of a similar headed end bar with $147 \mathrm{~mm}$ bonded straight portion of the bar was $148.34 \mathrm{kN}$. This leads to increase in headed bar capacity by $15 \%$ with the addition of bonded portion to transfer the tensile force in the bar to concrete.

3- In pre-installed bar tests, it can be observed that the pullout capacity decreased from 152.49 $\mathrm{kN}$ to $144.83 \mathrm{kN}$ (i.e. by 5\%) with the increase in bar embedment length from 150 to $200 \mathrm{~mm}$. However, results for $175 \mathrm{~mm}$ embedment length did not follow the same trend. This may be attributed to possible flaws in the bar installation as a result of uneven distribution of adhesives around the bar.

4- The average pullout capacity of the tested GFRP bars with straight- or headed-ends exceeded the minimum value of $100 \mathrm{kN}$ specified in MTO Standard Drawing for TL-5 barriers.

\subsection{Static Load Testing on TL-5 Bridge Barrier Takeaways}

Based on the data generated from this research, the following conclusions can be drawn.

1- It is recommended to use the proposed GFRP-reinforced barrier system for barrier lengths greater than or equal to $3 \mathrm{~m}$ in the case of slab-on-girder and box girder bridges with deck slab cantilever lengths up to $2 \mathrm{~m}$.

2- The vertical embedment length of $195 \mathrm{~mm}$ for the GFRP bars in the deck slab is adequate to maintain the required barrier-deck anchorage capacity. Given the dimensions of the concrete 
base supporting the barrier wall during tests, the proposed design is acceptable for applications in solid-slab and voided-slab bridge cross-sections with minimum deck slab thickness of 500 $\mathrm{mm}$.

3- All barrier specimens showed load carrying capacity at the barrier deck junction greater than the CHBDC applied factored transverse loading with and without the durability factor.

4- It is recommended replacing Fig. C16.2 in the 2014 CHBDC Commentaries with the proposed TL-5 barrier reinforced with high-modulus GFRP bars given (i) the significant reduction in cost with the elimination of low-modulus bar bents, (ii) the use of high modulus GFRP bars with almost double the tensile strength of GFRP bars specified in Fig. C16.2, and (iii) the proposed design reduces the amount of GFRP bars in the barrier detailing in Fig. C16.2 by about $40 \%$.

\subsection{Future Recommendations}

The following are a few ideas for future research in this topic.

1- Conducting vehicle crash testing on the developed barrier to ensure meeting the crash test requirements set forth by MASH of 2009 to qualify its use in bridges.

2- Conducting a feasibility study on the use of fibre reinforced concrete with the GFRP bars to reduce barrier thickness.

3- Conducting nonlinear finite-element modeling on barrier-deck system to assist in studying possible changes in barrier details without going through expensive testing of actual-size structural elements. 


\section{Appendix: Pullout load-POT reading relationships}

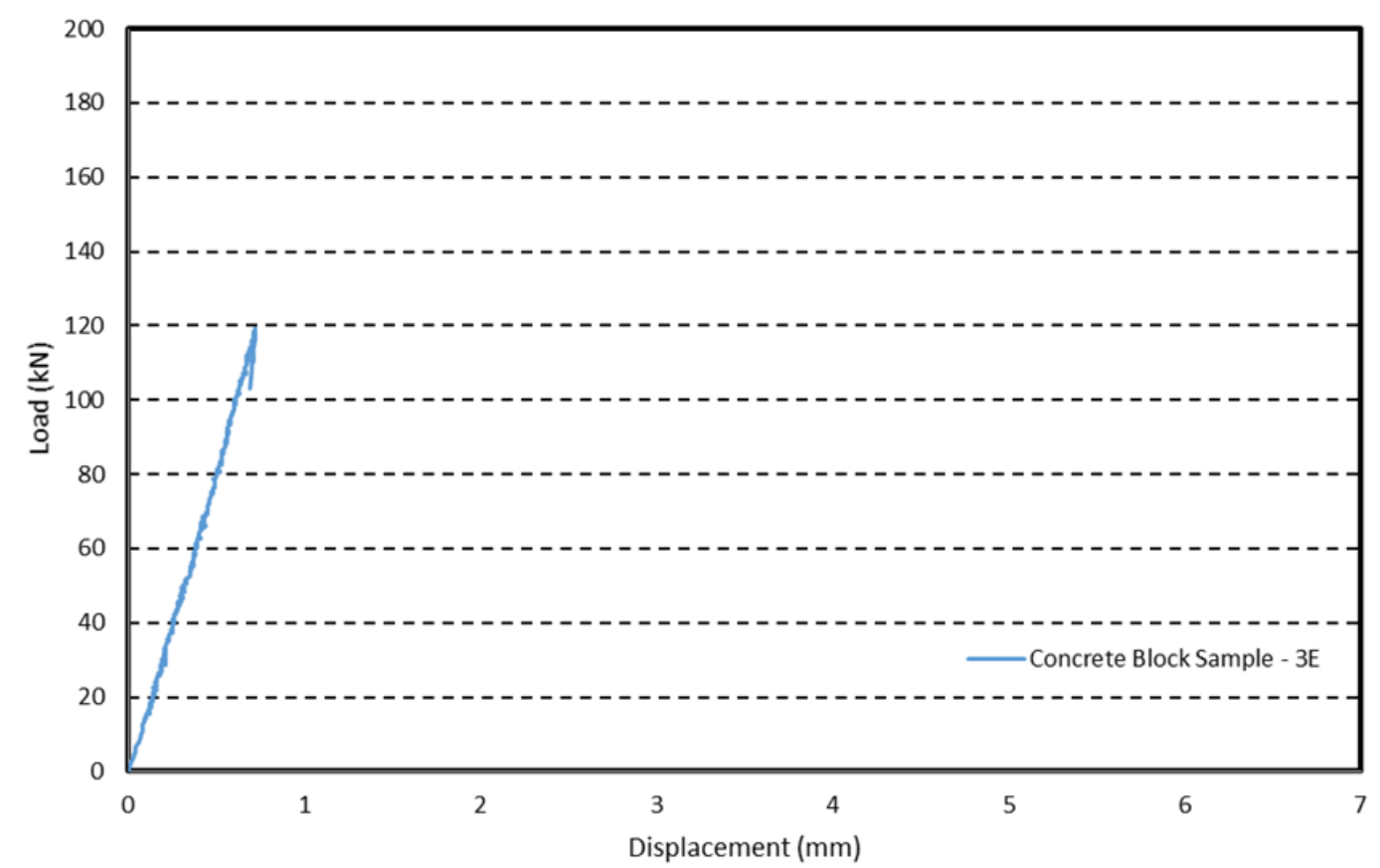

Figure A.1: Pullout load-POT reading relationship for pre-installed headed bar in a concrete block

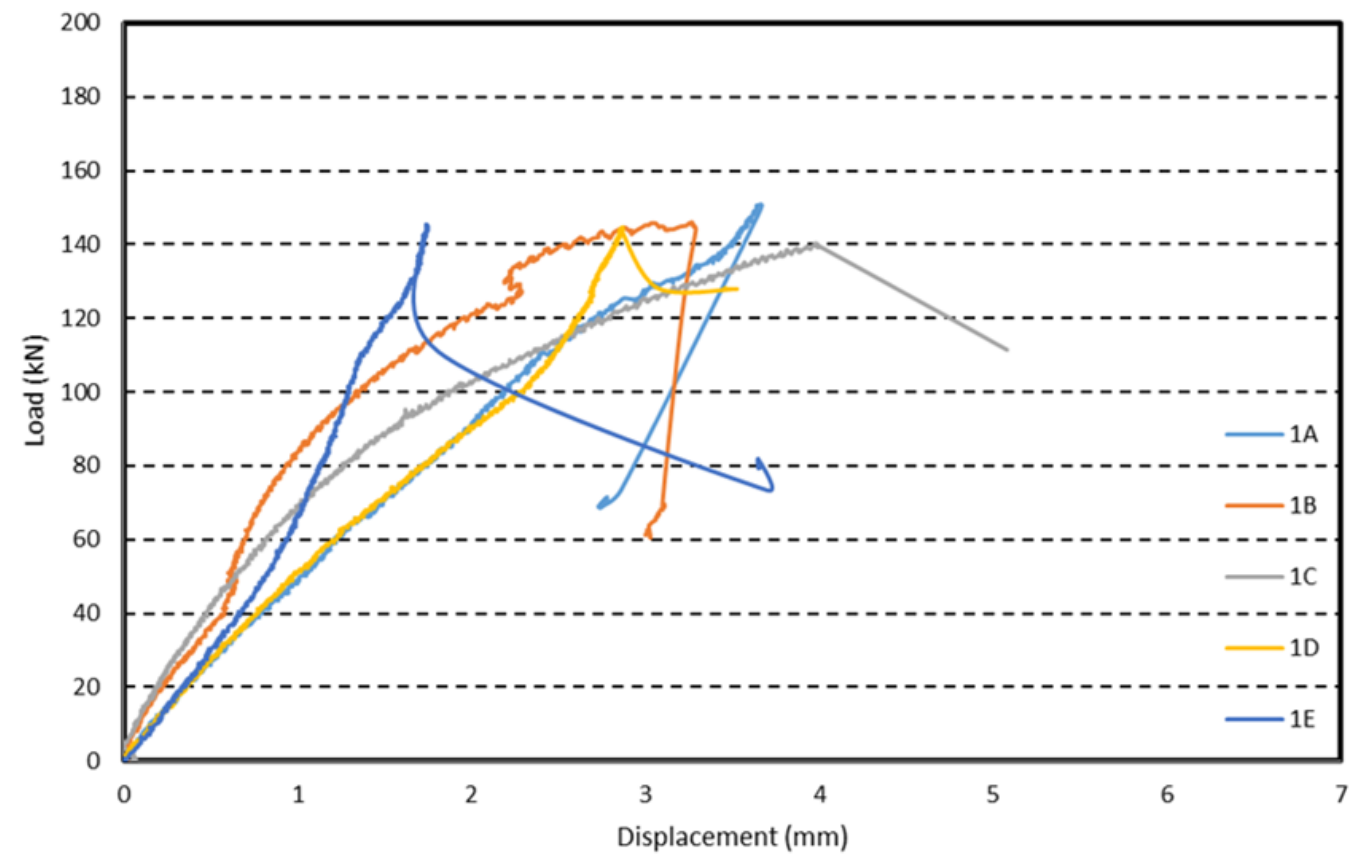

Figure A.2: Pullout load-POT reading relationship for pre-installed bars in Group 1 


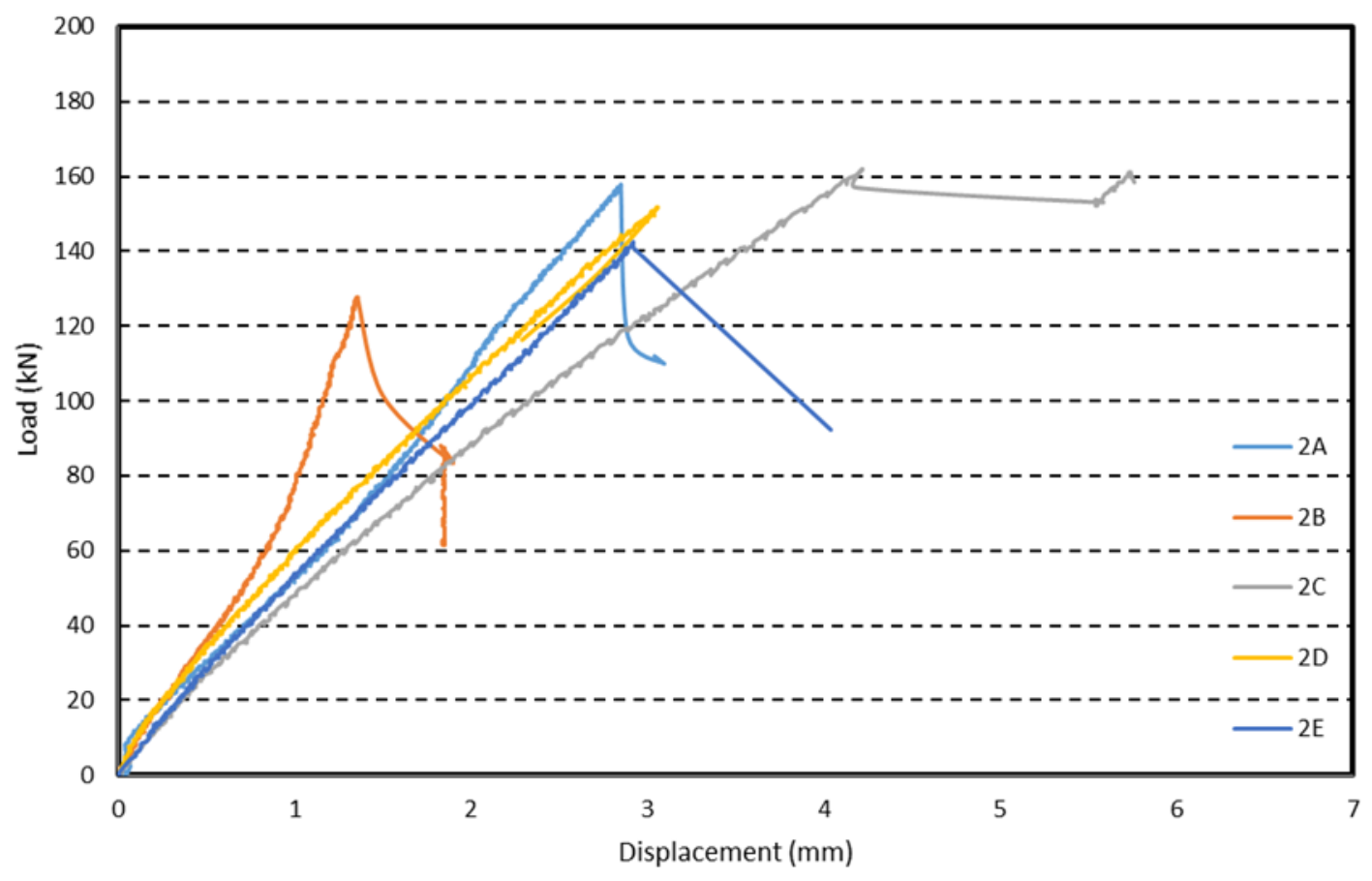

Figure A.3: Pullout load-POT reading relationship for pre-installed bars in Group 2

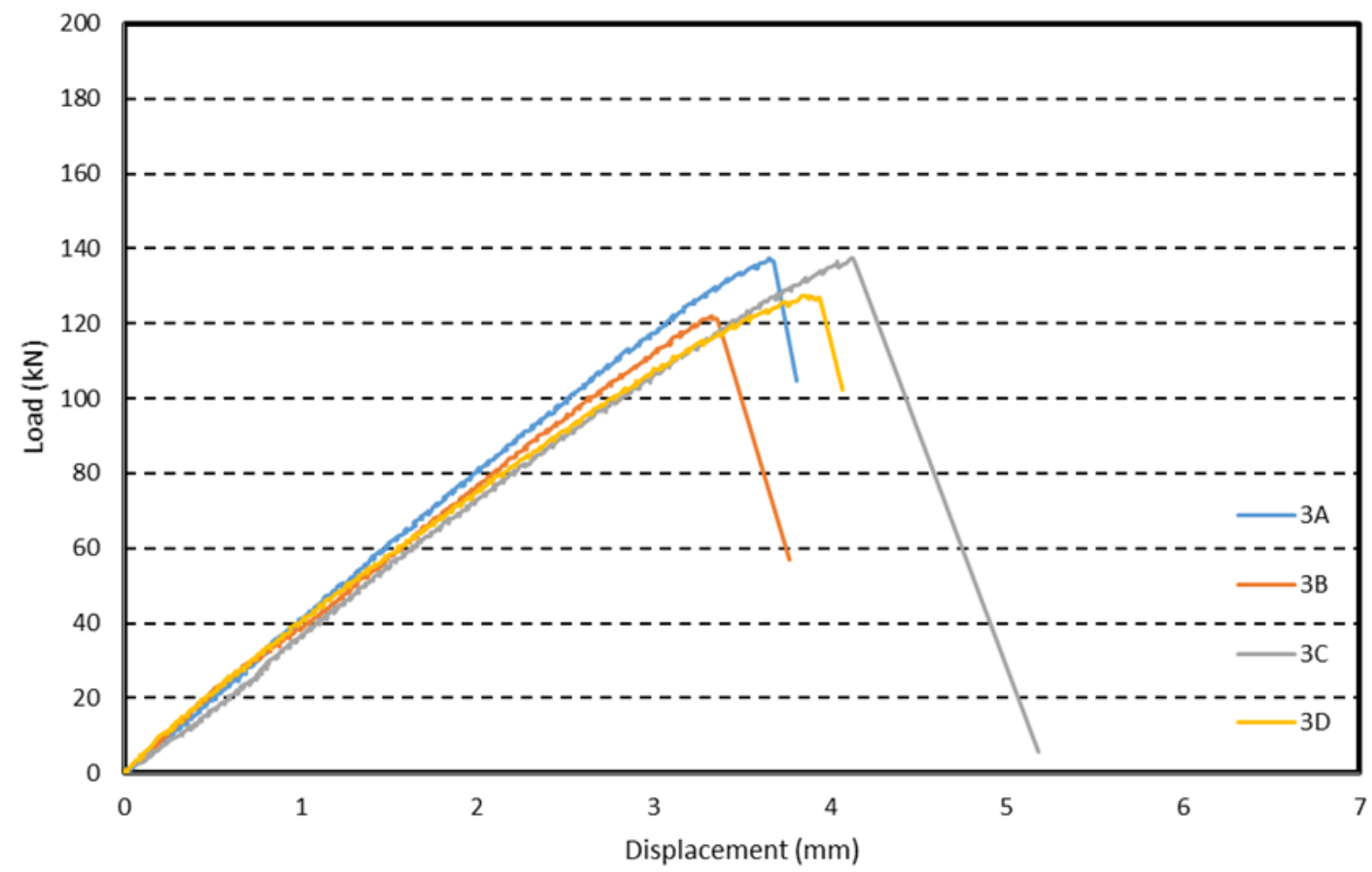

Figure A.4: Pullout load-POT reading relationship for pre-installed bars in Group 3 


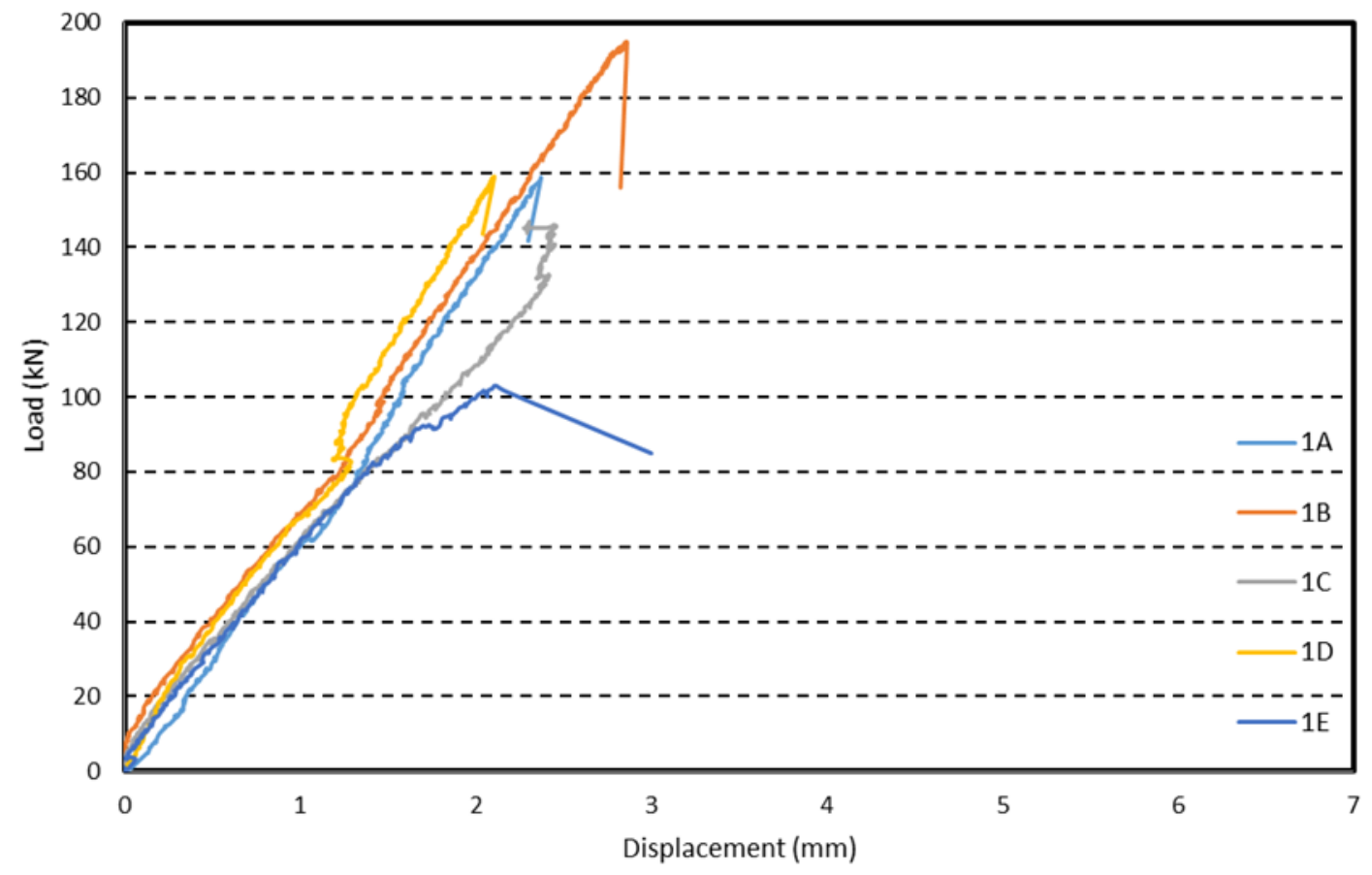

Figure A.5: Pullout load-POT reading relationship for post-installed bars in Group 1

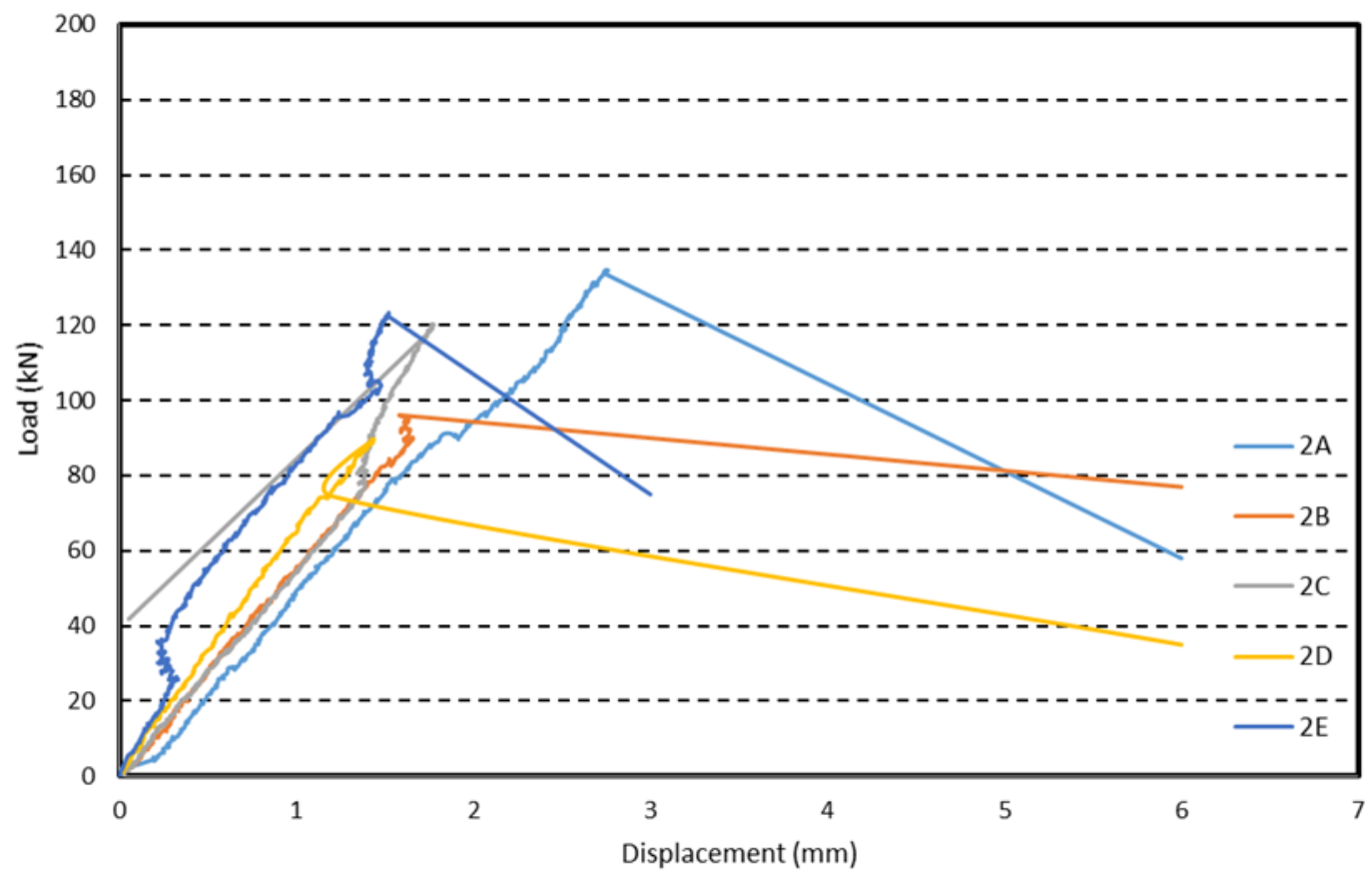

Figure A.6: Pullout load-POT reading relationship for post-installed bars in Group 2 


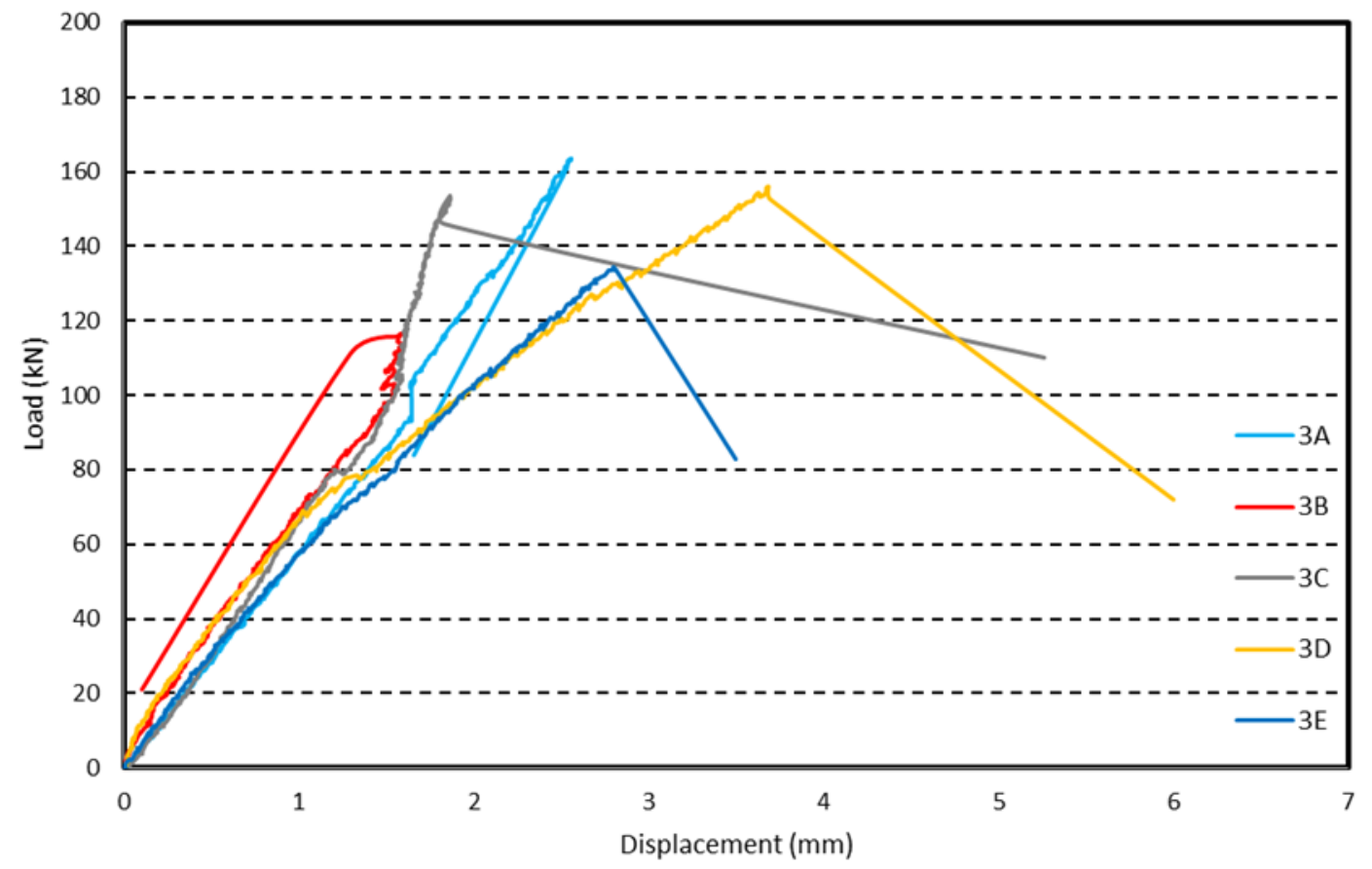

Figure A.7: Pullout load-POT reading relationship for post-installed bars in Group 3 


\section{References}

AASHTO. (2014). AASHTO-LRFD Bridge Design Specifications. American Association of State Highway and Transportation Officials, Washington DC.

Abolghasem, A. (2013). Experimental Investigation on Pull-Out Strength of Pre- and Post-Installed GFRP Bars for Bridge Barrier Construction. Toronto, Ontario: Ryerson University.

Achillides, Z., Pilakoutas, K. (2004). Bond Behavior of Fiber Reinforced Polymer Bars under Direct Pullout Conditions. Journal of Composite Construction, 8(2): 173-181.

Ametrano, D. (2011). Bond characteristics of glass fibre reinforced polymer bars embedded in high strength and ultra-high strength concrete. MASc thesis, Dept. of Civil Engineering, Ryerson Univ., Toronto.

ASTM. (2015). Standard Test Methods for Strength of Anchors in Concrete Elements, ASTM E488 / E488M - 15. American Society for Testing and Materials Pennsylvania, USA.

Azimi, H., Abolghasem, A., and Sennah, K. (2014a). Experimental Study on the Pullout Capacity of Post-Installed GFRP Bars for Bridge Barrier Replacement. $9^{\text {th }}$ International Conference on Short and Medium Span Bridges, Calgary, Alberta, Canada, pp. 1-10.

Azimi, H., Sennah, K., Tropynina, E., Goremykin, S., Lucic, S., and Lam, M. (2014b). Anchorage Capacity of Concrete Bridge Barriers Reinforced with GFRP Bars with Headed Ends. ASCE Journal of Bridge Engineering, 19(9): 1-15.

B\&B FRP Manufacturing Inc. (2016). MST-BAR ${ }^{\circledR}$ GIII Material Specification. Retrieved from B\&B Manufacturing Inc.: https://www.bandbfrp.com/ on November 23, 2016.

Baena, M., Torres, L., Turon, A., and Barris, C. (2009). Experimental Study of Bond Behavior between Concrete and FRP Bars using a Pull-out Test. Composites: B, 40: 784-797.

Benmokrane, B., Mohamed, M.H., Manalo, A., and Cousin, P. (2017). Evaluation of Physical and Durability Characteristics of New Headed Glass-Fiber-Reinforced-Polymer (GFRP) Bars. ASCE Journal of Composites for Construction, 21(2): 1-12.

CAN Group. (2012). Design and construction of building components with fibre reinforced polymers, CAN/CSA S806-12. Canadaian Standards Association, Toronto, Ontario, Canada.

CSA Group. (2006). S6.1-06 Commentary on CAN/CSA-S6-06, Canadian Highway Bridge Design Code. Canadaian Standards Association, Toronto, Ontario, Canada.

CSA Group. (2014). S6-14 Canadian Highway Bridge Design Code. Canadaian Standards Association, Toronto, Ontario, Canada. 
Di Luzio, G., Muciaccia, G., \& Biolzi, L. (2009). Size Effect in Thermally Damaged Concrete. International Journal of Damage Mechanics, 631-656.

El-Badry, M., Moravvej, M., and Joulani, P. (2017). Performance of a Hybrid FRP-Reinforced Bridge Truss Girder System - Experimental Assessment. Proceedings of the $4^{\text {th }}$ International Conference on Smart Monitoring, Assessment, and Rehabilitation of Civil Structures, SMAR 2017, Zurich, Switzerland, p. 1-9.

El-Salakawy, E., and Islam, M. R. (2014). Repair of GFRP-Reinforced Concrete Bridge Barriers. Journal of Bridge Engineering, 19(6): 04014016-1-11.

Firas, S. A., Gilles, F., and Robert, L. R. (2011). Bond Between Carbon Fibre-reinforced Polymer (CFRP) Bars and Ultra-High Performance Fibre Reinforced Concrete (UHPFRC): Experimental study. Construction and Building Materials, 25: 479-485.

Gudonis, E., Kacianaukas, R., Gribniak, V., Weber, A., Jakubovskis, R., and Kaklauskas, G. (2014). Mechanical Properties of the Bond Between GFRP Reinforcing Bars and Concrete. Mechanics of Composite Materials, 457-466.

Hasaballa, M. and El-Salakawy, E. (2014). Seismic performance of beam-column joints reinforced with GFRP headed bars. $3^{\text {rd }}$ Asia-Pacific conference on FRP is structures (APFIS 2012), Hokkaido, Japan.

Hilti Canada Corporation. (2016). HIT-RE 500 V3 Epoxy Adhesive Anchoring System. North American Product Technical Guide- Volume 2: Anchor Fastening Technical Guide, Edition 17. Tulsa, Hilti Corporation OK, United States of America, Retrieved from Hilti website.

Hossain, K. M., Ametrano, D., and Lachemi, M. (2014). Bond Strength of Standard and High Modulus GFRP Bars in High Strength Concrete. Journal of Materials in Civil Engineering, 26(3): 449-456.

Islam, S., Afefy, H., Sennah, K., and Azimi, H. (2015). Bond characteristics of straight- and headedend ribbed-surface GFRP bars embedded in high-strength concrete. Journal of Construction and Building Materials, 83: 283-298.

Jacobson, D., Bank, I., Olivia, M., and Russell, J. (2005). Punching Shear Capacity of Double Layer FRP Grid Reinforced Slabs. ACI Special Publications, SP-230-49, pp. 857-857.3.

Johnson, D., and Sheikh, S. (2013). Experimental Investigation of Glass Fiber-Reinforced PolymerReinforced Normal-Strength Concrete Beams. ACI Structural Journal, 113(6): 1165-1174.

Kabir, M., Samali, B., and Shrestha, R. (2017). Pull-out Strengths of GFRP-Concrete Bond Exposed to Applied Environmental Conditions. International Journal of Concrete Structures and Materials, 69-84. 
Khederzadeh, H. (2014). Development of Innovative Designs of Bridge Barrier System Incorporating Reinforcing Steel or GFRP Bars. Ph.D. Thesis, Ryerson University, Toronto, Ontario, Canada.

Khederzadeh, H. and Sennah, K. (2013). Pullout Strength of Pre-installed GFRP Bars in Concrete. Proceedings of the CSCE Annual Conference, Canadian Society for Civil Engineering, Montreal, pp. 1-10.

Khederzadeh, H., and Sennah, K. (2014). Development of Cost-Effective PL-3 Concrete Bridge Barrier Reinforced with Sand-coated Glass Fibre Reinforced Polymer (GFRP) Bars: Static Load Tests. Canadian Journal of Civil Engineering, 368-379.

Lai, D., and Raven, R. (2010). Performance of Epoxy Coated Reinforcement in Bridge Barriers Subjected to Direct Salt Splashing. Proceedings of the $8^{\mathrm{TH}}$ International Conference on Short and Medium Span Bridges, Niagara Falls, Ontario, Paper \# 76, pp. 424-434.

Lu, J., Sennah, K., and Sayed-Ahmed, M. (2015). Development Length of Sand-Coated Glass Fiber Reinforced Polymer Bars with Headed-End Embedded in High-Performance Concrete. Proceedings of the CSCE Annual Conference, Canadian Society for Civil Engineering, Regina, SK, pp. 1-10.

Mak, C. (2011). Experimental and Theoretical Investigation of Glass Fibre Reinforced Polymer Tension Lap Splices in Ultra High Performance Concrete. MASc thesis, Dept. of Civil Engineering, Ryerson Univ., Toronto, Canada.

Manning, D. (1996). Corrosion Performance of Epoxy-Coated Reinforcing Steel: North American Experience. Journal of Construction and Building Materials. 10(5): 349-365.

Maranan, G., Manalo, A., Karunasena, W., and Benmokrane, B. (2015a). Pullout Behavior of GFRP bars with Anchor in Geopolymer Concrete. Journal of Composite Structure, 132: 11131121.

Maranan, G., Manalo, A., Karunasena, W., and Benmokrane, B. (2015b). Bond Stress-Slip Behavior: Case of GFRP Bars in Geopolymer Concrete. Journal of Materials in Civil Engineering, 27:1-9.

MASH. (2009). Manual for Assessing Safety Hardware. American Association of State Highway and Transportation Officials, Washington DC, USA.

Mazaheripour, H., Barros, J., Cruz, S., and Soltanzadeh, F. (2013). Analytical Bond Model for GFRP Bars to Steel Fiber Reinforced Self-Compacting Concrete. Journal of Composites for Construction, 17(6): 1-16.

MMM Group. (2007). Ontario's Bridges Bridging the Gap. RCCAO, IIC. 
Mohamed, H., Zaki, M., and Benmokrane, B. (2012). New Developed FRP-Headed Rebars for Infrastructure Applications. Proceedings of the $3^{\text {rd }}$ International Structural Specialty Conference, Canadian Society for Civil Engineering, Edmonton, Canada, pp. 1-9.

Pagani, R., Bocciarelli, M., Carvelli, V., and Pisani, M. A. (2014). Modelling high temperature effects on bridge slabs reinforced with GFRP. Engineering Structures, 318-326.

Sennah, K., and Khederzadeh, H. (2014). Development of Cost-Effective PL-3 Concrete Bridge Barrier Reinforced with Sand-Coated Glass Fibre Reinforced Polymer (GFRP) bars: Vehicle Crash Test. Canadian Journal of Civil Engineeering, 357-367.

Sennah, K., Tropynina, E. and Mahmoud, Z. (2012). Ultimate Load Tests on PL-3 Bridge Barrier Reinforced with GFRP bars with Ribbed Surface and Headed ends. Proceedings of the $3^{\text {rd }}$ International Structural Specialty Conference, Canadian Society for Civil Engineering, Edmonton, Alberta, pp. 1-10.

Smith, J., and Virmani, Y. (1996). Performance of Epoxy-Coated Rebars in Bridge Decks. Public Roads Magazine, Federal Highway Administration (FHWA), 60(2): 1-12.

Vint, L. (2012). Investigation of Bond Properties of Glass Fibre Reinforced Polymer (GFRP) Bars in Concrete under Direct Tension. M.A.SC. Thesis, Department of Civil Engineering, University of Toronto. Toronto, Canada.

Vint, L., and Sheikh, S. (2015). Investigation of Bond Properties of Alternate Anchorage Schemes for Glass Fiber-Reinforced Polymer Bars. ACI Structural Journal, 112(1): 59- 68.

Won, J., Park, C., Kim, H., Lee, S., and Jang, C. (2008). Effect of Fibers on the Bonds between FRP Reinforcing Bars and High-Strength Concrete. Composites: B, 39: 747-755.

Yoo, D.-Y., Kwon, K.-Y., Park, J.-J., and Yoon, Y.-S. (2015). Local Bond-Slip Response of GFRP Rebar in Ultra-High Performance Fiber-Reinforced Concrete. Composite Structures, 120: 53-64. 